\title{
FUNCTIONAL CONNECTIVITY OF CORAL REEF FISHES IN A TROPICAL SEASCAPE ASSESSED BY COMPOUND-SPECIFIC STABLE ISOTOPE ANALYSES
}

\author{
By \\ Kelton Wells McMahon \\ B.S., Bates College, 2005 \\ Submitted in partial fulfillment of the requirements for the degree of \\ Doctor of Philosophy \\ at the \\ MASSACHUSETTS INSTITUTE OF TECHNOLOGY \\ and the \\ WOODS HOLE OCEANOGRAPHIC INSTITUTION
}

February 2011

\section{C) 2011 Kelton Wells McMahon \\ All rights reserved}

The author hereby grants to MIT and WHOI permission to reproduce and to distribute publicly paper and electronic copies of this thesis document in whole or in part in any medium now known or hereafter created.

Signature of Author

Joint Program in Oceanography/Applied Ocean Science and Engineering Massachusetts Institute of Technology and Woods Hole Oceanographic Institution Certified by

December 21, 2010

Dr. Simon R. Thorrold

Thesis Supervisor

Accepted by

Dr. Simon R. Thorrold

Chair, Joint Committee for Biological Oceanography

Woods Hole Oceanographic Institution 


\title{
FUNCTIONAL CONNECTIVITY OF CORAL REEF FISHES IN A TROPICAL SEASCAPE ASSESSED BY COMPOUND-SPECIFIC STABLE ISOTOPE ANALYSES
}

\author{
By \\ Kelton Wells McMahon
}

Submitted to the MIT-WHOI Program in Oceanography/Applied Ocean Science and Engineering on December 21, 2010 in Partial Fulfillment of the Requirements for the Degree of Doctor of Philosophy in Biological Oceanography

\begin{abstract}
The ecological integrity of tropical habitats, including mangroves, seagrass beds and coral reefs, is coming under increasing pressure from human activities. Many coral reef fish species are thought to use mangroves and seagrass beds as juvenile nurseries before migrating to coral reefs as adults. Identifying essential habitats and preserving functional linkages among these habitats is likely necessary to promote ecosystem health and sustainable fisheries on coral reefs. This necessitates quantitative assessment of functional connectivity among essential habitats at the seascape level. This thesis presents the development and first application of a method for tracking fish migration using amino acid (AA) $\delta^{13} \mathrm{C}$ analysis in otoliths. In a controlled feeding experiment with fish reared on isotopically distinct diets, we showed that essential AAs exhibited minimal trophic fractionation between consumer and diet, providing a $\delta^{13} \mathrm{C}$ record of the baseline isoscape. We explored the potential for geochemical signatures in otoliths of snapper to act as natural tags of residency in seagrass beds, mangroves and coral reefs in the Red Sea, Caribbean Sea and Eastern Pacific Ocean. The $\delta^{13} \mathrm{C}$ values of otolith essential AAs varied as a function of habitat type and provided a better tracer of residence in juvenile nursery habitats than conventional bulk stable isotope analyses (SIA). Using our otolith AA SIA approach, we quantified the relative contribution of coastal wetlands and reef habitats to Lutjanus ehrenbergii populations on coastal, shelf and oceanic coral reefs in the Red Sea. L. ehrenbergii made significant ontogenetic migrations, traveling more than $30 \mathrm{~km}$ from juvenile nurseries to coral reefs and across deep open water. Coastal wetlands were important nurseries for $L$. ehrenbergii; however, there was significant plasticity in L. ehrenbergii juvenile habitat requirements. Seascape configuration played an important role in determining the functional connectivity of L. ehrenbergii populations in the Red Sea. The compound-specific SIA approach presented in this thesis will be particularly valuable for tracking the movement of species and life-stages not amenable to conventional tagging techniques. This thesis provides quantitative scientific support for establishing realistic population connectivity models that can be used to design effective marine reserve networks.
\end{abstract}

Thesis Supervisor: Dr. Simon R. Thorrold Title: Senior Scientist, Department of Biology, Woods Hole Oceanographic Institution 


\section{ACKNOWLEDGEMENTS}

This thesis would not have been possible were it not for the support of many people. During my time in the MIT-WHOI Joint Program, I have been supported by an Ocean Life Institute Fellowship, a National Science Foundation Graduate Research Fellowship, and the WHOI Academic Programs Office. The research presented in this thesis was supported by an Ocean Life Institute student research grant to K. McMahon, an International Society for Reef Studies-Ocean Conservancy Coral Reef Research Fellowship to K. McMahon, and King Abdullah University of Science and Technology (KAUST) Award Nos. USA 00002 and KSA 00011 to S. Thorrold. Additional support came from the Woods Hole Oceanographic Institution, the Large Pelagics Research Center at the University of New Hampshire, the Carnegie Institution of Washington and the W.M. Keck Foundation.

I am very grateful to my advisor, Dr. Simon Thorrold, who was a tremendous resource for me both academically and personally. He has been an exceptional mentor, colleague and friend throughout my graduate career. Without him, this thesis would not have been possible. I would also like to thank my thesis committee, Dr. Lauren Mullineaux of WHOI, Dr. Ed Boyle of MIT, and Dr. Marilyn Fogel of the Carnegie Institution of Washington for all of the time, effort and insight they provided during this process. My committee and I would like to thank Dr. Jesus Pineda of WHOI, the chair of both my thesis proposal defense and my final thesis defense, for ensuring a smooth and productive process during both events.

Numerous people have helped me with my thesis during the past five years. Thank you to all of the current and former members of the Fish Ecology lab, headed by Dr. Thorrold, for their support in the field and in lab: Leah Houghton, Li Ling Hamaday, Dr. Michael Berumen, Dr. Benjamin Walther, Dr. Travis Elsdon, Harvey Walsh, and Camrin Braun. I would also like to thank Dr. Fogel, Dr. Michael Bermun of KAUST, Dr. Beverly Johnson of Bates College, Dr. Chris Reddy of WHOI, and Dr. Gerard Olack of Yale University for allowing me to use their labs at various times during my thesis research. Much of this work would not have possible without their generous donation of time, resources and guidance. Dr. Vicke Starczak was a valuable resource for all of the statistical analyses performed for my thesis research. Thank you to the crew of Dream Divers in Jeddah, Saudi Arabia for logistic assistance with boating and diving operations. They were instrumental in the field collection of many of my samples. I would like to thank WHOI Academic Programs, and especially Marsha Armando, Julia Westwater, Jim Yoder and Ronni Schwartz, for all of their assistance. They are an important part of what makes the MIT-WHOI Joint Program so successful. I would also like to thank the Mullineaux lab group for accepting me into their weekly lab meetings and for providing valuable feedback on several of my thesis chapters and presentations.

Finally, I would like to extend my deepest gratitude to all of my friends and family for their continued support, patience and encouragement throughout my graduate career. They are a huge part of the person I am today, and I could not have done this without all of them. There is not enough room to do justice to all those who have helped me complete this thesis. Please know that I greatly appreciate everyone's time and effort in making this thesis possible. 


\section{TABLE OF CONTENTS}

THESIS ABSTRACT................................................................................ 3

ACKNOWLEDGEMENTS.................................................................. 5

TABLE OF CONTENTS_..................................................................... 7

CHAPTER 1: AN INTRODUCTION TO FUNCTIONAL CONNECTIVITY IN CORAL REEF SEASCAPES.............................. 11

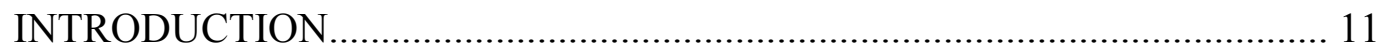

Connectivity conservation ................................................................... 12

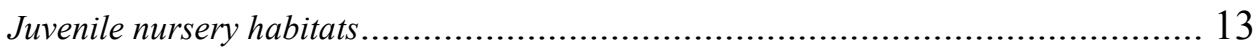

Tracking movement with traditional extrinsic markers ...................................... 16

Tracking movement with ecogeochemistry.................................................. 18

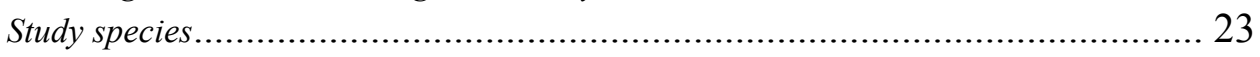

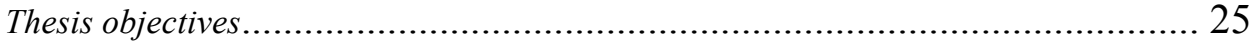

\section{CHAPTER 2: CARBON ISOTOPE FRACTIONATION OF AMINO ACIDS IN FISH MUSCLE REFLECTS BIOSYNTHESIS AND ISOTOPIC ROUTING FROM DIETARY PROTEIN............................ 27}

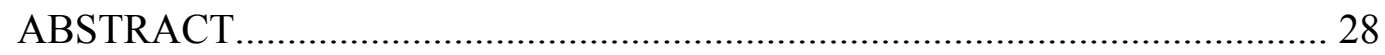

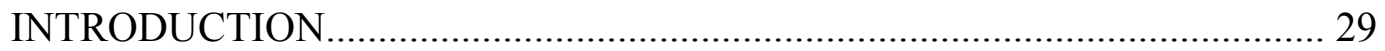

METHODS AND MATERIALS............................................................... 32

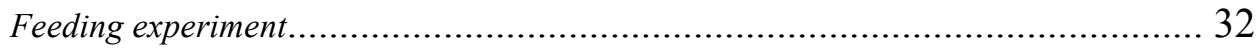

Sample preparation and analysis......................................................... 33

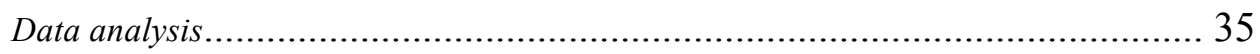

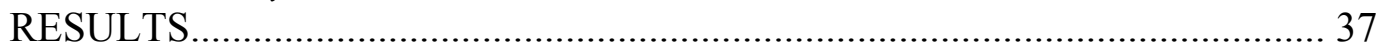

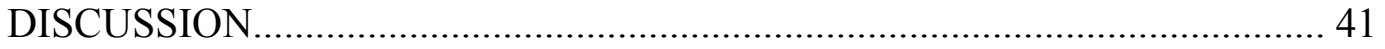

ACKNOWLEDGEMENTS.................................................................... 49

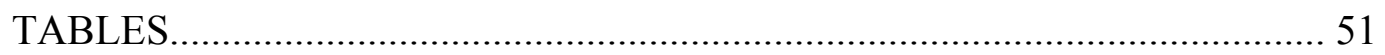

Table 2.1 Proximate analyses of feeding experiment diets............................... 51

Table 2.2 Linear regression of Fundulus heteroclitus muscle amino acid $\delta^{13} \mathrm{C}$ values.. 52

FIGURES.

Fig. 2.1 Bulk tissue and individual amino acid $\delta^{13} \mathrm{C}$ values of diet and $F$. heteroclitus

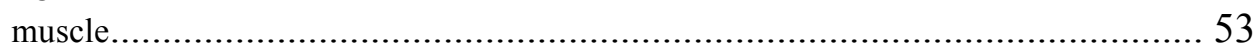

Fig. 2.2 Bulk tissue and individual amino acid $\Delta^{13} \mathrm{C}$ values............................... 54

Fig. 2.3 Amino acid percent abundance of diet and $F$. heteroclitus muscle............... 55

Fig. 2.4 Amino acid percent abundance versus $\Delta^{13} \mathrm{C}$ value............................... 56 


\section{CHAPTER 3: RECONSTRUCTING FISH DIET AND MOVEMENT PATTERNS USING STABLE CARBON ISOTOPE ANALYSIS OF OTOLITH AMINO ACIDS......................................................................... 57}

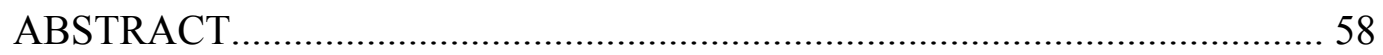

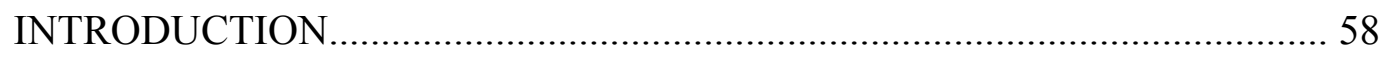

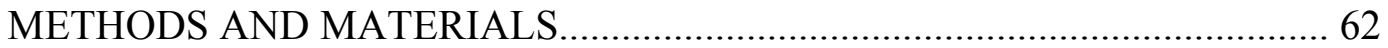

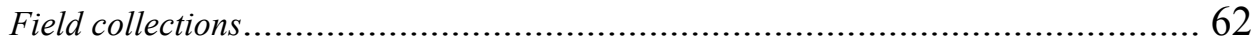

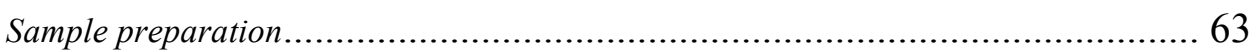

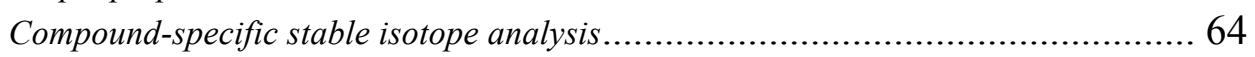

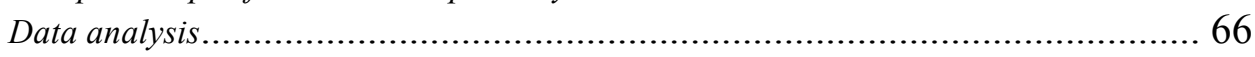

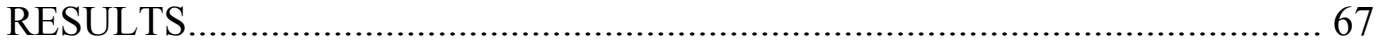

DISCUSSION

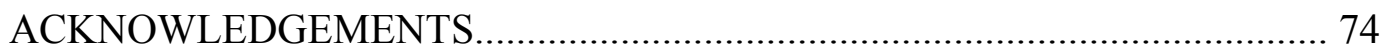

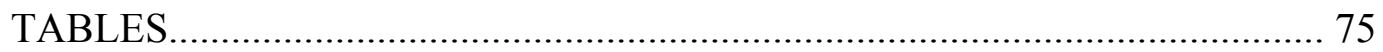

Table 3.1 Relative abundance of otolith and muscle amino acids in Lutjanus

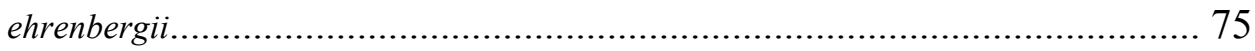

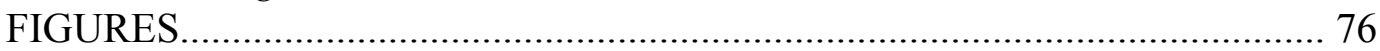

Fig. 3.1 Collection sites of $L$. ehrenbergii in the Red Sea.................................. 76

Fig. 3.2 Bulk otolith versus muscle $\delta^{13} \mathrm{C}$ values from $L$. ehrenbergii...................... 77

Fig. 3.3 Gas chromatogram of otolith amino acids from L. ehrenbergii................... 78

Fig. 3.4 Amino acid $\delta^{13} \mathrm{C}$ values of a standard as a function of time since

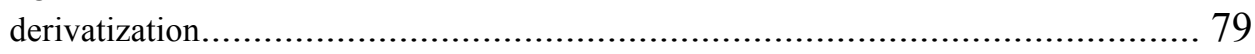

Fig. 3.5 Otolith versus muscle amino acid $\delta^{13} \mathrm{C}$ values from $L$. ehrenbergii............. 80

Fig. 3.6 Bulk tissue and otolith amino acid $\delta^{13} \mathrm{C}$ values from L. ehrenbergii............ 81

\section{CHAPTER 4: STABLE ISOTOPE SIGNATURES IN OTOLITH} AMINO ACIDS OF JUVENILE SNAPPER (FAMILY: LUTJANIDAE) RECORD HABITAT-SPECIFIC ISOSCAPES FROM COASTAL

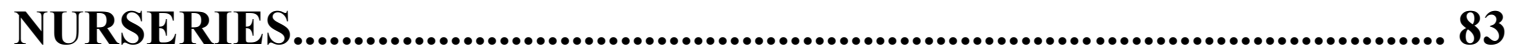

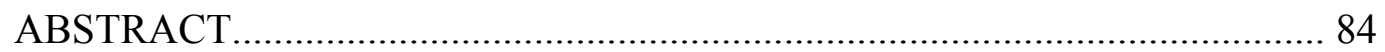

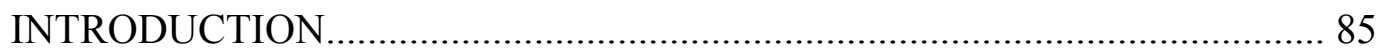

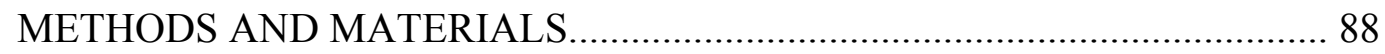

Field collections ...................................................................................... 88

Sample preparation and analysis........................................................ 90

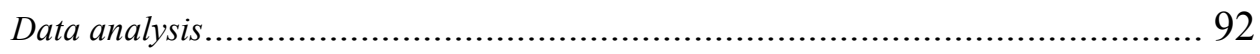

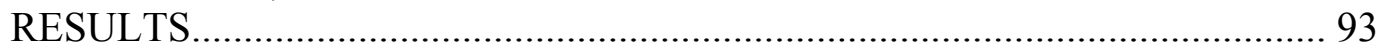

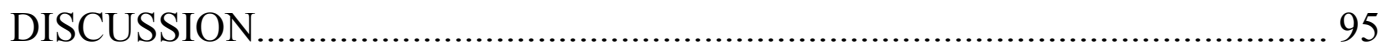

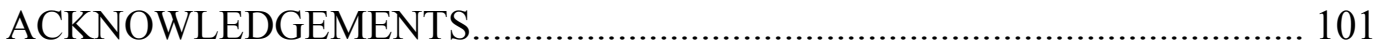

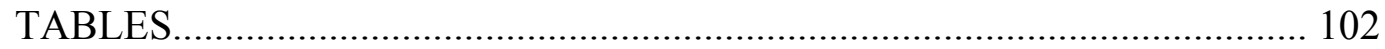

Table 4.1 Bulk otolith $\delta^{13} \mathrm{C}$ and $\delta^{18} \mathrm{O}$ and bulk tissue $\delta^{13} \mathrm{C}$ and $\delta^{15} \mathrm{~N}$ values from $L$. ehrenbergii and food web components.................................................. 102 


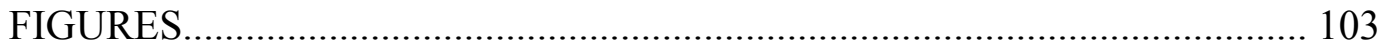

Fig. 4.1 Collection sites of $L$. ehrenbergii in the Red Sea................................. 103

Fig. 4.2 Bulk tissue $\delta^{13} \mathrm{C}$ and $\delta^{15} \mathrm{~N}$ values of $L$. ehrenbergii and food web components.

Fig. 4.3 Principal component analysis of muscle amino acid $\delta^{13} \mathrm{C}$ values of $L$.

ehrenbergii and food web components.

Fig. 4.4 Bulk otolith $\delta^{13} \mathrm{C}$ and $\delta^{18} \mathrm{O}$ value regional comparison.......................... 106

Fig. 4.5 Otolith versus muscle amino acid $\delta^{13} \mathrm{C}$ value regional comparison............. 107

Fig. 4.6 Otolith amino acid $\delta^{13} \mathrm{C}$ value regional comparison............................. 108

\section{CHAPTER 5: QUANTIFYING JUVENILE HABITAT USE BY}

\section{LUTJANUS EHRENBERGII IN A CORAL REEF SEASCAPE FROM}

THE RED SEA.................................................................................... 109

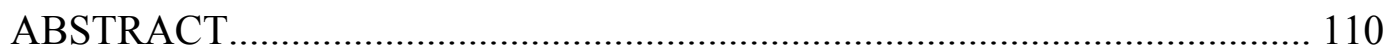

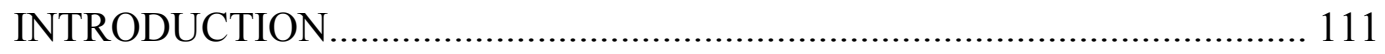

METHODS AND MATERIALS............................................................... 115

Field collections ............................................................................... 115

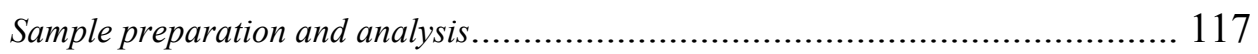

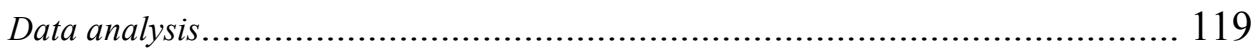

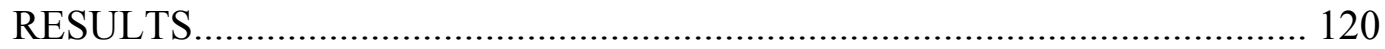

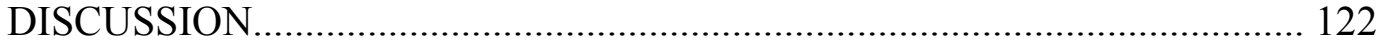

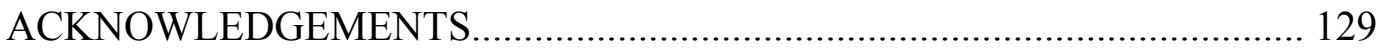

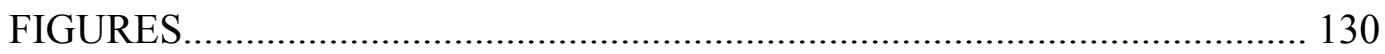

Fig. 5.1 Collection sites of L. ehrenbergii in the Red Sea............................... 130

Fig. 5.2 Total length and muscle $\delta^{15} \mathrm{~N}$ values of $L$. ehrenbergii.......................... 130

Fig. 5.3 Isolation of juvenile core of adult L. ehrenbergii otoliths........................ 133

Fig. 5.4 Discriminant function analysis of juvenile habitat signatures.................. 134

Fig. 5.5 Relative contributions of juvenile habitats to L. ehrenbergii populations..... 135

CHAPTER 6: CONCLUSIONS ........................................................ 137

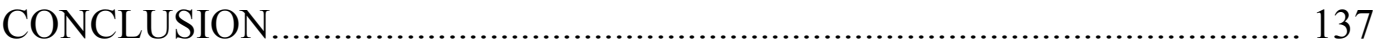

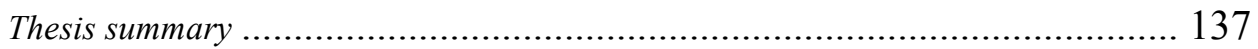

Future directions ........................................................................ 142

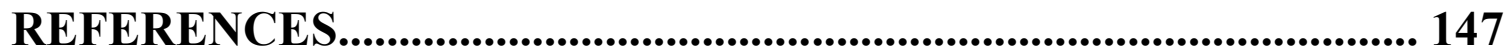


APPENDIX 1: CHAPTER 2 DATA TABLES...................................... 167

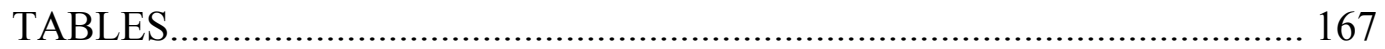

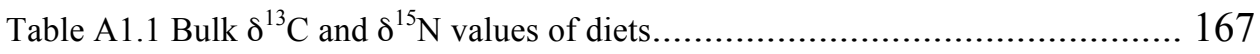

Table A1.2 Bulk $\delta^{13} \mathrm{C}$ values of $F$. heteroclitus muscle.................................. 168

Table A1.3 Amino acid $\delta^{13} \mathrm{C}$ values of diets.................................................. 169

Table A1.4 Amino acid $\delta{ }^{13} \mathrm{C}$ values of $F$. heteroclitus muscle.......................... 170

Table A1.5 Amino acid percent abundance of diets....................................... 171

Table A1.6 Amino acid percent abundance of $F$. heteroclitus muscle................... 172

APPENDIX 2: CHAPTER 3 DATA TABLES..................................... 175

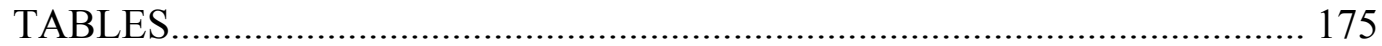

Table A2.1 Bulk muscle and otolith $\delta^{13} \mathrm{C}$ values of L. ehrenbergii in the Red Sea.... 175

Table A2.2 Derivatized amino acid standard $\delta^{13} \mathrm{C}$ values............................... 177

Table A2.3 Muscle amino acid $\delta^{13} \mathrm{C}$ values of $L$. ehrenbergii in the Red sea........... 178

Table A2.4 Otolith amino acid $\delta^{13} \mathrm{C}$ values of L. ehrenbergii in the Red Sea........... 179

APPENDIX 3: CHAPTER 4 DATA TABLES..................................... 181

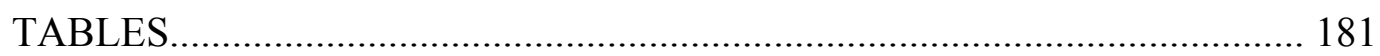

Table A3.1 Bulk otolith $\delta^{13} \mathrm{C}$ and $\delta^{18} \mathrm{O}$ values of L. ehrenbergii in the Red Sea....... 181

Table A3.2 Bulk otolith $\delta^{13} \mathrm{C}$ and $\delta^{18} \mathrm{O}$ values of $L$. apodus in the Caribbean Sea...... 181

Table A3.3 Bulk otolith $\delta^{13} \mathrm{C}$ and $\delta^{18} \mathrm{O}$ values of $L$. argentiventris in the Eastern

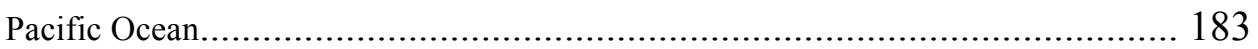

Table A3.4 Bulk muscle $\delta^{13} \mathrm{C}$ and $\delta^{15} \mathrm{~N}$ values of L. ehrenbergii in the Red Sea....... 184

Table A3.5 Bulk tissue $\delta^{13} \mathrm{C}$ and $\delta^{15} \mathrm{~N}$ values of food web components in the Red

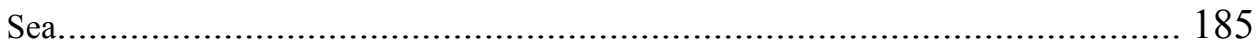

Table A3.6 Muscle amino acid $\delta^{13} \mathrm{C}$ values of L. ehrenbergii in the Red Sea.......... 186

Table A3.7 Muscle amino acid $\delta^{13} \mathrm{C}$ values of L. apodus in the Caribbean Sea......... 189

Table A3.8 Tissue amino acid $\delta^{13} \mathrm{C}$ values of food web components in the Red Sea.. 191

Table A3.9 Otolith amino acid $\delta^{13} \mathrm{C}$ values of L. ehrenbergii in the Red Sea........... 192

Table A3.10 Otolith amino acid $\delta^{13} \mathrm{C}$ values of L. apodus in the Caribbean Sea........ 196

Table A3.11 Otolith amino acid $\delta^{13} \mathrm{C}$ values of $L$. argentiventris in the Eastern

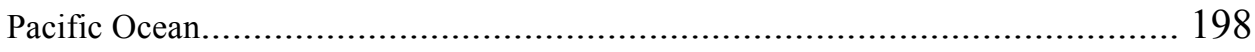

APPENDIX 4: CHAPTER 5 DATA TABLES.................................... 199

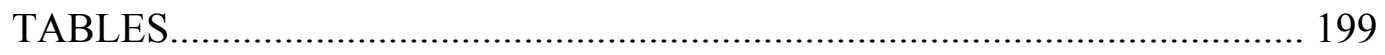

Table A4.1 Total length and muscle $\delta^{15} \mathrm{~N}$ values of L. ehrenbergii in the Red Sea.... 199

Table A4.2 Muscle amino acid $\delta^{13} \mathrm{C}$ values of L. ehrenbergii in the Red Sea........... 202

Table A4.3 Otolith amino acid $\delta^{13} \mathrm{C}$ values of L. ehrenbergii in the Red Sea........... 209 


\section{CHAPTER ONE}

\section{An introduction to functional connectivity in coral reef seascapes}

\section{INTRODUCTION}

Coral reef fishes are some of the most conspicuous animals on coral reefs. They are also major drivers behind eco-tourism, the primary source of food from a billion dollar fishery and important components of reef ecosystem biodiversity (Moberg and Folke 1999). As such, coral reef fishes are vital contributors to the economic value of reef ecosystems, estimated to be worth more than $\$ 375$ billion each year (Costanza et al. 1997). With this great value comes a tremendous amount of pressure from anthropogenic disturbance that threatens the function of coral reefs and the fisheries they support (Hughes 1994; Jackson et al. 2001a; Pandolfi et al. 2003; Cote et al. 2005). Overfishing is a chronic problem that directly affects the distribution and abundance of coral reef fish and indirectly impacts the health and resilience of coral reef ecosystems (Jackson et al. 2001a; Pauly et al. 2002). Severe depletions of coral reef fishes that exert important topdown controls on coral reef structure and function, including large predatory snapper and grouper and herbivorous parrotfish, illustrates the conflict between the global demand for reef fishes and the need to sustain functional groups to promote coral reef resilience.

Marine protected areas (MPAs) have received increased attention as a management tool to enhance coral reef fish biomass and sustainable fisheries on coral reefs as well as promote healthy ecosystem structure and function (Guenette et al. 1998; Roberts et al. 2001; Pauly et al. 2002; Mumby and Hastings 2008). Currently there are over 900 MPAs in the world containing coral reef habitats (Mora et al. 2006). However, 
effectively managed, no-take MPAs tend to be small and isolated, covering less than $0.1 \%$ of the worldwide coral reef area (Mora et al. 2006). Furthermore, management has primarily focused on protecting offshore coral reefs. However, many ecologically and commercially important coral reef fishes, including representatives from the families Lutjanidae (snapper), Serranidae (grouper), Haemulidae (grunts) and Scaridae (parrotfish), are thought to use coastal wetlands as nurseries before undergoing ontogenetic migrations to join adult populations on coral reefs (Nagelkerken et al. 2000; Nagelkerken and van der Velde 2004; Adams et al. 2006). The size and spatial arrangement of these reserves and their proximity to juvenile nursery habitats can affect reef fish assemblage patterns through animal movements, and in turn, impact ecosystem dynamics (Appeldoorn et al. 2003; Christensen et al. 2003; Mumby et al. 2004; GroberDunsmore et al. 2007, 2008).

\section{Connectivity conservation}

Tropical seascapes are complex mosaics of patchily distributed habitats, including coastal wetlands, nearshore patch reefs and offshore coral reefs, that can be linked through fish movement. Effective management of coral reefs and the fisheries they sustain, therefore, requires that we not only identify essential habitat types for coral reef fishes, but also maintain the functional linkages among these habitats that underlie ecosystem health and resilience. As anthropogenic disturbance continues to degrade and fragment tropical seascape habitats, a quantitative understanding of connectivity among habitats becomes increasingly important. 
In its most basic sense, connectivity is the flux of items between spatially distinct locations (Crooks and Sanjayan 2006). However, the metrics used to determine how habitats or populations are connected, the impacts of such connectivity on ecosystem dynamics and the subsequent application to conservation efforts depend on the species of interest and the scales at which these processes occur. As a result, no all-inclusive definition of connectivity has been developed. Coral reef fish ecology typically addresses population connectivity (Mora and Sale 2002; Sale 2006): the movement of individuals among spatially separated populations and the subsequent influence on population demographics or dynamics. This definition focuses on dispersal of individuals (typically pelagic larvae) among populations residing on spatially separated coral reefs at regional scales. However, successful management of coral reef fish populations also requires conservation of habitats essential to different life-history stages within populations. Functional connectivity is the movement of individuals among spatially separated habitats within a population resulting from interactions between behavioral processes and the seascape configuration (adapted from the landscape ecology literature [Taylor et al. 1993]). Functional connectivity is an emergent property of species-seascape interactions, and is particularly well suited for assessing functional linkages among juvenile nursery habitats and coral reefs within a tropical seascape.

\section{Juvenile nursery habitats}

The nursery concept was first adapted to marine systems a century ago for mobile fish and invertebrates with complex life histories in which larvae are transported to 
estuaries, metamorphose, grow to subadults and then move to adult habitats offshore (Hay 1905; Hildebrand and Schroeder 1928). Beck et al. (2001) defined a nursery as a habitat for juveniles whose contribution of individuals to the adult population is, per unit area, greater than other habitats where juveniles occur. This nursery definition provided a rationale for evaluating juvenile habitat productivity in the context of management efforts, particularly when priorities must be set for limited resources. However, under this definition a high quality but very small habitat could be a significant contributor per unit area but do little to actually sustain adult populations. Dahlgren et al. (2006) revised the nursery definition to encompass juvenile habitats that contribute a greater proportion of individuals to the adult population than the mean level for all habitats that juveniles occupy, regardless of area. While this definition does not account for the affects of scale or the reproductive output of individuals from the nursery (Sheaves et al. 2006), it does provide a practical measure of nursery value that can be used to guide marine conservation efforts and stimulate future research (Layman et al. 2006).

Nursery habitats are thought to support higher juvenile densities through several potential mechanisms, including faster growth rates, reduced predation and higher levels of larval settlement (Laegdsgaard and Johnson 2001; Cocheret de la Morinière et al. 2004; Verweij et al. 2006). Numerous studies have provided correlative evidence of a relationship between availability of juvenile habitats and the abundance of adults on nearby reefs (Nagelkerken et al. 2002; Dorenbosch et al. 2004b; Mumby et al. 2004; Grober-Dunsmore et al. 2007). Ecological theory related to species that shift habitats suggests that ontogenetic migration from nurseries to adult habitats are driven by 
conflicting demands for growth and survival that vary between habitats and change through an animal's ontogeny (Werner and Gilliam 1984; Dahlgren and Eggleston 2000; Grol et al. 2008).

Identifying essential juvenile habitats for coral reef fish has been a difficult proposition. Previous studies typically relied on visual surveys of juvenile fish abundance among juvenile habitats (e.g. Nagelkerken et al. 2000; Nagelkerken and van der Velde 2002). Habitats with the highest juvenile abundances were deemed the most important juvenile nurseries. It is typically assumed that this juvenile biomass is successfully transferred to the adult population on coral reefs. However, the question remains: What if juveniles from these habitats do not successfully migrate to offshore coral reefs? Management efforts are beginning to focus attention on understanding connectivity of coral reef fish populations, both ontogenetically and among subpopulations (Cowen et al. 2007; McCook et al. 2009). The current paradigm of ontogenetic migration of coral reef fishes is a simple linear progression from coastal wetlands to offshore coral reefs (Nagelkerken 2007). However, conservation and management efforts are still hampered by a lack of knowledge concerning the functional connectivity of coral reef fishes in tropical seascapes. Identifying essential juvenile habitats for coral reef fish, and the movement of individuals among these habitats is particularly critical given that juvenile nursery habitats, including coastal wetlands are being destroyed at a rate of over $2 \% \mathrm{yr}^{-1}$, resulting in losses of 30 to $60 \%$ of the world's mangroves and seagrass beds (Valiela et al. 2001; Alongi et al. 2002; Duarte et al. 2002; Orth et al. 2006; Duke et al. 2007). Quantifying the relative contribution of individuals from potential juvenile habitats to 
adult populations is critical for distinguishing between habitats that are productive for resident juveniles and habitats that are actually serving as valuable nurseries for adult reef fish populations on offshore coral reefs.

\section{Tracking movement with traditional extrinsic markers}

To assess the relative contribution of individuals from juvenile habitats to coral reefs, we must track fish movement among these habitats. Previous studies have used spatial and temporal patterns in size distribution of species throughout the coral reef seascape to infer ontogenetic migration (Cocheret de la Morinière et al. 2002; Nagelkerken 2007). For instance, Cocheret de la Morinière et al. (2002) used underwater visual surveys of density and size-frequency distribution of nine reef fish species (including herbivores, zoobenthivores and piscivores) to infer ontogenetic migration patterns in a Caribbean coral reef seascape. Lutjanus griseus and L. apodus appeared to undertake long distance migrations, as juveniles were abundant in bays while adults only found on offshore reefs. Conversely, Acanthurus bahianus and Scarus taeniopterus were seen only in bay habitats at close proximity to the coral reef or on the reef itself, indicating short distance ontogenetic movements. Haemulon flavolineatum and Ocyurus chrysurus displayed a stepwise pattern in which the smallest juveniles occupied the mouth of the bay, intermediate-sized individuals were found deeper in the bay and adults were found on nearby coral reefs. These correlation-based studies suggest ontogenetic movement patterns; however, differences in growth rates or differential mortality among habitats could result in similar density and size distribution patterns (Gillanders et al. 
2003). A more direct measure of connectivity between these habitats is necessary to truly understand the importance of coastal nursery habitats to supporting coral reef fish populations.

The most effective means of assessing functional connectivity in a coral reef seascape is to directly measure the movement of individuals between juvenile and adult habitats. Tracking animal migration has historically been accomplished using markrecapture techniques with extrinsic markers (Seber 1982; Hobson and Norris 2008). Advances in archival tag technology have provided impressive data on long distance migrations of large tunas (Block et al. 2005) and sharks (Skomal et al. 2009). Acoustic tags have provided similar movement data on smaller spatial scales (Parsons et al. 2003; Luo et al. 2009). Luo et al. (2009) quantified gray snapper, L. griseus, movement among seagrass beds, mangroves and coastal coral reefs in southern Florida using ultrasonic acoustic and mini-archival tags, as well as an underwater video monitoring system. They found that $L$. griseus exhibited diel movement between mangroves and seagrass beds and seasonal bay-to-ocean movements during the known spawning season of L. griseus. However, the study was conducted on large bodied individuals over relatively short spatial scales, and as the authors noted, there were numerous ways for fish to move between the bay and reefs while avoiding detection by the receivers. While extrinsic tags provide some of the most direct measures of movement patterns of mobile fishes, not all species or life stages are amenable to archival or acoustic tags (Fairweather and Quinn 1993). Many species of coral reef fish species are highly fecund, producing millions of tiny offspring that are difficult to tag without introducing significant handling effects. In 
addition, the high mortality rate of young fish makes the probability of recovering tagged individuals extremely low. Dealing with these limitations over the potentially large spatial and temporal scales at which these linkages occur makes the use of conventional mark-recapture techniques daunting (Thorrold et al. 2002).

\section{Tracking movement with ecogeochemistry}

Ecogeochemistry is the use of stable isotopes to reconstruct the movement and dietary histories of animals. The ecogeochemistry approach relies on spatial variations in the abundances of ambient isotope or elemental ratios (e.g. isoscapes [West et al. 2010]) that are recorded in the chemical composition of tissues as an animal lives and feeds in different habitats. This approach has several distinct advantages over conventional tagging techniques for tracking ontogenetic movement of small-bodied species and early life-history stages. All animals within a specified habitat are inherently labeled without having to be captured and tagged. Therefore, every individual captured some time later and assigned to a habitat based on geochemical signatures is effectively a recapture. While extrinsic markers come with tagging and handling effects that limit their use to large bodied animals, stable isotopes are natural tags and do affect the behavior or mortality rates of fish (McFarlane 1990).

To be successfully applied in the field, an ecogeochemistry approach must do each of the following (Hobson et al. 2010): 1) establish a baseline isoscape that characterizes distinct geochemical signatures in different habitats, 2) constrain tissue turnover rates that determine the period of spatial integration of geochemical signatures 
for a particular animal tissue and 3) identify isotope or elemental fractionation factors between consumer and $\operatorname{diet}\left(\Delta^{13} \mathrm{C}_{\mathrm{C}-\mathrm{D}}\right)$, or between animals and the ambient environment, that offset animal geochemical signatures from the baseline isoscape.

The mangrove-coral reef-seagrass continuum provides an excellent system for tracking the movement of fish between coastal wetlands and coral reefs using an ecogeochemistry approach (Marguillier et al. 1997; Lugendo et al. 2006; Nagelkerken et al. 2008a). Measurements of $\delta^{13} \mathrm{C}$ have proven particularly useful in distinguishing production based on marine phytoplankton, $\mathrm{C} 4$ plants such as seagrasses, and $\mathrm{C} 3$ plants such as mangroves (Fry and Sherr 1984). Phytoplankton often exhibit a cross-shelf gradient in $\delta^{13} \mathrm{C}$ values, ranging from -16 to $-22 \%$, with nearshore signatures more ${ }^{13} \mathrm{C}$ heavy than offshore signatures (Hobson 1999). This is typically due to higher nutrient concentrations nearshore resulting in greater overall productivity, coupled with patterns in phytoplankton species composition and growth rates with distance offshore (Michener and Schell 1994). In coastal wetlands, photosynthesis using phosphoenolpyruvatecarboxylase produces significantly higher $\delta^{13} \mathrm{C}$ signatures (-5 to $-12 \%$ ) in bulk tissues of seagrass compared to mangroves that use ribulose 1,5-bisphosphate-carboxylase and generate $\delta^{13} \mathrm{C}$ values of -26 to $-30 \%$ in bulk tissues (Farquhar et al. 1989). These habitatspecific carbon isotope signatures are reflected in the tissues of resident invertebrates and fishes from mangroves, seagrass beds and coral reefs (Fry et al. 1982; Marguillier et al. 1997; Nagelkerken and van der Velde 2004). The result is a well-constrained isoscape in coastal tropical environments that can be used to track the movement of animals through the seascape. For instance, Fry (1981) found that resident brown shrimp, Penaeus 
aztecus, on offshore habitats with a phytoplankton-based food web were ${ }^{13} \mathrm{C}$-depleted relative to those from a seagrass-based food web. However, many newly settled sub-adult P. aztecus collected on offshore reefs had $\delta^{13} \mathrm{C}$ values typical of individuals in seagrass meadows, suggesting that they had recently migrated from seagrass nursery habitats. Similarly, Nakamura et al. (2008) found that L. fulvus collected on coral reefs gradually shifted from a mangrove $\delta^{13} \mathrm{C}$ signature to a coral reef $\delta^{13} \mathrm{C}$ signature with increased size. Based on the muscle $\delta^{13} \mathrm{C}$ values of the subadult population of $L$. fulvus on the coral reef, they suggested that $88 \%$ of individuals analyzed used mangroves as juvenile nurseries.

The second issue that needs to be resolved before ecogeochemistry can be used to track fish movement is constraining tissue turnover rates. For metabolically active tissues, the time period over which the spatial isotope information is integrated varies with tissue type and life stage (Tieszen et al. 1983; Herzka 2005). Fast turnover rates in soft tissues, including muscle, can make it challenging to distinguish recent immigrants from those that have equilibrated to the isotopic signature of the new habitat (Hesslein et al. 1991; Fry et al. 1999; Herzka et al. 2002). Stable isotope signatures in metabolically inactive tissues, including otoliths, are not reworked following deposition. Indeed, otoliths have several properties that make them an ideal tissue for retrospective analysis of ontogenetic migration (Campana and Neilson 1985; Campana 1999; Campana and Thorrold 2001). Otoliths accurately record information about the fish's metabolic activity and the physical and chemical characteristics of the water in which the fish resides (Thorrold et al. 1997). In addition, otoliths grow throughout the life of a fish by means of successive addition of daily and annual aragonitic growth bands on a proteinaceous 
matrix, providing a life-long record of geochemical signatures (Degens et al. 1969; Campana 1999).

Although differences in bulk otolith $\delta^{13} \mathrm{C}$ signatures have been documented along the mangrove-coral reef-seagrass continuum (Chittaro et al. 2004; Nakamura et al. 2008; Mateo et al. 2010), interpreting carbon isotope signatures in otoliths remains a difficult proposition. Otolith carbon comes from dissolved inorganic carbon (DIC) and metabolic sources in the form of respired $\mathrm{CO}_{2}$ and dietary derived protein. These two sources have $\delta^{13} \mathrm{C}$ values that can differ by more than $20 \%$. Because DIC typically contributes the majority of carbon in otoliths (Kalish 1991; Thorrold et al. 1997; Solomon et al. 2006), dietary signatures in otoliths are almost inevitably diluted by this DIC signature. More importantly, there is no consensus regarding the exact contributions of these two end members, making it difficult to mathematically correct for the DIC dilution effect. Variations in bulk otolith $\delta^{13} \mathrm{C}$ values appear to reflect a number of factors, including metabolism (Kalish 1991; Weidman and Millner 2000; Stephenson et al. 2001), diet and DIC $\delta^{13} \mathrm{C}$ values (Schwartz et al. 1998), and environmental conditions (Mulcahy et al. 1979; Kalish 1991).

One potential method for avoiding the confounding effect of DIC-derived carbon on otolith $\delta^{13} \mathrm{C}$ values is to focus on otolith protein that may constitute up to $10 \%$ (by weight) of a fish otolith (Degens et al. 1969; Sasagawa and Mugiya 1996; Murayama et al. 2002). Analyzing otolith proteins provides an unambiguous dietary signature that avoids the effects of DIC dilution and variable metabolic carbon contribution on otolith $\delta^{13} \mathrm{C}$. Bulk protein SIA, however, is not without problems. Otolith protein represents a 
mixture of amino acids (AAs) directly routed from dietary protein and AAs biosynthesized from a bulk carbon pool consisting of dietary protein, lipids and carbohydrates (Schwarcz 1991; Ambrose and Norr 1993). Furthermore, it can be difficult to distinguish between changes in $\delta^{13} \mathrm{C}$ associated with diet or trophic shifts versus changes due to movement among habitats with different $\delta^{13} \mathrm{C}_{\text {Base }}$ values (Post 2002). This is particularly true when tracking the ontogenetic shifts of highly migratory fishes, where juveniles and adults often occupy different habitats and different trophic levels (Eggleston et al. 1998; Cocheret de la Morinière et al. 2003).

The third underlying principle of ecogeochemistry requires well-constrained fractionation factors between consumer and $\operatorname{diet}\left(\Delta^{13} \mathrm{C}_{\mathrm{C}-\mathrm{D}}\right)$ for specific tissues. While carbon is typically thought to fractionate conservatively through marine food webs $\left(\Delta{ }^{13} \mathrm{C}_{\mathrm{C}-\mathrm{D}}=0\right.$ to $1 \%$ [DeNiro and Epstein 1978; Fry et al. 1978]), there can be significant variation in $\Delta^{13} \mathrm{C}_{\mathrm{C}-\mathrm{D}}$, ranging from -3 to $+5 \%$, depending on consumer taxa, diet and tissues analyzed (Vander Zanden and Rasmussen 2001; McCutchan et al. 2003; Elsdon et al. 2010). Furthermore, the $\delta^{13} \mathrm{C}$ value of a consumer tissue may not always follow bulk diet $\delta^{13} \mathrm{C}$ values because the carbon skeletons of different dietary constituents (proteins, lipids and carbohydrates) can be routed to different tissue constituents ("isotopic routing"; Schwarcz 1991). These factors can make interpretations of animal movement through isoscapes based on bulk protein $\delta^{13} \mathrm{C}$ values challenging.

The opportunity now exists to increase the specificity of ecogeochemical studies by analyzing $\delta^{13} \mathrm{C}$ values of specific biochemical compounds, including AAs, thanks to recent advances in gas chromatography-combustion-isotope ratio monitoring-mass 
spectrometry (GC-C-irm-MS) (Merritt et al. 1994; Meier-Augenstein 1999; Sessions 2006). This compound-specific SIA approach has the potential to provide more detailed information about diet (Fantle et al. 1999; Fogel and Tuross 2003; Popp et al. 2007) and the sources of complex mixtures of organic matter (Uhle et al. 1997; McCarthy et al. 2004) than conventional bulk tissue SIA. Several studies have shown that typical bulk muscle fractionation factors of 0 to $1 \%$ are underlain by little to no fractionation in essential AAs and large fractionations in non-essential AAs (> 7\%) (Hare et al. 1991; Howland et al. 2003; Jim et al. 2006). Essential AAs, whose carbon skeletons cannot be synthesized de novo, reflect the $\delta^{13} \mathrm{C}_{\text {Base }}$ values without the confounding influence of trophic fractionation. These AAs should provide a more accurate tracer of the environmental isoscapes in which the animal was feeding. Conversely, non-essential AA $\delta^{13} \mathrm{C}$ values reflect metabolic processing and correlate with diet quality and composition. The compound-specific SIA technique has been applied to muscle and biominerals, such as eggs shells, mollusk shells and bones, to assess changes in diet and habitat use (Hare et al. 1991; Johnson et al. 1993; Silfer et al. 1994; Popp et al. 2007) for a variety of marine and terrestrial taxa. However, researchers have yet to apply compound-specific SIA to accretionary tissues in fishes, including otoliths, that would allow for retrospective analyses of diet and movement.

\section{Study species}

Ehrenberg's snapper (Lutjanus ehrenbergii, Family: Lutjanidae, Peters 1869) is a common reef-associated snapper species in the tropical Indo-West Pacific that is widely 
distributed from the Red Sea and East Africa to the Solomon and Mariana Islands (Allen 1985; Allen and Talbot 1985). L. ehrenbergii is a commercially targeted species throughout its range (Sumaila et al. 2007). Adult L. ehrenbergii form large schools on coral reefs between 5 and $20 \mathrm{~m}$ deep, often with the congeneric species $L$. kasmira, $L$. fulviflamma and L. monostigma. L. ehrenbergii is an important predator in tropical seascapes, feeding primarily on small fish and invertebrates, with no notable ontogenetic diet shift (Blaber et al. 1990). Mean total length (TL) of adult L. ehrenbergii is $200 \mathrm{~mm}$ but can reach a maximum of $350 \mathrm{~mm}$ (Allen 1985). While the length at maturity for $L$. ehrenbergii is not well known, it is thought to be greater than $120 \mathrm{~mm}$. Minimum population doubling time is 1.4 to $4.4 \mathrm{yrs}$.

L. ehrenbergii is a dioecious, batch spawning species on coral reefs that releases gametes into the water column for external fertilization (Allen 1985). The pelagic larval duration (PLD) of L. ehrenbergii larvae is not currently known, however mean PLDs for the family Lutjanidae are typically between three to four weeks but can be up to six weeks (Brothers et al.1983; Stobutzki and Bellwood 1997; Zapata and Herron 2002). Larvae are thought to settle in high numbers in coastal wetland habitats due to a combination of the hydrodynamic properties of seagrass beds and coral reefs, coupled with active selection behavior of larvae for coastal wetland habitats (Verweij et al. 2006; Huijbers et al. 2008). Juvenile L. ehrenbergii $(<120 \mathrm{~mm})$ are very abundant in coastal wetlands, including mangroves and seagrass beds, but can also be found in other nearshore estuarine habitats, including tidal channels and patch reefs (Dorenbosch et al. 2004b; Unsworth et al. 2009). Juvenile L. ehrenbergii show strong site-fidelity to 
relatively small home ranges, but do exhibit diel movements between mangroves typically used as shelter during the day and seagrass beds used for feeding at night (Dorenbosch et al. 2004a). Sub-adult L. ehrenbergii $(\mathrm{TL}>120 \mathrm{~mm}$ ) are thought to undergo an ontogenetic habitat shift from coastal wetland nursery habitats to coral reefs. As such, L. ehrenbergii is an excellent species for tracking ontogenetic migration of a commercially and economically important coral reef fish between juvenile nurseries and coral reefs in a tropical seascape.

\section{Thesis objectives}

The goal of this thesis was to demonstrate the functional connectivity of a coral reef fish in a tropical seascape. Specific objectives were to: i) develop a method to analyze individual AA $\delta^{13} \mathrm{C}$ values from otoliths via GC-C-irm-MS (Chapters 2 and 3), and ii) evaluate the contribution of wetland and reef habitats to L. ehrenbergii populations on coastal, shelf and oceanic coral reefs in the Red Sea (Chapters 4 and 5). The objectives of this thesis were accomplished in four chapters.

In chapter two, common mummichogs (Fundulus heteroclitus, Linnaeus 1766) were reared on four isotopically distinct diets to determine stable carbon isotope fractionation factors $\left(\Delta^{13} \mathrm{C}_{\mathrm{C}-\mathrm{D}}\right)$ for individual AAs between diet and consumer. Modest bulk tissue $\Delta^{13} \mathrm{C}_{\mathrm{C}-\mathrm{D}}$ values reflected relatively large fractionation for many non-essential AAs and little to no fractionation for all essential AAs. The AA $\Delta{ }^{13} \mathrm{C}_{\mathrm{C}-\mathrm{D}}$ values from this study were used in subsequent chapters to examine residence of fish in isotopically distinct habitats. The third chapter described the application of compound-specific SIA to 
analyze AA $\delta^{13} \mathrm{C}$ values from otoliths. Carbon isotope values of AAs in otolith and muscle of L. ehrenbergii were highly correlated within and among coastal habitats, providing a robust $\delta^{13} \mathrm{C}$ tracer of residence in isotopically distinct habitats.

Chapter four explored the potential for geochemical signatures in otoliths of snapper (Family: Lutjanidae) to act as natural tags of residency in seagrass beds, mangroves and coral reefs in the Red Sea, Caribbean Sea and Eastern Pacific Ocean. Essential AA $\delta^{13} \mathrm{C}$ values in otoliths varied as a function of habitat type and provided a better tracer of residence in different juvenile nursery habitats than conventional bulk SIA alone. In the fifth chapter, we evaluated the relative contribution of coastal wetland and reef habitats to L. ehrenbergii populations on coastal, shelf and oceanic coral reefs in the Red Sea. This chapter examined the role that seascape attributes, including configuration, habitat spacing and water depth, played in determining the functional connectivity of $L$. ehrenbergii populations in the Red Sea. This thesis presents the development and first application of a method for tracking fish movement in the marine environment using otolith AA $\delta^{13} \mathrm{C}$ analysis. This research provides quantitative scientific support for establishing realistic population connectivity models that can be used to design and implement effective marine reserve networks. 


\title{
CHAPTER TWO
}

\section{Carbon isotope fractionation of amino acids in fish muscle reflects biosynthesis and isotopic routing from dietary protein}

\author{
Kelton W. McMahon ${ }^{1}$ \\ ${ }^{1}$ Massachusetts Institute of Technology and Woods Hole Oceanographic Institution \\ Joint Program in Oceanography and Ocean Engineering, \\ Woods Hole Oceanographic Institution, Woods Hole, MA 02543, USA \\ Marilyn L. Fogel ${ }^{2}$ \\ ${ }^{2}$ Geophysical Laboratory, \\ Carnegie Institution of Washington, Washington, D.C. 20015, USA \\ Travis S. Elsdon ${ }^{3}$ \\ ${ }^{3}$ Southern Seas Ecology Laboratories, School of Earth and Environmental Sciences, \\ University of Adelaide, Adelaide, SA 5005, Australia \\ Simon R. Thorrold ${ }^{4}$ \\ ${ }^{4}$ Biology Department, \\ Woods Hole Oceanographic Institution, Woods Hole, MA 02543, USA
}

Reprinted with permission from the Journal of Animal Ecology (modified to MIT thesis specifications) (C 2010 British Ecological Society and John Wiley \& Sons, Inc.

McMahon KW, Fogel ML, Elsdon TS, Thorrold SR (2010) Carbon isotope fractionation of amino acids in fish muscle reflects biosynthesis and isotopic routing from dietary protein. Journal of Animal Ecology 79:1132-1141 


\section{ABSTRACT}

Analysis of stable carbon isotopes is a valuable tool for studies of diet, habitat use, and migration. However, significant variability in the degree of trophic fractionation $\left(\Delta^{13} \mathrm{C}_{\mathrm{C}-\mathrm{D}}\right)$ between consumer $(\mathrm{C})$ and diet $(\mathrm{D})$ has highlighted our lack of understanding of the biochemical and physiological underpinnings of stable isotope ratios in tissues. An opportunity now exists to increase the specificity of dietary studies by analyzing the $\delta^{13} \mathrm{C}$ values of amino acids (AAs). Common mummichogs (Fundulus heteroclitus, Linnaeus 1766) were reared on four isotopically distinct diets to examine individual $A A \Delta \Delta^{13} \mathrm{C}_{\mathrm{C}-\mathrm{D}}$ variability in fish muscle. Modest bulk tissue $\Delta^{13} \mathrm{C}_{\mathrm{C}-\mathrm{D}}$ values reflected relatively large trophic fractionation for many non-essential AAs and little to no fractionation for all essential AAs. Essential AA $\delta^{13} \mathrm{C}$ values were not significantly different between diet and consumer $\left(\Delta^{13} \mathrm{C}_{\mathrm{C}-\mathrm{D}}=0.0 \pm 0.4 \%\right.$ ) , making them ideal tracers of carbon sources at the base of the food web. Stable isotope analysis of muscle essential AAs provides a promising tool for dietary reconstruction and identifying baseline $\delta^{13} \mathrm{C}$ values to track animal movement through isotopically distinct food webs. Non-essential AA $\Delta{ }^{13} \mathrm{C}_{\mathrm{C}-\mathrm{D}}$ values showed evidence of both de novo biosynthesis and direct isotopic routing from dietary protein. We attributed patterns in $\Delta^{13} \mathrm{C}_{\mathrm{C}-\mathrm{D}}$ to variability in protein content and $\mathrm{AA}$ composition of the diet as well as differential utilization of dietary constituents contributing to the bulk carbon pool. This variability illustrates the complicated nature of metabolism and suggests caution must be taken with the assumptions used to interpret bulk stable isotope data in dietary studies. Our study is the first to investigate the 
expression of AA $\Delta{ }^{13} \mathrm{C}_{\mathrm{C}-\mathrm{D}}$ values for a marine vertebrate and should provide for significant refinements in studies of diet, habitat use, and migration using stable isotopes.

\section{INTRODUCTION}

Stable isotope analysis (SIA) has become a routine tool in ecology for studies of diet and trophic dynamics (Peterson and Fry 1987; Gannes et al. 1998; Michener and Kaufmann 2007), habitat use (McMahon et al. 2005; Cherel et al. 2007) and animal migration (Hansson et al. 1997; Hobson 1999; Rubenstein and Hobson 2004). Bulk tissue SIA studies using carbon rely upon the assumption that the isotope composition of a consumer reflects the weighted average of the carbon isotope compositions of its diet with a small amount of diet (D) to consumer (C) fractionation, hereafter $\Delta^{13} \mathrm{C}_{\mathrm{C}-\mathrm{D}}$ (typically 0 to 1\%o [DeNiro and Epstein 1978; Fry et al. 1978]). Despite the prevalence of bulk SIA in ecological studies of diet and food webs, there are still a number of confounding factors that can complicate interpretations of bulk SIA data.

The carbon isotope composition at the base of the food web $\left(\delta^{13} \mathrm{C}_{\text {base }}\right)$ ultimately determines the $\delta^{13} \mathrm{C}$ values of higher trophic level consumers. Without suitable estimates of $\delta^{13} \mathrm{C}_{\text {base, }}$, which can vary both spatially and temporally (Vander Zanden and Rasmussen 1999; Graham et al. 2010), it is difficult to interpret consumer $\delta^{13} \mathrm{C}$ values using bulk SIA in light of potential changes in food web structure versus variations in $\delta^{13} \mathrm{C}_{\text {base }}$ (Post 2002). This can be particularly problematic when studying the diet and trophic dynamics of highly migratory marine organisms that move among isotopically distinct food webs (Estrada et al. 2005; Graham et al. 2010). There can also be significant variation in 
$\Delta{ }^{13} \mathrm{C}_{\mathrm{C}-\mathrm{D}}$, ranging from -3 to $+5 \%$, depending on consumer taxa, diet, and tissues analyzed (Gannes et al. 1997; Vander Zanden and Rasmussen 2001; McCutchan et al. 2003; Olive et al. 2003). Furthermore, the $\delta^{13} \mathrm{C}$ value of consumer tissue may not always follow bulk diet $\delta^{13} \mathrm{C}$ values because the carbon skeletons of different dietary constituents (proteins, lipids, and carbohydrates) can be routed to different tissue constituents ("isotopic routing" [Schwarcz 1991]). Several studies have emphasized the problems that isotopic routing poses to the interpretation of stable isotope data in diet reconstructions (Parkington 1991; Schwarcz and Schoeninger, 1991; Ambrose and Norr 1993). All of these factors can make interpretations of bulk tissue SIA challenging for studies of diet and migration, prompting a call for studies that examine the biochemical and physiological basis of stable isotope ratios in ecology (Gannes et al. 1997; Gannes et al. 1998; Karasov and Martínez del Rio 2007).

The opportunity now exists to increase the specificity of dietary studies by analyzing $\delta^{13} \mathrm{C}$ values of specific biochemical compounds, including amino acids (AAs), thanks to recent advances in gas chromatography-combustion-isotope ratio monitoring mass spectrometry (GC-C-irmMS) (Merritt et al. 1994; Meier-Augenstein 1999; Sessions 2006). Stable isotope analysis of individual AAs has the potential to provide more detailed information about diet (Fantle et al. 1999; Fogel and Tuross 2003; Popp et al. 2007) and the sources of complex mixtures of organic matter (Uhle et al. 1997; McCarthy et al. 2004) than conventional bulk tissue SIA.

There have been very few controlled feeding experiments examining the trophic fractionation of individual AAs between diet and consumer (Hare et al. 1991; Howland et 
al. 2003; Jim et al. 2006). Studies to date found modest bulk tissue $\Delta{ }^{13} \mathrm{C}_{\mathrm{C}-\mathrm{D}}$ values $(\sim 1 \%)$ actually reflected an average of relatively large fractionations in many non-essential AAs and comparatively little fractionation in most essential AAs. However, there was considerable variation in $\Delta{ }^{13} \mathrm{C}_{\mathrm{C}-\mathrm{D}}$ across diets and individual AAs among studies. Furthermore, these studies all dealt with terrestrial vertebrates (pigs and rats), yet no controlled feeding experiments looking at compound-specific $\Delta{ }^{13} \mathrm{C}_{\mathrm{C}-\mathrm{D}}$ have been conducted on an aquatic vertebrate. Given the variability in bulk tissue $\Delta{ }^{13} \mathrm{C}_{\mathrm{C}-\mathrm{D}}$ across terrestrial and aquatic taxa (Vander Zanden and Rasmussen 2001; McCutchan et al. 2003), it is important to determine the mechanisms leading to variability in the fractionation of $\mathrm{AA} \delta^{13} \mathrm{C}$ values for aquatic taxa.

We reared common mummichogs (Fundulus heteroclitus, Linnaeus 1766) on four isotopically distinct diets to examine trophic fractionation $\left(\Delta^{13} \mathrm{C}_{\mathrm{C}-\mathrm{D}}\right)$ of individual AAs between diet and consumer. By choosing an herbivorous diet, two carnivorous diets and an omnivorous diet, we aimed to examine the potential variability in $\mathrm{AA} \Delta \Delta^{13} \mathrm{C}_{\mathrm{C}-\mathrm{D}}$. We addressed the specific question: What is the isotopic relationship between diet and consumer for individual AAs in fish muscle? We focused on muscle tissue, because it is one of the most commonly used tissues in ecological studies of diet and trophic dynamics. We hypothesized that non-essential AA $\delta^{13} \mathrm{C}$ values would show evidence of both de novo biosynthesis and direct isotopic routing from dietary protein while essential AA $\delta^{13} \mathrm{C}$ values would only reflect isotopic routing. Similar results were found for pigs (Hare et al. 1991; Howland et al. 2003) and rats (Jim et al. 2006), although the magnitude and direction of trophic fractionation was quite variable. We also hypothesized that fish 
fed a high protein content diet would exhibit a greater degree of isotopic routing because routing is thought to be more efficient than de novo biosynthesis when non-essential AAs are sufficiently available (Ambrose and Norr 1993, Tieszen and Fagre 1993, Jim et al. 2006). Finally, we predicted that a deficit in non-essential AA abundance in diet relative to consumer tissue would result in higher trophic fractionation than would be expected from diets with excess non-essential AAs due to enhanced biosynthesis. Our study is the first to investigate the expression of individual AA $\Delta{ }^{13} \mathrm{C}_{\mathrm{C}-\mathrm{D}}$ values for an aquatic vertebrate and should provide significant refinements to studies of diet, habitat use and migration using stable isotopes.

\section{METHODS AND MATERIALS}

\section{Feeding experiment}

We conducted a controlled feeding experiment on juvenile mummichogs (Fundulus heteroclitus) reared at the Atlantic Ecology Division, U.S. Environmental Protection Agency, in Narragansett, Rhode Island, USA. Adult $F$. heteroclitus collected from a salt marsh in Sandwich, Massachusetts were held in flow through seawater at temperatures elevated above ambient to induce spawning. Eggs from two spawnings were collected and transferred to tanks and allowed to hatch. Juvenile fish were reared on an Artemia diet for six weeks (approximate length: $11 \mathrm{~mm}$ ), after which they were transferred to experimental tanks.

Experimental tanks consisted of twelve 40 gallon aquaria with flow through seawater at ambient temperature $\left(20^{\circ} \mathrm{C}\right)$ in two randomly positioned rows under a $12: 12$ 
hr light:dark cycle from fluorescent tubes. Twenty juvenile $F$. heteroclitus were placed in each tank. Dietary manipulations consisted of triplicate tanks of fish reared on one of four isotopically distinct diets. A plant-based commercial fish pellet (Vegi-Pro, Freedom Feeds Inc., Urbana, OH, USA) consisted primarily of wheat and soy with a small contribution from corn meal. A second commercial fish pellet (Bio-Vita, Bio-Oregon, Westbrook, ME, USA) consisted of fish and krill meal, wheat gluten and whey protein. Two natural animal-based diets, squid and clam, were obtained from a local supermarket, homogenized and then freeze-dried before being fed to the experimental fish. Proximate analysis of moisture by loss on drying at $135^{\circ} \mathrm{C}$ for 2 hours (Method 930.15 [AOAC 2005]), crude protein by combustion (Method 990.03 [AOAC 2005]), crude fat by ether extraction (Method 920.39 [AOAC 2005]), crude fiber (Method 978.10 [AOAC 2005]), and ash (Method 942.05 [AOAC 2005]) were conducted on all four diets at the New Jersey Feed Laboratory, Trenton, New Jersey, USA. Carbohydrate content was determined as $100 \%$ minus the sum of moisture, protein, fat, and ash. Amino acid compositions (16 individual AAs) (Method 994.12 [AOAC 2005]) of the four diets and fish muscle from each treatment were also determined at the New Jersey Feed Laboratory $(\mathrm{n}=3$ replicates $)$.

\section{Sample preparation and analysis}

Fish were fed to saturation once per day, and tanks were cleaned of excess food and bio-films every three days. Fish were reared on isotopically distinct diets for eight weeks and more than doubled in biomass during that time. All fish were then sacrificed in 
an ice slurry, frozen and freeze-dried for $72 \mathrm{hrs}$. White muscle was removed from each fish, homogenized using a mortar and pestle, and subdivided into two portions, one for bulk tissue SIA and the other for compound-specific SIA. Results from the bulk tissue analyses are presented elsewhere (Elsdon et al. 2010).

Approximately $2 \mathrm{mg}$ of each sample, both diet and fish muscle, were acid hydrolyzed in $1 \mathrm{ml}$ of $6 \mathrm{~N} \mathrm{HCl}$ at $110^{\circ} \mathrm{C}$ for $20 \mathrm{hrs}$ to isolate the total free AAs. Samples were neutralized with ultra-pure water and evaporated to dryness via rotary evaporation to remove $\mathrm{HCl}$ before being resuspended in $1 \mathrm{~mL}$ of ultra-pure water. Samples were then passed through solid phase extraction-C18 columns to remove particulates and melanoidins. After drying under a stream of $\mathrm{N}_{2}$ gas, the total free AAs were derivatized by esterification with acidified iso-propanol followed by acetylation with trifluoroacetic anhydride (Silfer et al. 1991). The resulting derivatized AAs were diluted to a concentration of $2 \mu \mathrm{g} \mu \mathrm{l}^{-1}$ in dichloromethane.

Approximately $2 \mu \mathrm{g}$ of AAs (via $1 \mu$ injection) were injected on column in splitless mode at $220^{\circ} \mathrm{C}$ and separated on an HP Ultra- 1 column $(50 \mathrm{~m}$ length, $0.32 \mathrm{~mm}$ inner diameter and $0.52 \mu \mathrm{m}$ film thickness; Hewlett Packard, Wilmington, Delaware, USA) in a Varian 3400 Gas Chromatograph (GC) at the Carnegie Geophysical Laboratory, Washington, D.C., USA. Gas chromatography conditions were set to optimize peak separation and shape as follows: initial temperature $75^{\circ} \mathrm{C}$ held for $2 \mathrm{~min}$; ramped to $90^{\circ} \mathrm{C}$ at $4{ }^{\circ} \mathrm{C} \min ^{-1}$, held for 4 min.; ramped to $185^{\circ} \mathrm{C}$ at $4^{\circ} \mathrm{C} \min ^{-1}$, held for 5 min.; ramped to $250^{\circ} \mathrm{C}$ at $10{ }^{\circ} \mathrm{C} \min ^{-1}$, held $2 \mathrm{~min}$.; ramped to $300^{\circ} \mathrm{C}$ at $20^{\circ} \mathrm{C} \min ^{-1}$, held for 8 min. The separated AA peaks were combusted in a Finnegan GC continuous flow 
interface at $980^{\circ} \mathrm{C}$, then measured as $\mathrm{CO}_{2}$ on a Finnegan MAT Delta ${ }^{\text {Plus }} \mathrm{XL}$ or Delta V Advantage isotope ratio mass spectrometer. Twelve of the 16 individual AAs identified had sufficient baseline separation for stable carbon isotope analysis, accounting for approximately $80 \%$ of the total AA percent abundance. Glutamic acid and aspartic acid peaks contained unknown contributions from glutamine and asparagine, respectively, due to conversion to their dicarboxylic acids during acid hydrolysis. For consumer muscle, three replicate tanks were analyzed per treatment, with three fish analyzed per tank. Three replicate samples of each of the four diets were analyzed following the same procedure as the fish muscle. All compound-specific SIA samples were analyzed in duplicate along with AA standards of known isotopic composition.

\section{Data analysis}

Stable isotopes were expressed in standard delta $(\delta)$ notation:

$$
\delta^{13} C_{\text {sample }}=\left(\frac{{ }^{13} C / /{ }^{12} C_{\text {sample }}}{{ }^{13} C /{ }^{12} C_{\text {std }}}-1\right) * 1000
$$

where the standard for carbon was VPDB. Trophic fractionation factors $\left(\Delta^{13} \mathrm{C}_{\mathrm{C}-\mathrm{D}}\right)$ were calculated for each treatment as $\Delta{ }^{13} \mathrm{C}_{\mathrm{C}-\mathrm{D}}=\delta^{13} \mathrm{C}_{\mathrm{C}}-\delta^{13} \mathrm{C}_{\mathrm{D}}$, where $\delta^{13} \mathrm{C}_{\mathrm{C}}$ and $\delta^{13} \mathrm{C}_{\mathrm{D}}$ represent the $\delta^{13} \mathrm{C}$ values of the consumer and diet, respectively. Standardization of runs was achieved using intermittent pulses of a $\mathrm{CO}_{2}$ reference gas of known isotopic value.

To correct for the introduction of exogenous carbon and kinetic fractionation during derivatization (Silfer et al. 1991), AA standards of known isotopic value were derivatized and analyzed concurrently with the samples. Error for determining the 
isotopic composition of the exogenous carbon added during derivatization averaged \pm 0.4\% . Differences in bulk $\delta^{13} \mathrm{C}$ of diet and fish muscle among treatments were assessed using separate one-way analyses of variance (ANOVAs) and Tukey's honestly significant difference (HSD) post-hoc tests $(\alpha=0.05)$. Differences in individual AA $\delta^{13} \mathrm{C}$ values within and among treatments for both diet and fish muscle were determined using separate model I (treatment and AA factors fixed) two-way ANOVAs and Tukey's HSD post-hoc tests $(\alpha=0.05)$. To examine differences in individual AA $\Delta{ }^{13} \mathrm{C}_{\mathrm{C}-\mathrm{D}}$ both within and among treatments, AAs were a priori subdivided into non-essential and essential AAs. Differences in non-essential and essential AA $\Delta{ }^{13} \mathrm{C}_{\mathrm{C}-\mathrm{D}}$ values were analyzed using separate model I (treatment and AA factors fixed) two-way ANOVAs and Tukey's HSD post-hoc tests. Separate two-sided one sample t-tests were used to determine if AA $\Delta{ }^{13} \mathrm{C}$ values were significantly different from $0 \%$. Linear regressions were performed to compare AA $\delta^{13} \mathrm{C}$ values in muscle $\left(\delta^{13} \mathrm{C}_{\text {muscle_AA }}\right)$ to 1$)$ their respective dietary AAs $\left(\delta^{13} \mathrm{C}_{\text {diet_AA }}\right)$ and 2$)$ the bulk diets $\left(\delta^{13} \mathrm{C}_{\text {bulk_diet }}\right)$. Using the AA composition data, we determined the difference in AA percent abundance between diet and muscle, with negative values indicating a deficit in AA abundance in diet relative to muscle. To look for trends in trophic fractionation as a function of AA composition, we conducted a correlation analysis between the AA percent abundance difference and $\mathrm{AA} \Delta \Delta^{13} \mathrm{C}_{\mathrm{C}-\mathrm{D}}$ for all AAs showing de novo biosynthesis $\left(\Delta^{13} \mathrm{C}_{\mathrm{C}-\mathrm{D}}\right.$ significantly different from $0 \%$ ). All statistics were performed in Prism version 4.0. 


\section{RESULTS}

Bulk $\delta^{13} \mathrm{C}$ values were significantly different among the diets (one-way ANOVA, $\mathrm{df}=3,19, \mathrm{~F}=717.7, \mathrm{p}<0.05$; Fig. 2.1) and fish muscle (one-way ANOVA, $\mathrm{df}=3,11, \mathrm{~F}$ $=321.8, \mathrm{p}<0.05 ;$ Fig. 2.1) across treatments. The Vegi-Pro diet had the highest carbohydrate content (73\%) and lowest crude fat $(6 \%)$ and protein (8\%) content, while the squid and clam diets had the highest crude fat (18\%) and protein $(69 \%$ and $71 \%$ respectively) content and almost no carbohydrates (Table 2.1). Bio-Vita content was generally intermediate between the Vegi-Pro and the animal-based diets, with the exception of a high crude fat content (24\%).

The mean range in $\delta^{13} \mathrm{C}$ values across all $12 \mathrm{AAs}$ analyzed was $27.9 \pm 6.9 \%$ for $\operatorname{diet}$ (Fig. 2.1a) and $23.6 \pm 2.6 \%$ for fish muscle (Fig. 2.1b). We found significant differences in dietary $\delta^{13} \mathrm{C}$ values (Fig. 2.1a) among individual AAs (two-way ANOVA, $\mathrm{df}=11,96, \mathrm{~F}=1239.0, \mathrm{p}<0.05$ ) and among diet treatments (two-way ANOVA, $\mathrm{df}=3$, $96, \mathrm{~F}=552.0, \mathrm{p}<0.05)$. However, variability in $\mathrm{AA} \delta^{13} \mathrm{C}$ values was not consistent among diet treatments, generating a significant diet*AA interaction (two-way ANOVA, $\mathrm{df}=33,96, \mathrm{~F}=21.71, \mathrm{p}<0.05$ ). Fish muscle AA $\delta^{13} \mathrm{C}$ values (Fig. $2.1 \mathrm{~b}$ ) showed similar patterns to those of the diets, with significant differences among individual AAs (twoway ANOVA, $\mathrm{df}=11,96, \mathrm{~F}=2681.0, \mathrm{p}<0.05$ ) and among diet treatments (two-way ANOVA, $\mathrm{df}=3,96, \mathrm{~F}=642.7, \mathrm{p}<0.05$ ), including a significant interaction term (twoway ANOVA, $\mathrm{df}=33,96, \mathrm{~F}=18.72, \mathrm{p}<0.05)$.

Despite significant variability in individual $\mathrm{AA} \delta^{13} \mathrm{C}$ values in diet and muscle, there were several consistent patterns in our data. All AAs from the Vegi-Pro treatment, 
both diet and fish muscle, were the most ${ }^{13} \mathrm{C}$-depleted, while AAs from the squid and clam treatments were typically the most ${ }^{13} \mathrm{C}$-enriched. Glycine and serine were always the most ${ }^{13} \mathrm{C}$-enriched AAs in all treatments for both diet and fish muscle, where as valine, phenylalanine and leucine were always the most ${ }^{13} \mathrm{C}$-depleted $\mathrm{AAs}$ in all treatments. The $\delta^{13} \mathrm{C}$ value of aspartic acid, glutamic acid and proline were generally similar to one another in each treatment for both diet and muscle, although the values diverged more so for the Vegi-Pro diet. Finally, the non-essential AAs were ${ }^{13} \mathrm{C}$-enriched relative to the essential AAs by $7.5 \pm 2.9 \%$ for diet and $7.3 \pm 0.8 \%$ for fish muscle.

Muscle essential AA $\delta^{13} \mathrm{C}$ values showed stronger linear relationships to their respective dietary AA $\delta^{13} \mathrm{C}$ values with slopes closer to unity $(m=0.9 \pm 0.2, b=-2.7 \pm$ $\left.3.8, \mathrm{R}^{2}=0.95 \pm 0.04\right)$ than was found for non-essential AAs $(m=0.51 \pm 0.14, b=-7.0 \pm$ $\left.3.5, \mathrm{R}^{2}=0.71 \pm 0.21\right)\left(\right.$ Table 2.2). Muscle essential AA $\delta^{13} \mathrm{C}$ values were also more closely related to their dietary AA $\delta^{13} \mathrm{C}$ values than they were to bulk diet $\delta^{13} \mathrm{C}$ values $(m$ $\left.=0.7 \pm 0.4, b=-5.7 \pm 11.7, \mathrm{R}^{2}=0.78 \pm 0.18\right)($ Table 2.2$)$. Non-essential AAs $\delta^{13} \mathrm{C}$ values in muscle tissue typically showed stronger correlations to bulk diet $\delta^{13} \mathrm{C}$ values $(m=0.9$ $\left.\pm 0.5, b=5.7 \pm 15.3, \mathrm{R}^{2}=0.69 \pm 0.26\right)$ than to their respective dietary AA $\delta^{13} \mathrm{C}$ values (Table 2.2).

Bulk fish muscle showed positive, albeit diet-specific, trophic fractionation (Fig. 2.2) for all treatments, with Vegi-Pro having the highest $\Delta{ }^{13} \mathrm{C}_{\mathrm{C}-\mathrm{D}}$ values and the squid and clam treatments having the lowest $\Delta{ }^{13} \mathrm{C}_{\mathrm{C}-\mathrm{D}}$ values. There was a large range in $\Delta{ }^{13} \mathrm{C}_{\mathrm{C}-\mathrm{D}}$ $(12.5 \%$ ) values across individual AAs and dietary treatments (Fig. 2.2), from $-7.9 \pm$ $0.7 \%$ for glycine in the Bio-Vita treatment to $4.7 \pm 0.5 \%$ for glutamic acid in the Vegi- 
Pro treatment. Even within individual AAs, the mean range in $\Delta{ }^{13} \mathrm{C}_{\mathrm{C}-\mathrm{D}}$ across all four diets was large $(5.8 \pm 2.9 \%)$, ranging from aspartic acid $(3.5 \%)$ to glycine $(11.2 \%)$. While there was significant variability in $\Delta{ }^{13} \mathrm{C}_{\mathrm{C}-\mathrm{D}}$ values among diets and individual $\mathrm{AAs}$, we observed several consistent patterns in the data. Essential AA $\Delta{ }^{13} \mathrm{C}_{\mathrm{C}-\mathrm{D}}$ values were very consistent among individual AAs (two-way ANOVA, $\mathrm{df}=4,40, \mathrm{~F}=2.5, \mathrm{p}>0.05$ ) and dietary treatments (two-way ANOVA, $\mathrm{df}=3,40, \mathrm{~F}=1.7, \mathrm{p}>0.05$ ). All essential AA $\Delta{ }^{13} \mathrm{C}_{\mathrm{C}-\mathrm{D}}$ values were not significantly different from $0 \%$ (mean $\Delta \Delta^{13} \mathrm{C}_{\mathrm{C}-\mathrm{D}}=0.02 \pm 0.44 \%$ ) (one sample t-test, $\mathrm{p}>0.05$ for all essential AAs).

Conversely, $\Delta{ }^{13} \mathrm{C}_{\mathrm{C}-\mathrm{D}}$ values of non-essential AAs showed much larger deviations from $0 \%$ and considerably more variation among AAs (two-way ANOVA, $\mathrm{df}=5,48, \mathrm{~F}$ $=165.0, \mathrm{p}<0.05$ ) and among treatments (two-way ANOVA, $\mathrm{df}=3,48, \mathrm{~F}=218.4, \mathrm{p}<$ 0.05), including a significant interaction term (two-way ANOVA, $\mathrm{df}=15,48, \mathrm{~F}=35.1, \mathrm{p}$ $<0.05$ ). Only arginine in the Vegi-Pro treatment (one sample $\mathrm{t}$-test, $\mathrm{t}=0.8, \mathrm{p}>0.05$ ) and glutamic acid in the Bio-Vita (one sample t-test, $\mathrm{t}=0.3, \mathrm{p}>0.05$ ), squid (one sample $\mathrm{t}$ test, $\mathrm{t}=0.6, \mathrm{p}>0.05$ ), and clam (one sample t-test, $\mathrm{t}=0.8, \mathrm{p}>0.05$ ) treatments had $\Delta{ }^{13} \mathrm{C}_{\mathrm{C}-\mathrm{D}}$ values that were not significantly different from $0 \%$. Non-essential $A A \Delta \Delta^{13} \mathrm{C}_{\mathrm{C}-\mathrm{D}}$ values generally followed the patterns observed in the bulk tissues $\Delta^{13} \mathrm{C}$ values (Fig. 2.2). Non-essential AA $\Delta{ }^{13} \mathrm{C}_{\mathrm{C}-\mathrm{D}}$ values were typically the most positive in the Vegi-Pro treatment with the exceptions of serine and arginine, where Bio-Vita showed the highest $\Delta \Delta^{13} \mathrm{C}_{\mathrm{C}-\mathrm{D}}$ values. Conversely, $\Delta{ }^{13} \mathrm{C}_{\mathrm{C}-\mathrm{D}}$ values of non-essential $\mathrm{AAs}$ from the squid and clam treatments were never significantly different from one another (Tukey's HSD posthoc test, $\mathrm{p}>0.05$ ) and were generally the lowest values. 
There was notable variation in the percent abundance of AAs for both diets (Fig. 2.3a) and fish muscle (Fig. 2.3b). In general, the non-essential AAs glutamic acid, aspartic acid and arginine were the most abundant AAs. Although lysine was also quite abundant in both diet and muscle, it was not analyzed for $\delta^{13} \mathrm{C}$ due to coelution with tyrosine. Leucine was the most abundant essential AA that was analyzed for $\delta^{13} \mathrm{C}$. The patterns of percent abundance of AAs were very consistent across treatments for muscle (Fig. 2.3b), with a mean standard deviation of $0.1 \pm 0.1 \%$ across all AAs. There was considerably more variation in AA percent abundance across the four diets (Fig. 2.3a), with a mean standard deviation of $1.0 \pm 0.8 \%$ across all AAs. In the Vegi-Pro and BioVita treatments, all of the non-essential AAs analyzed were less abundant in the diets than they were in the muscle (mean difference in percent abundance, Vegi-Pro: $-2.0 \pm$ $1.6 \%$ and Bio-Vita: $-1.5 \pm 1.0 \%$ ). The squid and clam diets usually, but not exclusively, had a surplus of non-essential AAs $(0.0 \pm 0.9 \%$ and $0.4 \pm 1.2 \%$, respectively $)$.

There was a significant negative correlation between the difference in nonessential AA percent abundance in diet and muscle versus AA $\Delta{ }^{13} \mathrm{C}_{\mathrm{C}-\mathrm{D}}$ (correlation coefficient, $\mathrm{r}=-0.43, \mathrm{p}<0.05$; Fig. 2.4). Biosynthesized non-essential AAs tended to exhibit larger $\Delta^{13} \mathrm{C}_{\mathrm{C}-\mathrm{D}}$ values when there was a greater deficit in AA percent abundance in the diet relative to fish muscle. The Bio-Vita treatment showed the most variability in $\Delta{ }^{13} \mathrm{C}_{\mathrm{C}-\mathrm{D}}$ values, with the $\Delta^{13} \mathrm{C}_{\mathrm{C}-\mathrm{D}}$ values of aspartic acid and proline in the Bio-Vita treatment closer those in the Vegi-Pro treatment and the $\Delta^{13} \mathrm{C}_{\mathrm{C}-\mathrm{D}}$ value of glycine more similar to those in the natural animal diet treatments (Fig. 2.2). Both aspartic acid and proline showed large deficits in the Bio-Vita diet compared to fish muscle, as was the 
case for Vegi-Pro (Fig. 2.3). Conversely, glycine was much closer to the percent abundance in muscle for the Bio-Vita, squid and clam treatments (Fig. 2.3).

\section{DISCUSSION}

We examined variability in carbon isotope fractionation of individual AAs in a common marine fish across a wide range of potential diets. Modest diet-specific $\Delta{ }^{13} \mathrm{C}_{\mathrm{C}-\mathrm{D}}$ values in bulk tissue reflected relatively large trophic fractionations for many nonessential AAs and little to no fractionation for all essential AAs. Essential AA $\delta^{13} \mathrm{C}$ values reflected a purely dietary signature with $\Delta^{13} \mathrm{C}_{\mathrm{C}-\mathrm{D}}$ values near $0 \%$, making them ideal tracers of carbon sources at the base of the food web $\left(\delta^{13} \mathrm{C}_{\mathrm{Base}}\right)$. Consumer nonessential AAs showed a large range in $\Delta{ }^{13} \mathrm{C}_{\mathrm{C}-\mathrm{D}}$ across diets and a variable, diet-specific degree of isotopic routing from dietary protein, which together may contribute significantly to the high variability in bulk tissue $\Delta^{13} \mathrm{C}_{\mathrm{C}-\mathrm{D}}$ observed in th natural environment. The diet-specific fractionation we found should promote discussion about the assumptions of minimal and invariant bulk tissue carbon isotope fractionation in dietary reconstructions.

The patterns observed in the bulk $\delta^{13} \mathrm{C}$ values (Elsdon et al. 2010) were reflected in the ${ }^{13} \mathrm{C}$ values of individual AAs. For instance, AAs from the Vegi-Pro treatment (diet and muscle) were always the most ${ }^{13} \mathrm{C}$-depleted, while those from the clam and squid treatments were typically the most ${ }^{13} \mathrm{C}$-enriched. This is not surprising given that protein was a significant component (up to $71 \%$ ) of the diets and fish muscle, making AAs a major contributor to bulk tissue $\delta^{13} \mathrm{C}$ values. There were several consistent 
patterns in $\mathrm{AA} \delta^{13} \mathrm{C}$ values across all treatments. The large range in $\mathrm{AA} \delta^{13} \mathrm{C}$ values of $\operatorname{diet}(27.9 \pm 6.9 \%)$ and consumer muscle $(23.6 \pm 2.6 \%)$ likely reflected the varied metabolic histories of these AAs. These ranges were similar to previous results on a variety of taxa including vertebrates (Hare et al. 1991; Fogel and Tuross 2003; Howland et al. 2003; Jim et al. 2006), invertebrates (Uhle et al. 1997; Fantle et al. 1999; O’Brien et al. 2002) and plants (Fogel and Tuross 1999) from terrestrial and aquatic systems. This consistency likely reflects the influence of two main factors: 1) similarities in the major biosynthetic pathways that produce AAs in plants and animals and 2) incorporation of dietary constituents directly into consumer tissue.

The patterns of $\Delta{ }^{13} \mathrm{C}_{\mathrm{C}-\mathrm{D}}$ of individual AAs generally mirrored those of the bulk tissue, with $\Delta^{13} \mathrm{C}_{\mathrm{C}-\mathrm{D}}$ values in the Vegi-Pro and Bio-Vita treatments significantly higher than those in the squid and clam treatments. A closer look at the $\Delta{ }^{13} \mathrm{C}_{\mathrm{C}-\mathrm{D}}$ values of individual AAs revealed some interesting insights into metabolic processes impacting the synthesis of muscle from dietary constituents. All essential AAs had $\Delta^{13} \mathrm{C}_{\mathrm{C}-\mathrm{D}}$ values near $0 \%$, indicating no significant carbon isotope fractionation between diet and consumer muscle AAs. This observation was supported by the strong correlation and nearly 1:1 relationship between $\delta^{13} \mathrm{C}_{\text {diet_essential_AA }}$ and $\delta^{13} \mathrm{C}_{\text {muscle_essential_AA. Small deviations from }}$ $\Delta{ }^{13} \mathrm{C}_{\mathrm{C}-\mathrm{D}}=0 \%$, and thus a slope of 1 , most likely represented minor kinetic isotope fractionation during catabolism or conversion of essential AAs to other metabolites. If we interpret the slope of this regression to be roughly equivalent to the proportion of carbon routed into muscle directly from the diet, the results support our hypothesis of a high degree of isotopic routing of essential AAs into consumer muscle. Our data support 
previous work on a variety of taxa and tissues (Hare et al. 1991; Fantle et al. 1999; Howland et al. 2003; O'Brien et al. 2003; Jim et al. 2006), indicating that these findings are generally applicable to a wide range of taxa and tissue types.

Although plants and bacteria can synthesize essential AAs de novo, most animals have lost the necessary enzymatic pathways to synthesize these AAs at a rate sufficient for normal growth, and thus must incorporate them directly from their diet (Borman et al. 1946, Reeds 2000). As a result, the $\delta^{13} \mathrm{C}$ value of consumer essential AAs, such as phenylalanine and leucine, must represent the isotopic fingerprint of primary producers at the base of the food web $\left(\delta^{13} \mathrm{C}_{\text {Base }}\right)$. It should be noted that this relationship could be obscured when dealing with strict herbivores that receive a significant contribution of bacterially synthesized AAs from their symbiotic gut microbial community (Rimmer and Wiebe 1987). The fidelity with which essential AAs reflect dietary sources makes compound-specific SIA a powerful tool for foraging ecology and dietary reconstruction. Essential AA $\delta^{13} \mathrm{C}$ values have provided insights into the diet of ancient humans and herbivores (Stott et al. 1999; Fogel and Tuross 2003), the allocation of adult resources to eggs in butterflies (O'Brien et al. 2002, 2003, 2005), the contributions of carbon sources to marine dissolved organic matter (McCarthy et al. 2004), and the importance of marshderived diets in supporting the growth of juvenile blue crabs (Fantle et al. 1999). This approach may also provide a powerful new tool for reconstructing the diet of highly mobile consumers that move among isotopically distinct food webs. Certainly compound-specific SIA avoids the confounding variable of determining whether consumers with different bulk tissue $\delta^{13} \mathrm{C}$ values represent feeding in the same food web 
but at different trophic levels, or feeding at the same trophic level but in isotopically distinct food webs (Post 2002).

Non-essential AAs showed significant deviations from $\Delta{ }^{13} \mathrm{C}_{\mathrm{C}-\mathrm{D}}=0 \%$, and much greater variability both among AAs and across diet treatments compared to essential AAs. This variability most likely reflects the influence of the varied metabolic processes that shape the isotopic signatures of non-essential AAs during biosynthesis. The Vegi-Pro treatment exhibited primarily positive $\Delta{ }^{13} \mathrm{C}_{\mathrm{C}-\mathrm{D}}$ values while the natural diet treatments, squid and clam, typically showed large negative $\Delta{ }^{13} \mathrm{C}_{\mathrm{C}-\mathrm{D}}$ values. The large $\Delta{ }^{13} \mathrm{C}_{\mathrm{C}-\mathrm{D}}$ values that shifted muscle non-essential AA $\delta^{13} \mathrm{C}$ towards bulk diet $\delta^{13} \mathrm{C}$ values suggest a high degree of de novo biosynthesis. This hypothesis was supported by linear regressions between $\delta^{13} C_{\text {diet_non-essential_AA }}$ and $\delta^{13} C_{\text {muscle_non-essential_AA, where the mean slopes were far }}$ from unity, indicating a disparity between the $\delta^{13} \mathrm{C}$ values of dietary and muscle nonessential AAs.

The high degree of biosynthesis is surprising for the three diets containing animal matter, Bio-Vita, squid and clam, given the high protein content of those diets $(53 \%$, $69 \%$, and $71 \%$, respectively). Previous research suggested that when fed high protein diets, organisms typically route most AAs, including non-essentials, directly from diet as a means of energy conservation, because dietary routing is typically more efficient than de novo biosynthesis (Ambrose and Norr 1993, Tieszen and Fagre 1993, Jim et al. 2006). Fish, however, use a significant portion of dietary protein for energetic purposes (Kim et al. 1991; Dosdat et al. 1996), and thus it is possible that fish exhibit a lower degree of dietary routing than terrestrial vertebrates. Only the Vegi-Pro diet had a low protein 
content (8\%) that would likely require biosynthesis, resulting in the high $\Delta{ }^{13} \mathrm{C}_{\mathrm{C}-\mathrm{D}}$

observed across most individual AAs in that treatment. Hare et al. (1991) found that $\delta^{13} \mathrm{C}$ of proline and glutamate differed by $5.7 \%$ in the bone collagen of pigs, suggesting that proline was being directly routed from diet into the consumer tissue. We found that proline had $\delta^{13} \mathrm{C}$ signatures closer to those of glutamic acid rather than dietary proline and had $\Delta{ }^{13} \mathrm{C}_{\mathrm{C}-\mathrm{D}}$ values significantly different from $0 \%$. This suggests that proline was biosynthesized from glutamic acid via reduction through a Schiff base intermediate (Baich and Pierson 1965) rather than being directly routed from the diet.

Arginine in the Vegi-Pro treatment and glutamic acid in the Bio-Vita, squid and clam treatments showed strong evidence of isotopic routing directly from dietary protein, yet evidence of biosynthesis in the other dietary treatments. Arginine is synthesized from glutamate via glutamyl- $\gamma$-semialdehyde and thus if arginine and glutamic acid were both biosynthesized or both isotopically routed, we would expect them to have similar $\delta^{13} \mathrm{C}$ values, as was the case for glutamic acid and proline discussed earlier. However, arginine and glutamic acid had different $\delta^{13} \mathrm{C}$ values, reflecting the different pathways leading to arginine and glutamic acid incorporation into fish muscle. Glutamic acid and arginine account for over $18 \%$ of the AAs in fish muscle alone, and it is probable that other AAs can be directly routed as well. We found that when glutamic acid was biosynthesized in the Vegi-Pro treatment, it exhibited relatively large $\Delta{ }^{13} \mathrm{C}_{\mathrm{C}-\mathrm{D}}$ values $(\sim 5 \%)$ similar to the $\Delta{ }^{13} \mathrm{C}_{\mathrm{C}-\mathrm{D}}$ values Hare et al. (1991) and Howland et al. (2003) found for biosynthesized glutamic acid in pig bone collagen ( $\sim 6$ to $7 \%$ ). Thus varying degrees of isotopic routing versus de novo biosynthesis for these abundant AAs could significantly alter consumer 
tissue $\delta^{13} \mathrm{C}$ values relative to diet, further complicating the stable isotope relationship between diet and consumer.

We hypothesized that an underrepresentation of non-essential AAs in diet relative to muscle composition would necessitate a higher degree of biosynthesis than would be expected from diets with excess non-essential AAs. We found a significant correlation between diet and muscle AA percent abundance and $\Delta{ }^{13} \mathrm{C}_{\mathrm{C}-\mathrm{D}}$ for biosynthesized nonessential AAs. The AA composition of fish muscle is highly conserved (Wilson and Cowey 1985) as evidenced by the fact that muscle AA percent abundance was very consistent across treatments (mean SD across treatments $0.1 \pm 0.1 \%$ ) despite feeding on diets with highly variable AA content $(1.0 \pm 0.8 \%)$. When there was a deficit in AA percent abundance in the diet relative to the muscle, there tended to be greater trophic fractionation. This was particularly true for the Vegi-Pro and Bio-Vita treatments, where all non-essential AAs analyzed were less abundant in the diets than they were in fish muscle, and typically had the highest $\Delta{ }^{13} \mathrm{C}_{\mathrm{C}-\mathrm{D}}$ values. The disparity in AA percent abundance was perhaps not surprising given that Vegi-Pro and Bio-Vita both contained plant matter, while the other diets were entirely animal protein.

Bio-Vita showed the most variability in $\Delta{ }^{13} \mathrm{C}_{\mathrm{C}-\mathrm{D}}$ values, with some AAs trending towards Vegi-Pro and other towards the squid and clam treatments. For example, aspartic acid and proline had similar $\Delta{ }^{13} \mathrm{C}_{\mathrm{C}-\mathrm{D}}$ values in the Bio-Vita and Vegi-Pro treatments. Those AAs also showed large deficits in the Bio-Vita and Vegi-Pro diets compared to fish muscle. Conversely, glycine in the Bio-Vita treatment had a very negative $\Delta{ }^{13} \mathrm{C}_{\mathrm{C}-\mathrm{D}}$ value closer to those of the squid and clam treatments. In this case, the disparity in 
glycine percent abundance between diet and fish muscle was small for the Bio-Vita, squid, and clam treatments. Differences in AA abundance in the diet relative to consumer muscle likely required varying the degree of biosynthesis and catabolism to meet the muscle composition demand, which may explain the corresponding shifts in AA trophic fractionation. However, disparities in diet and muscle AA composition alone only explain a relatively small fraction $\left(\mathrm{R}^{2}=0.19\right)$ of $\Delta{ }^{13} \mathrm{C}_{\mathrm{C}-\mathrm{D}}$ values.

The differences in $\Delta^{13} \mathrm{C}_{\mathrm{C}-\mathrm{D}}$ values between the Vegi-Pro treatment and the squid and clam treatments may reflect differences in utilization of the bulk carbon pool from a plant based-diet versus an animal-based diet. The Vegi-Pro diet had far more carbohydrates (73\%) than lipids (6\%), while the animal-based diets showed the opposite trend (18\% lipid, $<1 \%$ carbohydrate). The biosynthesis of non-essential AAs in the VegiPro treatment appeared to rely on a more ${ }^{13} \mathrm{C}$-enriched carbon pool than the other treatments, possibly indicating a greater contribution of carbohydrates to the bulk carbon pool (Teece and Fogel 2007). Howland et al. (2003) reared pigs on a plant-based diet with a $\delta^{13} \mathrm{C}$ value close to the Vegi-Pro diet used in our study. Our results were similar to those of pig collagen $\Delta{ }^{13} \mathrm{C}_{\mathrm{C}-\mathrm{D}}$ values, showing large positive $\Delta{ }^{13} \mathrm{C}_{\mathrm{C}-\mathrm{D}}$ values for most nonessential AAs, particularly glutamic acid, proline, and aspartic acid. Similar metabolic processes may, therefore, control $\Delta{ }^{13} \mathrm{C}_{\mathrm{C}-\mathrm{D}}$ values for many animals feeding on plantbased diets.

If lipids in the animal-based diets were being catabolized as a significant source of energy (Post et al. 2007), they would provide a very ${ }^{13} \mathrm{C}$-depleted carbon pool relative to bulk diet values (6 to 8\% [DeNiro and Epstein 1977]) from which non-essential AAs 
were biosynthesized. This may explain why the $\Delta^{13} \mathrm{C}_{\mathrm{C}-\mathrm{D}}$ values in the animal-based dietary treatments were significantly more negative than in the Vegi-Pro treatment. The divergence in $\Delta{ }^{13} \mathrm{C}_{\mathrm{C}-\mathrm{D}}$ between Vegi-Pro and the squid and clam treatments is greatest for glycine, serine and alanine, which are also the first AAs synthesized from carbohydrates entering the glycolysis as glucose. Glucose is converted to 3-phosphogylcerate, which is the precursor for both glycine and serine. Alanine is synthesized from pyruvate several steps after 3-phosphogylcerate and showed less of a difference in $\Delta{ }^{13} \mathrm{C}_{\mathrm{C}-\mathrm{D}}$ between the plant and animal-based diets. The remaining non-essential AAs are synthesized from oxaloacetate and $\alpha$-ketogluterate intermediates many steps later in the TCA cycle and showed the smallest differences in $\Delta{ }^{13} \mathrm{C}_{\mathrm{C}-\mathrm{D}}$ between the plant and animal-based diets. If different carbon pools are in fact driving the diet-specific differences in $\Delta{ }^{13} \mathrm{C}_{\mathrm{C}-\mathrm{D}}$ values of non-essential AAs, the impact appears to be greatest near the source of carbon entering glycolysis and gets diluted or altered as carbon flows through the TCA cycle. Our work supports previous observations that organisms feeding on apparently homogeneous diets can show substantially different $\delta^{13} \mathrm{C}$ values when routing of dietary components and alterations of available carbon pool $\delta^{13} \mathrm{C}$ values become important (O'Brien et al. 2002, 2003; Jim et al. 2006).

The diets chosen for this study ranged from solely plant matter to solely animal matter in order to examine the potential variability in diet to consumer carbon isotope fraction. Without knowing the fractionation between steps as lipid and carbohydrate carbon enter the TCA cycle and get incorporated into AAs, we cannot accurately predict how the precursor $\delta^{13} \mathrm{C}$ signatures will be manifested in the product $\mathrm{AA} \delta^{13} \mathrm{C}$ values. The 
next step will be to identify the mechanisms behind the high, diet-specific variability in $\Delta{ }^{13} \mathrm{C}_{\mathrm{C}-\mathrm{D}}$ and determine what information non-essential $\mathrm{AA} \delta^{13} \mathrm{C}$ values hold about consumer diet and metabolic history. This calls for targeted feeding experiments that track the fractionation of individual, potentially isotopically labeled dietary constituents as they are metabolically processed. While it is currently unclear how much useful information about diet and metabolic history is recorded in non-essential AA $\delta^{13} \mathrm{C}$ values, the fact that the $\Delta^{13} \mathrm{C}_{\mathrm{C}-\mathrm{D}}$ values in both animal diet treatments tracked very closely and were always significantly different from the plant-based Vegi-Pro diet holds promise that there may be some valuable underlying principles controlling consumer individual AA $\delta^{13} \mathrm{C}$ values.

\section{ACKNOWLEDGEMENTS}

The authors would like to thank S. Ayvazian, D. Champlin, J. Serbert, and B. Miner of the Atlantic Ecology Division, U.S. Environmental Protection Agency, in Narragansett, Rhode Island for assistance rearing fish and L. Houghton for assistance in sample analysis. The authors would also like to thank the Mullineaux lab group for comments on an early draft of the manuscript and M. McCarthy for a thorough review of this manuscript. The feeding experiment was supported by the Atlantic Ecology Division, U.S. Environmental Protection Agency, and funding from the Ocean Life Institute and an Australian Research Council fellowship to T. Elsdon. Additional funding was provided by the University of New Hampshire's Large Pelagics Research Center, the Woods Hole Oceanographic Institution, the Carnegie Institution of Washington, and the W. M. Keck 
Foundation. K. McMahon received support from the National Science Foundation Graduate Research Fellowship Program and T. Elsdon received support from the Post Doctoral Scholar Program at the Woods Hole Oceanographic Institution. 
Table 2.1. Proximate analysis of moisture, crude protein, crude fat, crude fiber, ash and carbohydrate content (\%) of four diets Vegi-Pro, Bio-Vita, squid, and clam $(\mathrm{n}=1)$.

\begin{tabular}{lcccc}
\hline Analysis & Vegi-Pro & Bio-Vita & Squid & Clam \\
\hline \hline Moisture & 6.8 & 6.0 & 10.0 & 8.8 \\
Protein (Crude) & 8.0 & 53.3 & 69.1 & 71.0 \\
Fat (Crude) & 5.9 & 23.9 & 17.6 & 18.0 \\
Fiber (Crude) & 2.0 & 0.3 & 0.3 & 0.2 \\
Ash & 6.7 & 10.9 & 2.9 & 2.1 \\
Carbohydrates & 72.6 & 6.0 & 0.3 & 0.2 \\
\hline
\end{tabular}




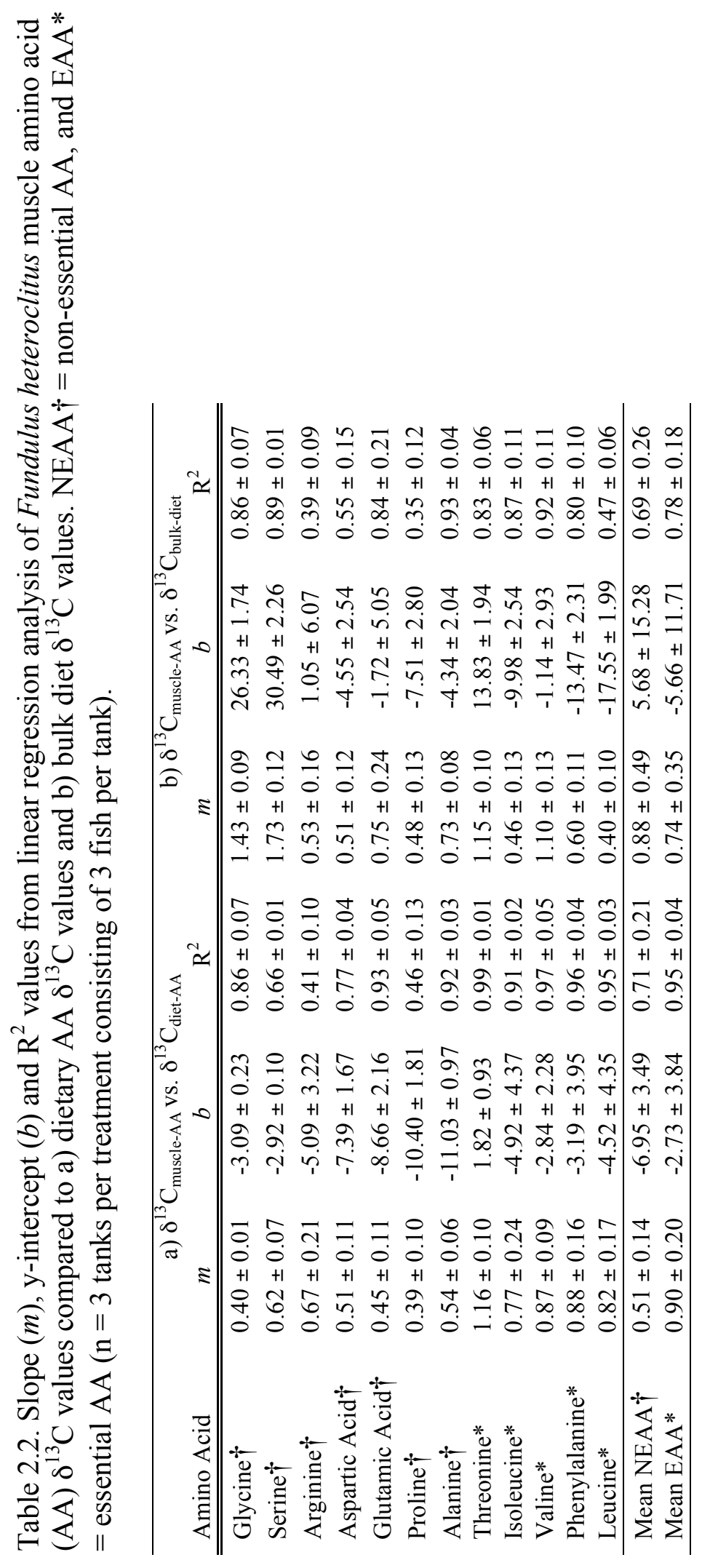



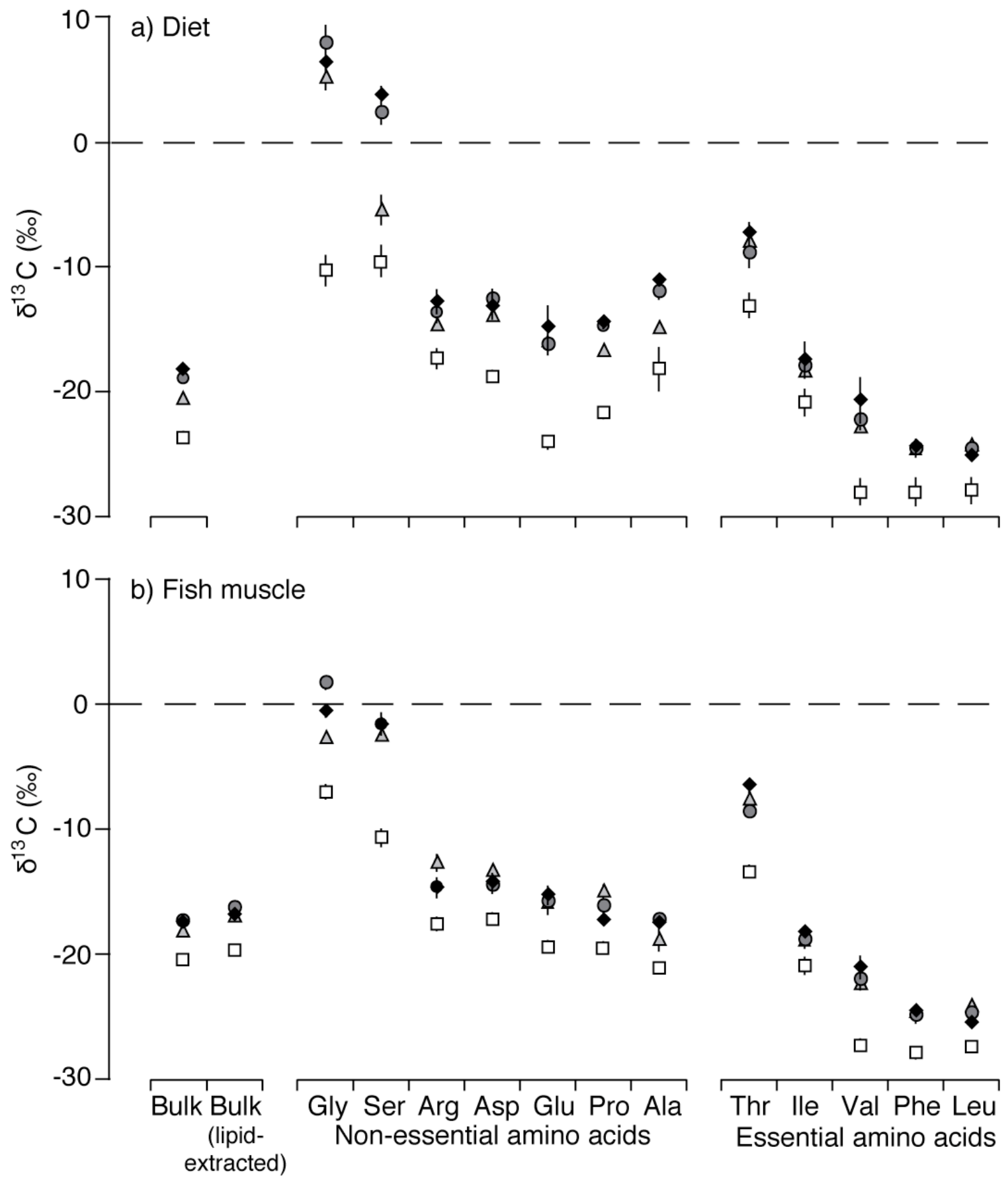

Figure 2.1. Mean $\left( \pm\right.$ SD) bulk tissue and individual amino acid $\delta^{13} \mathrm{C}$ values of a) diet and b) Fundulus heteroclitus muscle from four dietary treatments: Vegi-Pro (open squares), Bio-Vita (light gray triangles), squid (dark gray circles), and clam (black diamonds) ( $\mathrm{n}=$ 5 replicates per treatment for diets and $n=3$ tanks per treatment, consisting of 3 fish per tank for fish muscle). 


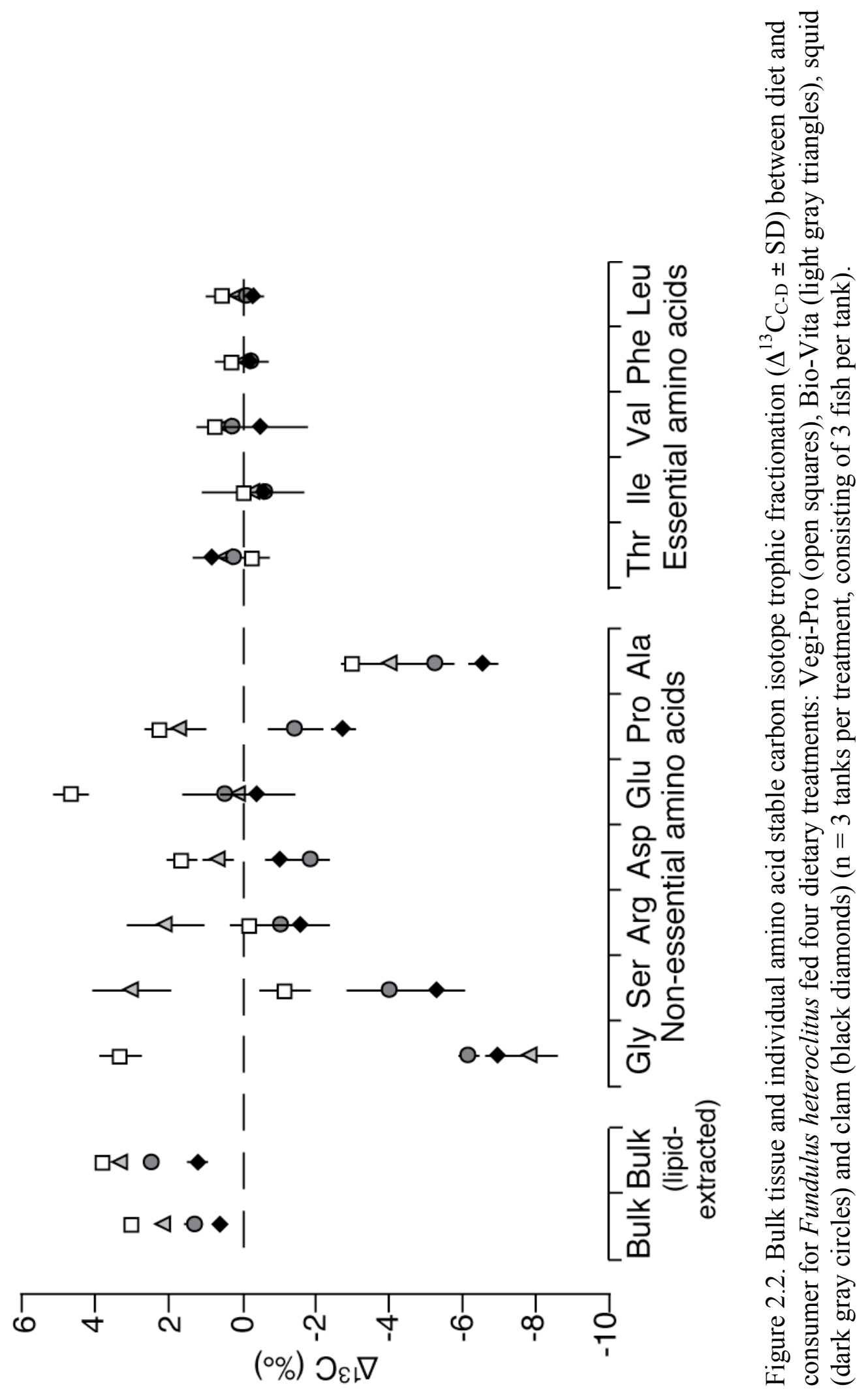



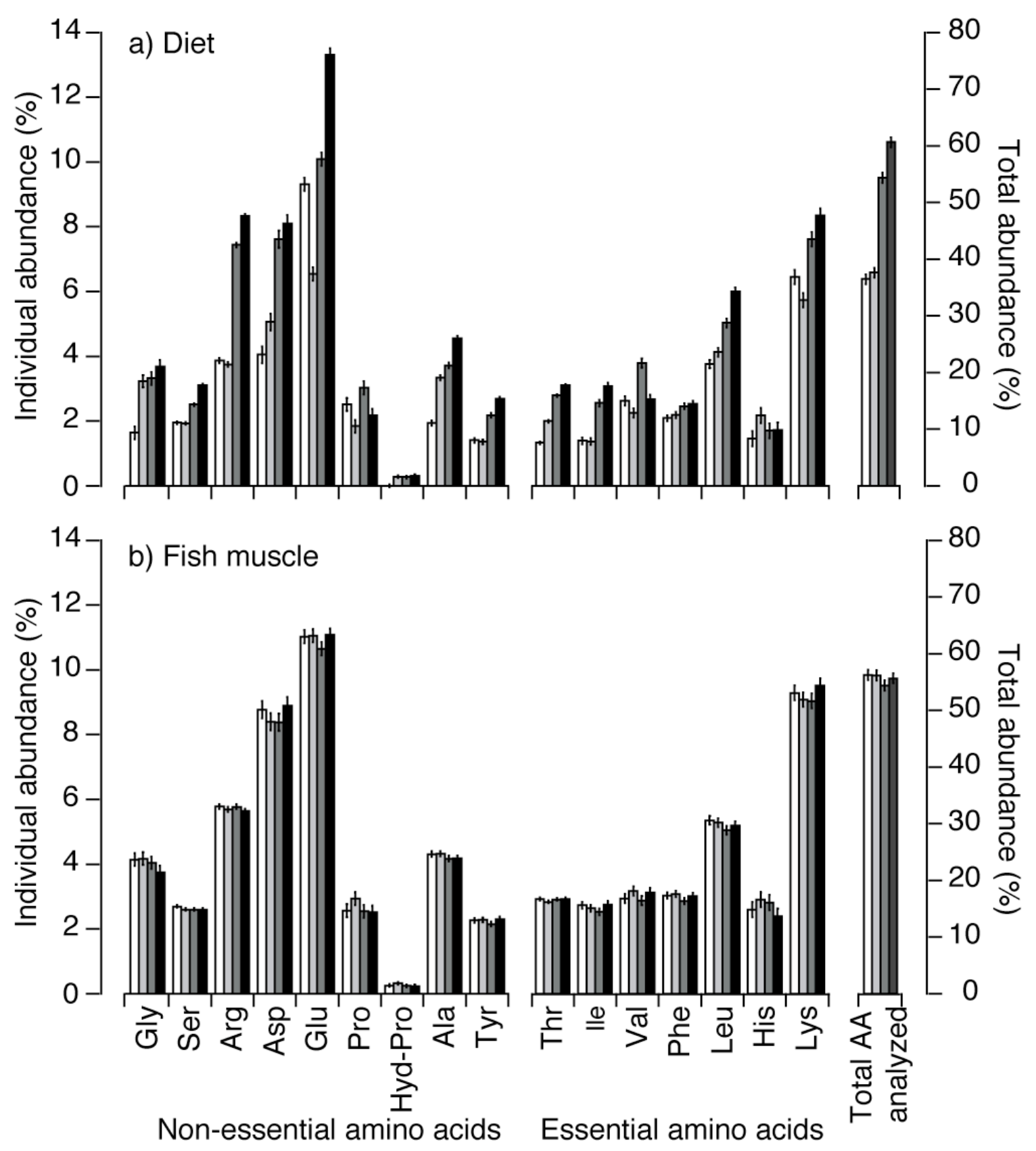

Figure 2.3. Mean percent abundance $(\% \pm \mathrm{SD})$ of 16 individual amino acids (left axis) and the total percent abundance of the 12 amino acids analyzed for $\delta^{13} \mathrm{C}$ values (right axis) in a) diet and b) Fundulus heteroclitus muscle from four dietary treatments: VegiPro (open bars), Bio-Vita (light gray bars), squid (dark gray bars), and clam (black bars) $(\mathrm{n}=3$ replicates per treatment). 


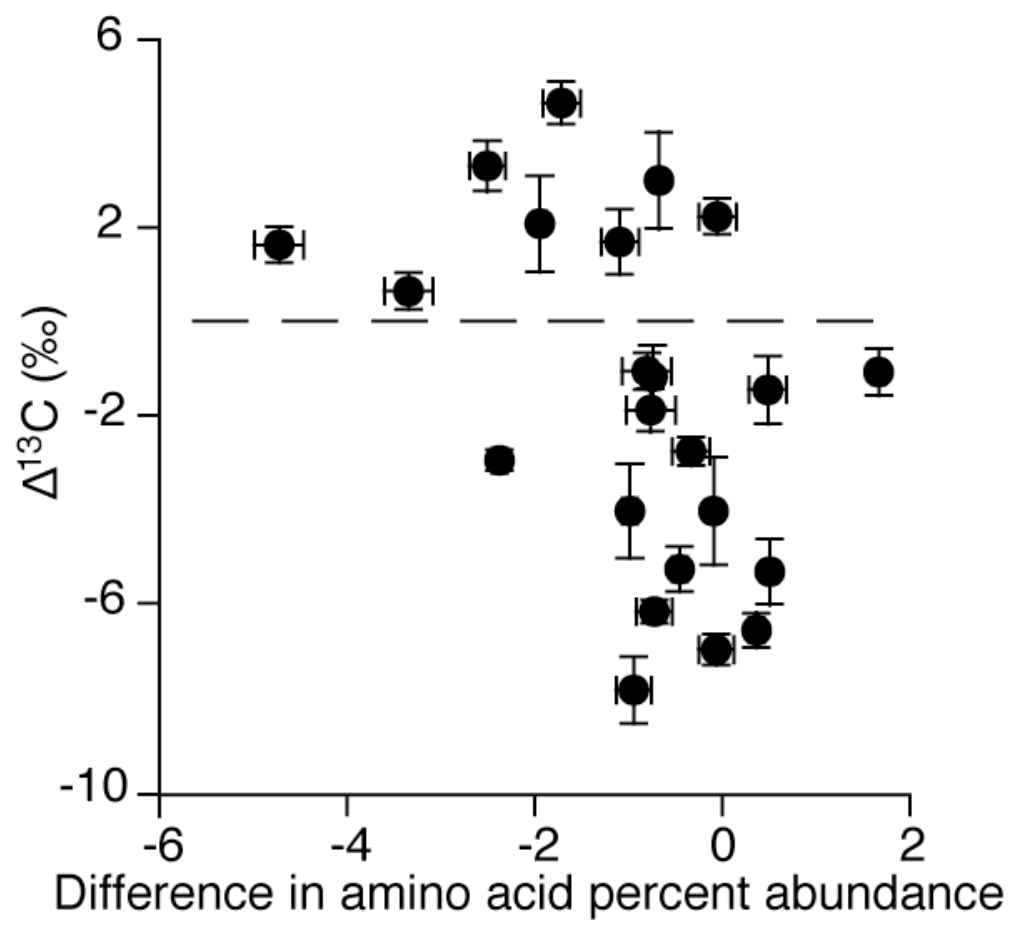

Figure 2.4. Differences between amino acid percent abundance in diet and muscle (mean $\% \pm \mathrm{SD})$ versus stable carbon isotope trophic fractionation $\left(\Delta^{13} \mathrm{C}_{\mathrm{C}-\mathrm{D}} \pm \mathrm{SD}\right)$. Negative values signify a lower percent abundance or $\delta^{13} \mathrm{C}$ value in the diet relative to the muscle respectively $(n=3$ for percent abundance and $n=3$ tanks per treatment, consisting of 3 fish per tank for $\left.\Delta^{13} \mathrm{C}_{\mathrm{C}-\mathrm{D}}\right)$. 


\title{
CHAPTER THREE
}

\section{Reconstructing fish diet and movement patterns using stable carbon isotope analysis of otolith amino acids}

\author{
Kelton W. McMahon ${ }^{1}$ \\ ${ }^{1}$ Massachusetts Institute of Technology and Woods Hole Oceanographic Institution \\ Joint Program in Oceanography and Ocean Engineering, \\ Woods Hole Oceanographic Institution, Woods Hole, MA 02543, USA \\ Marilyn L. Fogel ${ }^{2}$ \\ ${ }^{2}$ Geophysical Laboratory, \\ Carnegie Institution of Washington, Washington, D.C. 20015, USA \\ Beverly J. Johnson ${ }^{3}$ \\ ${ }^{3}$ Department of Geology, \\ Bates College, Lewiston, ME 04240 \\ Leah A. Houghton and Simon R. Thorrold ${ }^{4}$ \\ ${ }^{4}$ Biology Department, \\ Woods Hole Oceanographic Institution, Woods Hole, MA 02543, USA
}

In review for publication in the Canadian Journal of Fisheries and Aquatic Sciences 


\begin{abstract}
Fish ecologists have used geochemical signatures in otoliths to examine habitat use, migration and population connectivity for decades. However, it remains difficult to determine an unambiguous dietary $\delta^{13} \mathrm{C}$ signature from bulk analysis of otoliths. Studies to date have focused on the aragonite component of otoliths with less attention paid to an organic fraction. We describe the application of compound-specific stable isotope analysis (SIA) to analyze amino acid (AA) $\delta^{13} \mathrm{C}$ values from small amounts $(<1 \mathrm{mg})$ of otolith powder. We examined $\delta^{13} \mathrm{C}$ values of otolith and muscle AAs from a reefassociated snapper (Lutjanus ehrenbergii) collected along a carbon isotope gradient (isoscape) from seagrass beds to coral reefs. Carbon isotope values in otolith and muscle samples were highly correlated within and among coastal habitats. Moreover, $\delta^{13} \mathrm{C}$ values of otolith AAs provided a purely dietary signature that avoided many of the challenges associated with conventional bulk otolith SIA, including dilution of dietary $\delta^{13} \mathrm{C}$ signatures by dissolved inorganic carbon and variable metabolic carbon contribution to otolith $\delta^{13} \mathrm{C}$ values. Otolith AAs provided a robust tracer of $\delta^{13} \mathrm{C}$ values at the base of the food web, making compound-specific SIA a powerful tool for dietary reconstructions and tracking the movement of fishes across isoscapes.
\end{abstract}

\title{
INTRODUCTION
}

The use of geochemical signatures in animal tissues as tags to track movement patterns of animals across isotope gradients (isoscapes) in the environment has become increasingly popular in terrestrial and aquatic systems (West et al. 2010). These studies 
have conducted bulk stable isotope analyses (SIA) on a variety of tissues, including bird feathers, whale baleen and fish scales (Hobson 1999; Rubenstein and Hobson 2004). Some of the most comprehensive examples of this new approach have been conducted using fish otoliths to address questions of habitat residency, migration and population connectivity (reviewed by Campana and Thorrold 2001, Elsdon et al. 2008). To date, studies have focused almost exclusively on the inorganic aragonite fraction of otoliths to provide information on the environment inhabited by individuals at different life history stages (Secor et al. 1995; Thorrold et al. 2001; Kennedy et al. 2002; Rooker et al. 2006). Recent work has suggested that the bulk carbon isotope composition of otoliths may also record a significant dietary signature (Elsdon et al. 2010). These results raise the intriguing possibility of using otolith geochemistry to retrospectively identify both lifetime movement patterns and diets of fishes.

Despite considerable promise, interpreting carbon isotope signatures in otoliths remains a difficult proposition. The carbon deposited in otoliths comes from dissolved inorganic carbon (DIC) and metabolic sources in the form of respired $\mathrm{CO}_{2}$ and dietaryderived protein. These two sources have $\delta^{13} \mathrm{C}$ values that may differ by as much as $20 \%$. Most studies have found that DIC contributes the majority of carbon to otolith (Kalish 1991; Thorrold et al. 1997; Tohse and Mugiya 2004; Solomon et al. 2006) and therefore dietary signatures in otoliths are inevitably diluted by DIC. More importantly, there is no consensus regarding the exact contributions of these two end members, making it difficult to mathematically correct for the DIC dilution effect. Indeed, variations in bulk otolith $\delta^{13} \mathrm{C}$ appear to reflect a number of factors, including metabolism (Kalish 1991; 
Weidman and Millner 2000; Stephenson et al. 2001), diet $\delta^{13} \mathrm{C}$ and trophic position (Gauldie 1996; Begg and Wiedman 2001), DIC $\delta^{13} \mathrm{C}$ (Schwarcz et al. 1998) and environmental conditions (Mulcahy et al. 1979; Kalish 1991). It remains, therefore, difficult to determine an unambiguous dietary $\delta^{13} \mathrm{C}$ signature from bulk analysis of otoliths.

One potential method for avoiding the confounding effect of DIC-derived carbon on otolith $\delta^{13} \mathrm{C}$ values is to focus on otolith protein that may constitute up to $10 \%$ (by weight) of a fish otolith (Degens et al. 1969; Morales-Nin 1986a, 1986b; Sasagawa and Mugiya 1996; Murayama et al. 2002). Analyzing otolith proteins (e.g. Otolin_1, Otolith Matrix Protein 1, Sparc [Degens et al. 1969; Sasagawa and Mugiya 1996; Murayama et al. 2002]) may provide a purely dietary signature that avoids both the effect of DIC dilution and variable metabolic carbon contribution. This protein signature represents a mixture of amino acids (AAs) directly routed from dietary protein and AAs biosynthesized from a bulk carbon pool consisting of dietary protein, lipids and carbohydrates (Schwarcz 1991; Ambrose and Norr 1993; Jim et al. 2006; McMahon et al. 2010). Bulk protein SIA is not, however, without challenges. For instance, it can be difficult to distinguish between changes in $\delta^{13} \mathrm{C}$ associated with diet or trophic shifts versus changes due to movement among habitats with different $\delta^{13} \mathrm{C}$ values at the base of the food web $\left(\delta^{13} \mathrm{C}_{\text {Base }}\right.$; Post 2002). This is particularly true when tracking the ontogenetic shifts of highly migratory fishes, where juveniles and adults often occupy different habitats and different trophic levels (Cocheret de la Morinière et al. 2003; Graham et al. 2007). 
Compound-specific SIA is a more powerful tool for examining diet and habitat use than conventional bulk SIA alone (Fantle et al. 1999; Popp et al. 2007; McMahon et al. 2010). Targeting essential AAs, which exhibit little to no fractionation between diet and consumer, provides tracers of $\delta^{13} \mathrm{C}_{\text {Base }}$ without the confounding influence of trophic fractionation (Hare et al. 1991; Howland et al. 2003; Jim et al. 2006; McMahon et al. 2010). Conversely, non-essential AAs $\delta^{13} \mathrm{C}$ values reflect metabolic processing and correlate with diet quality and composition. The compound-specific SIA technique has recently been applied to fish muscle to assess diet and habitat use (Popp et al. 2007; McMahon et al. 2010), and several other biominerals, including egg shells (Johnson et al. 1993; Johnson et al; 1998), mollusk shells (Silfer et al. 1994; Engel et al. 1994; O’Donnell et al. 2007), bones (Hare et al. 1991; Howland et al. 2003) and teeth (Bada et al. 1990) to reconstruct past climates, examine diagenesis and assess seasonal or ontogenetic shifts in consumer diet. Researchers have yet to apply compound-specific analyses to accretionary tissues in fishes, such as otoliths, that would allow for retrospective analyses of diet and movement.

Here, we present a method for stable carbon isotope analysis of AAs in otoliths. To test the method, we compared conventional bulk muscle and otolith $\delta^{13} \mathrm{C}$ values with individual $\mathrm{AA} \delta^{13} \mathrm{C}$ values from wild caught snapper, Lutjanus ehrenbergii, from three isotopically distinct habitats near Al Lith, Saudi Arabia in the Red Sea. We hypothesized that the $\delta^{13} \mathrm{C}$ values of otolith AAs would be strongly correlated with those of muscle AAs, providing access to dietary signatures in otoliths that avoid the DIC dilution effect observed in bulk otolith SIA. We also hypothesized that otolith AA $\delta^{13} \mathrm{C}$ values would 
also provide a reliable tracer of residence in isotopically distinct habitats. Our study will provide ecologists with a new tool for reconstructing dietary histories and establishing $\delta^{13} C_{\text {Base }}$ values to track fish movement through isotopically distinct food webs.

\section{METHODS AND MATERIALS}

\section{Field collections}

Ehrenberg's snapper, L. ehrenbergii (Peters 1869), were collected from three locations along a cross-shelf transect from Al Lith, Saudi Arabia in the Red Sea in March 2009 (Fig. 3.1). L. ehrenbergii are coral reef-associated fish as adults that are abundant as juveniles in coastal wetland habitats, making them model species for examining residence along an isotopic gradient. Juvenile L. ehrenbergii (total length $[\mathrm{TL}]=77 \pm 6 \mathrm{~mm}$ ) were collected from seagrass beds in Al Lith Bay using cast nets. Adult L. ehrenbergii were speared from a coastal reef $2 \mathrm{~km}$ from the entrance of Al Lith Bay (Coast Guard Reef, TL $=209 \pm 48 \mathrm{~mm}$ ) and from a shelf reef approximately $14 \mathrm{~km}$ off the coast of Al Lith (Ron's Reef, TL $=232 \pm 5 \mathrm{~mm}$ ). Sagittal otoliths and white muscle tissue were dissected from each fish in the field. Otoliths were cleaned of residual surface tissue with water and stored dry in $1.5 \mathrm{ml}$ vials. White muscle samples from the dorsal surface of each fish were frozen on the boat prior to transport to an onshore laboratory. In the lab, white muscle samples were frozen at $-20^{\circ} \mathrm{C}$ and then lyophilized (freeze-dried) for 48 hours. Paired otoliths and freeze-dried muscle samples were transferred back to the Woods Hole Oceanographic Institution, Woods Hole, MA, USA for further preparation and analysis.

Seventy-three fish were analyzed for paired bulk otolith and muscle $\delta^{13} \mathrm{C}$ values. Of those 
fish, five were randomly selected per location for paired compound-specific SIA of otoliths and muscle.

\section{Sample preparation}

A single sagittal otolith was randomly selected from each fish. All otoliths were scrubbed and rinsed in ultra-pure water, cleaned ultrasonically for $5 \mathrm{~min}$ in ultra-pure water and then air-dried under a class-100 positive-flow fume hood for $24 \mathrm{hrs}$. Whole otoliths from juvenile L. ehrenbergii were used for SIA. For adult L. ehrenbergii, we extracted otolith powder after the last annulus, corresponding to the most recent several months of growth, using a Merchantek MicroMill with a Leica GZ6 microscope (Electro Scientific Industries, Portland, OR, USA) to provide the closest temporal match possible between muscle and otolith material.

Otolith material was homogenized with a mortar and pestle and then subdivided into two portions for bulk inorganic and compound-specific SIA. Approximately $50 \mu \mathrm{g}$ of otolith material was analyzed for bulk $\delta^{13} \mathrm{C}$ analysis on a Thermo Finnigan Mat 253 isotope ratio monitoring-mass spectrometer (irm-MS) with a Kiel III carbonate device at the Woods Hole Oceanographic Institution, Woods Hole, MA, USA following the methods of Ostermann and Curry (2000). External precision of the mass spectrometer for

$\delta^{13} \mathrm{C}$ measurements in carbonate standards was $\pm 0.03 \%$. Approximately $10 \mathrm{mg}$ of otolith material from each fish was processed for compound-specific SIA. Samples of homogenized otolith powder were acid hydrolyzed in $4 \mathrm{ml}$ Teflon-lined screw cap vials with $0.1 \mathrm{ml}$ of $6 \mathrm{~N} \mathrm{HCl} \mathrm{mg}^{-1}$ otolith under an atmosphere of $\mathrm{N}_{2}$ at $110^{\circ} \mathrm{C}$ for $20 \mathrm{hrs}$. 
Samples were neutralized with ultra-pure water and evaporated to dryness under a gentle stream of $\mathrm{N}_{2}$ to remove $\mathrm{HCl}$. Samples were stored frozen until they were derivatized just prior to compound-specific SIA.

Freeze-dried, homogenized white muscle samples from each fish were also subdivided into two portions. Approximately $1 \mathrm{mg}$ of muscle for each sample was weighed into a tin cup and analyzed for bulk $\delta^{13} \mathrm{C}$ values using a Europa Hydra 20/20 irm-MS at the UC Davis Stable Isotope Facility, Davis, CA, USA. A second portion of each sample (approx. $500 \mu \mathrm{g}$ ) was acid hydrolyzed with $1 \mathrm{ml}$ of $6 \mathrm{~N} \mathrm{HCl} \mathrm{mg}^{-1}$ freezedried muscle tissue as described above for the otolith samples. Dried, neutralized samples were also stored frozen until derivatization.

\section{Compound-specific stable isotope analysis}

Acid hydrolyzed otolith and muscle samples were derivatized prior to compoundspecific SIA according to the following procedure, as modified from Silfer et al. (1991) and Johnson et al. (1998). First, each sample underwent an acid-catalyzed esterification using $0.8 \mathrm{ml}$ of 2-propanol and acetyl chloride ( $4: 1$ by volume) under an atmosphere of $\mathrm{N}_{2}$ at $110^{\circ} \mathrm{C}$ for $1 \mathrm{hr}$. The reactions were quenched in an ice bath, and the otolith samples were quantitatively transferred to new $4 \mathrm{ml}$ vials using dichloromethane (DCM), leaving behind salts associated with the acid hydrolysis of carbonate. All samples were dried under a gentle stream of $\mathrm{N}_{2}$. To remove any remaining acidified iso-propanol, samples were brought up in $0.5 \mathrm{ml}$ of DCM and dried under $\mathrm{N}_{2}$ three times. Each sample was then acylated with $0.5 \mathrm{ml}$ of triflouroacetic anhydride (TFAA) and $0.5 \mathrm{ml}$ of DCM under an 
atmosphere of $\mathrm{N}_{2}$ at $110^{\circ} \mathrm{C}$ for $10 \mathrm{~min}$. Again, reactions were quenched in an ice bath, and excess TFAA was removed as described above using three rinses of DCM. An AA standard was created to correct for the introduction of exogenous carbon and potential kinetic fractionation during derivatization. The $\delta^{13} \mathrm{C}$ values of the eleven AAs in the standard spanned the full range in $\delta^{13} \mathrm{C}$ values expected from our samples. The AA standard was derivatized concurrently with each batch of samples.

Samples were brought up in DCM and injected on column in splitless mode at $220^{\circ} \mathrm{C}$ and separated on an HP Ultra- 1 column (50 m length, $0.32 \mathrm{~mm}$ inner diameter and $0.5 \mu \mathrm{m}$ film thickness; Hewlett Packard, Wilmington, Delaware, USA) in a Agilent 6890N Gas Chromatograph (GC) at the Woods Hole Oceanographic Institution, Woods Hole, MA, USA. Sample concentrations were adjusted to achieve a minimum $2 \mathrm{~V}$ output for all AAs. Gas chromatography conditions were set to optimize peak separation and shape as follows: initial temperature $75^{\circ} \mathrm{C}$ held for $2 \mathrm{~min}$; ramped to $90^{\circ} \mathrm{C}$ at $4{ }^{\circ} \mathrm{C} \mathrm{min}^{-1}$, held for 4 min.; ramped to $185^{\circ} \mathrm{C}$ at $4^{\circ} \mathrm{C} \min ^{-1}$, held for 5 min.; ramped to $250^{\circ} \mathrm{C}$ at $10^{\circ} \mathrm{C}$ $\min ^{-1}$, held 2 min.; ramped to $300^{\circ} \mathrm{C}$ at $20^{\circ} \mathrm{C} \mathrm{min}^{-1}$, held for $8 \mathrm{~min}$. The separated AA peaks were combusted online in a Finnigan gas chromatography-combustion (GC-C) continuous flow interface at $930^{\circ} \mathrm{C}$, then measured as $\mathrm{CO}_{2}$ on a Thermo Finnigan Mat 253 irm-MS (hereafter GC-C-irm-MS). Standardization of runs was achieved using intermittent pulses of a $\mathrm{CO}_{2}$ reference gas of known isotopic composition. All compoundspecific SIA samples were analyzed in duplicate along with AA standards of known isotopic composition. We assigned AAs as non-essential or essential according to Karasov and Martínez del Rio (2007). The glutamic acid and aspartic acid peaks 
contained unknown contributions from glutamine and asparagine, respectively, due to conversion to their dicarboxylic acids during acid hydrolysis. The relative abundance (\%) of individual AAs in otoliths and muscle were calculated from mass 44 peak area based upon standards of known concentration.

\section{Data analysis}

Stable isotope ratios were expressed in standard delta $(\delta)$ notation:

$$
\delta^{13} C_{\text {sample }}=\left(\frac{{ }^{13} C / /{ }^{12} C_{\text {sample }}}{{ }^{13} C /{ }^{12} C_{\text {std }}}-1\right) * 1000
$$

where the standard for carbon was VPDB. We compared $\delta^{13} \mathrm{C}$ values in bulk muscle and otoliths from 73 fish collected at the three locations using linear regression and tested for differences in $\delta^{13} \mathrm{C}$ of bulk muscle and otoliths among locations using separate one-way analyses of variance (ANOVAs) and Tukey's honestly significant difference (HSD) posthoc tests $(\alpha=0.05)$. The relationships between $\delta^{13} \mathrm{C}$ values of individual AAs from otoliths and muscle were determined by linear regression analysis ( $\mathrm{n}=11$ AAs per fish, five fish per site, three sites). Differences in $\delta^{13} \mathrm{C}$ values of non-essential AAs (6 AAs per fish) and essential AAs (5 AAs per fish) across individual AAs and among sites were analyzed using separate model I (location and AA were fixed factors) two-way ANOVAs and Tukey's HSD post-hoc tests ( $\alpha=0.05, \mathrm{n}=5$ fish per site).

We determined minimum sample sizes necessary for compound-specific SIA of otolith and muscle by extrapolation of sample sizes used in this study down to the GC-C- 
irm-MS lower limit of detection for the least abundant AAs. Three aliquots of the same AA standard were derivatized at the same time under the same reaction conditions (for within-batch variability) on three separate days (for among-batch variability). To examine the variability in $\mathrm{AA} \delta^{13} \mathrm{C}$ values within and among derivatization batches, the mean relative standard deviation (RSD) within batch and among batch was calculated across all eleven AAs. The desktop stability of derivatives was assessed by analyzing three aliquots of the same AA standard a total of twenty times each over the course of nine days. Overall external precision of the $\delta^{13} \mathrm{C}$ measurements after correcting for the fractionation associated with derivatization was $0.80 \pm 0.96 \%$ (mean $\pm \mathrm{SD})$, averaged across all AAs.

\section{RESULTS}

Ehrenberg's snapper, L. ehrenbergii, collected from three locations near Al Lith, Saudi Arabia had distinct $\delta^{13} \mathrm{C}$ values for bulk otoliths (one-way ANOVA, $\mathrm{df}=2,14, \mathrm{~F}=$ 13.3, $\mathrm{p}<0.05$ ) and bulk muscle (one-way ANOVA, $\mathrm{df}=2,14, \mathrm{~F}=58.9, \mathrm{p}<0.05$ ). Only L. ehrenbergii from Coast Guard Reef and Ron's Reef had statistically similar otolith $\delta^{13} \mathrm{C}$ values, with $\mathrm{p}<0.05$ for all other pairwise comparisons (Fig. 3.2). There was a significant linear relationship between bulk muscle and bulk otolith $\delta^{13} \mathrm{C}$ values (linear regression, $y=0.38 x+3.31, R^{2}=0.83$; Fig. 3.2). However, the overall range in $\delta^{13} C$ values among locations was much larger for bulk muscle (7.2\%) than it was for bulk otolith (2.6\%). L. ehrenbergii from seagrass habitats in Al Lith Bay had the most enriched $\delta^{13} \mathrm{C}$ values for muscle (mean $\pm \mathrm{SD}-10.3 \pm 1.0 \%$ ) and otoliths $(-0.7 \pm 0.6 \%$ ) 
while the fish from the offshore shelf reef had the most depleted $\delta^{13} \mathrm{C}$ values for muscle ($17.5 \pm 0.8 \%$ ) and otoliths $(-3.3 \pm 1.1 \%$ ). Fish from the coastal reef adjacent to Al Lith Bay had intermediate $\delta^{13} \mathrm{C}$ values for muscle $(-14.6 \pm 1.2 \%$ ) and otoliths $(-2.3 \pm 0.6 \%$ ). Eleven individual AAs were identified and analyzed for $\delta^{13} \mathrm{C}$ using a GC-C-irmMS (Fig. 3.3). Glutamic acid was the most abundant AA in fish muscle and otolith followed by aspartic acid, while leucine and threonine were the most abundant essential AAs in muscle and otoliths, respectively (Table 3.1). Based upon the least abundant AA in our analyses, isoleucine for otoliths and proline for muscle, and the lower limit of detection ( $250 \mathrm{mV}$ signal output) for the MAT 253 irm-MS, we calculated a theoretical minimum sample size of 10-15 $\mu \mathrm{g}$ of muscle tissue and 500 - $1000 \mu \mathrm{g}$ of bulk otolith necessary for compound-specific SIA. However, it should be noted that otolith organic content can range from less than 1 to $10 \%$ depending upon species and life history stage (Degens et al. 1969; Morales-Nin 1986a; Payan et al. 2004; Jolivet et al. 2008). The derivatization process lowered the $\delta^{13} \mathrm{C}$ values of the AAs in the standard, although the shifts were not uniform among AAs. Variability in the $\delta^{13} \mathrm{C}$ values of derivatized AA standards was much smaller within derivatization batches (mean RSD $\pm \mathrm{SD}=0.8 \pm$ $0.2 \%)$ than among batches $(2.2 \pm 1.6 \%)$. Repeated injections of the same derivatized standard were very consistent, showing low variability (mean SD for all AAs $=0.35 \pm$ $0.14 \% \mathrm{SD}$ ) for the first 160 hours post-derivatization (Fig. 3.4). After approximately 160 hours the $\delta^{13} \mathrm{C}$ values of AAs in the standard became significantly more variable $(1.25 \pm$ $0.57 \%$ ) and tended to become more positive with time. The shift was not consistent 
among AAs, with serine and threonine typically becoming unstable first. Similar patterns were also observed in the fish muscle samples.

We found a strong linear relationship between individual otolith and muscle AA $\delta^{13} \mathrm{C}$ values (linear regression, $\mathrm{y}=1.00 \mathrm{x}+0.52, \mathrm{R}^{2}=0.96$ ) in L. ehrenbergii (Fig. 3.5). Mean differences in $\delta^{13} \mathrm{C}$ values between muscle and otolith AAs averaged $0.89 \%$ ( \pm $0.34 \%$ SD), and the difference between otolith and muscle essential AAs $\delta^{13} \mathrm{C}$ values $(0.75 \pm 0.27 \%$ o SD) was smaller than that for non-essential AAs $(1.01 \pm 0.36 \% \mathrm{SD})$. Otolith $\mathrm{AA} \delta^{13} \mathrm{C}$ values generally tracked the patterns observed in the bulk muscle and otoliths, although the otolith $\mathrm{AA} \delta^{13} \mathrm{C}$ range was closer to the bulk muscle range, particularly for several of the essential AAs (Fig. 3.6). Individual AAs from otoliths of fish collected in $\mathrm{Al}$ Lith Bay had the highest $\delta^{13} \mathrm{C}$ values and those from the shelf reef typically had the lowest $\delta^{13} \mathrm{C}$ values, with otolith $\mathrm{AA} \delta^{13} \mathrm{C}$ values from fish collected in the coastal reef adjacent to Al Lith Bay intermediate (Fig. 3.6). We found significant differences in otolith $\delta^{13} \mathrm{C}$ values among habitats (two-way $\mathrm{ANOVA}, \mathrm{df}=2,132, \mathrm{~F}=$ 89.7, $\mathrm{p}<0.05$ ) and among individual AAs (two-way ANOVA, $\mathrm{df}=10,132, \mathrm{~F}=396.3, \mathrm{p}$ $<0.05)$. However, variability in $\delta^{13} \mathrm{C}$ values of the AAs was not consistent among habitats, generating a significant interaction between the habitat and AA terms (two-way ANOVA, $\mathrm{df}=20,132, \mathrm{~F}=10.1, \mathrm{p}<0.05)$.

\section{DISCUSSION}

Stable isotope analysis (SIA) of AAs in otolith protein may provide a new way to retrospectively address questions of diet, habitat use and migration in fishes. The otolith 
AA $\delta^{13} \mathrm{C}$ method avoids many of the complications associated with conventional bulk SIA of fish otoliths, including DIC dilution of dietary signatures and variable metabolic carbon contribution to otolith $\delta^{13} \mathrm{C}$ values. We tested this new approach by sampling muscle and otoliths from Ehrenberg's snapper, L. ehrenbergii, along a carbon isotope gradient from coastal seagrass habitats to offshore coral reefs. Fish from Al Lith Bay had the most enriched muscle $\delta^{13} \mathrm{C}$ values (-10.4\%), likely reflecting the carbon contribution of $\mathrm{C} 4$ seagrasses with $\delta^{13} \mathrm{C}$ values of between -8 to $-12 \%$ at the the base of the food web (Hemminga and Mateo 1996). In contrast, L. ehrenbergii muscle tissue from the shelf reef $14 \mathrm{~km}$ offshore had the most depleted $\delta^{13} \mathrm{C}$ values (-17.5\%), reflecting a marine phytoplankton $\delta^{13} \mathrm{C}_{\mathrm{Base}}$ signature that typically ranges between -17 to $-21 \%$ (DescolasGros and Fontungne 1990). Fish from the coastal reef adjacent to Al Lith Bay had intermediate $\delta^{13} \mathrm{C}$ values for muscle (-14.6\%) that presumably indicated carbon inputs from both seagrasses and phytoplankton sources. The observed $\delta^{13} \mathrm{C}$ isoscape proved an ideal system for testing the ability of AAs in otoliths to accurately record $\delta^{13} \mathrm{C}$ signatures of metabolic carbon from individual fish.

We found that bulk otolith $\delta^{13} \mathrm{C}$ values were significantly different among the three habitats, and significantly correlated with bulk muscle $\delta^{13} \mathrm{C}$ values. Several recent studies have also suggested that bulk otolith records some dietary information even though most of the carbon comes from DIC in the ambient water (Dufour et al. 2007, Mateo et al. 2009, Elsdon et al. 2010). However, otoliths recorded less than half of the $\delta^{13} \mathrm{C}$ range seen in muscle tissue. As a result, the ability to discriminate among habitats using the bulk otolith data was reduced compared to muscle $\delta^{13} \mathrm{C}$ values. This was 
particularly true when comparing fish from the coastal and shelf reefs, where muscle $\delta^{13} \mathrm{C}$ values showed significantly larger differences between habitats $(\sim 3 \%)$ than otolith $\delta^{13} \mathrm{C}$ values $(\sim 1 \%)$.

Bulk otolith $\delta^{13} \mathrm{C}$ values were unable to capture the range of $\delta^{13} \mathrm{C}$ values in muscle; however, this was not the case for individual AAs in otoliths. Muscle AA $\delta^{13} \mathrm{C}$ values accounted for $96 \%$ of the observed variation in otolith $\mathrm{AA} \delta^{13} \mathrm{C}$ values, with a slope indistinguishable from 1. Otolith AAs were, therefore, recording identical dietary information to that of muscle AAs. This is perhaps not surprising considering both muscle and otoliths likely receive AAs for protein synthesis from a common AA pool in the blood. Our results also suggest that any fractionation during transport of AAs from blood to the site of protein synthesis and subsequent release from the macula (Murayama 2000; Murayama et al. 2004) was negligible. As such, $\delta^{13} \mathrm{C}$ analysis of otolith AAs should provide an archival record of fish diet that has previously been inaccessible with conventional inorganic otolith SIA.

Stable isotope analysis of individual AAs has greatly improved the study of diet (Fantle et al. 1999; Fogel and Tuross 2003), habitat use (Popp et al. 2007) and the sources of complex mixtures of organic matter (Uhle et al. 1997; McCarthy et al. 2004) for a number of terrestrial and aquatic taxa. Most recently, McMahon et al. (2010) showed in a controlled feeding experiment that essential AAs in fish muscle recorded the $\delta^{13} \mathrm{C}$ values of diet with little to no trophic fractionation, thereby providing an accurate recorded $\delta^{13} C_{\text {Base }}$ signatures. This result should be particularly valuable when comparing populations of fish from different habitats or examining the migration of individuals 
through distinct isoscapes, as it can be challenging with bulk SIA to distinguish changes in $\delta^{13} \mathrm{C}$ due to shifts in trophic level versus changes in $\delta^{13} \mathrm{C}_{\text {Base. }}$.

O’Donnell et al. (2007) examined $\delta^{13} \mathrm{C}$ values of AAs from modern and fossil Mercenaria shells to look at preservation of AAs in biominerals and examine regional and ontogenetic variability in $\delta^{13} \mathrm{C}$ values. The authors concluded that the range of $\delta^{13} \mathrm{C}$ values in AAs from modern Mercenaria collected from coastal Virginia and Florida suggested the preservation of a dietary signal in the bivalve shells. In addition, the authors showed significant variation in Mercenaria shell AA $\delta^{13} \mathrm{C}$ values within and among years, likely reflecting a shift in the relative contribution of primary producers at the base of the food web. Similar work by Johnson et al. (1998) provides another example of using AA SIA of biominerals to examine diet and local habitat use. These authors showed that $\mathrm{AA} \delta^{13} \mathrm{C}$ values from ostrich egg shells reflected the diet of ostrich at the time of egg formation and could be used to reconstruct local climate and vegetation conditions. Our data, in concert with these studies, suggest that compound-specific SIA of otoliths will be a valuable new tool to retrospectively examine diet and movement of fishes.

In addition to determining $\delta^{13} \mathrm{C}_{\text {Base }}$ signatures, $\mathrm{AA} \delta^{13} \mathrm{C}$ values in otoliths may record other valuable information about diet that was previously difficult to assess with conventional bulk otolith SIA. McMahon et al. (2010) found that non-essential AAs in fish muscle showed diet-specific evidence of de novo biosynthesis and direct isotopic routing from dietary protein. Both the AA composition and lipid to carbohydrate ratio of the diet appeared to play a role in determining the $\delta^{13} \mathrm{C}$ value of muscle non-essential 
AAs. The mechanisms driving non-essential AA $\delta^{13} \mathrm{C}$ variability remain unknown and deserve further investigation. However, our work supports previous research on other biominerals, including bones of pigs and rats (Hare et al. 1991; Howland et al. 2003; Jim et al. 2006), suggesting that non-essential $\mathrm{AA} \delta^{13} \mathrm{C}$ values contain valuable information about diet and food quality.

In conclusion, $\delta^{13} \mathrm{C}$ analysis of AAs in otoliths provides a powerful new tool for retrospective analysis of diet and movement patterns of fishes. Otolith $\mathrm{AA} \delta^{13} \mathrm{C}$ signatures were highly correlated with muscle values and provided a purely dietary signature that avoided the confounding factors of DIC dilution and variable metabolic carbon contribution found in bulk otolith $\delta^{13} \mathrm{C}$ analysis. Although the sample size necessary for compound-specific analyses using GC-C-irm-MS work is larger than that necessary for bulk otolith $\delta^{13} \mathrm{C}$ measurements, $\delta^{13} \mathrm{C}$ values of otolith AAs contain a wealth of information not available from conventional bulk analyses. Otolith essential AAs provided a valuable tracer of residence in isotopically distinct habitats, which will greatly increases our ability to track the movement of migratory fish or determine the $\delta^{13} C_{\text {Base }}$ values for resident fish. Conversely, non-essential AAs may provide access to important archived information about fish diet that is difficult to interpret from bulk otolith SIA. The application of compound-specific SIA to otolith research is still in its infancy and the potential applications are broad and diverse. It will be exciting to see where this compound-specific SIA technique is taken in the future. 


\section{ACKNOWLEDGEMENTS}

The authors would like to thank M. Berumen for field assistance and the crew of Dream Divers, Jeddah, Saudi Arabia for logistic assistance with boating and diving operations. Figure 3.1 was created by C. Braun. The authors would also like to thank the Mullineaux lab group for comments on an early draft of the manuscript. This research was supported by King Abdullah University of Science and Technology (KAUST) Award Nos. USA 00002 and KSA 00011 to S. Thorrold and an International Society for Reef Studies-Ocean Conservancy Coral Reef Fellowship to K. McMahon. Additional funding was provided by the Woods Hole Oceanographic Institution. K. McMahon received support from the National Science Foundation Graduate Research Fellowship Program. 
Table 3.1. The relative abundance (mean $\% \pm \mathrm{SD}$ ) of eleven individual amino acids in otolith and muscle of Lutjanus ehrenbergii calculated from mass 44 peak area and standards of known concentration ( $\mathrm{n}=3$ sites, 5 fish per site).

\begin{tabular}{lrr}
\hline Amino acids & \multicolumn{1}{c}{ Otolith } & \multicolumn{1}{c}{ Muscle } \\
\hline \hline Gylcine $\dagger$ & $7.2 \pm 0.6$ & $5.8 \pm 0.2$ \\
Serine $\dagger$ & $9.2 \pm 0.5$ & $5.1 \pm 0.6$ \\
Aspartic acid $\dagger$ & $16.5 \pm 1.0$ & $16.6 \pm 0.3$ \\
Glutamic acid $\dagger$ & $27.0 \pm 1.2$ & $26.1 \pm 1.2$ \\
Proline $\dagger$ & $9.8 \pm 1.5$ & $4.6 \pm 2.5$ \\
Alanine $\dagger$ & $6.6 \pm 0.8$ & $7.5 \pm 0.3$ \\
Threonine* & $6.6 \pm 0.8$ & $5.4 \pm 0.1$ \\
Isoleucine* & $3.2 \pm 0.9$ & $5.1 \pm 0.1$ \\
Valine* & $4.0 \pm 0.3$ & $5.6 \pm 0.2$ \\
Phenylalanine* & $4.0 \pm 0.3$ & $5.3 \pm 0.1$ \\
Leucine* & $5.9 \pm 0.5$ & $13.0 \pm 0.4$ \\
\hline$\dagger=$ non-essential amino acids, & $*=$ essential amino acids
\end{tabular}




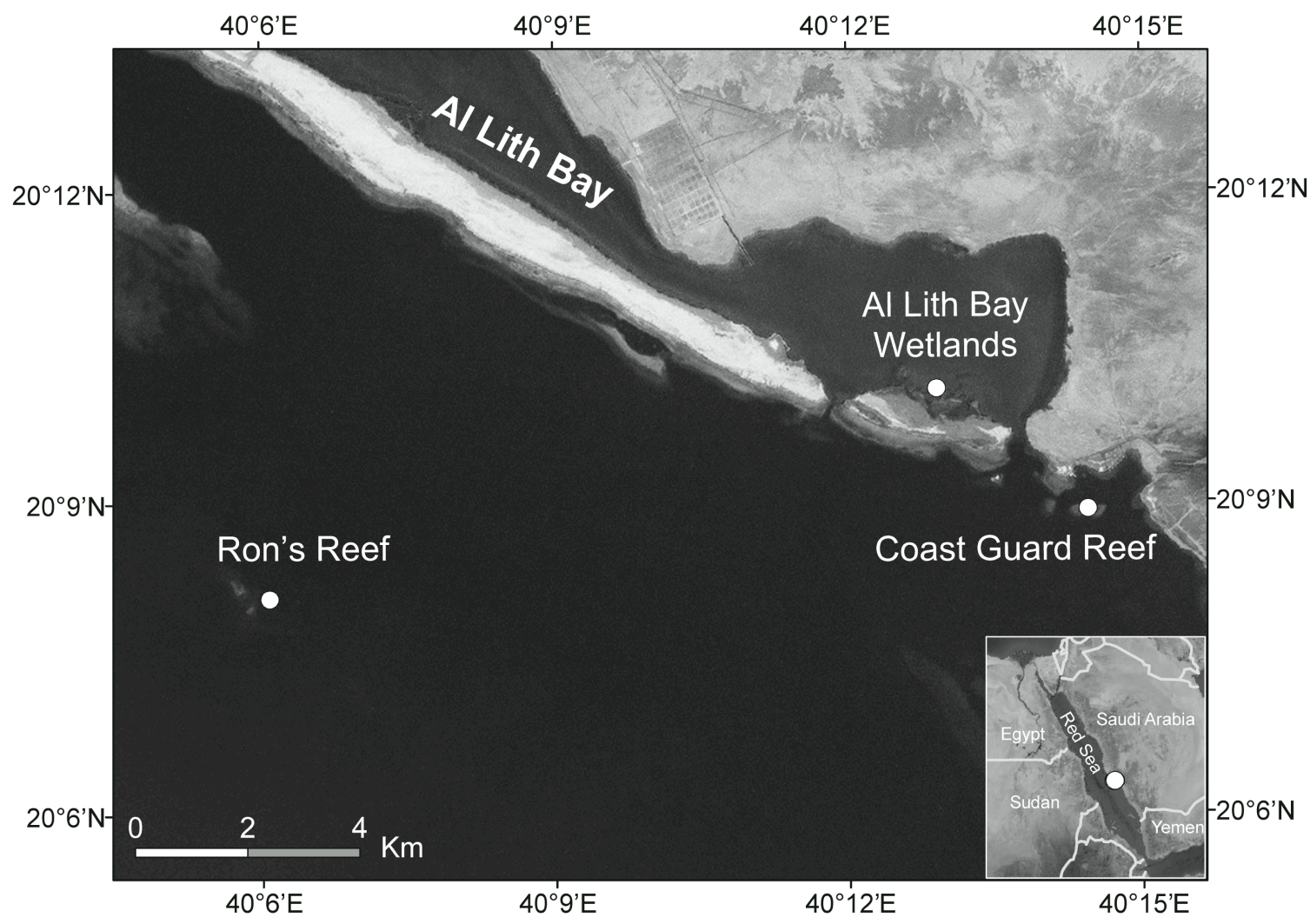

Figure 3.1. Ehrenberg's snapper, Lutjanus ehrenbergii, collection sites from three sites near Al Lith, Saudi Arabia in the Red Sea in March 2009. Juvenile L. ehrenbergii were collected from seagrass beds (Al Lith Bay) and adult L. ehrenbergii were collected from a coastal reef adjacent to Al Lith Bay (Coast Guard Reef) and a shelf reef $14 \mathrm{~km}$ offshore (Ron's Reef). 


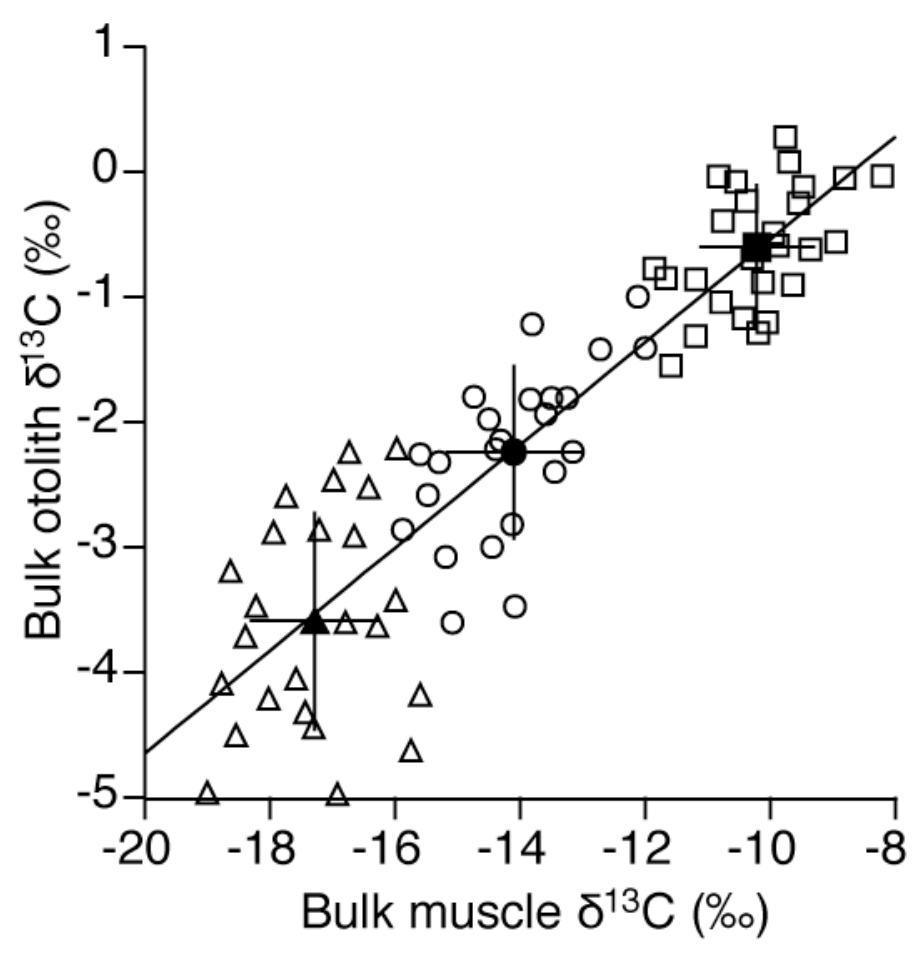

Figure 3.2. Linear relationship between bulk otolith and muscle $\delta^{13} \mathrm{C}$ values from Lutjanus ehrenbergii collected from three isotopically distinct habitats near Al Lith, Saudi Arabia in the Red Sea: Al Lith Bay (square; $\mathrm{n}=26$ fish), Coast Guard Reef (circle, $\mathrm{n}=23$ fish) and Ron's Reef (triangle; $\mathrm{n}=24$ fish). Individual fish are represented by open symbols and means \pm SD for each site are represented by filled symbols. 


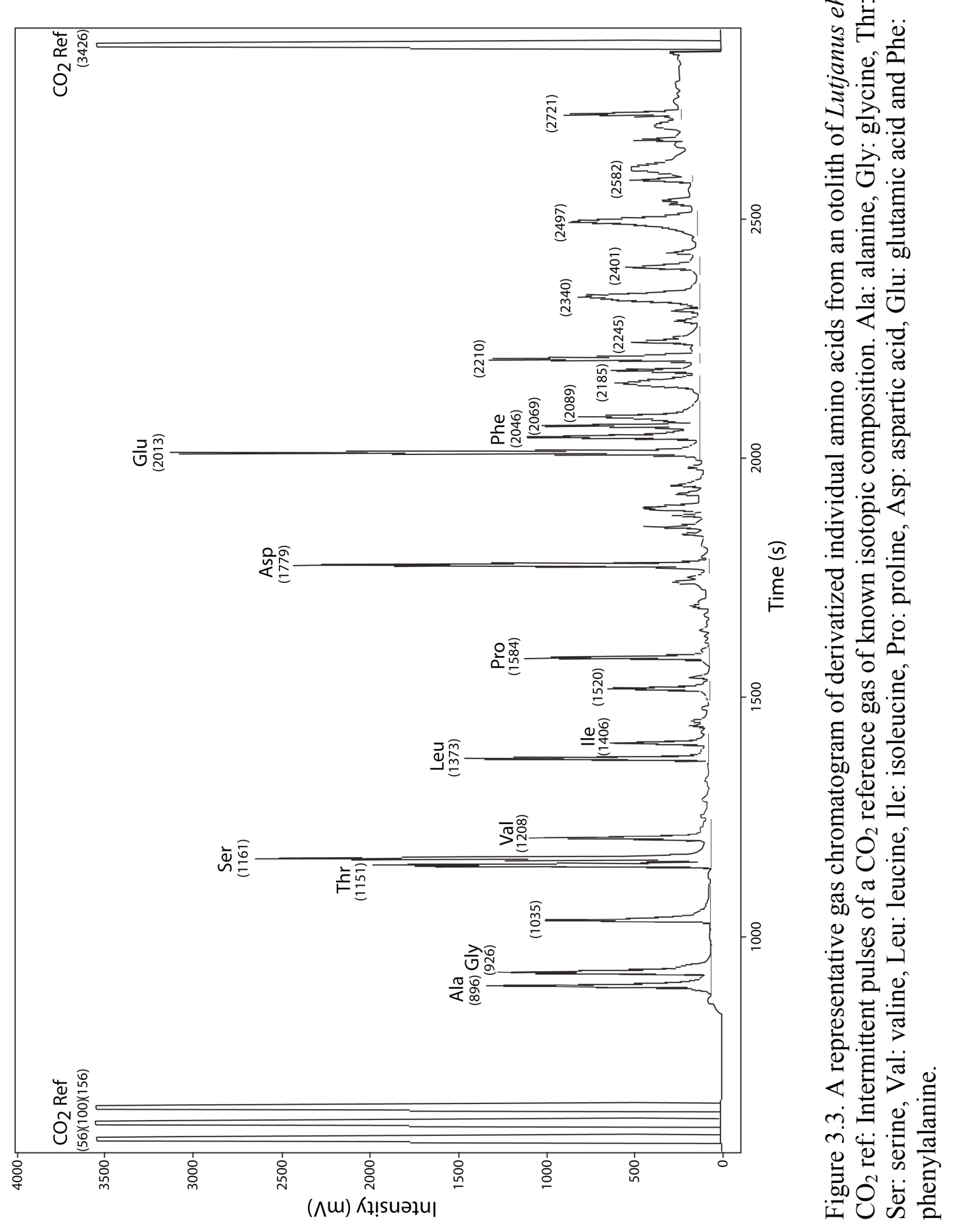




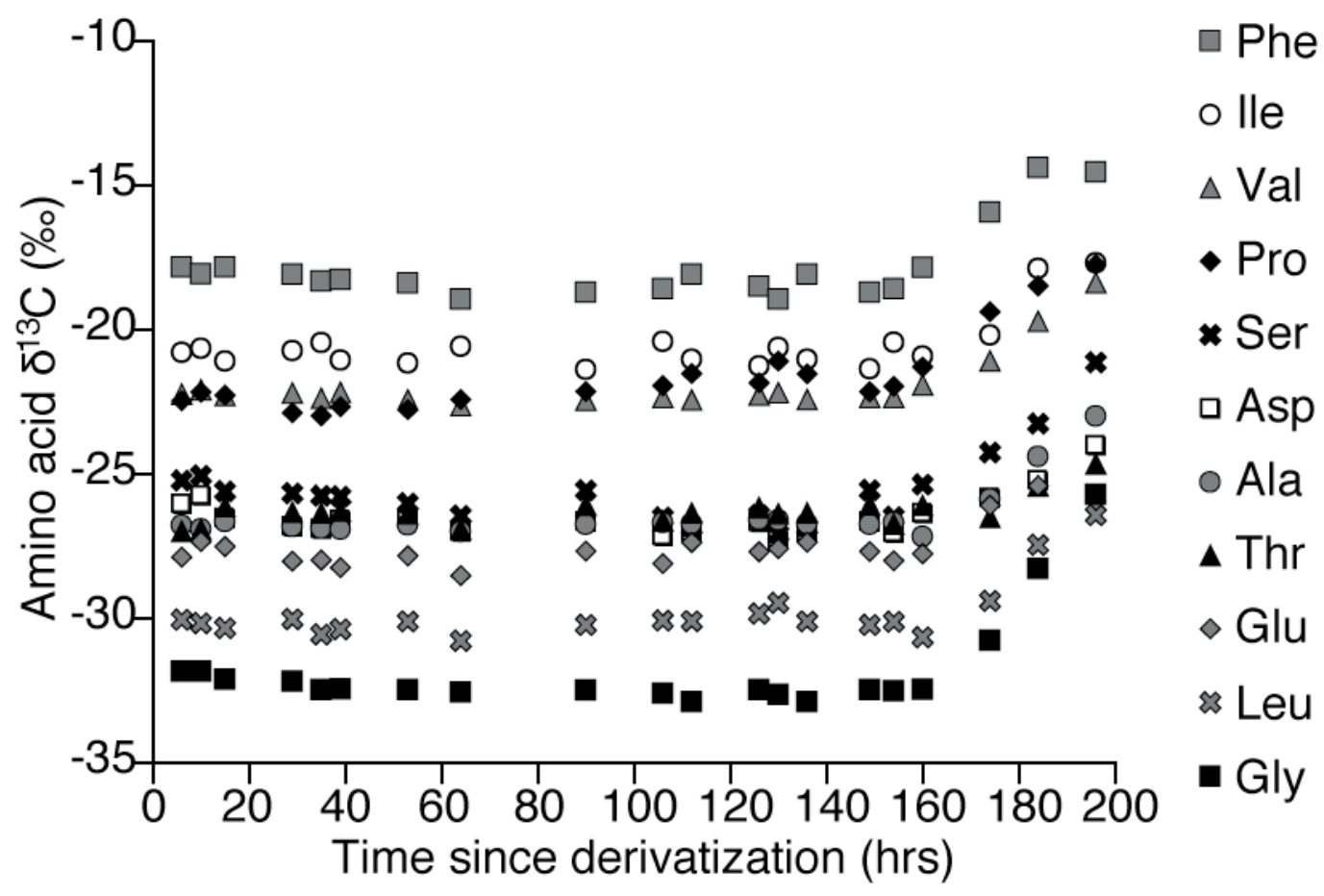

Figure 3.4. Amino acid $\delta^{13} \mathrm{C}$ values of a derivatized standard analyzed 20 times over the course of nine days via gas chromatography-combustion-isotope ratio monitoring-mass spectrometry. Ala: alanine, Gly: glycine, Thr: threonine, Ser: serine, Val: valine, Leu: leucine, Ile: isoleucine, Pro: proline, Asp: aspartic acid, Glu: glutamic acid and Phe: phenylalanine. 


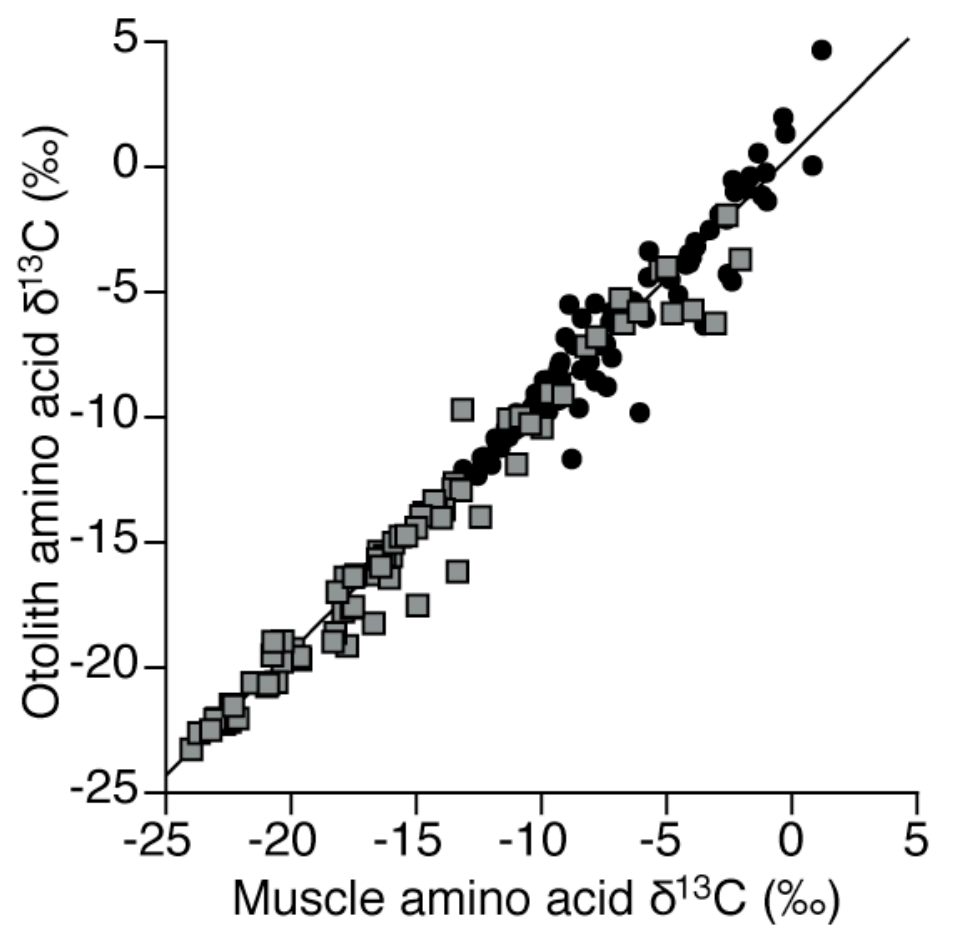

Figure 3.5. Linear relationship between individual amino acid $\delta^{13} \mathrm{C}$ values of otoliths and muscle from Lutjanus ehrenbergii collected from three isotopically distinct habitats near Al Lith, Saudi Arabia in the Red Sea (black circles = (6) non-essential amino acids; gray squares $=(5)$ essential amino acids $)(n=11$ amino acids per fish, five fish per site, three sites). 


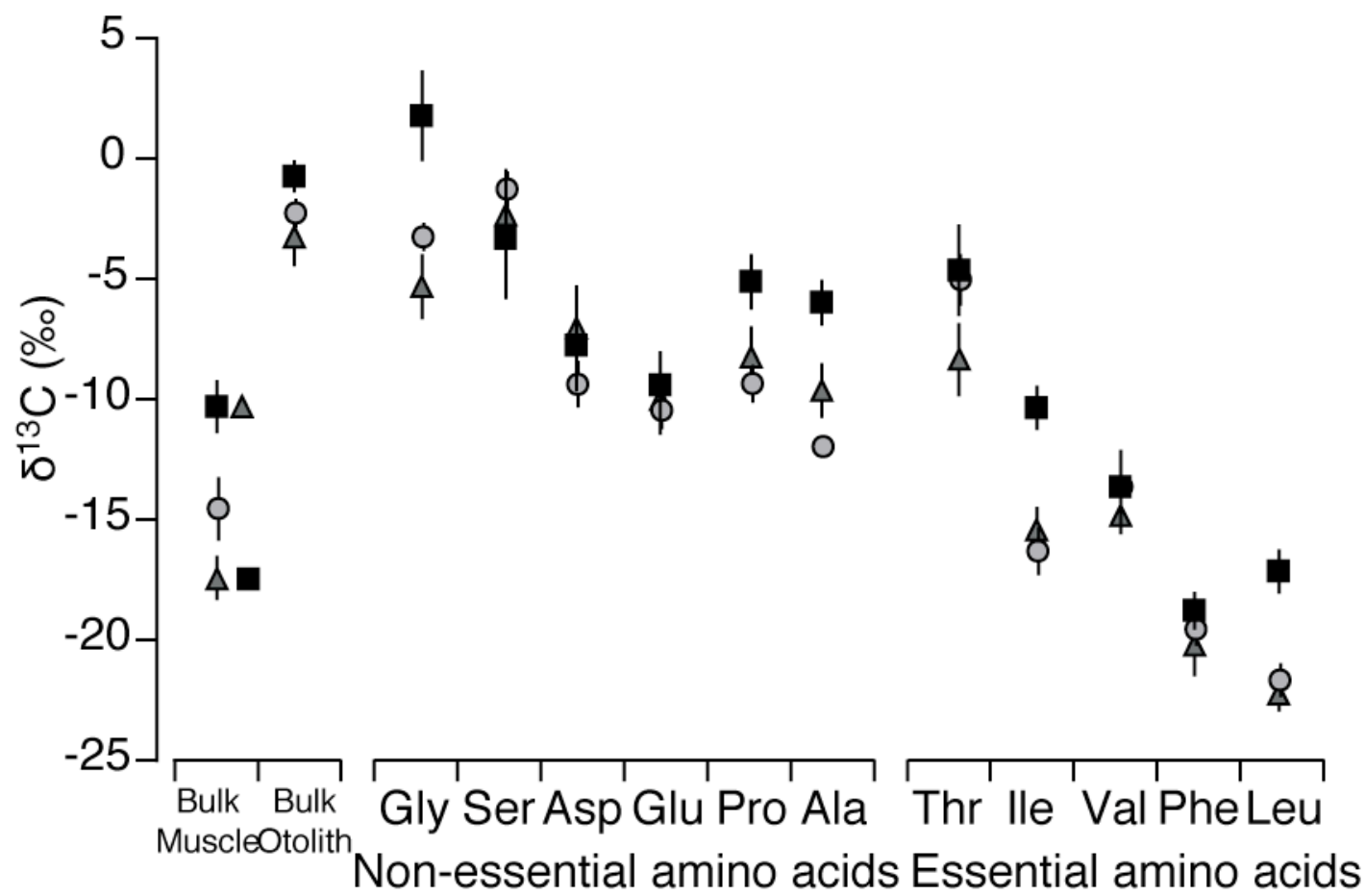

Figure 3.6. Bulk muscle and otolith $\delta^{13} \mathrm{C}$ values (mean $\pm \mathrm{SD}$ ) and otolith non-essential and essential amino acid $\delta^{13} \mathrm{C}$ values (mean $\pm \mathrm{SD}$ ) from Lutjanus ehrenbergii collected from three isotopically distinct habitats: Al Lith Bay (black squares), Coast Guard Reef (light gray circles) and Ron's Reef (dark gray triangles) near Al Lith, Saudi Arabia in the Red Sea ( $=5$ fish per site). 


\title{
CHAPTER FOUR
}

Stable isotope signatures in otolith amino acids of juvenile snapper (Family: Lutjanidae) record habitat-specific isoscapes from coastal nurseries

\author{
Kelton W. McMahon ${ }^{1}$ \\ ${ }^{1}$ Massachusetts Institute of Technology and Woods Hole Oceanographic Institution \\ Joint Program in Oceanography and Ocean Engineering, \\ Woods Hole Oceanographic Institution, Woods Hole, MA 02543, USA \\ Michael L. Berumen
${ }^{2}$ Red Sea Research Center, \\ King Abdullah University of Science and Technology, Thuwal, Kingdom of Saudi \\ Arabia \\ Ivan Mateo $^{3}$ \\ ${ }^{3}$ Department of Fisheries, Animal and Veterinary Sciences, \\ University of Rhode Island, Kingston, RI 02881, USA \\ Travis S. Elsdon ${ }^{4}$ \\ ${ }^{4}$ Southern Seas Ecology Laboratories, School of Earth and Environmental Sciences, \\ University of Adelaide, Adelaide, SA 5005, Australia \\ Simon R. Thorrold ${ }^{5}$ \\ ${ }^{5}$ Biology Department, \\ Woods Hole Oceanographic Institution, Woods Hole, MA 02543, USA
}




\begin{abstract}
We explored the potential for geochemical signatures in otoliths of snapper (Family: Lutjanidae) to act as natural tags of residency in juvenile nursery habitats with distinctive carbon isotope signatures. We compared conventional bulk otolith $\delta^{13} \mathrm{C}$ and $\delta^{18} \mathrm{O}$ analysis with essential amino acids (AA) $\delta^{13} \mathrm{C}$ analysis of snapper collected from seagrass beds, mangroves and coral reefs in the Red Sea, Caribbean Sea, and Eastern Pacific Ocean. We found a strong linear relationship between otolith and muscle essential AA $\delta^{13} \mathrm{C}$ values regardless of species, geographic region or habitat type, indicating that otolith AAs recorded the same dietary information as muscle AAs. Our results revealed that detrital carbon was an important component of the food webs supporting snapper production in coastal reefs of the Red Sea. Essential AA $\delta^{13} \mathrm{C}$ values in otoliths varied as a function of habitat type and provided a better tracer of residence in unique juvenile nursery habitats than conventional bulk stable isotope analysis alone. Juvenile snapper in the Red Sea sheltered in mangroves but fed in seagrass beds, while snapper from the Caribbean Sea and Eastern Pacific Ocean showed much greater reliance on mangrovederived carbon. The development of robust juvenile nursery residence tracers in this study will be crucial for reconstructing ontogenetic migration patterns of fishes among coastal wetlands and coral reefs. This information is important for determining the importance of nursery habitats to coral reef fish populations and can provide valuable scientific support for the design of networked marine protected areas.
\end{abstract}




\section{INTRODUCTION}

Many commercially and ecologically important coral reef fishes, including species of Lutjanidae (snappers), Serranidae (grouper), Haemulidae (grunts) and Scaridae (parrotfish), are thought to use coastal mangroves and seagrass beds as juvenile nursery areas before migrating to coral reef habitats as adults (see reviews by Beck et al. 2001; Adams et al. 2006; Faunce and Serafy 2006; Nagelkerken et al. 2008a). Nearshore habitats can provide a number of benefits to resident juvenile reef fishes, including an abundance of food, refuge from predators and shelter from physical disturbance (Laegdsgaard and Johnson 2001; Cocheret de al Morinière et al. 2004; Manson et al. 2005; Verweij et al. 2006). These benefits may result in higher growth and survival rates leading to locally elevated juvenile densities within habitats and, presumably, the movement of significant numbers of individuals from these nursery areas to adult habitats (Beck et al. 2001; Sheridan and Hays 2003; Adams et al. 2006).

Few would argue against the idea that mangroves and seagrass beds typically harbor higher densities of many juvenile reef fish species compared to reef habitats (Jackson et al. 2001b; Manson et al. 2005). However, do juveniles within these coastal habitats successfully recruit to the adult populations on reefs? Most studies to date have either assumed successful migration from nursery habitats to reef environs or inferred movements based upon differential size class distributions among habitats (Nagelkerken 2007). Only a handful of studies have provided direct evidence for such ontogenetic movements (Chittaro et al. 2004; Nakamura et al. 2008; Mateo et al. 2010), and even 
fewer have quantified the relative contribution of different juvenile habitats to adult populations on coral reefs.

Tracking movement of fishes between juvenile and adult habitats requires the ability to either follow individuals between habitats over long time scales or retrospectively identify juvenile habitat associations in adult fishes. Conventional markrecapture approaches suffer a number of limitations when applied to early life history stages of marine fishes including tagging effects on mortality and behavior, difficulties tagging a high proportion of the individuals within a location and low recapture rates of tagged fish (Thorrold et al. 2002). More recently, fish ecologists have used geochemical signatures in otoliths to overcome many of the problems associated with conventional tagging (reviewed by Elsdon at al. 2008). Otoliths are paired aragonite structures deposited on a proteinaceous matrix in daily and annual bands throughout the life of a fish (Campana 1999). As such, otoliths preserve a chronological record of the fish's metabolic activity and the physical and chemical characteristics of the water in which the fish resided during the time of deposition (Campana 1999). In regions of the ocean where different habitats have unique base-of-the-food-web isotopic signatures $\left(\delta^{13} \mathrm{C}_{\text {Base }}\right)$, stable isotope analysis (SIA) of otoliths may be used to retrospectively identify periods of residence in habitats with distinctive isoscapes (isotope landscapes [West et al. 2010]). For instance, mangroves, coral reefs, and seagrass beds have unique $\delta^{13} \mathrm{C}_{\text {Base }}$ signatures resulting from the distinct $\delta^{13} \mathrm{C}$ values of the dominant primary producers in those locations (Marguillier et al. 1997; Layman 2007). Similarly, estuarine environments often exhibit unique dissolved inorganic carbon (DIC) $\delta^{13} \mathrm{C}$ and $\delta^{18} \mathrm{O}$ values of ambient water 
$\left(\delta^{18} \mathrm{O}_{\mathrm{H}_{2}} \mathrm{O}\right)$ associated with freshwater inputs that have distinctive isotopic compositions (Dansgaard 1964; Siegenthaler and Oeschger 1980; Stewart and Taylor 1981).

We have recently developed a technique for analyzing $\delta^{13} \mathrm{C}$ values of essential amino acids (AAs) in otoliths that may provide a new source of information on habitat use by juvenile reef fishes (McMahon et al. 2010; McMahon et al. Chapter 3 this thesis). Essential AAs are excellent tracers of dietary carbon sources because most animals cannot synthesize essential amino acids de novo but rather incorporate them into tissues directly from their diet with little to no isotope fractionation (Hare et al. 1991; Howland et al. 2003; Jim et al. 2006; McMahon et al. 2010). Therefore $\delta^{13} \mathrm{C}$ values in essential AAs of otoliths provide a way of distinguishing among habitats with different $\delta^{13} \mathrm{C}_{\text {Base }}$ values. The approach is complementary to traditional bulk analysis of $\delta^{13} \mathrm{C}$ and $\delta^{18} \mathrm{O}$ in otolith aragonite where isotope values are a function of physico-chemical properties of ambient water (McMahon et al. Ch 3 this thesis).

Here, we explore the potential for geochemical signatures in otoliths from snapper (Family: Lutjanidae) to act as natural tags of residency in juvenile nursery habitats with distinctive $\delta^{13} \mathrm{C}_{\text {Base }}$ values. We compared bulk $\delta^{13} \mathrm{C}$ and $\delta^{18} \mathrm{O}$ signatures in otoliths of juvenile Lutjanus ehrenbergii with essential AA $\delta^{13} \mathrm{C}$ values among three coastal wetlands sites along the Red Sea coast of Saudi Arabia. A common species of snapper in the Indo-west Pacific, L. ehrenbergii is abundant as juveniles in coastal wetlands and as adults on coral reefs (Unsworth et al. 2009). To examine the generality of these results, we analyzed otoliths from juvenile schoolmaster snapper (L.apodus) collected in seagrass beds and mangrove lagoons around the islands of St. Croix and Puerto Rico in 
the Caribbean Sea and juvenile yellow snapper (L.argentiventris) sampled from mangrove lagoons along the west coast of Panama. We hypothesized that essential AA $\delta^{13} \mathrm{C}$ values in otoliths would vary as a function of habitat type while bulk $\delta^{13} \mathrm{C}$ and $\delta^{18} \mathrm{O}$ would vary regionally due to unique coastal water mass properties at each of the locations but not at smaller spatial scales within locations. Successful demonstration of habitatspecific stable isotope signatures in the organic component of otoliths would, in turn, allow for definitive studies of the importance of coastal wetland habitats to coral reef fisheries.

\section{METHODS AND MATERIALS}

\section{Field collections}

Ehrenberg's snapper, L. ehrenbergii (Peters 1869), were collected at five locations along the coast of Saudi Arabia in the Red Sea in November 2008, March 2009, and June 2010 (Fig. 4.1). Juvenile L. ehrenbergii (total length [TL] $85 \pm 17 \mathrm{~mm}$ ) were collected with cast nets from three different coastal wetland systems along the coast of central Saudi Arabia. Khor Al Kharrar Bay is a large, shallow semi-enclosed bay that is dominated by ribbon seagrass, Halodule uninervis, with fringing white mangroves, Avicennia marina. Al Lith Bay is a smaller shallow semi-enclosed bay with a similar distribution of H. uninervis, but a sparser coverage of A. marina. Cape Al-Askar Bay is a coastal seagrass embayment with significantly more A. marina than the other two bays and is protected by fringing coral patch reefs. Adult $L$. ehrenbergii were speared from a coastal reef adjacent to the entrance of Al Lith Bay (Coast Guard Reef; fish TL $=188 \pm$ 
$41 \mathrm{~mm}$ ) and a shelf reef approximately $14 \mathrm{~km}$ off the coast of Al Lith (Ron's Reef; fish $\mathrm{TL}=217 \pm 18 \mathrm{~mm}$ ) to characterize $\delta^{13} \mathrm{C}$ signatures of reef residence, as we observed no juvenile L. ehrenbergii on any reefs outside of Al Lith Bay. To constrain $\delta^{13} \mathrm{C}_{\text {Base }}$ values of coastal food webs, we collected seagrass blades (H. uninervis) and mangrove leaves (A. marina) by hand from Al Lith Bay. Detritus feeding crabs, a major component of $L$. ehrenbergii diet, were collected from Al Lith Bay (Metopograpsus thukuhar), Coast Guard Reef (Trapezia tigrina) and Ron's Reef (T. tigrina) by hand. Zooplankton samples, consisting predominantly of calenoid copepods, were collected with a $1 \mathrm{~m}$ diameter, $333 \mu \mathrm{m}$ mesh net in Al Lith Bay, and in open water adjacent to Coast Guard Reef and Ron's Reef. Crab and zooplankton samples served as proxies for detritus and phytoplankton food web end members in the system, respectively. Triplicate samples were collected for all food web samples.

Juvenile snapper in the genus Lutjanus were also collected from two islands in the Caribbean Sea and along the Pacific coast of Panama to examine regional variability in juvenile nursery habitat signatures. Juvenile schoolmaster snapper, L. apodus (Walbaum 1792) (fish $\mathrm{TL}=75 \pm 40 \mathrm{~mm}$ ), were collected with seine nets and wire traps at two

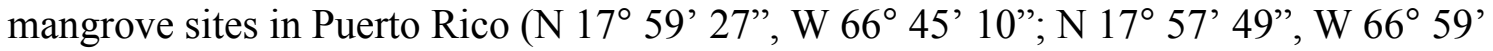
08”), a mangrove site in St. Croix (N $\left.17^{\circ} 46^{\prime} 30^{\prime \prime}, \mathrm{W} 64^{\circ} 45^{\prime} 36^{\prime \prime}\right)$ and a seagrass site in St. Croix (N $17^{\circ} 43 ; 23 ”$, W $\left.64^{\circ} 38^{\prime} 45^{\prime \prime}\right)$. Juvenile yellow snapper, L. argentiventris (Peters 1869) (fish TL $=83 \pm 7 \mathrm{~mm}$ ), were collected with seine nets from three mangrove sites near Bahia Honda, Panama (N $7^{\circ} 45^{\prime} 50^{\prime \prime}, \mathrm{W} 81^{\circ} 32^{\prime} 56^{\prime \prime}$; N $7^{\circ} 45^{\prime} 56^{\prime \prime}, \mathrm{W} 81^{\circ} 30^{\prime}$ 46”; N $\left.7^{\circ} 44^{\prime} 55^{\prime}, \mathrm{W} 81^{\circ} 29^{\prime} 55^{\prime \prime}\right)$ in the Eastern Pacific Ocean. 
Sagittal otoliths and white muscle tissue were dissected from each fish in the field, with the exception of $L$. argentiventris, where only otoliths were retained. Otoliths were cleaned of residual surface tissue with water and stored dry in $1.5 \mathrm{ml}$ vials. White muscle samples from the dorsal surface of each fish as well as food web samples were frozen on the boat prior to transport to an onshore laboratory. In the lab, white muscle and food web samples were frozen at $-20^{\circ} \mathrm{C}$ and then lyophilized (freeze-dried) for 48 hrs. Samples were transferred to the Woods Hole Oceanographic Institution, Woods Hole, MA, USA for further preparation and analysis. Ten L. ehrenbergii were collected from each of the five sites in the Red Sea, four L. apodus were collected from each of the four sites in the Caribbean Sea and five L. argentiventris were collected from each of the three sites on the west coast of Panama.

\section{Sample preparation and analysis}

A single, randomly selected, sagittal otolith from each fish was used for bulk and compound-specific SIA. All otolith samples were scrubbed and rinsed in ultra-pure water, cleaned ultrasonically for $5 \mathrm{~min}$ in ultra-pure water and then air-dried under a class-100 positive-flow fume hood for $24 \mathrm{hrs}$. Whole otoliths from juvenile Lutjanus spp. were used for SIA. For adult $L$. ehrenbergii, we extracted otolith powder after the last annulus, corresponding to the most recent several months of growth, using a Merchantek MicroMill with a Leica GZ6 microscope (Electro Scientific Industries, Portland, OR, USA) to isolate the stable isotope signature of the most recent location of residence. 
Otolith material was homogenized with a mortar and pestle and then subdivided into two portions for bulk inorganic and compound-specific SIA. Approximately $50 \mu \mathrm{g}$ of otolith material was analyzed for bulk $\delta^{13} \mathrm{C}$ and $\delta^{18} \mathrm{O}$ on a Thermo Finnigan Mat 253 isotope ratio monitoring-mass spectrometer (irm-MS) with a Kiell III carbonate device at the Woods Hole Oceanographic Institution, Woods Hole, MA, USA following the methods of Ostermann and Curry (2000). External precision of the mass spectrometer for $\delta^{13} \mathrm{C}$ measurements in carbonate standards was $\pm 0.03 \%$. Approximately $10 \mathrm{mg}$ of otolith material from each fish was acid hydrolyzed to isolate individual AAs according to McMahon et al. (Chapter 3 this thesis).

Freeze-dried, homogenized white muscle samples from each fish and food web samples from the Red Sea were also subdivided into two portions. Approximately $1 \mathrm{mg}$ of each sample was weighed into a tin cup and analyzed for bulk $\delta^{13} \mathrm{C}$ and $\delta^{15} \mathrm{~N}$ values using a Europa Hydra 20/20 irm-MS at the UC Davis Stable Isotope Facility, Davis, CA, USA. A second portion of each sample (approx. $500 \mu \mathrm{g}$ for muscle and $1 \mathrm{mg}$ for plant matter) was acid hydrolyzed in the same manner as the otolith samples for $\mathrm{AA} \delta^{13} \mathrm{C}$ measurements.

Acid hydrolyzed otolith, muscle and food web samples were derivatized prior to SIA according to McMahon et al. (Chapter 3 this thesis) as modified from Silfer et al. (1991) and Johnson et al. (1998). Samples were brought up in dichloromethane (DCM) and injected on column in splitless mode at $260^{\circ} \mathrm{C}$ and separated on a forte SolGel-1ms column (60 m length, $0.25 \mathrm{~mm}$ inner diameter and $0.25 \mu \mathrm{m}$ film thickness; SGE Analytical Science, Sydney, Australia) in a Agilent 6890N Gas Chromatograph (GC) at 
the Woods Hole Oceanographic Institution, Woods Hole, MA, USA. The separated AA peaks were combusted online in a Finnigan gas chromatography-combustion continuous flow interface at $1030^{\circ} \mathrm{C}$, then measured as $\mathrm{CO}_{2}$ on a Thermo Finnigan Mat 253 irm-MS (hereafter GC-C-irm-MS). Standardization of runs was achieved using intermittent pulses of a $\mathrm{CO}_{2}$ reference gas of known isotopic composition. All compound-specific SIA samples were analyzed in duplicate along with AA standards of known isotopic composition. We focused on five essential AAs with sufficient peak size and baseline GC separation: threonine, isoleucine, valine, phenylalanine and leucine.

\section{Data analysis}

Stable isotope ratios were expressed in standard delta $(\delta)$ notation:

$$
\delta^{13} C_{\text {sample }}=\left(\frac{{ }^{13} C /{ }^{12} C_{\text {sample }}}{{ }^{13} C /{ }^{12} C_{\text {std }}}-1\right) * 1000
$$

where the standard for carbon was VPDB. Differences in bulk otolith $\delta^{13} \mathrm{C}$ and $\delta^{18} \mathrm{O}$ values and bulk muscle $\delta^{13} \mathrm{C}$ and $\delta^{15} \mathrm{~N}$ values among L. ehrenbergii from different habitats were assessed using separate one-way analyses of variance (ANOVAs), with Tukey's honestly significant difference (HSD) post-hoc tests $(\alpha=0.05)$. We visualized differences in essential AA signatures from L. ehrenbergii and food web components using principal component analysis (PCA). The relationships between $\delta^{13} \mathrm{C}$ values of individual essential AAs from paired otolith and muscle samples were determined by linear regression analysis for L. ehrenbergii and L. apodus, separately. We calculated 
$95 \%$ confidence ellipses for the bulk otolith $\delta^{13} \mathrm{C}$ and $\delta^{18} \mathrm{O}$ values from fish collected in the Red Sea, the Caribbean Sea and the west coast of Panama.

\section{RESULTS}

Ehrenberg's snapper, L. ehrenbergii, collected from five sites along the coast of Saudi Arabia differed significantly in bulk otolith $\delta^{13} \mathrm{C}$ values (one-way ANOVA, $\mathrm{df}=4$, $48, \mathrm{~F}=38.2, \mathrm{p}<0.05$ ) and bulk muscle $\delta^{13} \mathrm{C}$ values (one-way ANOVA, $\mathrm{df}=4,48, \mathrm{~F}=$ 163.4, $\mathrm{p}<0.05$ ) (Table 4.1). L. ehrenbergii from the three coastal wetland sites, Khor Al Kharrar Bay, Al Lith Bay and Cape Al-Askar Bay, had statistically similar bulk muscle and otolith $\delta^{13} \mathrm{C}$ values that were higher than either Coast Guard Reef or Ron's Reef. Bulk otolith $\delta^{18} \mathrm{O}$ values were similar among sites, with the exception of L. ehrenbergii from Khor Al Kharrar Bay (one-way ANOVA, $\mathrm{df}=4,48, \mathrm{~F}=3.8, \mathrm{p}<0.05$ ). Bulk muscle $\delta^{15} \mathrm{~N}$ values were similar among sites with the exception of L. ehrenbergii from Khor Al Kharrar Bay and Cape Al-Askar Bay, which had significantly lower $\delta^{15} \mathrm{~N}$ values than fish from the other sites (one-way ANOVA, $\mathrm{df}=4,48, \mathrm{~F}=23.3, \mathrm{p}<0.05$ ) (Table 4.1). There were significant differences in zooplankton bulk $\delta^{13} \mathrm{C}$ values (one-way ANOVA, $\mathrm{df}=2,8, \mathrm{~F}=19.5, \mathrm{p}<0.05$ ) and bulk $\delta^{15} \mathrm{~N}$ (one-way ANOVA, $\mathrm{df}=2,8, \mathrm{~F}=$ 5.4, $\mathrm{p}<0.05$ ) among sites (Table 4.1, Fig 4.2). There were also significant differences in crab bulk $\delta^{13} \mathrm{C}$ values (one-way ANOVA, $\mathrm{df}=2,8, \mathrm{~F}=205.9, \mathrm{p}<0.05$ ) but not bulk $\delta^{15} \mathrm{~N}$ (one-way ANOVA, $\mathrm{df}=2,8, \mathrm{~F}=1.7, \mathrm{p}<0.05$ ) among sites (Table 4.1, Fig. 4.2).

Almost all the variation in ${ }^{13} \mathrm{C}$ values of five essential AAs in L. ehrenbergii muscle and food web components was captured in principal components one (92\%) and 
two (5\%) of the PCA analysis (Fig. 4.3). The first principal component (PC) clearly separated carbon produced by mangroves, zooplankton (a proxy for phytoplankton) and seagrass from each other. Alternatively, PC 2 distinguished detritivores from signatures of the primary producers and their proxies. Variate loadings for the first PC were all positive and of similar magnitude for all five essential AAs. However, loadings for the second PC were positive for isoleucine (0.50) and leucine (0.47), and negative for valine $(-0.67)$, threonine $(-0.26)$ and phenylalanine $(-0.05)$.

Essential AA $\delta^{13} \mathrm{C}$ values from $L$. ehrenbergii muscle samples were generally within the PC coordinate space delineated by zooplankton, detritivores and seagrass (Fig. 4.3). Juvenile L. ehrenbergii in the coastal wetland habitats fell along a continuum between seagrass on one side and either zooplankton or detritivores on the other side. Conversely, adult $L$. ehrenbergii had principal component values similar to local detritusfeeding crabs, which were quite different from those of the juvenile L. ehrenbergii in the coastal wetlands. L. ehrenbergii muscle essential AA $\delta^{13} \mathrm{C}$ values had much greater variability in the second principal component (mean relative standard deviation [RSD \pm $\mathrm{SD}]=67.9 \pm 64.0)$ than the first principal component $(21.1 \pm 7.9)$.

While bulk otolith $\delta^{13} \mathrm{C}$ and $\delta^{18} \mathrm{O}$ values varied little among sites in the Red Sea, we found large differences in values among congeneric snapper species from the Red Sea, Caribbean Sea and west coast of Panama locations (Fig. 4.4). Locations were clearly separated in isotope space; however, L. apodus samples from seagrass and mangrove sites in the Caribbean Sea were not significantly different. Essential AA $\delta^{13} \mathrm{C}$ from the same samples showed a very different pattern. First, we found a strong linear relationship 
between individual otolith and muscle essential $\mathrm{AA} \delta^{13} \mathrm{C}$ values for L. ehrenbergii $(\mathrm{y}=$ $\left.0.99 \mathrm{x}+0.35, \mathrm{R}^{2}=0.97\right)$ and L. apodus $\left(\mathrm{y}=0.97 \mathrm{x}-2.39, \mathrm{R}^{2}=0.98\right)$ (Fig. 4.5). Slopes of the linear regressions were the same for both species and not significantly different from 1, however the y-intercepts had non-overlapping $95 \%$ confidence intervals at $\alpha=0.05$. Unlike the bulk otolith $\delta^{13} \mathrm{C}$ and $\delta^{18} \mathrm{O}$ results, essential AA signatures distinguished between samples from mangrove and seagrass habitats regardless of the species or location (Fig. 4.6).

\section{DISCUSSION}

A number of species, including many examples from the family Lutjanidae (snapper), are thought to use coastal wetlands as nursery habitats prior to moving offshore to join adult populations on coral reefs. Functional connectivity between juvenile and adult habitats (i.e. the degree to which the landscape configuration affects movement among habitat patches [Taylor et al. 1993]), therefore, likely plays a crucial role in structuring these populations. However, in order to determine the importance of wetland nurseries, we must be able to quantify habitat use by juveniles that successfully recruit to adult populations. Using $\delta^{13} \mathrm{C}$ values in essential AAs from otoliths, we were able to distinguish residence of juvenile snappers in mangroves versus seagrass beds where conventional $\delta^{13} \mathrm{C}$ and $\delta^{18} \mathrm{O}$ analyses in otolith aragonite were inconclusive. Analysis of $\delta^{13} \mathrm{C}$ signatures in essential AAs from otoliths provides a powerful new tool for reconstructing ontogenetic migration patterns that should be widely applicable in reef ecosystems around the world. 
We found that juvenile L. ehrenbergii in coastal wetland habitats had essential AA $\delta^{13} \mathrm{C}$ signatures that were very different from adult L. ehrenbergii on coastal and shelf reefs. The distinction was clear even when comparing L. ehrenbergii from Al Lith Bay and Coast Guard Reef, which were only $2 \mathrm{~km}$ apart. This is in agreement with earlier research suggesting that while mangroves and adjacent seagrass beds were tightly coupled in terms of particulate organic matter flux, adjacent coral reefs appeared to be relatively isolated from the carbon exchange (Rodelli et al. 1984; Hemminga et al. 1994). Furthermore, our data imply that adult $L$. ehrenbergii do not migrate into the coastal wetlands to feed. Nagelkerken et al. (2008b) showed that grunts on coral reefs near semienclosed bays had significantly depleted $\delta^{13} \mathrm{C}$ values compared to grunts on reefs adjacent to open bays. The authors suggested that the restricted width and depth of channels connecting coral reefs to lagoons reduced the likelihood of reef fish entering the seagrass beds compared to open seagrass systems. At our study location, coastal wetland $\delta^{13} \mathrm{C}$ signatures from essential AAs appeared to be both unique and localized, providing an excellent tracer of residence in wetlands compared to coral reefs.

The unique habitat signatures in coastal wetlands and coral reefs can be traced to the local food web signatures in those habitats. All L. ehrenbergii juveniles fell within the detritivore-zooplankton-seagrass signature space, despite being collected within mangrove prop roots during the day. Mangrove carbon contributed little to the $\delta^{13} \mathrm{C}$ values of L. ehrenbergii in any of the wetland sites we sampled along the coast of Saudi Arabia. Our data support previous research on a variety of fish and invertebrate species (Sheaves and Molony 2000; Bouillon et al. 2002; Kieckbush et al. 2004; Abed-Navandi 
and Dworschak 2005) indicating the limited role of mangrove carbon as a direct and significant source of carbon for these fauna. Many coastal wetland species that use mangroves as daytime shelter have been shown to vacate the security of mangroves in favor of more food-rich seagrass beds at night (Rooker and Dennis 1991; Nagelkerken et al. 2000; Dorenbosch et al. 2004b; Luo et al. 2009).

While seagrass was an important contributor to the $\delta^{13} \mathrm{C}$ signature of juvenile $L$. ehrenbergii in the coastal wetlands, fresh seagrass carbon was not the only carbon source supporting L. ehrenbergii production. Bulk tissue SIA suggested that zooplankton and crabs were potentially important dietary components of juvenile L. ehrenbergii. However, the relative importance of a water column-based phytoplankton food web versus a benthic detrital food web was difficult to tease apart with bulk muscle $\delta^{13} \mathrm{C}$ and $\delta^{15} \mathrm{~N}$ values alone. Compound-specific $\delta^{13} \mathrm{C}$ analyses, on the other hand, clearly distinguished zooplankton and crab contributions to juvenile L. ehrenbergii diets. Detritivorous crabs, or at least food web components with similar $\delta^{13} \mathrm{C}$ signatures, appeared to be the dominant food source for both juvenile and adult L. ehrenbergii in our system.

The distinction between zooplankton and detritivorous crabs likely represented the impact of microbial processing on the $\delta^{13} \mathrm{C}$ signature of essential AAs. Microorganisms with the enzymatic capabilities to break down the fibrous, often refractory, components of seagrass and mangrove leaves play a crucial role in making the carbon from these dominant primary producers bioavailable (Zieman et al. 1984). In particular, the isotopic signature of valine provides a valuable tool for assessing the contribution of microbial 
reworking in the detrital pathway. Plants use acetolactetate mutase during the first step in the biosynthesis of valine while bacteria use acetohydroxy acid synthase (Gottschalk 1988; Rawn 1989). As a result, valine synthesized by bacteria shows depleted $\delta^{13} \mathrm{C}$ values compared to valine produced by plants. Valine $\delta^{13} \mathrm{C}$ values have been used to examine microbial reworking of particulate organic matter in the aquatic environment (Fogel and Tuross 1999; Keil and Fogel 2001; Ziegler and Fogel 2003; McCarthy et al. 2004). We found depleted $\delta^{13} \mathrm{C}$ valine values in L. ehrenbergii on both the coastal and shelf reefs compared to mangroves, seagrasses and zooplankton. Thus it appears that the microbially-mediated detrital carbon pool was an important source of carbon for higher trophic levels in these reef systems.

Essential AA $\delta^{13} \mathrm{C}$ values in fish muscle provided an accurate tracer of residence in coastal wetlands and coral reefs with unique food web $\delta^{13} \mathrm{C}_{\text {Base }}$ signatures. However, due its rapid turnover rate, particularly in fast-growing juvenile fish, muscle is not an ideal tissue for tracking ontogenetic migration of coral reef fish from juvenile nursery habitats to coral reefs over the potentially long temporal scales of such migrations (Herzka 2005). As a result, previous studies have attempted to use bulk otolith $\delta^{13} \mathrm{C}$ and $\delta^{18} \mathrm{O}$ values to examine the relative contributions of mangroves and seagrass beds as nursery habitats for coral reef fishes (Dorval et al. 2005; Huxham et al. 2007; Verweij et al. 2008; Mateo et al. 2010). Bulk otolith $\delta^{13} \mathrm{C}$ and $\delta^{18} \mathrm{O}$ values differed significantly between seagrass-dominated Red Sea coastal wetlands and the mangrove-dominated sites on the west coast of Panama. This was likely due to regional variability in coastal water mass properties impacting DIC $\delta^{13} \mathrm{C}$ and water $\delta^{18} \mathrm{O}$ values (Dufour et al. 1998). Mateo et 
al. (2010) were able to show small separations in bulk otolith $\delta^{13} \mathrm{C}$ values between $L$. apodus residing in mangroves and seagrass beds for some sites in the Caribbean Sea. However, in our study, this was not the case, as $\delta^{13} \mathrm{C}$ values from L. apodus collected in the mangroves and seagrass beds in Puerto Rico and St. Croix were not significantly different. Otolith essential AA $\delta^{13} \mathrm{C}$ values, on the other hand, were able to clearly distinguish residence in Caribbean mangroves versus seagrass beds. Otolith essential AAs thus provided a reliable tracer of residence in mangroves and seagrass beds regardless of species or region.

We have expanded the relationship between muscle and otolith $\mathrm{AA} \delta \delta^{13} \mathrm{C}$ values first presented by McMahon et al. (Chapter 3 this thesis) to include two species of Lutjanid snapper (L. ehrenbergii and L. apodus) in mangroves, seagrass beds, coastal reefs and shelf reefs from the Red Sea and Caribbean Sea. Linear regressions between muscle and otolith essential AA $\delta^{13} \mathrm{C}$ values had a slope of 1 in both locations, indicating that otolith essential AAs provide an excellent tracer of dietary signature in an archival tissue. Interestingly, the regression intercept for L. ehrenbergii in the Red Sea data was approximately $2 \%$ higher than that for $L$. apodus from the Caribbean Sea. We remain unsure of the mechanism generating this difference but it was likely sufficiently small to have few, if any, ecological implications.

Essential AA $\delta^{13} \mathrm{C}$ values from $L$. apodus and L. argentiventris residing in mangrove habitats were significantly lower than L. apodus and L. ehrenbergii from seagrass habitats regardless of region. The most parsimonious reason for this difference among locations is the limited extent of fringing mangroves at our Red Sea study sites 
compared to Puerto Rico, St. Croix and the west coast of Panama. Frequent exposure of mangroves during low tide in the Red Sea also reduces the foraging time of $L$. ehrenbergii in mangroves. Lugendo et al. (2007) found that the $\delta^{13} \mathrm{C}$ values of fishes from mangrove-lined creeks that retained water during low tide indicated feeding within the mangrove habitat, while fish from fringing mangroves that drain completely during low tide had significantly more enriched $\delta^{13} \mathrm{C}$ values. Although there is some notable variability in essential AA $\delta^{13} \mathrm{C}$ values across mangrove species and regions (Smallwood et al. 2003), our data suggest that the differences in $\mathrm{AA} \delta^{13} \mathrm{C}$ within habitat types is small relative to the differences between mangrove and seagrasses.

In this study we showed that $\delta^{13} \mathrm{C}$ values in essential AAs from otoliths provide an accurate tracer of residence in different juvenile habitat types. Further, our approach was better able to better distinguish habitat use and $\delta^{13} \mathrm{C}_{\text {Base }}$ contributions of congeneric snapper species than conventional bulk SIA alone. We found that while juvenile $L$. ehrenbergii in the Red Sea used mangroves as daytime shelter, they likely fed in seagrass beds at night. This pattern was not universal, as snapper from the Caribbean Sea and west coast of Panama showed much greater reliance on mangrove-derived carbon. The unique habitat signatures illustrated in this study can be used to reconstruct ontogenetic migration pathways and examine functional connectivity between coastal wetlands and coral reefs. This information is crucial for determining the importance of nursery habitats to coral reef fish populations and can provide valuable scientific support for incorporating connectivity into the design of networked marine protected areas (Grober-Dunsmore et al. 2007; McCook et al. 2009). 


\section{ACKNOWLEDGEMENTS}

The authors would like to thank H. Walsh, L. Houghton, M. Noble, N. DesRosiers and G. Nanninga for field assistance, C. Braun for creating Figure 4.1 and Dream Divers, Jeddah, Saudi Arabia for logistic assistance with boating and diving operations. Work in the Red Sea was supported by King Abdullah University of Science and Technology (KAUST) Award Nos. USA 00002 and KSA 00011 to S. Thorrold. Collections of snapper in the Caribbean Sea were funded by a Puerto Rico Sea Grant Program (Grant No. AN05-05-030) to I. Mateo, PADI Aware Foundation, Sigma Xi, and the Caribbean Coral Reef Institute. Additional funding was provided by the Woods Hole Oceanographic Institution and an International Society for Reef Studies-Ocean Conservancy Coral Reef Fellowship to K. McMahon. K. McMahon received support from the National Science Foundation Graduate Research Fellowship Program. 
Table 4.1: Bulk otolith $\delta^{13} \mathrm{C}$ and $\delta^{18} \mathrm{O}$ values (mean $\pm 1 \mathrm{SD}$ ) and bulk tissue $\delta^{13} \mathrm{C}$ and $\delta^{15} \mathrm{~N}$ values (mean $\pm 1 \mathrm{SD}$ ) of Lutjanus ehrenbergii and selected food web components collected from coastal wetlands (Khor Al Kharrar Bay, Al Lith Bay and Cape Al-Askar Bay), a coastal coral reef (Coast Guard Reef) and a shelf coral reef (Ron's Reef) along the coast of Saudi Arabia in the Red Sea. Means with the same superscript letter were not significantly different from one another by one-way ANOVA and Tukey's HSD post-hoc test $(\alpha=0.05)$. $(n=10$ L. ehrenbergii per site except for Al Lith Bay* where $n=9$, and $n$ $=3$ for food web components).

\begin{tabular}{|c|c|c|c|c|}
\hline \multirow[b]{2}{*}{ Lutjanus ehrenbergii } & \multicolumn{2}{|c|}{ Bulk Otolith } & \multicolumn{2}{|c|}{ Bulk Muscle } \\
\hline & $\delta^{13} \mathrm{C}$ & $\delta^{18} \mathrm{O}$ & $\delta^{13} \mathrm{C}$ & $\delta^{15} \mathrm{~N}$ \\
\hline Khor Al Kharrar Bay & $-0.5 \pm 0.6^{\mathrm{a}}$ & $-0.2 \pm 0.4^{\mathrm{a}}$ & $-10.2 \pm 0.3^{\mathrm{a}}$ & $7.0 \pm 0.3^{\mathrm{a}}$ \\
\hline Al Lith Bay* & $-0.7 \pm 0.6^{\mathrm{a}}$ & $-0.8 \pm 0.4^{\mathrm{b}}$ & $-10.5 \pm 0.8^{\mathrm{a}}$ & $8.6 \pm 0.5^{b}$ \\
\hline Cape Al-Askar Bay & $-1.4 \pm 0.7^{\mathrm{a}}$ & $-0.5 \pm 0.4^{\mathrm{a}, \mathrm{b}}$ & $-10.6 \pm 0.6^{\mathrm{a}}$ & $8.2 \pm 0.5^{b}$ \\
\hline Coast Guard Reef & $-2.6 \pm 0.5^{b}$ & $-0.7 \pm 0.2^{b}$ & $-14.9 \pm 0.8^{b}$ & $8.6 \pm 0.6^{\mathrm{b}}$ \\
\hline Ron's Reef & $-3.8 \pm 0.9^{\mathrm{c}}$ & $-0.5 \pm 0.3^{\mathrm{a}, \mathrm{b}}$ & $-16.9 \pm 1.1^{\mathrm{c}}$ & $8.3 \pm 0.4^{\mathrm{b}}$ \\
\hline \multicolumn{5}{|c|}{ Ribbon Seagrass (Halodule uninervis) } \\
\hline Al Lith Bay & & & $-7.9 \pm 0.7$ & $-0.3 \pm 1.5$ \\
\hline \multicolumn{5}{|c|}{ White Mangrove (Avicennia marina) } \\
\hline Al Lith Bay & & & $-27.7 \pm 0.6$ & $1.4 \pm 0.6$ \\
\hline \multicolumn{5}{|l|}{ Zooplankton } \\
\hline Al Lith Bay & & & $-18.8 \pm 0.3^{\mathrm{a}}$ & $5.1 \pm 0.5^{\mathrm{a}}$ \\
\hline Coast Guard Reef & & & $-16.9 \pm 1.0^{\mathrm{b}}$ & $4.6 \pm 0.4^{\mathrm{a}, \mathrm{b}}$ \\
\hline Ron's Reef & & & $-20.0 \pm 0.2^{\mathrm{a}}$ & $4.1 \pm 0.1^{\mathrm{b}}$ \\
\hline \multicolumn{5}{|l|}{ Crab } \\
\hline Al Lith Bay (Metopog & grapsus thuk & ar) & $-12.8 \pm 0.4^{\mathrm{a}}$ & $5.0 \pm 0.2^{\mathrm{a}}$ \\
\hline Coast Guard Reef ( $T r$ & apezia tigrin & & $-15.2 \pm 0.2^{b}$ & $5.7 \pm 0.8^{\mathrm{a}}$ \\
\hline Ron's Reef (Trapezia & tigrina) & & $-17.5 \pm 0.2^{\mathrm{c}}$ & $5.7 \pm 0.5^{\mathrm{a}}$ \\
\hline
\end{tabular}




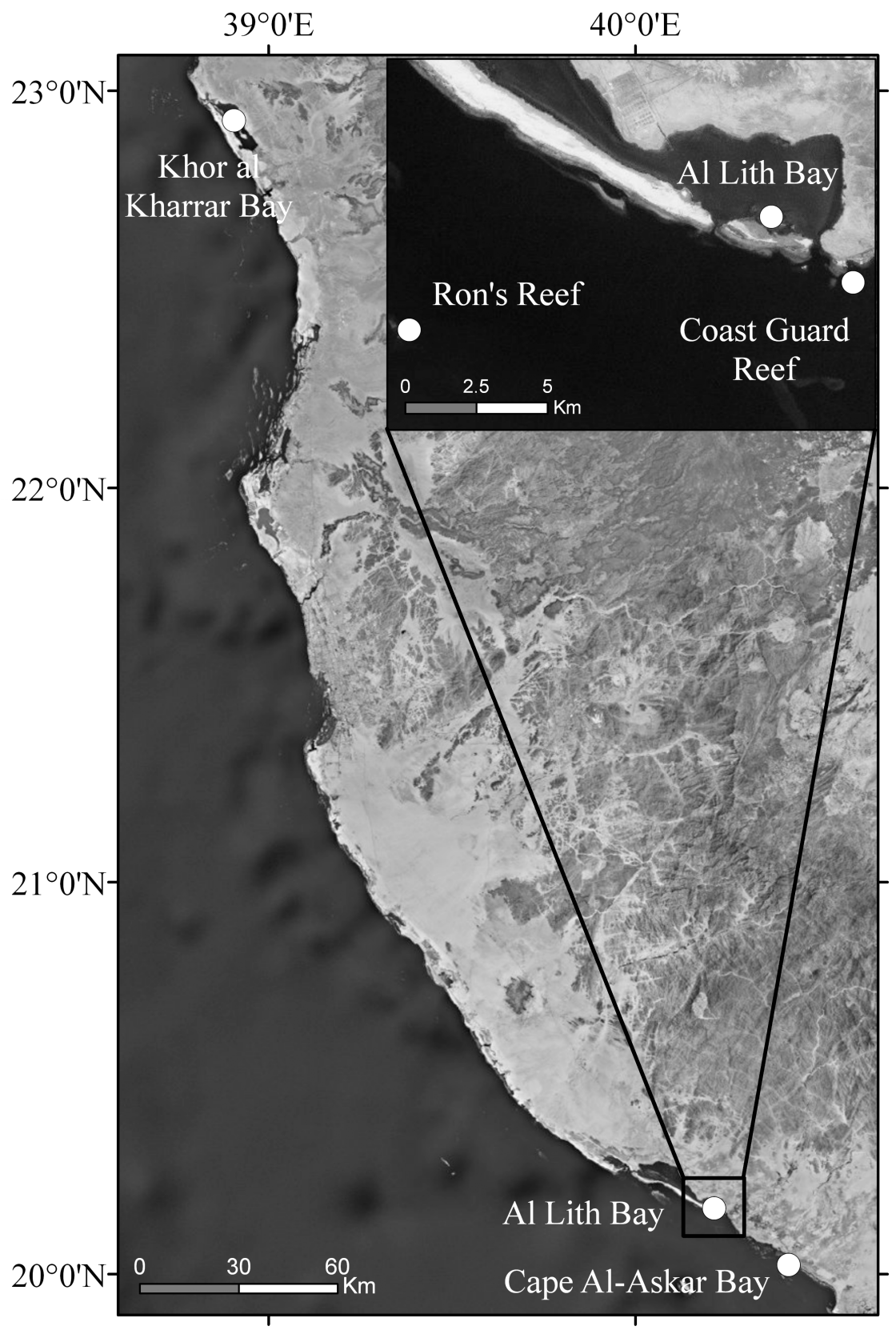

Figure 4.1. Ehrenberg's snapper, Lutjanus ehrenbergii, collection sites from three coastal wetland habitats (Khor Al Kharrar Bay, Al Lith Bay and Cape Al-Askar Bay), a coastal coral reef (Coast Guard Reef) and a shelf coral reef (Ron's Reef) near Al Lith, Saudi Arabia in the Red Sea. 


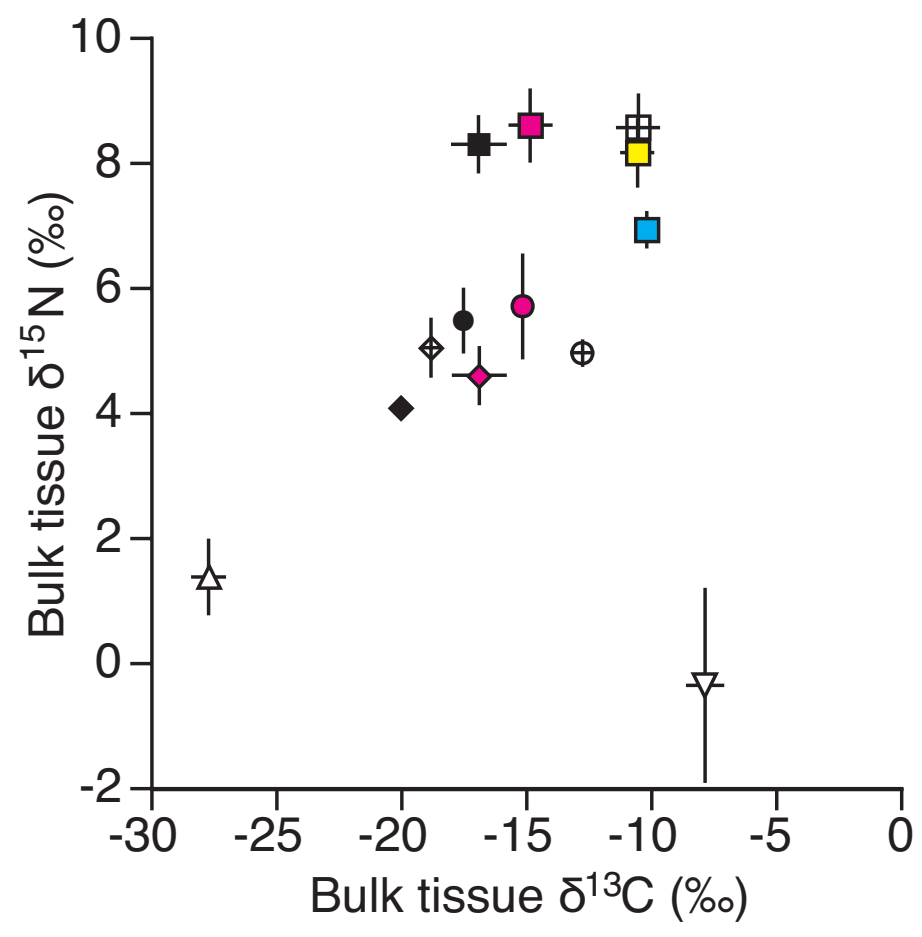

Figure 4.2. Bulk tissue $\delta^{13} \mathrm{C}$ and $\delta^{15} \mathrm{~N}$ values (mean $\pm \mathrm{SD}$ ) of Lutjanus ehrenbergii (square symbols, $\mathrm{n}=10$ fish per site except Al Lith Bay where $\mathrm{n}=9$ ), crabs (circles, $\mathrm{n}=$ 3 ), zooplankton (diamonds, $n=3$ ), seagrass blades (inverted triangles, $n=3$ ) and mangrove leaves (triangles, $\mathrm{n}=3$ ) collected from three coastal wetland habitats: Khor $\mathrm{Al}$ Kharrar Bay (Cyan), Al Lith Bay (white) and Cape Al-Askar Bay (yellow), a coastal coral reef: Coast Guard Reef (magenta) and a shelf coral reef: Ron's Reef (black) near Al Lith, Saudi Arabia in the Red Sea. 


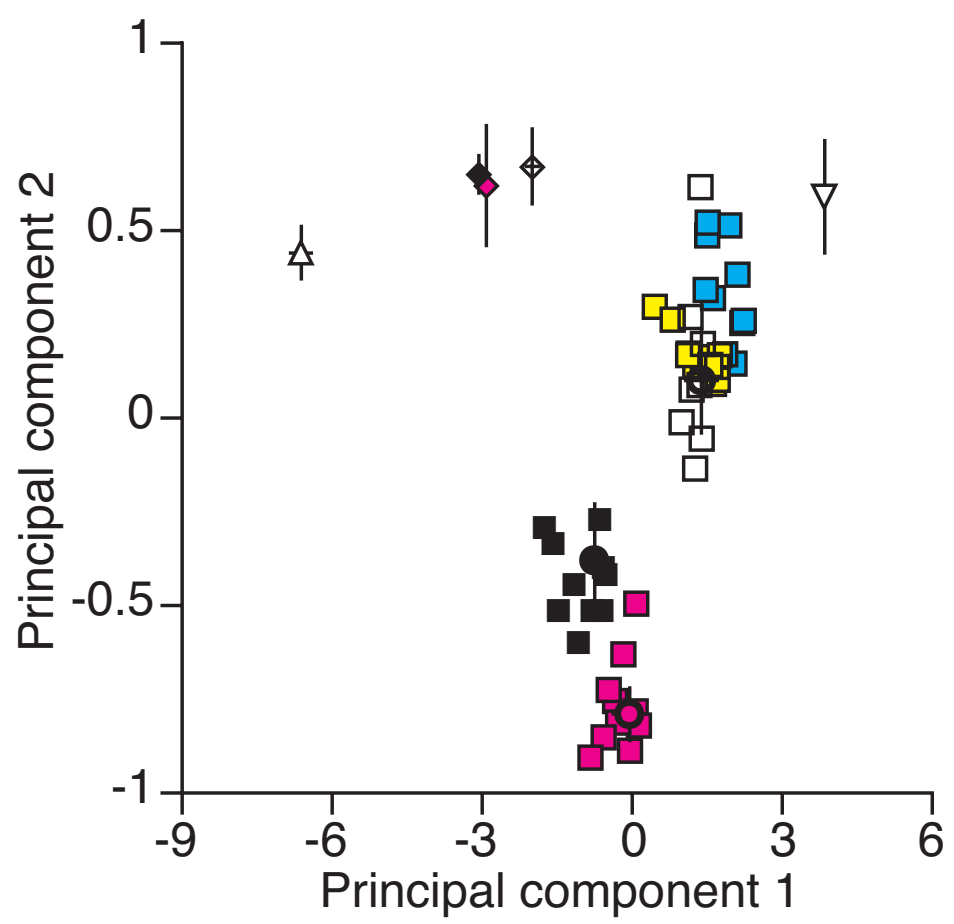

Figure 4.3. First and second principal components generated from a principal component analysis of five essential amino acid $\delta^{13} \mathrm{C}$ values from Lutjanus ehrenbergii (square symbols, $n=10$ fish per site except Al Lith Bay where $n=9$ ), crabs (circles, $n=3$ ), zooplankton (diamonds, $n=3$ ), seagrass blades (inverted triangles, $n=3$ ) and mangrove leaves (triangles, $\mathrm{n}=3$ ) collected from three coastal wetland habitats: Khor Al Kharrar Bay (Cyan), Al Lith Bay (white) and Cape Al-Askar Bay (yellow), a coastal coral reef: Coast Guard Reef (magenta) and a shelf coral reef: Ron's Reef (black) near Al Lith, Saudi Arabia in the Red Sea. 


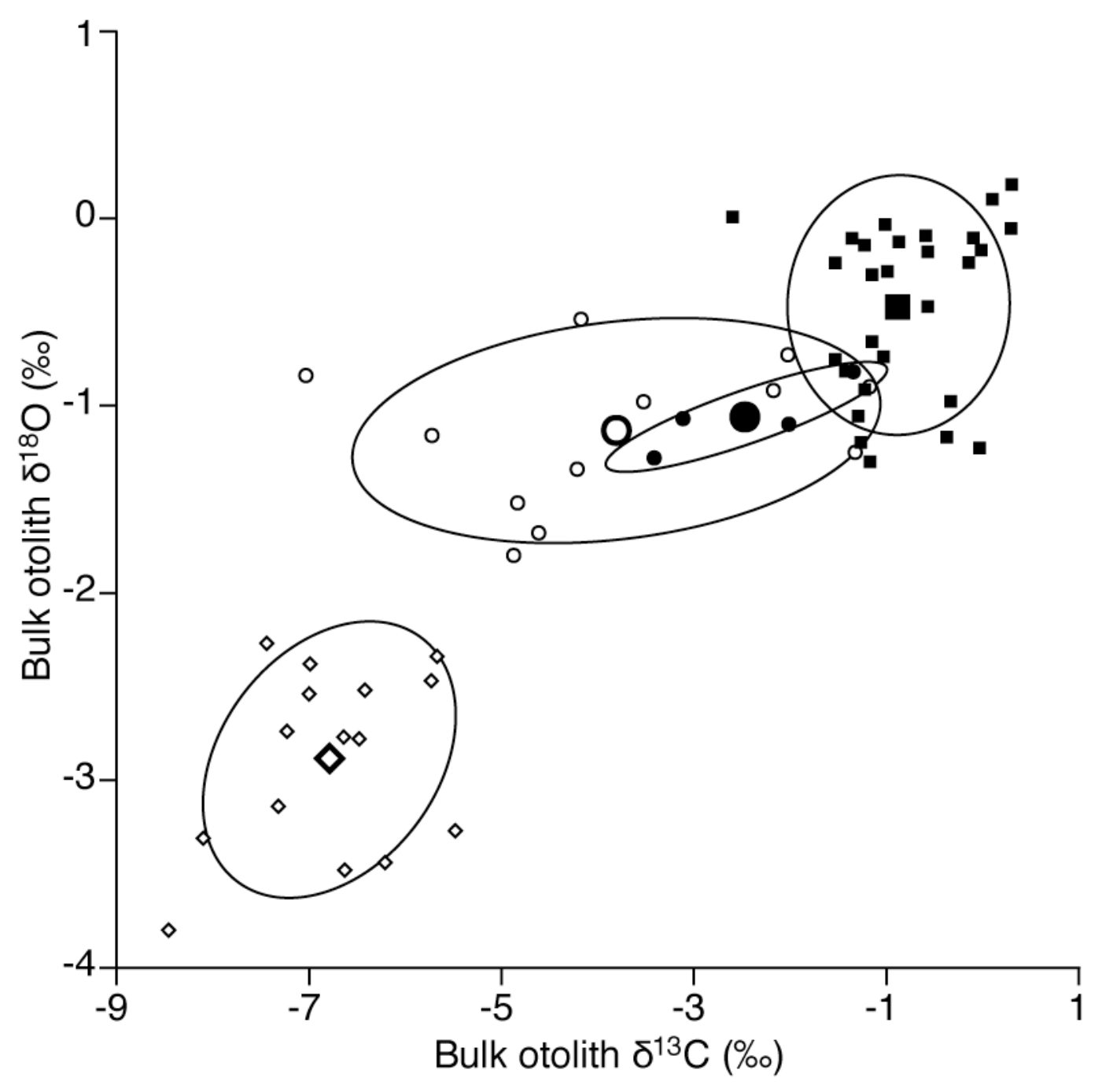

Figure 4.4. Bulk otolith $\delta^{13} \mathrm{C}$ and $\delta^{18} \mathrm{O}$ values (with $95 \%$ confidence ellipses) from Lutjanus ehrenbergii collected from seagrass bays (black square symbols, $\mathrm{n}=29$ fish) in the Red Sea, L. apodus collected from seagrass bays (black circles, $\mathrm{n}=4$ fish) in the Caribbean Sea, mangrove lagoons (white circles, $\mathrm{n}=12$ fish) in the Caribbean Sea and $L$. argentiventris collected from mangrove lagoons (white diamonds, $\mathrm{n}=15$ fish) on the west coast of Panama. 


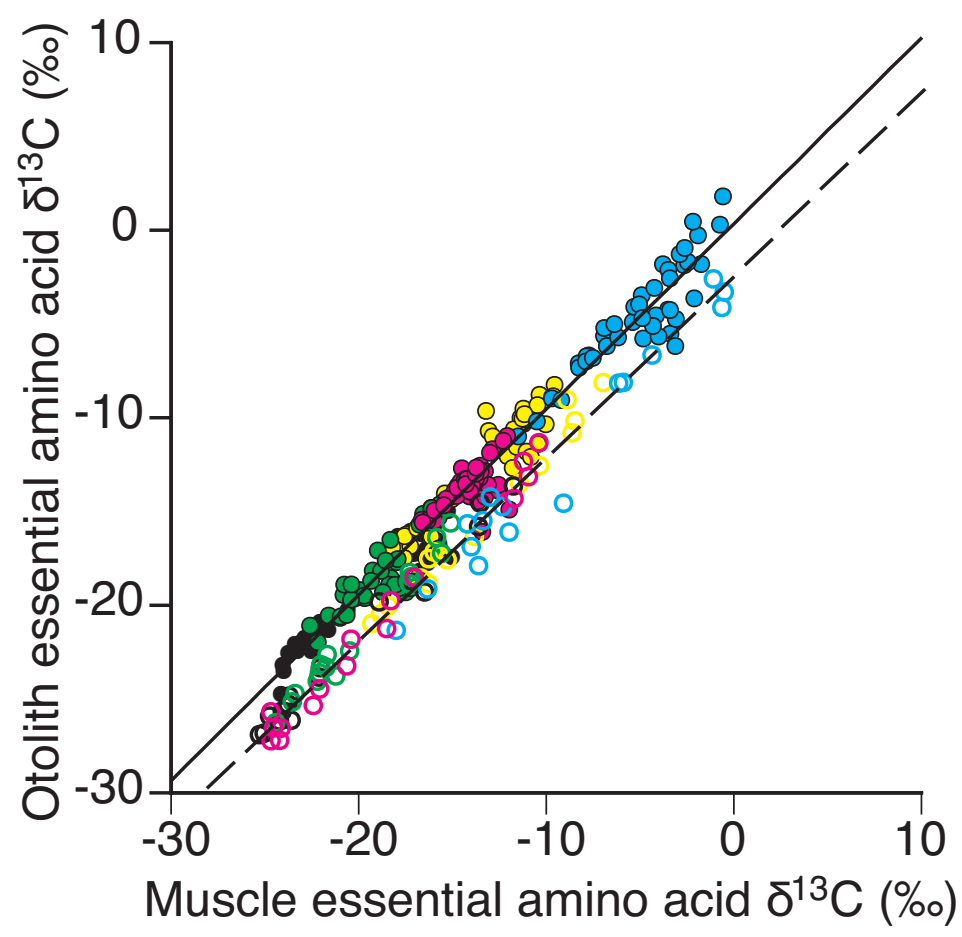

Figure 4.5. Linear relationship between individual essential amino acid $\delta^{13} \mathrm{C}$ values of otoliths and muscle from Lutjanus ehrenbergii collected from the Red Sea (filled circle symbols, $\mathrm{n}=43$ fish, 5 amino acids per fish) and L. apodus collected from the Caribbean Sea (open circles, $\mathrm{n}=16$ fish, five amino acids per fish). Threonine = cyan symbols, isoleucine $=$ yellow, valine $=$ magenta, phenylalanine $=$ green and leucine $=$ black . 


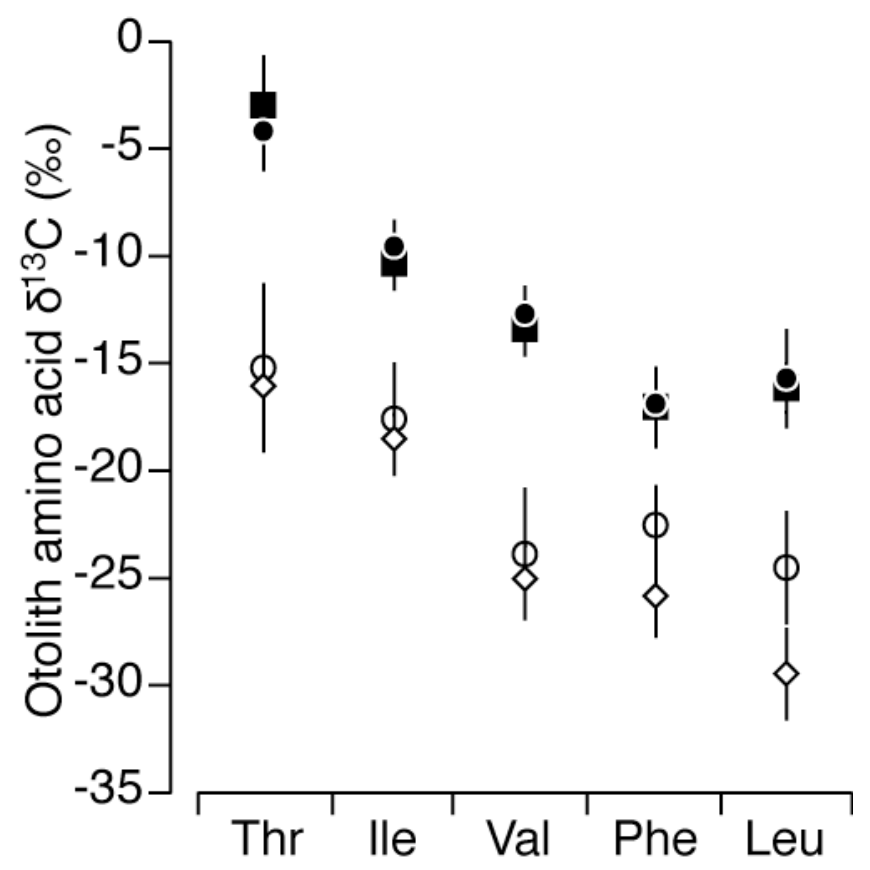

Figure 4.6. Essential amino acid $\delta^{13} \mathrm{C}$ values from Lutjanus ehrenbergii collected from seagrass bays (black square symbols, $\mathrm{n}=$ three sites, 10 fish per site) in the Red Sea, $L$. apodus collected from seagrass bays (black circles, $\mathrm{n}=$ four fish) and mangrove lagoons (white circles, $\mathrm{n}=$ three sites, four fish per site) in the Caribbean Sea, and $L$. argentiventris collected from mangrove lagoons (white diamonds, $\mathrm{n}=$ three sites, four fish per site) on the west coast of Panama. 


\title{
CHAPTER FIVE
}

Quantifying juvenile habitat use by Lutjanus ehrenbergii in a coral reef seascape from the Red Sea

\author{
Kelton W. McMahon ${ }^{1}$ \\ ${ }^{1}$ Massachusetts Institute of Technology and Woods Hole Oceanographic Institution \\ Joint Program in Oceanography and Ocean Engineering, \\ Woods Hole Oceanographic Institution, Woods Hole, MA 02543, USA \\ Michael L. Berumen ${ }^{2,3}$ \\ ${ }^{2}$ Red Sea Research Center, \\ King Abdullah University of Science and Technology, Thuwal, Kingdom of Saudi \\ Arabia \\ Simon R. Thorrold ${ }^{3}$ \\ ${ }^{3}$ Biology Department, \\ Woods Hole Oceanographic Institution, Woods Hole, MA 02543, USA
}




\begin{abstract}
Many commercially and ecologically important coral reef fishes, including species from the family Lutjanidae (snappers), are thought to use mangroves and seagrass beds as juvenile nursery areas before migrating to coral reef habitats as adults. However, few studies have examined the functional connectivity of coral reef fish in tropical seascape. This study presents the first application of a new method for tracking fish migration in the marine environment using otolith essential amino acid $\delta^{13} \mathrm{C}$ analysis. We quantified the relative contribution of coastal wetland and reef habitats to Lutjanus ehrenbergii populations on coastal, shelf and oceanic coral reefs in the Red Sea. Coastal wetlands were important nurseries for L. ehrenbergii; however, there was significant plasticity in L. ehrenbergii juvenile habitat requirements. Our data indicate that a habitat can still be a valuable juvenile nursery even if juveniles are not visually abundant in that habitat, indicating that caution must be taken when interpreting juvenile habitat importance from visual surveys of abundance alone. Seascape configuration played an important role in determining the functional connectivity of L. ehrenbergii populations in the Red Sea. Our results provided the first direct evidence of a remarkable migration by juvenile snapper from coastal wetlands to coral reefs at least $30 \mathrm{~km}$ from the coast and across deep open water. We found the current paradigm of a simple linear ontogenetic migration from coastal wetlands to offshore reefs is likely a gross oversimplification of the migratory capabilities of coral reef fishes. This study highlights the need to identify essential habitats and preserve functional linkages among these habitats to promote ecosystem health and sustainable fisheries on coral reefs.
\end{abstract}




\section{INTRODUCTION}

The ecological integrity of tropical habitats, including mangroves, seagrass beds and coral reefs, is coming under increasing pressure from human activities (Hughes 1994; Jackson et al. 2001a; Pandolfi et al. 2003; Cote et al. 2005). Habitat destruction and unsustainable exploitation has lead to a decline in the function and resilience of these ecosystems and the fisheries they support on a global scale (Mumby and Hastings 2008). Efforts to promote ecological integrity and sustainable harvest from coral reefs have traditionally focused solely on protecting coral reefs. More recently, attention has been directed at the issue of preserving critical seascape functions as well as habitat types, with particular emphasis on connectivity (McCook et al. 2009). For instance, many commercially and ecologically important coral reef fishes, including species of Lutjanidae (snappers), Serranidae (grouper) and Scaridae (parrotfish), are thought to use mangroves and seagrass beds as juvenile nursery areas before migrating to coral reef habitats as adults (see reviews by Beck et al. 2001; Adams et al. 2006; Faunce and Serafy 2006; Nagelkerken et al. 2008a). These productive coastal wetlands provide a number of benefits to juvenile coral reef fishes, including an abundance of food, refuge from predators and shelter from physical disturbance (Laegdgaard and Johnoson 2001; Cocheret de la Morinière et al. 2004; Manson et al. 2005; Verweij et al. 2006). These benefits can enhance local growth and survival rates, which may, in turn, lead to locally elevated juvenile densities and an increased likelihood of successful movement to adult habitats (Beck et al. 2001; Sheridan and Hays 2003; Adams et al. 2006). 
Identifying essential juvenile habitats for coral reef fish has been a difficult proposition. Studies identifying mangroves and seagrass beds as nurseries have typically noted higher densities of juvenile fishes in those habitats relative to other habitats where juveniles could reside (Nagelkerken et al. 2000; Cocheret de la Morinière et al. 2002; Lecchini and Poignonec 2009; Jones et al. 2010). It is typically assumed that this juvenile biomass is successfully transferred to the adult population on coral reefs. However, if juveniles from these coastal wetlands do not successfully recruit to the adult population, then these habitats are not functioning as productive nurseries regardless of the juvenile densities they support. The current paradigm of ontogenetic migration of coral reef fish is a simple linear progression from coastal wetlands to offshore coral reefs (Nagelkerken 2007). Yet surprisingly few studies have directly measured the ontogenetic movement of coral reef fishes between coastal nurseries and coral reefs and the resulting functional connectivity of the tropical seascape (Beck et al. 2001; Nagelkerken 2007). Functional connectivity is the movement of individuals among spatially separated habitats within a population resulting from interactions between behavioral processes and the seascape configuration (adapted from the landscape ecology literature [Taylor et al. 1993]). Preserving functional connectivity in the tropical seascape is likely necessary to promote ecosystem resilience and integrity as well as sustainable fisheries on coral reefs. In order for managers to enact measures to this end, however, it is necessary to understand the relative contributions of each potential juvenile nursery habitat to adult populations. Our current understanding of this type of functional connectivity is severely hindered by a 
lack of empirical data stemming from methodological deficiencies in tracking movement of juvenile coral reef fish.

Determining movements of fishes between juvenile and adult habitats requires the ability to either track individuals between habitats or retrospectively identify juvenile habitat associations in adult fishes. Tracking animal migration has historically been accomplished using mark-recapture techniques with extrinsic markers (Seber 1982; Hobson and Norris 2008). While extrinsic markers provide some of the most direct measures of movement patterns of mobile fishes, not all species or life stages are amenable to archival or acoustic tags (reviewed by Thorrold et al. 2002).

Ecogeochemistry provides an appealing alternative for reconstructing movement patterns of fish, relying on spatial variations in the stable isotope values (isoscapes [West et al. 2010]) that are recorded in the chemical composition of tissues as an animal lives and feeds in different habitats (Hobson et al. 2010). Fish otoliths have several properties that make them an ideal tissue for retrospective analysis of ontogenetic migration (Campana and Neilson 1985; Campana 1999; Campana and Thorrold 2001). Otoliths accurately record information about the fish's metabolic activity and the local isoscape signature of the habitat in which the fish resides (Thorrold et al. 1997). Once this signature has been deposited, it is no longer metabolically reworked, providing an archival record of geochemical signatures from the habitats in which that fish has resided (Degens et al. 1969; Campana 1999). In addition, otoliths grow continuously throughout by means of successive addition of daily and annual growth bands of aragonite on a 
proteinaceous matrix. As such, otolith provide an archival, chronological record of the past diet and residence of fish throughout the life of a fish.

Bulk analysis of $\delta^{13} \mathrm{C}$ and $\delta^{18} \mathrm{O}$ values in otoliths has been used to assess stock structure, habitat use, and migration of fish for decades (reviewed by Campana and Thorrold 2001, Elsdon et al. 2008). Stable isotope analysis (SIA) of otoliths is a particularly useful approach for tracking ontogenetic migration of fish from coastal wetland nurseries to coral reefs because there is a distinct carbon isotope gradient at the base of the food web $\left(\delta^{13} C_{\text {Base }}\right)$ along the mangrove-coral reef-seagrass continuum (Marguiller et al. 1997; Lugendo et al. 2006; Nagelkerken et al. 2008a). However, bulk otolith SIA is not without problems. In particular, the dietary signature in otoliths is inevitably diluted by dissolved inorganic carbon (DIC), making it challenging to track fish movement among isoscapes. We recently described a method for quantifying $\delta^{13} \mathrm{C}$ in essential amino acids (AAs) extracted from otolith material that avoids many of the challenges associated with conventional bulk otolith SIA (McMahon et al. 2010; McMahon et al. Chapter 3 this thesis). Using this method, McMahon et al. (Chapter 4 this thesis) were able to distinguish residence of juvenile snapper (Family Lutjanidae) in a number of different coastal wetlands and coral reefs. Because otoliths are archival tissues, the essential AA technique allows for retrospective analysis of juvenile nursery habitat use of individuals that have successfully recruited to adult populations on coral reefs.

Here, we evaluate the relative contribution of individual Ehrenberg's snapper (Lutjanus ehrenbergii, Peters 1869) from wetland and reef habitats to adult populations on coastal, shelf and oceanic coral reefs in the Red Sea. We assigned adult L. ehrenbergii 
from reefs at six distances offshore along a $50 \mathrm{~km}$ cross-shelf transect to five potential juvenile habitats based on essential AA $\delta^{13} \mathrm{C}$ signatures in otolith cores. At our study site, juvenile L. ehrenbergii were only observed in coastal mangrove and seagrass habitats, while adults were abundant on offshore coral reefs (M. Berumen, pers. comm.). We therefore hypothesized that coastal wetlands would be the dominant nursery source of individuals to adult populations on coral reefs in the region. Our study provides a first glimpse into the role that seascape configuration plays in determining functional connectivity of a reef fish species that is both ecologically and commercially important in the region.

\section{METHODS AND MATERIALS}

\section{Field Collections}

Ehrenberg's snapper, L. ehrenbergii, were collected from five distinct habitats, 1) coastal wetlands, 2) coastal reefs, 3) shelf reefs, 4) offshore island patch reefs and 5) oceanic reefs, along a $50 \mathrm{~km}$ cross-shelf transect from coastal Saudi Arabia in the Red Sea in November 2008, March 2009 and June 2010 (Fig. 5.1). Al Lith Bay and Cape AlAskar Bay are shallow, semi-enclosed bays that are dominated by ribbon seagrass, Halodule uninervis, with fringing white mangroves, Avicennia marina. The offshore island, Abu Latt Island, is a partially vegetated island located approximately $24 \mathrm{~km}$ offshore at the edge of the continental shelf that is fringed by patch reefs and seagrass lined channels. The oceanic reefs are primarily steep vertical walls surrounded by open water greater than $300 \mathrm{~m}$ deep (Fig. 5.1). Juvenile L. ehrenbergii (total length [TL] $=75$ 
$\pm 11 \mathrm{~mm}$, Fig. 5.2) were collected with cast nets from two coastal wetland systems near Al Lith, Saudi Arabia. Adult L. ehrenbergii $(\mathrm{TL}=195 \pm 32 \mathrm{~mm}$, Fig. 5.2) were speared from 11 reef systems at six distances along the $50 \mathrm{~km}$ cross-shelf transect near Al Lith, Saudi Arabia: 1) coastal reefs within $2 \mathrm{~km}$ of shore: Coast Guard Reef and Cape AlAskar Reef, 2) shelf reefs 16 km offshore: Ron's Reef and LJ's Reef 3) an offshore island 24 km offshore: Abu Latt Island, 4) shelf reefs 32 km offshore: Saut Reef and Brown Reef, 5) oceanic reefs $40 \mathrm{~km}$ offshore: Canyon Reef and Shi'b Sulaym Reef and 6) oceanic reefs $50 \mathrm{~km}$ offshore: MarMar Reef and Dohra Reef.

Sagittal otoliths and white muscle tissue were dissected from each fish in the field. Otoliths were cleaned of residual surface tissue with water and stored dry in $1.5 \mathrm{ml}$ vials. White muscle samples from the dorsal surface of each fish were frozen on the boat prior to transport to an onshore laboratory. In the lab, white muscle samples were frozen at $20^{\circ} \mathrm{C}$ and then lyophilized (freeze-dried) for 48 hours. Samples were transferred to the Woods Hole Oceanographic Institution, Woods Hole, MA, USA for further preparation and analysis. Muscle tissue from L. ehrenbergii at each site was used to identify local habitat signatures because muscle has a very fast turnover rate and its isotopic signature represented the most recent residence signature. We did not find any juvenile $L$. ehrenbergii on offshore coral reefs; however, we wanted to know the potential contribution of individuals from these coral reefs to the adult population. Therefore, muscle samples from adult $L$. ehrenbergii were used to characterize the habitat signatures of the offshore reefs where no juveniles were collected. We justified this in two ways. Despite a large range in TL across juvenile and adult L. ehrenbergii in this study, there 
was no significant trend in muscle $\delta^{15} \mathrm{~N}$ values with TL $\left(\mathrm{y}=0.004 \mathrm{x}+8.04, \mathrm{R}^{2}=0.15\right.$;

Fig. 5.2). This indicates that juvenile and adult L. ehrenbergii were feeding at the same trophic level. In addition, detritivore crabs are a significant component of both juvenile and adult L. ehrenbergii diet (McMahon et al. Chapter 4 this thesis), suggesting no ontogenetic dietary shift for L. ehrenbergii in this region. Thus, we are confident that adult muscle signatures provided an accurate reflection of juvenile muscle signatures in the same habitat.

\section{Sample preparation and analysis}

Approximately $1 \mathrm{mg}$ of freeze-dried, homogenized white muscle tissue from each fish was weighed into a tin cup and analyzed for bulk $\delta^{15} \mathrm{~N}$ with a Europa Hydra 20/20 isotope ratio monitoring-mass spectrometer (irm-MS) at the UC Davis Stable Isotope Facility, Davis, CA, USA. A second portion of each muscle sample ( 1 mg) was acid hydrolyzed to isolate free AAs by refluxing samples in $6 \mathrm{~N} \mathrm{HCl}$ at $110^{\circ} \mathrm{C}$ for $20 \mathrm{hrs}$, neutralizing in ultra-pure water and evaporating to dryness under a gentle stream of $\mathrm{N}_{2}$ gas. These samples were used to characterize the geochemical signature of the five juvenile habitats (discussed below). In order to retrospectively identify where each adult L. ehrenbergii spent its juvenile period, we isolated the juvenile core of adult $L$.

ehrenbergii otoliths (Fig. 5.3) from fish collected on reefs at six distances offshore along a $50 \mathrm{~km}$ cross-shelf transect. A single, randomly selected, sagittal otolith from each adult L. ehrenbergii was scrubbed and rinsed in ultra-pure water, cleaned ultrasonically for 5 min in ultra-pure water, and then air-dried under a class-100 positive-flow fume hood for 
$24 \mathrm{hrs}$. Then, we isolated a core from each adult otolith, representing the first year of growth. To do this, we cut along the first annulus using a Buehler Isomet Low Speed Saw with a diamond wafering blade (Buehler, Lake Bluff, Illinois, USA) and then ground down the resulting core from the top and bottom with a Buehler Ecomet3 variable speed grinder-polisher to remove post first year material deposited in the vertical plane. Next, we contoured the shape of the juvenile core to match the mean 3D shape (4 to $5 \mathrm{~mm}$ by 2 to $3 \mathrm{~mm}$ ) and mass (10 to $15 \mathrm{mg}$ ) of otoliths from juvenile L. ehrenbergii (TL $\sim 75 \mathrm{~mm}$ ) collected in the coastal wetlands using a Buehler Ecomet3 variable speed grinderpolisher. Each juvenile core was homogenized with a mortar and pestle and acid hydrolyzed in the same manner as the muscle samples.

Acid hydrolyzed samples were derivatized prior to SIA according to McMahon et al. (Chapter 3 this thesis) as modified from Silfer et al. (1991) and Johnson et al. (1998). Samples were brought up in dichloromethane (DCM) and injected on column in splitless mode at $260^{\circ} \mathrm{C}$ and separated on a forte SolGel-1ms column (60 m length, $0.25 \mathrm{~mm}$ inner diameter and $0.25 \mu \mathrm{m}$ film thickness; SGE Analytical Science, Sydney, Australia) in a Agilent $6890 \mathrm{~N}$ Gas Chromatograph (GC) at the Woods Hole Oceanographic Institution, Woods Hole, MA, USA. The separated AA peaks were combusted online in a Finnigan gas chromatography-combustion (GC-C) continuous flow interface at $1030^{\circ} \mathrm{C}$, then measured as $\mathrm{CO}_{2}$ on a Thermo Finnigan Mat 253 irm-MS. Standardization of runs was achieved using intermittent pulses of a $\mathrm{CO}_{2}$ reference gas of known isotopic composition. All compound-specific SIA samples were analyzed in duplicate along with AA standards of known isotopic composition. We focused on five essential AAs with sufficient peak 
size and baseline GC separation: threonine, isoleucine, valine, phenylalanine, and leucine.

\section{Data analysis}

Stable isotope ratios were expressed in standard delta $(\delta)$ notation:

$$
\delta^{13} C_{\text {sample }}=\left(\frac{{ }^{13} C /{ }^{12} C_{\text {sample }}}{{ }^{13} C / /{ }^{12} C_{\text {std }}}-1\right) * 1000
$$

where the standard for carbon was VPDB. Differences in total length of L. ehrenbergii among the five potential juvenile habitat regions were assessed using a one-way analysis of variance (ANOVA), with Tukey's honestly significant difference (HSD) post-hoc test $(\alpha<0.05)$. The relationship between TL and bulk muscle $\delta^{15} \mathrm{~N}$ values was determined by linear regression. We visualized the separation of potential juvenile habitats using a discriminant function analysis (DFA) on the muscle essential AA $\delta^{13} \mathrm{C}$ data of $L$. ehrenbergii grouped into five regions according to their collection location across the continental shelf. These were as follows: coastal wetlands $(n=2$ sites $)$, coastal reefs $(n=$ $2)$, shelf reefs $(n=4)$, Abu Latt Island $(n=1)$ and oceanic reefs $(n=4)$. The jackknife reclassification success rate of the DFA was evaluated by leave-one-out cross-validation and compared to the $1 / \mathrm{g}$ reclassification success expectation, where $\mathrm{g}$ was the number of groups analyzed (White and Ruttenberg 2007). We used a maximum likelihood estimator (MLE [Millar 1990]) to calculate the relative contribution of each of the five potential juvenile habitat regions to the adult populations on coral reefs at six distances $(2 \mathrm{~km}, 16$ $\mathrm{km}, \mathrm{Abu}$ Latt Island at $24 \mathrm{~km}, 32 \mathrm{~km}, 40 \mathrm{~km}$ and $50 \mathrm{~km}$ ) along the $50 \mathrm{~km}$ cross-shelf 
transect from Al Lith, Saudi Arabia. McMahon et al. (Chapter 4 this thesis) showed that muscle and otolith essential AA ${ }^{13} \mathrm{C}$ values had a strong 1:1 correlation and could be used interchangeably. Thus the training data set was comprised of muscle essential AA $\delta^{13} \mathrm{C}$ data from each potential juvenile habitat region. The otolith essential $\mathrm{AA} \delta^{13} \mathrm{C}$ data from juvenile cores of adult L. ehrenbergii were treated as unknowns to be classified by the training data set. We identified juvenile nurseries as any juvenile habitat that contributed more than the average if all five juvenile habitats had contributed to the adult population evenly (20\%). Note

\section{RESULTS}

We collected L. ehrenbergii spanning a range in total length (TL) from $51 \mathrm{~mm}$ to $248 \mathrm{~mm}$, with a trimodal distribution (Fig. 5.2). Mean lengths (TL \pm SD) of fish from the coastal wetlands were significantly smaller $(75 \pm 11 \mathrm{~mm})$ than fish from coastal reefs $(167 \pm 37 \mathrm{~mm})$, Abu Latt Island $(156 \pm 17 \mathrm{~mm})$ and offshore coral reefs $(210 \pm 16 \mathrm{~mm})$ (one-way ANOVA, df =2, 122, $\mathrm{F}=208.8, \mathrm{p}<0.05$ ). L. ehrenbergii from the coastal reefs (97 to $248 \mathrm{~mm}$ ) occupied a much larger range in total length than L. ehrenbergii from the coastal wetlands (51 to $94 \mathrm{~mm})$, Abu Latt Island (125-184 mm) or the offshore coral reefs (165 to $238 \mathrm{~mm}$ ). Despite the large range in fish length both among and within the habitats, there was no significant trend in $\delta^{15} \mathrm{~N}$ with total length $(\mathrm{y}=0.004 \mathrm{x}+8.04$, $\mathrm{R}^{2}=0.15$; Fig. 5.2)

Discriminant function analysis (DFA) on the muscle essential AA $\delta^{13} \mathrm{C}$ data of $L$. ehrenbergii showed that each of the five regions was clearly separated in multivariate 
space (Fig. 5.4). The first discriminant function identified a gradient from coastal wetlands to oceanic reefs, while the second discriminant function separated coastal wetlands from the shelf island habitat of Abu Latt Island. Moreover, we were able to assign individuals to each of these habitats with a high degree of accuracy based on the multivariate essential AA $\delta^{13} \mathrm{C}$ signatures. Jackknifed reclassification success rate to each potential juvenile habitat averaged $95 \%$ compared to a random reclassification success expectation of $20 \%$.

All of the potential juveniles habitats we identified appeared to have been used by at least some of the adult L. ehrenbergii on coral reefs, however, the relative contribution of each habitat to the adult populations on offshore reefs varied considerably throughout the seascape (Fig. 5.5). One obvious pattern in the data was that the contribution of juveniles from coastal wetlands habitats to the adult populations on coral reefs decreased with increasing distance offshore. Most adults L. ehrenbergii (72\%) on coastal reefs, within a few km of shore, spent their juvenile period in coastal wetlands, and nearly all fish $(96 \%)$ came from either wetlands or coastal reefs. However, at shelf reefs approximately $32 \mathrm{~km}$ from the coast only $18 \%$ of the adult $L$. ehrenbergii used coastal wetlands as juvenile nursery habitat. Most of the adult L. ehrenbergii on these reefs either used Abu Latt Island on the edge of the continental shelf as a juvenile nursery (46\%), or directly settled on shelf reefs (18\%). Adults on fringing reefs adjacent to Abu Latt Island showed no evidence of extensive juvenile movements as all individuals were assigned to the local habitat type around the island. Finally, L. ehrenbergii on reefs off the continental shelf (Fig. 5.1) showed a very different juvenile residence pattern to those on 
the shelf. We found little evidence for significant off-shelf movements, with the majority of adult $L$. ehrenbergii on oceanic reefs (75-80\%) residing on oceanic reefs as juveniles. A smaller but still significant number of fish $(25 \%)$ had moved a distance of up to $30 \mathrm{~km}$ from juvenile habitats around Abu Latt Island to the oceanic reefs.

\section{DISCUSSION}

Coastal wetland habitats have long been hypothesized to be valuable juvenile nurseries for many ecologically and commercially important coral reef fish species. Based on $\delta^{13} \mathrm{C}$ analysis of AAs in otoliths, we showed that some Lutjanus ehrenbergii resided in wetlands as juveniles before making long distance migrations to join adult populations on coral reefs. However, the use of seagrass and mangrove habitats was facultative, with many individuals appearing to have settled directly into reef habitats. Connectivity among habitats appeared to be dependent upon the arrangement of wetlands and coral reefs within the seascape (Dorenbosch et al. 2007). While juveniles apparently were able to migrate from wetland habitats to reefs on the edge of the continental shelf, we found no evidence of wetland use in fish on oceanic reefs. Our study provides direct support for calls to conserve both coastal nursery habitats and offshore coral reefs to promote resilience of coral reefs (e.g. McCook et al. 2009), particularly in light of this previously unconfirmed level of seascape connectivity via ontogenetic migration.

Analysis of $\delta^{13} \mathrm{C}$ values in essential AAs provided an accurate method for tracking ontogenetic migration of snapper between juvenile nursery habitats and coral reefs. The approach is predicated on the observation that essential AAs of fishes are 
transferred through food webs without ${ }^{13} \mathrm{C}$ fractionation (McMahon et al. 2010). We documented in earlier work that L. ehrenbergii residing in coastal wetlands had more ${ }^{13} \mathrm{C}$ enriched essential AA values than fish on coastal reefs (McMahon et al. Chapter 4 this thesis). Interestingly, most of the carbon in essential AAs from fish collected on reefs appeared to have passed through detrital pathways rather than having come directly from pelagic phytoplankton production. While the details of the mechanisms underlying the habitat-specific signatures deserve future investigation, the source of carbon in these habitats is irrelevant to the current application provided that isotope signatures were able to accurately identify juvenile habitats used by adults residing on reefs.

We only found juvenile L. ehrenbergii in coastal wetlands, and thus hypothesized that coastal wetlands would be the dominant juvenile nursery for L. ehrenbergii on coral reefs around Al Lith, Saudi Arabia in the Red Sea. However, there was clearly significant plasticity in the nursery habitat requirements of L. ehrenbergii at our study site. All five potential juvenile habitats were used by at least some juvenile L. ehrenbergii before making ontogenetic migrations to join the adult population on offshore coral reefs. The facultative use of coastal wetlands has been hypothesized for other snapper species as well. For instance, Nagelkerken et al. (2002) suggested that juvenile Lutjanus mahogoni showed a preference for, but not a dependence on, mangroves and seagrass beds as nurseries. This is not to say that coastal wetlands were not an important nursery for $L$. ehrenbergii.

While L. ehrenbergii were apparently not obligated to use mangroves and seagrass beds as nurseries, a significant portion of the adults on the continental shelf 
came from coastal wetlands. In our study, the contribution of individuals from wetland habitats was highest on coastal reefs and decreased with distance offshore. It is interesting to note that reefs with the highest connectivity to coastal wetlands also had the highest adult $L$. ehrenbergii densities. Densities of adult $L$. ehrenbergii on coastal reefs were seven fold higher than those on the outer shelf and oceanic reefs (Thorrold et al., unpubl. data). This correlation support previous studies showing higher adult abundance of nursery species on coral reefs closer to nursery sources (Nagelkerken et al. 2002; Dorenbosch et al. 2004b, 2007; Mumby et al. 2004; Aburto-Oropeza et al. 2008). While these relationships are correlative, they suggest that connectivity to coastal wetlands might facilitate larger adult populations on adjacent reefs compared to locations relying on direct settlement of larvae into reefs. The approach we used provided a measure of the relative importance of juvenile habitats to adults at each of the reef locations we sampled. However, a quantitative estimate of the total juvenile production that entered reef populations from different habitats would require knowledge of the total abundance of adults within the study population and the migration-associated mortality rates along with the data on juvenile habitat use that we have provided here

Our data indicate that a habitat can still be a valuable juvenile nursery and contribute individuals to the adult population even if juveniles were not visually abundant in that habitat. Notably, we have never seen juvenile L. ehrenbergii on oceanic reefs near Al Lith, despite several years of regular work on these reefs; yet, isotope signatures in otoliths revealed that many individuals had settled directly into these reef habitats. Given higher predation rates on coral reefs compared to coastal wetlands (Dorenbosch et al. 
2009), it is possible that juvenile L. ehrenbergii on coral reefs reside in highly cryptic habitats (e.g. inside the reef matrix itself or beyond the depth limitations of typical SCUBA-based surveys). L. ehrenbergii on offshore reefs appeared to rely heavily on detrital pathways, which may allow juvenile L. ehrenbergii to remain benthic while feeding and avoid exposure in the water column until they reach sufficient size to reduce their predation risk (McIvor and Odum 1988). Regardless of the reason for not seeing juvenile L. ehrenbergii on offshore reefs, we suggest that caution must be taken when inferring nursery function based upon visual surveys of fish density alone, as that could lead to misrepresentation of juvenile habitat importance and potentially miss essential nurseries completely.

Juvenile habitat use by L. ehrenbergii and subsequent functional connectivity to adult populations on coral reefs showed several interesting patterns in the context of the seascape configuration. Little is known about the regulatory processes that affect ontogenetic migration of coral reef fish (Mumby and Harborne 2006). Our results provided the first direct measurements of a remarkable migration by juvenile snapper from coastal wetlands to coral reefs at least $30 \mathrm{~km}$ from the coast and from a shelf island across deep open water to off-shelf oceanic reefs some $25 \mathrm{~km}$ away. Coastal and shelf reefs appeared to have greater functional connectivity within the seascape than Abu Latt Island and the oceanic reefs. At least three different juvenile source regions, likely consisting of multiple individual reefs, contributed to adult L. ehrenbergii populations coastal and shelf reefs. Conversely, Abu Latt Island appeared to be 100\% self-recruiting and the oceanic reefs were primarily locally recruiting with only small contributions from 
Abu Latt Island. As a result, the coastal and shelf reef habitats may have a greater source redundancy and thus be less vulnerable to fluctuations in juvenile supply from individual habitats. Perhaps the shallow continental shelf, typically less than $50 \mathrm{~m}$ deep, facilitated enhanced inter-reef movement compared to the deep open water between oceanic reefs. The consequences of a lack of functional redundancy on Abu Latt Island and the oceanic reefs are currently unknown, and would be difficult to examine experimentally. It should be noted, however, that there are many similar offshore reefs in this region, and ontogenetic movement among these reefs may occur undetected by our method. This would increase the source redundancy of these oceanic reefs. Abu Latt Island is a very unique habitat in our study site, as there are no other islands similar to Abu Latt within $100 \mathrm{~km}$. Abu Latt is a large, partially vegetated island that has fringing patch reefs and seagrass lined channels. Juvenile L. ehrenbergii from Abu Latt Island likely fed on the patch reefs used as shelter during the day and foraged in seagrass lined channels at night, analogous to the mangrove-seagrass diel migrations taking place in the coastal wetlands. As such, L. ehrenbergii from Abu Latt Island had essential AA $\delta^{13} \mathrm{C}$ values that plotted in between the coastal wetlands and offshore coral reefs in DFA canonical space. Assignments to this unique habitat carry a greater degree of spatial certainty than the other habitats in this system.

We found no evidence that adult $L$. ehrenbergii from oceanic reefs used coastal wetlands or reefs as juveniles. Juveniles from nearshore areas did not move beyond shelf reefs for reasons on which we could only speculate at this point. In contrast, juveniles that settled into habitats surrounding Abu Latt Island on the shelf edge apparently were 
able to swim across open water in excess of $300 \mathrm{~m}$ depth to settle on the oceanic reefs. There is little movement data on juvenile coral reef fishes to compare with our results due to the difficulties associated with tagging small fish (Gillanders et al. 2003). Acoustic tracking of adult coral reef fishes has revealed within-reef migrations to spawning aggregation sites over distances of up to $20 \mathrm{~km}$ (Starr et al. 2007) and inter-reef movements up to $16 \mathrm{~km}$ (Chateau and Wantiez 2009). However, it is often assumed that large expanses of unsuitable habitat, such as deep open water, are migration barriers for coral reef fishes (Bernardi 2000; Chapman and Kramer 2000; Rocha et al. 2002; Dorenbosch et al. 2007). The fact that significant numbers of juvenile L. ehrenbergii were migrating up to $30 \mathrm{~km}$ among reefs and across deep oceanic waters highlights how little we know about the migration capabilities of coral reef fishes.

We were able to show that $L$. ehrenbergii were capable of long distance movements from juvenile habitats to coral reefs over $30 \mathrm{~km}$ away. It remains to be seen whether L. ehrenbergii made these impressive ontogenetic movements as single, long distance migrations from juvenile nurseries to offshore reefs, or as a series of stepping stone migrations over shorter distances before eventually settling some $30 \mathrm{~km}$ away. Previous studies have used spatial patterns in size distribution of fish among habitats to infer stepping stone migrations (Cocheret de la Morinière et al. 2002; Nagelkerken et al. 2002). Our size distribution data suggest at least some stepwise post-settlement migration, as the smallest individuals were found in the coastal wetlands, intermediate sized individuals were typically found on the coastal reefs and island patch reefs and the largest individuals were most common on the offshore coral reefs. Analysis of AA $\delta^{13} \mathrm{C}$ 
values in otoliths may provide a more direct assessment of movement among these habitats throughout the ontogeny of a fish. In our study, we examined the juvenile core of adult otoliths to determine juvenile residence patterns. However, future work could subsample across otoliths at finer spatial resolutions that may, in turn, allow us to address this question of stepwise versus long distance post-settlement migration. Fishes that use a stepwise migration among several transition habitats would presumably have several distinct habitat signatures going from the juvenile core to the subadult and finally adult otolith material. As instrument sensitivity improves and sample size requirements decrease, our ability to track ontogenetic fish migration among habitats with greater spatial and temporal resolution should accordingly improve. This would greatly improve our understanding of the timing of ontogenetic migrations.

Identifying essential juvenile habitats has been a tricky proposition in the past, primarily relying on visual surveys of juvenile fish abundance and assuming successful migrations to offshore reefs. However, we showed that habitats could be important juvenile nurseries, even if juveniles were not visually abundant in those habitats. Using otolith amino acid ecogeochemistry, we found that L. ehrenbergii made long distance ontogenetic migrations, upwards of $30 \mathrm{~km}$, from nursery habitats to coral reefs. Coastal wetlands were an important nursery habitat for L. ehrenbergii, and connectivity to coastal wetlands by ontogenetic migration may facilitate larger adult populations than reefs relying on direct settlement. However, L. ehrenbergii were not obligated to use seagrass beds and mangrove as juvenile nurseries, and seascape configuration played an important role in determining the functional connectivity among essential habitats. The current 
paradigm of a simple linear migration from coastal wetlands to offshore reefs is likely a gross oversimplification of the migratory capabilities of coral reef fishes. Factors including habitat type, distance among habitats and proximity to seascape features such as the continental shelf break and deep open water, all played important roles in determining ontogenetic migration pathways of L. ehrenbergii. Given the high degree of functional connectivity within this tropical seascape, our data suggest that stress on one inter-connected habitat may have cascading effects on abundances of coral reef fish in other habitats within the seascape. Management plans for tropical coastal habitats and their associated fisheries should aim to preserve coastal wetlands and coral reefs in their natural configuration to promote sustainable fisheries and healthy ecosystem functions.

\section{ACKNOWLEDGEMENTS}

The authors would like to thank L. Houghton for laboratory assistance, C. Braun and S. Swift for assistance with Figure 5.1 and Dream Divers, Jeddah, Saudi Arabia for logistic assistance with boating and diving operations. This research was supported by King Abdullah University of Science and Technology (KAUST) Award Nos. USA 00002 and KSA 00011 to S. Thorrold. Additional funding was provided by the Woods Hole Oceanographic Institution and an International Society for Reef Studies-Ocean Conservancy Coral Reef Fellowship to K. McMahon. K. McMahon received support from the National Science Foundation Graduate Research Fellowship Program. 
A)

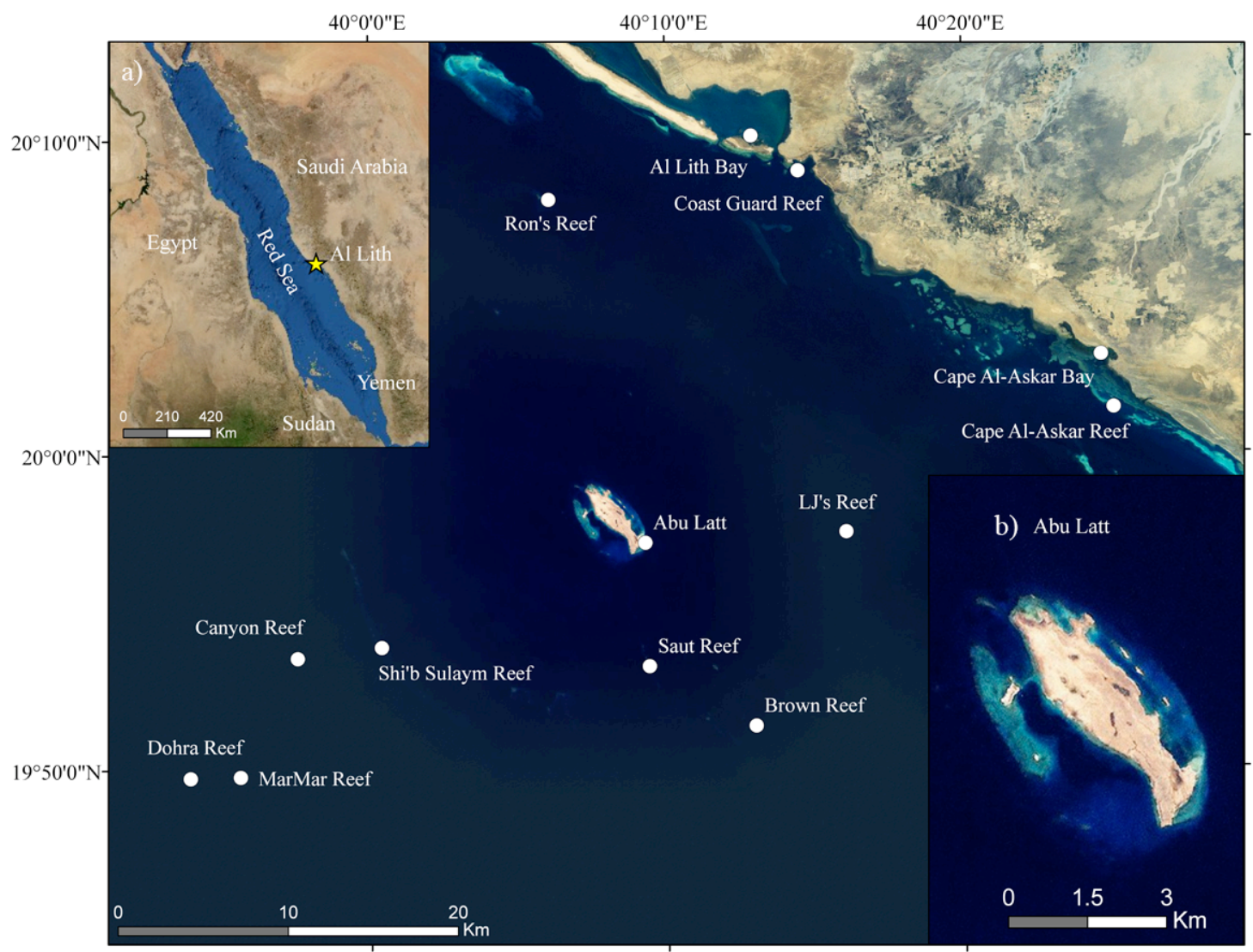


B)

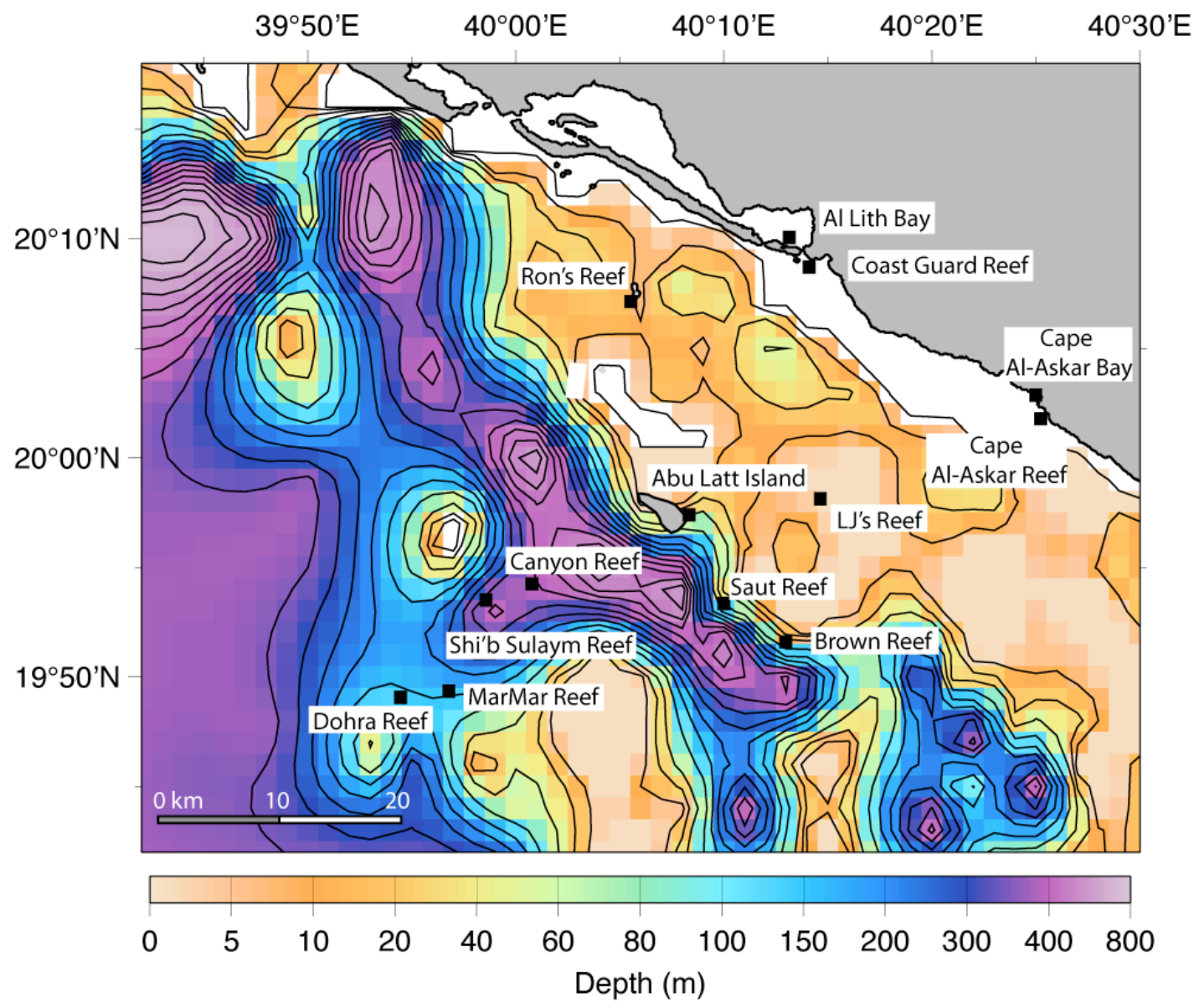

Figure 5.1. A) Ehrenberg's snapper, Lutjanus ehrenbergii, collection sites from two coastal wetlands (Al Lith Bay and Cape Al-Askar Bay), two coastal reefs (Coast Guard Reef and Cape Al-Askar Bay Reef), four shelf reefs (Ron's Reef, LJ's Reef, Saut Reef and Brown Reef), an offshore Island (Abu Latt) and four oceanic reefs (Shi'b Sulaym Reef, Canyon Reef, MarMar Reef and Dohra Reef) near Al Lith, Saudi Arabia in the Red Sea. Inset a) the study site location within the Red Sea and b) an enlarged view of Abu Latt Island. B) Study site bathymetry map. Color contours represent one arc-minute gridded bathymetry data for the study region, with gray representing land and white indicating no data (General Bathymetric Chart of the Oceans:

http://www.gebco.net/data_and_products/gridded_bathymetry_data/) 

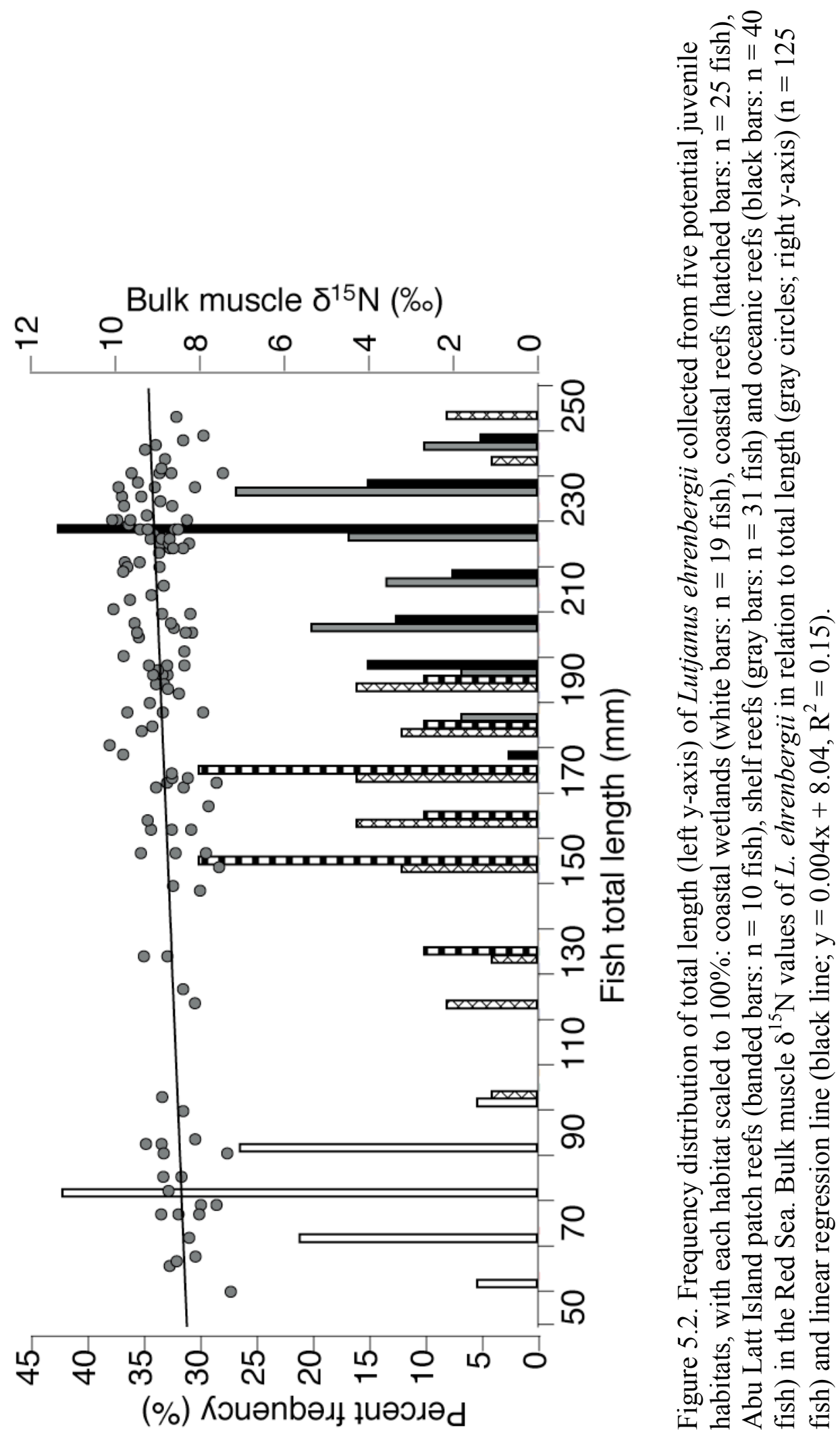


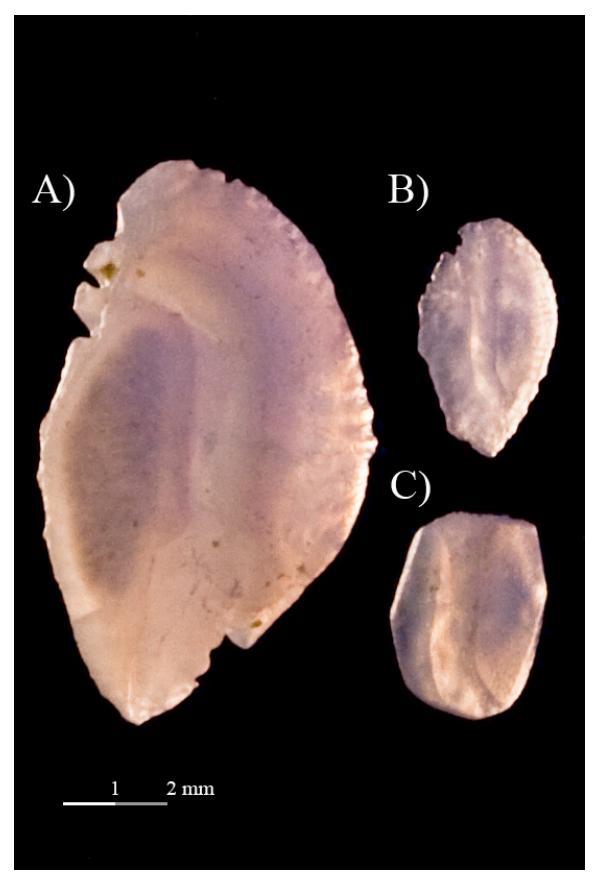

Figure 5.3. A) The otolith of an adult Lutjanus ehrenbergii (total length [TL] $=230 \mathrm{~mm}$ ) measuring 9.6 by $5.6 \mathrm{~mm}$ and weighing $125 \mathrm{mg}$, B) a juvenile L. ehrenbergii otolith (TL $=75 \mathrm{~mm}$ ) measuring 4.1 by $2.4 \mathrm{~mm}$ and weighing $8 \mathrm{mg}$, and C) the juvenile core isolated from the adult otolith and contoured to match the mean size and mass of otoliths from juvenile L. ehrenbergii (fish total length $\sim 75 \mathrm{~mm}$ ). 


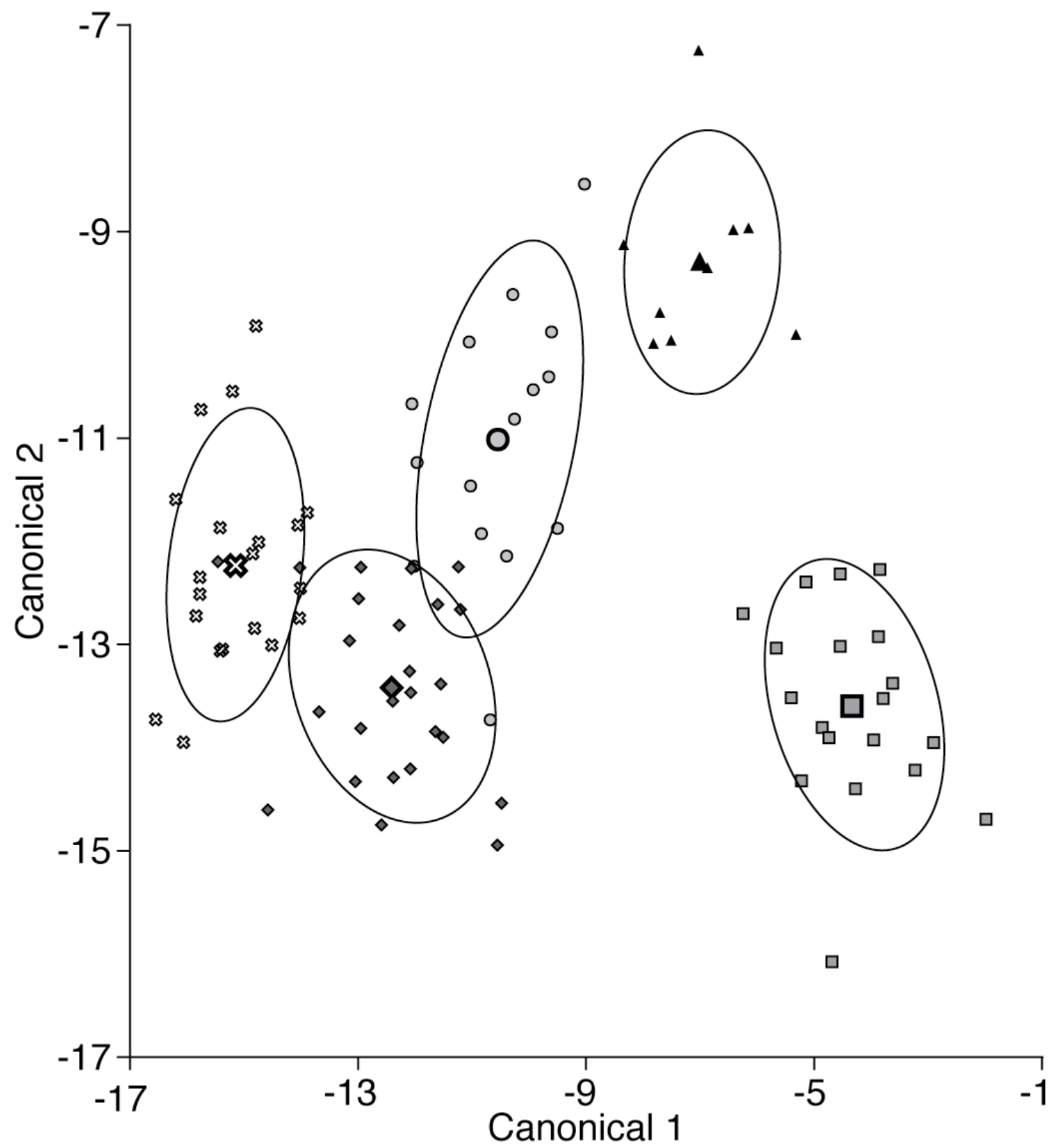

Figure 5.4. Juvenile habitat signature separation in canonical space with $95 \%$ confidence ellipses visualized by discriminant function analysis of muscle essential amino acid $\delta^{13} \mathrm{C}$ values from Lutjanus ehrenbergii collected from five potential juvenile habitats: coastal wetlands (squares: $\mathrm{n}=19$ fish), coastal reefs (circles: $\mathrm{n}=15$ fish), Abu Latt Island patch reefs (triangles: $\mathrm{n}=10$ fish), shelf reefs (diamonds: $\mathrm{n}=25$ fish) and oceanic reefs (crosses: $\mathrm{n}=20$ fish) in the Red Sea. 


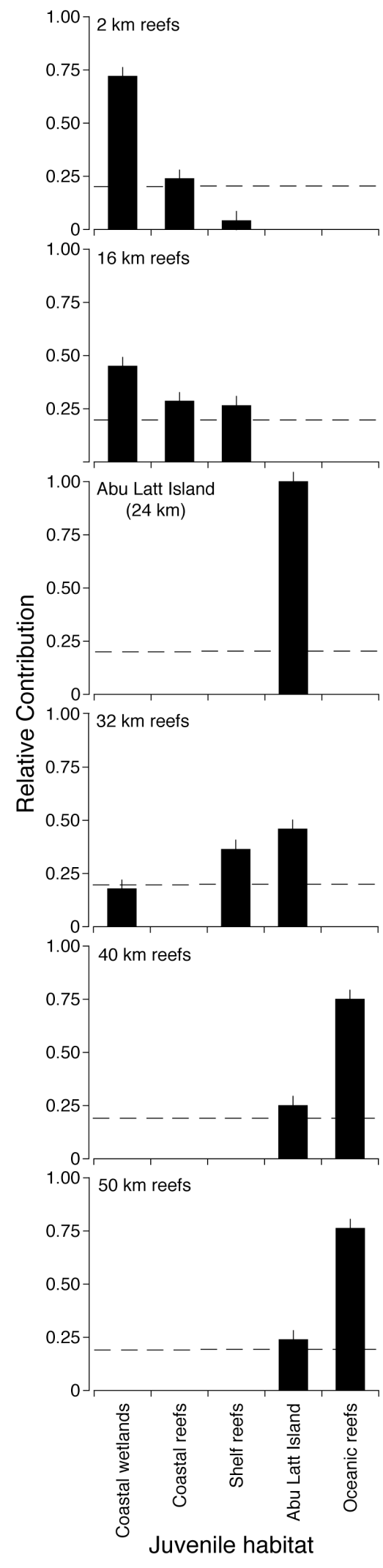

Figure 5.5. Relative contribution of Lutjanus ehrenbergii from five potential juvenile habitats to the adult populations on reefs at six distances along a $50 \mathrm{~km}$ crossshelf transect from Al Lith, Saudi Arabia in the Red Sea: $2 \mathrm{~km}$ reefs ( $\mathrm{n}=25$ fish), $16 \mathrm{~km}$ reefs ( $\mathrm{n}=20$ fish), Abu Latt Island $24 \mathrm{~km}(\mathrm{n}=10 \mathrm{fish}), 32 \mathrm{~km}$ reefs ( $\mathrm{n}=11 \mathrm{fish})$, $40 \mathrm{~km}$ reefs ( $\mathrm{n}=20$ fish) and $50 \mathrm{~km}$ reefs ( $\mathrm{n}=20$ fish). Horizontal dashed lines represent $20 \%$ contribution from all five juvenile habitats 


\section{CHAPTER SIX}

\section{CONCLUSION}

\section{Thesis summary}

Ontogenetic migration is an important step in the lives of many coral reef fish species. The ecological consequences of such movements are, however, only beginning to be understood. A significant implication of this functional connectivity is that coral reef ecosystem functions, including productivity, diversity and sustainable harvest levels, are not localized phenomena, but rather dependent on the spatial configuration of the seascape. This thesis presents the development and application of compound-specific stable isotope analysis (SIA) to small amounts of otolith material using gas chromatography-combustion-isotope ratio monitoring-mass spectrometry (GC-C-irmMS). The analysis of otolith amino acid (AA) $\delta^{13} \mathrm{C}$ values provides, for the first time, a

robust tracer of baseline isoscape signatures $\left(\delta^{13} C_{\text {Base }}\right)$ in an accretionary fish tissue. The approach will greatly improve our ability to track the movement of fish through marine isoscapes, particularly for species and life-stages not amenable to conventional tagging techniques. Amino acid $\delta^{13} \mathrm{C}$ signatures in otoliths of snapper (Family: Lutjanidae) acted as natural tags of residency in seagrass beds, mangroves and coral reefs. This allowed us to quantify the relative contribution of potential juvenile nursery habitats to adult populations of Lutjanus ehrenbergii in a coral reef seascape in the Red Sea.

In chapter two, Fundulus heteroclitus were reared on four isotopically distinct diets to examine individual AA trophic fractionation $\left(\Delta^{13} \mathrm{C}_{\mathrm{C}-\mathrm{D}}\right)$ variability in fish muscle (McMahon et al. 2010). Essential AAs showed little to no $\Delta^{13} \mathrm{C}_{\mathrm{C}-\mathrm{D}}$, and their $\delta^{13} \mathrm{C}$ values 
accurately reflected dietary signatures regardless of diet type. Our data support previous research indicating that essential $\mathrm{AA} \delta^{13} \mathrm{C}$ values are excellent tracers of $\delta^{13} \mathrm{C}_{\text {Base }}$ across a wide range of taxa and tissue types (Hare et al. 1991; Fantle et al. 1999; Howland et al. 2003; O’Brien et al. 2003; Jim et al. 2006). This multivariate ecogeochemistry approach greatly improved our ability to track movement of fish through the mangrove-coral reefseagrass isoscape in subsequent chapters. The patterns from non-essential AA $\Delta{ }^{13} \mathrm{C}_{\mathrm{C}-\mathrm{D}}$ values were less clear, but did show evidence of both de novo biosynthesis and direct isotopic routing from dietary protein. Variability in non-essential AA $\delta^{13} \mathrm{C}$ values appeared to be correlated with protein content and AA composition of the diet as well as differential utilization of dietary constituents contributing to the bulk carbon pool. Our work confirms that organisms feeding on apparently homogeneous diets can exhibit substantially different $\delta^{13} \mathrm{C}$ values when routing of dietary components and alterations of available carbon pool $\delta^{13} \mathrm{C}$ values become important (e.g. O'Brien et al. 2002; O'Brien, et al. 2003; Jim et al. 2006). The results also illustrated the complicated impacts of metabolism on consumer tissue $\delta^{13} \mathrm{C}$ values and suggest caution must be taken with the assumptions used to interpret bulk stable isotope data in dietary studies. Further research to constrain the mechanisms controlling non-essential AA $\Delta{ }^{13} \mathrm{C}_{\mathrm{C}-\mathrm{D}}$ variability will be necessary to fully realize the potential of this technique for refining dietary and trophic dynamic studies (see Future Directions section below).

In this thesis, we described the application of compound-specific SIA to fish ecology using AA $\delta^{13} \mathrm{C}$ values from small amounts $(<1 \mathrm{mg})$ of otolith and muscle tissue. We targeted five essential AAs with sufficient peak size and baseline separation: 
threonine, valine, isoleucine, phenylalanine, and leucine. We found that $\delta^{13} \mathrm{C}$ values in otolith and muscle AAs were highly correlated in a 1:1 relation regardless of species, geographic region or habitat type. While bulk otolith $\delta^{13} \mathrm{C}$ and $\delta^{18} \mathrm{O}$ values could not distinguish snapper residence in mangroves and seagrass beds in the Caribbean Sea, otolith AA $\delta^{13} \mathrm{C}$ values showed excellent separation between habitats. Analysis of AA $\delta^{13} \mathrm{C}$ values in otoliths avoided many of the complications associated with conventional bulk otolith SIA, including the dissolved inorganic carbon (DIC) dilution effect and variable metabolic carbon contribution to otolith $\delta^{13} \mathrm{C}$ values. The sample sizes necessary for compound-specific SIA using GC-C-irm-MS is currently larger than that necessary for bulk otolith $\delta^{13} \mathrm{C}$ measurements. However, otolith $\mathrm{AA} \delta{ }^{13} \mathrm{C}$ values provided a wealth of information not available from conventional bulk SIA. As instrument sensitivity continues to improve, the sample sizes required to conduct compound-specific SIA on otoliths will likely decrease in the future. This, in turn, will allow us to analyze otoliths from smaller fish and subsample across otoliths at finer spatial scales, expanding the potential applications of our otolith AA approach (see Future Directions section below). Many ecologically and economically important coral reef fish species are thought to use coastal wetlands as nurseries prior to moving offshore to join adult populations on coral reefs (e.g. Nagelkerken et al. 2000; Dorenbosch et al. 2004b). Functional connectivity between juvenile and adult habitats, therefore, plays a crucial role in structuring these reef fish populations (Dorenbosch et al. 2007; Turgeon et al. 2010) and must be understood to properly manage these species. While a handful of studies have provided direct evidence of ontogenetic movement of reef fishes between coastal 
nurseries and reef habitats (Chittaro et al. 2004; Nakamura et al. 2008; Mateo et al. 2010), very few studies have quantified the relative contribution of different juvenile habitats to adult populations on coral reefs (Nagelkerken et al. 2007).

We quantified, for the first time, the relative contribution of coastal wetlands, coastal reefs and offshore coral reefs to adult L. ehrenbergii populations in a tropical seascape in the Red Sea. We only found juvenile L. ehrenbergii in coastal wetlands, however, our ecogeochemical data indicated that all five potential juvenile habitats were used by at least some juvenile L. ehrenbergii before making ontogenetic migrations to join the adult population on offshore coral reefs. This raised two important conclusions. First, our data showed that a habitat can still be a valuable juvenile nursery, even if juveniles were not visually abundant in that habitat. This suggests that caution must be taken when inferring nursery function based upon visual surveys of fish density alone, as that could lead to misrepresentation of juvenile habitat importance and potentially miss essential nurseries completely. Second, coastal wetland habitat use was facultative and seascape configuration played an important role in determining the connectivity of $L$. ehrenbergii populations among essential habitats. Although we found substantial plasticity in the juvenile habitat use of L. ehrenbergii, coastal wetlands still appeared to be an important nursery habitat, especially for reefs on the continental shelf. Our data support previous work suggesting that that connectivity to coastal wetlands might facilitate larger adult populations on adjacent reefs compared to locations relying on direct settlement of larvae into reefs (Nagelkerken et al. 2002; Dorenbosch et al. 2004b, 2007; Mumby et al. 2004; Aburto-Oropeza et al. 2008). 
We found that L. ehrenbergii made long distance ontogenetic migrations, ultimately traveling more than $30 \mathrm{~km}$ from nursery habitats to coral reefs. While some temperate species are capable of long distance movements between juvenile and adult habitats (Gillanders 2005), this migration distance and subsequent functional connectivity has seldom been shown in coral reef fishes (Adams et al. 2006). Even more surprising was the fact that juvenile L. ehrenbergii from Abu Latt Island on the shelf edge appeared to have successfully navigated through at least $10 \mathrm{~km}$ of deep open water to settle on oceanic reefs. Large expanses of unsuitable habitat (e.g. bare sand and deep open water) are typically considered to be migration barriers for coral reef fishes (Bernardi 2000; Chapman and Kramer 2000; Rocha et al. 2002; Dorenbosch et al. 2007). It remains to be seen how and why L. ehrenbergii from Abu Latt Island made such migrations through deep open water. On the other hand, no juvenile L. ehrenbergii from coastal wetlands appeared to settle on reefs beyond the continental shelf break. The reason for this disparity in migration patterns is currently unknown, but could have important implications for local reef fish population resilience to disturbance.

This thesis introduces an otolith AA SIA approach that will open new doors for the exploration of diet and movement of fish in the marine environment. The first application of this approach expanded our knowledge of migration patterns and functional connectivity of snapper in a coral reef seascape. L. ehrenbergii were able to make long distance migrations from coastal wetlands to coral reefs some $30 \mathrm{~km}$ away and across habitats previously assumed to be migration barriers for coral reef fish. We found that habitat type, distance among habitats and proximity to seascape features such as the 
continental shelf break and deep open water, all played an important role in determining ontogenetic migration pathways of L. ehrenbergii. This work indicates that the current paradigm of a simple linear migration from coastal wetlands to offshore coral reefs is likely a gross oversimplification of the migration capabilities of coral reef fishes.

Our data suggests that stress on one inter-connected habitat may have cascading effects on population structure of coral reef fishes in other habitats within the seascape. For L. ehrenbergii in the Red Sea, protecting coastal wetlands and offshore coral reefs is likely an important first step to successful management of coral reef ecosystems and the fisheries they support. However, conservation of these habitats alone may not be sufficient to adequately protect all of the coral reef fish populations in tropical seascapes. Clearly, seascape configuration coupled with species-specific behavior and migratory capabilities plays an important role in determining migration pathways of coral reef fish, and will ultimately affect the connectivity of habitats and subpopulations within the seascape. Conventional metrics for identifying important juvenile nurseries and their connectivity to adult populations, including juvenile abundance data and inter-habitat distances are not sufficient to capture the full complexity of functional connectivity in these systems. The otolith AA SIA method now provides a valuable new tool for assessing functional connectivity of coral reef fish populations at the seascape level.

\section{Future directions}

As is often the case with scientific inquiry, this thesis has generated many additional questions that warrant investigation. Two important questions generated from 
the chapter two feeding experiment were: what drives non-essential $\mathrm{AA} \Delta \Delta^{13} \mathrm{C}_{\mathrm{C}-\mathrm{D}}$ variability, and how can non-essential AA $\delta^{13} \mathrm{C}$ values aid in the study of diet and movement in marine fish? We chose diets that ranged from solely plant matter to solely animal matter in order to examine potential variability in $\mathrm{AA} \Delta \Delta^{13} \mathrm{C}_{\mathrm{C}-\mathrm{D}}$. However, there were a number of confounding variables, including diet type, protein content and AA composition that made it challenging to identify mechanisms driving non-essential AA $\Delta{ }^{13} \mathrm{C}_{\mathrm{C}-\mathrm{D}}$ values. The next step will be to identify the mechanisms behind the high, dietspecific variability in $\Delta^{13} \mathrm{C}_{\mathrm{C}-\mathrm{D}}$ and determine what information non-essential AA $\delta^{13} \mathrm{C}$ values hold about consumer diet and metabolic history. This calls for targeted feeding experiments that track the fractionation of isotopically labeled dietary constituents, including lipids, proteins and carbohydrates, as they are metabolically processed through the TCA cycle and incorporated into consumer AAs. This would allow us to better predict how precursor $\delta^{13} \mathrm{C}$ signatures are manifested in product $\mathrm{AA} \delta^{13} \mathrm{C}$ values. Constraining the mechanisms behind non-essential AA fractionation would greatly improve our understanding of the biochemical and physiological underpinnings of stable isotope values used in diet and food web studies.

In chapter four we suggested that the distinction between zooplankton and detritivorous crabs, based upon compound-specific SIA, likely represented the impact of microbial processing on the $\delta^{13} \mathrm{C}$ signature of essential AAs. This was not surprising given the roll microorganisms play in reworking seagrass and mangrove carbon into more bioavailable forms (Zieman et al. 1984). This distinction was a major driver of the variability in habitat signatures across the tropical seascape. However, the detrital 
contribution to coral reef food webs was not apparent with conventional bulk SIA. Thus, a more detailed investigation into the food web structure of coastal wetlands and coral reefs would better constrain these habitat signatures. Incorporation of non-essential AA $\delta^{13} \mathrm{C}$ values into a food web study may provide valuable information about diet type and quality. The extent to which microbially-mediated detritus supports higher trophic level production on coral reefs is currently unclear. This approach may provide greater insight into the carbon sources fueling higher trophic levels on coral reefs than was previously available with conventional bulk SIA. Furthermore, understanding carbon flow within a coral reef ecosystem, particularly if detritus and phytoplankton sources can be uniquely identified, will significantly enhance the use of compound-specific SIA to track movement within tropical seascapes.

In chapter five, we showed that L. ehrenbergii traveled at least $30 \mathrm{~km}$ between coastal wetlands and offshore coral reefs. It remains unclear whether L. ehrenbergii from coastal wetlands made single, long distance migrations from juvenile nurseries to offshore reefs, or a series of stepping stone movements over shorter distances. Subsampling AA $\delta^{13} \mathrm{C}$ values across otoliths at finer spatial resolutions would allow us to address the question of stepwise versus long distance post-settlement migration. However, if fish reside in isotopically indistinguishable habitats, or move through habitats faster than the habitat signature is recorded, then the otolith AA SIA approach may not identify residence in all intermediate habitats. This will also be true when applying this technique to other species or systems. Analyzing additional isotopes with unique distributions will increase habitat signature separation, and improve the accuracy 
of habitat use classifications. This will be particularly important for tracking fish movement in open ocean systems that typically have smaller stable isotope gradients than coastal tropical seascapes. As instrument sensitivity improves and sample size requirements decrease, we will be able to distinguish residence in isotopically distinct habitats at shorter spatial scales. This type of data will greatly improve our knowledge of the timing of ontogenetic migration. Thus, while caution must taken when applying the otolith AA SIA approach to other systems, this technique should improve our ability to track ontogenetic fish migration among habitats and validate hypotheses generated from correlations between sizes of fish and their location in the seascape Management of coral reefs and the juvenile habitats that supply them will be a valuable step towards promoting healthy ecosystem function and sustainable fisheries on coral reefs. This thesis presented the first application of our otolith AA technique to quantify the contribution of juvenile nurseries to L. ehrenbergii populations on coral reefs in the Red Sea. While the patterns found in this thesis are likely to be species or seascape configuration specific, the otolith AA SIA method presented here provides an empirical tool to assess ontogenetic migration for other species and seascapes. The next step will be to apply this technique to other species and systems. For instance, we found that the continental shelf break appeared to offer a partial connectivity barrier, preventing juvenile L. ehrenbergii in coastal wetlands, but not Abu Latt Island, from migrating to oceanic reefs. Would L. ehrenbergii from coastal wetlands migrate through open water to oceanic reefs if the continental shelf break was only $15 \mathrm{~km}$ offshore? Do such connectivity barriers exist for other species or in other regions with potentially different 
seascape configurations? This thesis presented one application of the otolith AA SIA

method; however, the field is still in its infancy and the potential applications are broad and diverse. 


\section{REFERENCES}

Abed-Navandi D, Dworschak PC (2005) Food sources of tropical thalassidean shrimps: a stable-isotope study. Marine Ecology Progress Series 291:159-168

Aburto-Oropeza O, Ezcurra E, Danemann G, Valdez V, Murray J, Sala E (2008) Mangroves in the Gulf of California increase fishery yields. Proceedings of the National Academy of Science 105:10456-10459

Adams AJ, Dahlgren CP, Kellison GT, Kendall MS, Layman CA, Ley JA, Nagelkerken I, Serafy JE (2006) Nursery function of tropical back-reef systems. Marine Ecology Progress Series 318:287-301

Allen GR (1985) FAO species catalogue. Vol. 6. An annotated and illustrated catalogue of lutjanid species known to date. FAO Fisheries Synopsis 4:76-77

Allen GR, Talbot FH (1985) Review of the snappers of the genus Lutjanus (Pisces: Lutjanidae) from the Indo-Pacific, with the description of a new species. IndoPacific Fisheries 11:1-87

Alongi DM (2002) Present state and future of the world's mangrove forests. Environmental Conservation 29:331-349

Ambrose SH, Norr L (1993) Carbon isotopic evidence for routing of dietary protein to bone collagen, and whole diet to bone apatite carbonate: Purified diet growth experiments. In (eds. Lambert J, Grupe G) Molecular Archaeology of Prehistoric Human Bone), Springer-Verlag, Berlin, Germany, pp. 1-37

AOAC (2005) Official methods of analysis ( $17^{\text {th }}$ edition). AOAC International, Arlington, VA, USA

Appeldoorn RS, Friedlander A, Sladek Nowlis J, Usseglio P, Mitchell-Chui A (2003) Habitat connectivity in reef fish communities and marine reserve design in Old Providence-Santa Catalina, Columbia. Gulf and Caribbean Research 14:61-77

Bada JL, Peterson RO, Schimmelmann A, Hedges REM (1990) Moose teeth as monitors of environmental isotopic parameters. Oecologia 82:102-106

Baich A, Pierson DJ (1965) Control of proline synthesis in Escherichia coli. Biochimica et Biophysica Acta 104:397-404 
Beck MW, Heck KL, Able KW, Childers DL, Eggleston DB, Gillanders BM, Halpern B, Hays CG, Hoshino K, Minello TJ, Orth RJ, Sheridan PF, Weinstein MR (2001) The identification, conservation, and management of estuarine and marine nurseries for fish and invertebrates. Bioscience 51:633-641

Begg GA, Weidman CR (2001) Stable $\delta^{13} \mathrm{C}$ and $\delta^{18} \mathrm{O}$ isotopes in otoliths of haddock Melanogrammus aeglefinus from the northwest Atlantic Ocean. Marine Ecology Progress Series 216:223-233

BernardiG (2000) Barriers to gene flow in Embiotoca jacksoni, a marine fish lacking a pelagic larval stage. Evolution 54:226-237

Blaber SJM, Milton DA, Rawlinson NJF, Tiroba G, Nichols PV (1990) Diets of lagoon fishes of the Solomon Islands: predators of tuna baitfish and trophic effects of baitfishing on the subsistence fisheries. Fisheries Research 8:263-286

Block BA, Teo SH, Walli A, Boustany A, Stokesbury MJW, Farwell CJ, Weng KC, Dewar H, Williams TD (2005) Electronic tagging and populations structure of Atlanic bluefin tuna. Nature 434:1121-1127

Borman A, Wood TR, Black HC, Anderson EG, Oesterling MJ, Womack M, Rose WC (1946) The role of arginine in growth with some observations on the effects of argininic acid. Journal of Biological Chemistry 166: 585-594

Bouillon S, Raman AV, Dauby P, Dehairs F (2002) Carbon and nitrogen stable isotope ratios of subtidal benthic invertebrates in an estuarine mangrove ecosystem (Andhra Pradesh, India). Estuarine, Coastal and Shelf Science 54:901-903

Brothers EB, Williams DM, Sale PF (1983) Length of larval life in twelve families of fishes at "One Tree Lagoon", Great Barrier Reef, Australia. Marine Biology 76:319-324

Campana SE (1999) Chemistry and composition of fish otoliths: pathways, mechanisms and applications. Marine Ecology Progress Series 188:263-297

Campana SE, Neilson JD (1985) Microstructure of Fish Otoliths. Canadian Journal of Fisheries and Aquatic Sciences 42:1014-1032

Campana SE, Thorrold SR (2001) Otoliths, increments, and elements: keys to a comprehensive understanding of fish populations? Canadian Journal of Fisheries and Aquatic Sciences 58:30-38

Chapman MR, Kramer DL (2000) Movements of fishes within and among fringing coral reefs in Barbados. Environmental Biology of Fishes 57:11-24 
Chateau O, Wantiez L (2009) Movement patterns of four coral reef fish species in a fragmented habitat in New Caledonia: implications for the design of marine protected area networks. ICES Journal of Marine Science 66:50-55

Cherel Y, Hobson KA, Guinet C, Vanpe C (2007) Stable isotopes document seasonal changes in trophic niches and winter foraging individual specialization in diving predators from the Southern Ocean. Journal of Animal Ecology 76:826-836

Chittaro PM, Fryer BJ, Sale PF (2004) Discrimination of French grunts (Haemulon flavolineatum, Desmarest, 1823) from mangrove and coral reef habitats using otolith microchemistry. Journal of Experimental Biology and Ecology 308:169183

Christensen JD, Jeffrey CFG, Caldow C, Monaco M, Kendall MS, Appeldoorn RS (2003) Cross-shelf habitat utilization patterns of reef fishes in southwestern Puerto Rico. Gulf and Caribbean Research 14:9-27

Cocheret de la Morinière E, Ollux BJA, Nagelkerken I, van der Velde G (2002) Postsettlement life cycle migration patterns and habitat preference of coral reef fish that use seagrass and mangrove habitats as nurseries. Estuarine, Coastal and Shelf Science 55:309-321

Cocheret de la Morinière E, Pollux BJA, Nagelkerken I, Hemminga MA, Huiskes AHL, van der Velde $G$ (2003) Ontogenetic dietary changes of coral reef fishes in the mangrove-seagrass-reef continuum: stable isotopes and gut-content analysis. Marine Ecology Progress Series 246: 279-289

Cocheret de la Morinière E, Nagelkerken I, van der Meij H, van der Velde G (2004) What attracts juvenile coral reef fish to mangroves: habitat complexity or shade? Marine Biology 144:139-145

Costanza R, d'Arge R, de Groot R, Farber S, Grasso M, Hannon B, Limburg K, Naeem S, O'Neill R, Paruelo J, Raskin R, Sutton P and van den Belt M (1997) The value of the world's ecosystem services and natural capital. Nature 387: 253-260

Cote IM, Gill JA, Gardner TA, Watkinson AR (2005) Measuring coral reef decline through meta-analysis. Philosophical Transactions of the Royal Society B 360: 385-395

Cowen, RK, Gawarkiewicz GG, Pineda J, Thorrold SR, Werner FE (2007) Population connectivity in marine systems: an overview. Oceanography 20:14-21 
Crooks KR, Sanjayan M (2006) Connectivity Conservation. Cambridge University Press, Cambridge, UK.

Dahlgren CP, Eggleston DB (2000) Ecological processes underlying ontogenetic habitat shifts in coral reef fish. Ecology 81:2227-2240

Dahlgren CP, Kellison GT, Adams AJ, Gillanders BM, Kendall MS, Layman CA, Ley JA, Nagelkerken I, Serafy JE (2006) Marine nurseries and effective juvenile habitats: concepts and applications. Marine Ecology Progress Series 312:291-295

Dansgaard W (1964) Stable isotopes in precipitation. Tellus 16:436-468

Degens ET, Deuser WG, Haedrich RL (1969) Molecular structure and composition of fish otoliths. Marine Biology 2:105-113

DeNiro MJ, Epstein S (1977) Mechanism of carbon isotope fractionation associated with lipid synthesis. Science 197:261-263

DeNiro MJ, Epstein S (1978) Influence of diet on distribution of carbon isotopes in animals. Geochimica et Cosmochimica Acta 42:495-506

Descolas-Gros C, Fontungne M (1990) Stable carbon isotope fractionation by marine phytoplankton during photosynthesis. Plant Cell and Environment 13:207-218

Dorenbosch M, Verweij MC, Nagelkerken I, Jiddawi N, van der Velde G (2004a) Homing and daytime tidal movements of juvenile snapper (Lutjanidae) between shallow-water nursery habitats in Zanzibar, western Indian Ocean. Environmental Biology of Fishes 70:203-209

Dorenbosch M, van Riel MC, Nagelkerken I, van der Velde G (2004b) The relationship of reef fish densities to the proximity of mangrove and seagrass nurseries. Estuarine, Coastal and Shelf Science 60:37-48

Dorenbosch M, Verberk WCEP, Nagelkerken I, van der Velde G (2007) Influence of habitat configuration on connectivity between fish assemblages of Caribbean seagrass beds, mangroves and coral reefs. Marine Ecology Progress Series 332:103-116

Dorenbosch M, Grol MGG, de Groene A, van der Velde G, Nagelkerken I (2009) Piscivore assemblages and predation pressure affect relative safety of some backreef habitats for juvenile fish in a Caribbean Bay. Marine Ecology Progress Series 379:181-196 
Dorval E, Jones CM, Hannigan R, van Montfrans J (2005) Can otolith chemistry be used for identifying essential seagrass habitats for juvenile spotted seatrout, Cynoscion nebulosus, in Chesapeake Bay? Marine and Freshwater Research 56:645-653

Dosdat A, Servais F, Metailler R, Huelvan C, Desbruyeres E (1996) Comparison of nitrogenous losses in five teleost fish species. Aquaculture 141:107-127

Duarte CM (2002) The future of seagrass meadows. Environmental Conservation 29:192206

Dufour E, Gerdeaux D, Wurster CM (2007) Whitefish (Coregonus lavaretus) respiration rate governs intra-otolith variation of $\delta^{13} \mathrm{C}$ values in Lake Annecy. Canadian Journal of Fisheries and Aquatic Sciences 64:1736-1746

Duke NC, Meynecke JO, Dittmann S, Ellison AM, Anger K, Berger U, Cannicci S, Diele K, Ewel KC, Field CD, Koedam N, Lee SY, Marchand C, Nordhaus I, DahdouhGuebas F (2007) A world without mangroves? Science 317:41-42

Eggelston DB, Grover JJ, Lipicus RN (1998) Ontogenetic diet shifts in Nassau Grouper: trophic linkages and predatory impact. Bulletin of Marine Science 63:111-126

Elsdon TS, Wells BK, Campana SE, Gillanders BM, Jones CM, Limburg KE, Secor DH, Thorrold SR, Walther BD (2008) Otolith chemistry to describe movements and life-history parameters of fishes: hypotheses, assumptions, limitations and inferences. Oceanography and Marine Biology: An Annual Review 46:297-330

Elsdon TS, Ayvazian S, McMahon KW, Thorrold SR (2010) Experimental evaluation of stable isotope fractionation in fish muscle and otoliths. Marine Ecology Progress Series 408:195-205

Engel M, Goodfriend G, Qian Y, Macko S (1994). Indigeneity of organic matter in fossils: a test using stable isotope analysis of amino acid enantiomers in Quaternary mollusk shells. Proceedings of the National Academy of Science, USA 91:10475-10478

Estrada JA, Lutcavage M, Thorrold SR (2005) Diet and trophic position of Atlantic bluefin tuna (Thunnus thynnus) inferred from stable carbon and nitrogen isotope analysis. Marine Biology 147:37-45

Fairweather PG, Quinn GP (1993) Seascape ecology: the importance of linkages. In (eds. Battershill CB, Schiel D, Jones GP, Cresse RG, MacDiarmid AB) Proceedings of the Second International Temperate Reef Symposium. January 7-10, 1992. NIWA Marine, Auckland, p 77-83 
Fantle MS, Dittel AI, Schwalm SM, Epifanio CE, Fogel ML (1999) A food web analysis of the juvenile blue crab, Callinectes sapidus, using stable isotopes in whole animals and individual amino acids. Oecologia 120:416-426

Farquhar GD, Ehleringer JR, Hubick KT (1989) Carbon isotope discrimination and photosynthesis. Annual Review of Plant Physiology and Plant Molecular Biology 40:503-537

Faunce CH, Serafy JE (2006) Mangroves as fish habitats: 50 years of field studies. Marine Ecology Progress Series 318:1-18

Fogel ML, Tuross N (1999) Transformation of plant biochemicals to geological macromolecules during early diagenesis. Oecologia 120:336-346

Fogel ML, Tuross N (2003) Extending the limits of paleodietary studies of humans with compound specific carbon isotope analysis of amino acids. Journal of Archaeological Science 30:535-545

Fry B (1981) Natural stable isotope tag traces in Texas shrimp migrations. Fishery Bulletin 79:337-345

Fry B, Sherr EB (1984) $\delta^{13} \mathrm{C}$ measurements as indicators of carbon flow on marine and freshwater ecosystems. Contributions in Marine Science 27:13-47

Fry B, Joern A, Parker PL (1978) Grasshopper food web analysis: use of carbon isotope ratios to examine feeding relationships among terrestrial herbivores. Ecology 59:498-506

Fry B, Lutes R, Northam M, Parker PL, Ogden J (1982) A ${ }^{13} \mathrm{C} /{ }^{12} \mathrm{C}$ comparison of food webs in Caribbean seagrass meadows and coral reefs. Aquatic Botany 14:389-398

Fry B, Mumford P, Robblee M (1999) Stable isotope studies of pink shrimp (Farfantepenaeus duorarum Burkenroad) migrations on the southwestern Florida shelf. Bulletin of Marine Science 65:419-430

Gannes LZ, O’Brien DM, Martínez del Rio C (1997) Stable isotopes in animal ecology: Assumptions, caveats, and a call for more laboratory experiments. Ecology 78: $1271-1276$

Gannes LZ, Martínez del Rio C, Koch P (1998) Natural abundance variations in stable isotopes and their potential uses in animal physiological ecology. Comparative Biochemistry and Physiology 119A:725-737 
Gauldie RW (1996) Biological factors controlling the carbon isotope record in fish otoliths: principles and evidence. Comparative Biochemistry and Physiology B: Biochemistry and Molecular Biology 115:201-208

Gillanders BM (2005) Using elemental chemistry of fish otoliths to determine connectivity between estuarine and coastal habitats. Estuarine, Coastal and Shelf Science 64:47-57

Gillanders BM, Able KW, Brown JA, Eggleston DB, Sheridan PF (2003) Evidence of connectivity between juvenile and adult habitats for mobile marine fauna: an important component of nurseries. Marine Ecology Progress Series 247:281-295

Gottschalk G (1988) Bacterial Metabolism. Springer-Verlag, New York, NY

Graham BS, Grubbs D, Holland K, Popp BN (2007) A rapid ontogenetic shift in the diet of juvenile yellowfin tuna from Hawaii. Marine Biology 150:647-658.

Graham BS, Koch PL, Newsome SD, McMahon KW, Aurioles D (2010) Using isoscapes to trace the movements and foraging behavior of top predators in oceanic ecosystems. In (eds. West J, Bowen GJ, Dawson TE, Tu KP) Isoscapes: Understanding Movement, Pattern and Process on Earth Through Isotope Mapping, Springer, New York, NY, pp. 299-318

Grober-Dunsmore R, Frazer TK, Lindberg WJ, Beets J (2007) Reef fish habitat relationships in a Caribbean seascape: the importance of reef context. Coral Reefs 26:201-216

Grober-Dunsmore R, Frazer T, Beets JP, Lindeberg WL, Zwick P, Funicelli NA (2008) Influence of landscape structure on reef fish assemblages. Landscape Ecology 23:37-53

Grol MGG, Dorenbosch M, Kokkelmans EMG, Nagelkerken I (2008) Mangroves and seagrass beds do no enhance growth of early juveniles of coral reef fish. Marine Ecology Progress Series 366:137-146

Guenette S, Lauck T, Clark C (1998) Marine reserves: from Beverton and Holt to the present. Reviews in Fish Biology and Fisheries 8:251-272

Hansson S, Hobbie JE, Elmgren R, Larsson U, Fry B, Johansson S (1997) The stable nitrogen isotope ratio as a marker of food web interactions and fish migration. Ecology 78:2249-2257 
Hare PE, Fogel ML, Stafford TW, Mitchell AD, Hoering TC (1991) The isotopic composition of carbon and nitrogen in individual amino acids isolated from modern and fossil proteins. Journal of Archaeological Science 18:277-292

Hay WP (1905) The Life History of the Blue Crab, Callinectes sapidus. Washington, DC: US Bureau of Fisheries Appendix pp. 395-413

Hemminga MA, Mateo MA (1996) Stable carbon isotopes in seagrass: variability in ratios and use in ecological studies. Marine Ecology Progress Series 140:285-298

Herzka SZ (2005) Assessing connectivity of estuarine fishes based on stable isotope ratio analysis. Estuarine, Coastal and Shelf Science 64:58-69

Herzka SZ, Holt SA, Holt GJ (2002) Characterization of settlement patterns of red drum Sciaenops ocellatus larvae to estuarine nursery habitat: a stable isotope approach. Marine Ecology Progress Series 226:143-156

Hesslein RH, Capel MJ, Fox DE, Hallard KA (1991) Stable isotope of sulfur, carbon and nitrogen as indicators of trophic level and fish migration in the lower Mackenzie River Basin, Canada. Canadian Journal of Fisheries and Aquatic Sciences 48:2258-2265

Hildebrand E, Schroeder WC (1928) Fishes of Chesapeake Bay. Bulletin of the Bureau of Fisheries 43:1-388

Hobson KA (1999) Tracing origins and migration of wildlife using stable isotopes: a review. Oecologia 120:314-326

Hobson KA, Norris DR (2008) Animal migration: a context for using new techniques and approaches. Terrestrial Ecology 2:1-19

Hobson KA, Barnett-Johnson R, Cerling T (2010) Using isoscapes to track animal migration. In (eds. West J, Bowen GJ, Dawson TE, Tu KP) Isoscapes: Understanding Movement, Pattern and Process on Earth Through Isotope Mapping. Springer, New York, NY, pp. 273-298

Howland MR, Corr LT, Young SMM, Jones V, Jim S, van der Merwe NJ, Mitchell AD, Evershed RP (2003) Expression of the dietary isotope signal in the compoundspecific $\delta^{13} \mathrm{C}$ values of pig bone lipids and amino acids. International Journal of Osteoarchaeology 13:54-65

Hughes TP (1994) Catastrophes, phase shifts and large-scale degradation of a Caribbean coral reef. Science 265:1547-1551 
Huijbers CM, Mollee EM, Nagelkerken I (2008) Post-larval French grunts (Haemulon flavolineatum) distinguish between seagrass, mangrove and coral reef water: implications for recognition of potential nursery habitats. Journal of Experimental Marine Biology and Ecology 357:134-139

Huxham M, Kimani E, Newton J, Augley J (2007) Stable isotope records from otoliths as tracers of fish migration in a mangrove system. Journal of Fish Biology 70:15541567

Jackson JBC, Kirby MX, Berger WH, Bjorndal KA, Botsford LW, Bourque BJ, Bradbury RH, Cooke R, Erlandson J, Estes JA, Hughes TP, Kidwell S, Lange CB, Lenihan HS, Pandolfi JM, Peterson CH, Steneck RS, Tegner MJ, Warner RR (2001a) Historical overfishing and the recent collapse of coastal ecosystems. Science 293:629-637

Jackson EL, Rowden AA, Attrill MJ, Bossey SJ, Jones MB (2001b) The importance of seagrass beds as a nursery for fisheries species. Oceanography and Marine Biology: An Annual Review 39:269-303

Jim S, Jones V, Ambrose SH, Evershed RP (2006) Quantifying dietary macronutrient sources of carbon for bone collagen biosynthesis using natural abundance stable carbon isotope analysis. British Journal of Nutrition 95:1055-1062

Johnson BJ, Fogel ML, Miller GH (1993) Paleoecological reconstructions in southern Egypt based of the stable carbon and nitrogen isotopes in the organic fraction and stable carbon isotopes in individual amino acids of fossil ostrich eggshell. Chemical Geology 107:493-497

Johnson BJ, Fogel ML, Miller GH (1998) Stable isotopes in modern ostrich eggshell: a calibration for paleoenvironmental applications in semi-arid regions of southern Africa. Geochimica et Cosmochimica Acta 62:2451-2461

Jolivet A, Bardeau J-F, Fablet R, Paulet Y-M, de Pontual H (2008). Understanding otolith biomineralization processes: new insights into microscale spatial distributions of organic and mmineral fractions from Raman microspectrometry. Analytical and Bioanalytical Chemistry 392:551-50

Jones DL, Walter JF, Brooks EN, Serafy JE (2010) Connectivity through ontogeny: fish population linkages among mangrove and coral reef habitats. Marine Ecology Progress Series 401:245-258

Kalish JM $(1991){ }^{13} \mathrm{C}$ and ${ }^{18} \mathrm{O}$ isotopic disequilibria in fish otoliths: metabolic and kinetic effects. Marine Ecology Progress Series 75:191-203 
Karasov WH, Martínez del Rio C (2007) Physiological Ecology. Princeton University Press, Princeton, New Jersey

Keil RG, Fogel ML (2001) Reworking of amino acids in marine sediments: stable carbon isotopic composition of amino acids in sediments along the Washington coast. Limnology and Oceanography 46:14-23

Kennedy BP, Klaue A, Blum JD, Folt CL, Nislow KH (2002) Reconstructing the lives of fish using $\mathrm{Sr}$ isotopes in otoliths. Canadian Journal of Fisheries and Aquatic Sciences 59:925-929

Kieckbusch DK, Hock MS, Serafy JE, Anderson WT (2004) Trophic linkages among primary producers and consumers in fringing mangroves of subtropical lagoons. Bulletin of Marine Science 74:271-285

Kim K, Kayes TB, Amundson CH (1991) Purified diet development and re-evaluation of the dietary protein requirement of fingerling rainbow trout (Onchorynchus mykiss). Aquaculture 96:57-67

Laegdsgaard P, Johnson C (2001) Why do juvenile fish utilise mangrove habitats? Journal of Experimental Marine Biology and Ecology 257:229-253

Layman CA, Dahlgren CP, Kellison GT, Adams AJ, Gillanders BM, Kendall MS, Ley JA, Nagelkerken I, Serafy JE (2006) Marine nurseries and effective juvenile habitats. Marine Ecology Progress Series 318:307-308

Lecchini D, Poignonec D (2009) Spatial variability of ontogenetic patterns in habitat associations by coral reef fishes (Moorea lagoon - French Polynesia). Estuarine, Coastal and Shelf Science 82:553-556

Lugendo BR, Nagelkerken I, van der Velde G, Mgaya YD (2006) The importance of mangroves, mud and sand flats, and seagrass beds as feeding areas for juvenile fishes in Chwaka Bay, Zanzibar: gut content and stable isotope analyses. Journal of Fish Biology 69:1639-1661

Lugendo BR, Nagelkerken I, Kruitwagen G, van der Velde G, Mgaya YD (2007) Relative importance of mangroves as feeding habitats for fishes: a comparison between mangrove habitats with different settings. Bulletin of Marine Science 80:497-512

Luo J, Serafy JE, Sponaugle S, Teare PB, Kieckbusch D (2009) Movement of gray snapper Lutjanus griseus among subtropical seagrass, mangrove, and coral reef habitats. Marine Ecology Progress Series 380:255-269 
Manson FJ, Loneragan NR, Skilleter GA, Phinn SR (2005) An evaluation of the evidence for linkages between mangroves and fisheries: a synthesis of the literature and identification of research directions. Oceanography and Marine Biology: An Annual Review 43:483-513

Marguillier S, vanderVelde G, Dehairs F, Hemminga MA, Rajagopal S (1997) Trophic relationships in an interlinked mangrove-seagrass ecosystem as traced by $\delta^{13} \mathrm{C}$ and $\delta^{15} \mathrm{~N}$. Marine Ecology Progress Series 151:115-121

Mateo I (2009) Assessing essential fish habitat and connectivity of temperate and tropical fish populations using otolith microchemistry and stable isotopes. Ph.D. thesis, Department of Fisheries, Animal and Veterinary Sciences, University of Rhode Island, Kingston, RI

Mateo I, Durbin EG, Appeldoorn RS, Adams AJ, Juanes F, Kingsley R, Swart P, Durant D (2010) Role of mangroves as nurseries for French grunt Haemulon flavolinatum and schoolmaster Lutjanus apodus assessed by otolith elemental fingerprints. Marine Ecology Progress Series 402:197-212

McCarthy MD, Benner R, Lee C, Hedges JI, Fogel ML (2004) Amino acid carbon isotope fractionation patterns in oceanic dissolved matter: an unaltered photoautotrophic source for dissolved organic nitrogen in the ocean? Marine Chemistry 92:123-134

McCook LJ, Almany GR, Berumen ML, Day JC, Green AL, Jones GP, Leis JM, Planes S, Russ GR, Sale PF, Thorrold SR (2009) Management under uncertainty: guidelines for incorporating connectivity into the protection of coral reefs. Coral Reefs 28:353-366

McCutchan Jr. JH, Lewis Jr. WM, Kendall C, McGrath CC (2003) Variation in trophic shift for stable isotope ratios of carbon, nitrogen, and sulfur. Oikos 102:378-390

McFarlane GA (1990) Historical review of the development of external tags and marks. American Fisheries Society Symposium 7:9-29

McIvor CC, Odum WE (1988) Food, predation risk, and microhabitat selection in a marsh fish assemblage. Ecology 69:1341-1351

McMahon KW, Johnson BJ, Ambrose WG (2005) Diet and movement of the killifish, Fundulus heteroclitus, in a Maine salt marsh assessed using gut contents and stable isotope analyses. Estuaries 28:966-973 
McMahon KW, Fogel ML, Elsdon T, Thorrold SR (2010) Carbon isotope fractionation of amino acids in fish muscle reflects biosynthesis and isotopic routing from dietary protein. Journal of Animal Ecology 79:1132-1141

Meier-Augenstein W (1999) Applied gas chromatography coupled to isotope ratio mass spectrometry. Journal of Chromatography 842:351-371

Merritt DA, Brand WA, Hayes JM (1994) Isotope-ratio-monitoring gas chromatographymass spectrometry: methods for isotopic calibration. Organic Geochemistry 21:573-583

Michener RH, Kaufmann L (2007) Stable isotope ratios as tracers in marine aquatic food webs: An update. In (eds. Lajtha K, Michener RH) Stable Isotopes in Ecology and Environmental Science $2^{\text {nd }}$ edition, Blackwell Publishing, Malden, MA, pp. 238282

Millar RB (1990) A versatile computer program of mixed stock fishery composition estimation. Canadian Technical Report of Fisheries and Aquatic Sciences 1753:29-38

Moberg F, Folke C (1999) Ecological goods and services of coral reef ecosystems. Ecological Economics 29:215-233

Mora C, Sale PF (2002) Are populations of coral reef fish open or closed? Trends in Ecology and Evolution 17:422-428

Mora C, Andrefouet S, Costello MJ, Kranenburg C, Rollo A, Veron J, Gaston KJ, Myers RA (2006) Coral reefs and the global network of marine protected areas. Science 312:1750-1751

Morales-Nin B (1986a) Structure and composition of otoliths of Cape hake Merluccius capensis. South African Journal of Marine Science 4:3-10

Morales-Nin B (1986b) Chemical composition of the otoliths of the sea bass (Dicentrarchus labrax Linnaeus, 1758) (Pisces, Serranidae). Cybium 10:115-120

Mulcahy SA, Killingley JS, Phleger CF, Berger WH (1979) Isotopic composition of otoliths from a benthopelagic fish, Coryphaenoides acrolepis, Macrouridae: Gadiformes, Oceanology Acta 2:423-427

Mumby PJ, Harborne AR (2006) A seascape-level perspective of coral reef ecosystems. In: (eds. Cote IM, Reynolds JD) Coral reef conservation. Cambridge University Press, Cambridge, England, pp 78-114 
Mumby PJ, Hastings A (2008) The impact of ecosystem connectivity on coral reef resilience. Journal of Applied Ecology 45:854-862

Mumby, PJ, Edwards AJ, Arias-Gonzalez JE, Lindeman KC, Blackwell PG, Gall A, Gorczynska MI, Harborne AR, Pescod CL, Renken H, Wabnitz CCC, Llewellyn G (2004) Mangroves enhance the biomass of coral reef fish communities in the Caribbean. Nature 427:533-536

Murayama E (2000) Review of the growth regulation processes of otolith daily increment formation. Fisheries Research 46:53-67

Murayama E, Takagi Y, Ohira T, Davis JG, Greene MI, Nagasawa H (2002) Fish otolith contains a unique structural protein, otolin-1. European Journal of Biochemistry 269:688-696

Murayama E, Takagi Y, Nagasawa H (2004) Immunohistochemical localization of two otolith matrix proteins in the otolith and inner ear of the rainbow trout, Oncorhynchus mykiss: comparative aspects between the adult inner ear and embryonic otocysts. Histochemistry and Cell Biology 121:155-166

Nagelkerken I (2007) Are non-estuarine mangroves connected to coral reefs through fish migration? Bulletin of Marine Science 80:595-607

Nagelkerken I, van der Velde G (2002) Do non-estuarine mangroves harbour higher densities of juvenile fish than adjacent shallow-water and coral reef habitats in Curacao (Netherlands Antilles)? Marine Ecology Progress Series 245:191-204

Nagelkerken I, van der Velde G (2004) Relative importance of interlinked mangroves and seagrass beds as feeding habitats for juvenile reef fish on a Caribbean island. Marine Ecology Progress Series 274:153-159

Nagelkerken I, Dorenbosch M, Verberk W, de la Morinière EC, van der Velde G (2000) Importance of shallow-water biotopes of a Caribbean bay for juvenile coral reef fishes: patterns in biotope association, community structure and spatial distribution. Marine Ecology Progress Series 202:175-192

Nagelkerken I, Roberts CM, van der Velde G, Dorenbosch M, van Riel MC, de la Morinere EC, Nienhuis PH (2002) How important are mangroves and seagrass beds for coral-reef fish? The nursery hypothesis tested on an island scale. Marine Ecology Progress Series 244:299-305 
Nagelkerken I, Blaber SJM, Bouillon S, Green P, Haywood M, Kirton LG, Meyneck J-O, Pawlik J, Penrose HM, Sadekumar A, Somerfield PJ (2008a) The habitat function of mangroves for terrestrial and marine fauna: a review. Aquatic Botany 89:155185

Nagelkerken I, Bothwell J, Nemeth RS, Pitt JM, van der Velde G (2008b) Interlinkage between Caribbean coral reefs and seagrass beds through feeding migrations by grunts (Haemilidae) depends on habitat accessibility. Marine Ecology Progress Series 368:155-164

Nakamura Y, Horinouchi M, Shibuno T, Tanaka Y, Miyajima T, Koike I, Kurokura H, Sano M (2008) Evidence of ontogenetic migration from mangroves to coral reefs by black-tail snapper Lutjanus fulvus: stable isotope approach. Marine Ecology Progress Series 355:257-266

O’Brien DM, Fogel ML, Boggs CL (2002) Renewable and nonrenewable resources: amino acid turnover and allocation to reproduction in Lepidoptera. Proceedings of the National Academy of Science USA 99:4413-4418

O’Brien DM, Boggs CL, Fogel ML (2003) Pollen feeding in the butterfly Heliconius charitonia: isotopic evidence for essential amino acid transfer from pollen to eggs. Proceedings of the Royal Society of London B 270:2631-2636

O'Brien DM, Boggs CL, Fogel ML (2005) The amino acids used in reproduction by butterflies: a comparative study of dietary sources using compound-specific stable isotope analysis. Physiological and Biochemical Zoology 78:819-827

O’Donnell TH, Macko SA, Chou J, Wehmiller JF (2007) Stable carbon isotope composition of amino acids in modern and fossil Mercenaria. Organic Geochemistry 38:485-498

Olive PJW, Pinnegar JK, Polunin NVC, Richards G, Welch R (2003) Isotope trophic-step fractionation: a dynamic equilibrium model. Journal of Animal Ecology 72:608617

Orth RJ, Carruthers TJB, Dennison WC, Duarte CM, Fourqurean JW, Heck Jr KL, Huges AR, Kendrick GA, Kenworthy WJ, Olyarnik S, Short FT, Waycott M, Williams SL (2006) A global crisis for seagrass ecosystems. BioScience 56:987-996

Ostermann DR, Curry WB (2000) Calibration of stable isotope data: an enriched $\delta^{18} \mathrm{O}$ standard used for source gas mixing detection and correction. Paleoceanography 15:353-360 
Pandolfi JM, Bradbury RH, Sala E, Hughes TP, Bjorndal KA, Cooke RG, McArdle D, McClenachan L, Newman MJH, Paredes G, Warner RR, Jackson JBC (2003) Global trajectories of the long-term decline of coral reef ecosystems. Science 301:955-958

Parkington J (1991) Approaches to dietary reconstruction in the Western Cape: are you what you have eaten? Journal of Archaeological Science 18:331-342

Parsons DM, Babcock RD, Hankin RKS, Willis TJ, Aitken JP, O’Dor RK, Jackson GD (2003) Snapper Pagrus auratus (Sparidae) home range dynamics: Acoustic tagging studies in a marine reserve. Marine Ecology Progress Series 262:253-265

Pauly D, Christensen V, Guenette S, Pitcher TJ, Sumaila UR, Walters CJ, Watson R, Zeller D (2002) Towards sustainability in world fisheries. Nature 418:689-695

Payan P, de Pontual H, Boeuf G, Mayer-Gosan N (2004) Endolymph chemistry and otolith growth in fish. Comptes Rendus Palevol 3:535-547

Peterson BJ, Fry B (1987) Stable isotopes in ecosystem studies. Annual Review of Ecology and Systematics 18:293-320

Popp BN, Graham BS, Olson RJ, Hannides CCS, Lott MJ, López-Ibarra GA, GalvánMagaña F, Fry B (2007) Insight into the trophic ecology of yellowfin tuna, Thunnus albacares, from compound-specific nitrogen isotope analysis of proteinaceous amino acids. In (eds. Dawson TD, Siegwolf RTW) Stable Isotopes as Indicators of Ecological Change), Elsevier/Academic Press, Amsterdam, Netherlands, pp. 173-190

Post D. M. (2002) Using stable isotopes to estimate trophic position: models, methods, and assumptions. Ecology 83:703-718

Post DM, Layman CA, Arrington DA, Takimoto G, Quattrochi J, Montaña CG (2007) Getting to the fat of the matter: models, methods and assumptions for dealing with lipids in stable isotope analysis. Oecologia 152:179-189

Rawn DJ (1983) Biochemistry. Harper and Row, New York, NY

Reeds P (2000) Dispensable and indispensable amino acids for humans. Journal of Nutrition 130:1835S-1840S

Rimmer DW, Wiebe WJ (1987) Fermentative microbial digestion in herbivorous fish. Journal of Fish Biology 31:229-236 
Roberts CM, Bohnsack JA, Gell F, Hawkins JP, Goodridge R (2001) Effects of marine reserves on adjacent fisheries. Science 294:1920-1923

Rocha LA, Bass AL, Robertson R, Bowen BW (2002) Adult habitat preferences, larval dispersal, and the comparative phylogeography of three Atlantic surgeonfishes (Teleostei: Acanthuridae). Molecular Ecology 11:243-252

Rodelli MR, Gearing JN, Gearing PJ, Marshall N, Sasekumar A (1984) Stable isotope ratio as a tracer of mangrove carbon in Malaysian ecosystems. Oecologia 61:326333

Rooker JR, Dennis GD (1991) Diel, lunar and seasonal changes in a mangrove fish assemblage off southwestern Puerto Rico. Bulletin of Marine Science 49:684-698

Rooker JR, Secor DH, de Metrio G, Rodriquez-Martin E, Fenech Farrugia A (2006) Evaluation of population structure and mixing rates of Atlantic bluefin tuna from chemical signatures in otoliths. Collective Volume of Scientific Papers ICCAT 59:813-818

Rubenstein DR, Hobson KA (2004) From birds to butterflies: animal movement patterns and stable isotopes. Trends in Ecology and Evolution 19:256-263

Sale PF (2006) Coral reef fishes: dynamics and diversity in a complex ecosystem. Academic Press, Burlington, MA

Sasagawa T, Mugiya Y (1996) Biochemical properties of water-soluble otolith proteins and the immunobiochemical detection of the proteins in serum and various tissues in tilapia Oreochromis niloticus. Fisheries Science 62:970-976

Schwarcz HP (1991) Some theoretical aspects of isotope paleodiet studies. Journal of Archaeological Science 18:261-275

Schwarcz HP, Schoeninger MJ (1991) Stable isotope analyses in human nutritional ecology. Yearbook Physical Anthropology 34:283-321

Schwarcz HP, Gao Y, Campana S, Drowne D, Knyf M, Brand U (1998) Stable carbon isotope variations in otoliths of Atlantic cod (Gadus mohua). Canadian Journal of Fisheries and Aquatic Sciences 55:1798-1806

Seber GAF (1982) Estimation of animal abundance and related parameters. MacMillan Publishing Co, New York, NY 
Secor DH, Henderson-Arzapalo A, Piccoli PM (1995) Can otolith microchemistry chart patterns of migration and habitat utilization in anadromous fishes? Journal of Experimental Marine Biology and Ecology 192:15-33

Sessions AL (2006) Isotope-ratio detection for gas chromatography. Journal of Separation Science 29:1946-1961

Sheaves M, Molony B (2000) Short-circuit in the mangrove food chain. Marine Ecology Progress Series 199:97-109

Sheaves M, Baker R, Johnston R (2006) Marine nurseries and effective juvenile habitats: an alternative view. Marine Ecology Progress Series 318:303-306

Sheridan P, Hays C (2003) Are mangroves nursery habitat for transient fishes and decapods? Wetlands 23:449-458

Siegenthaler U, Oeschger $\mathrm{H}(1980)$ Correlation of ${ }^{18} \mathrm{O}$ in precipitation with temperature and altitude. Nature 285:314-317

Silfer JA, Engel MH, Macko SA, Jumeau EJ (1991) Stable carbon isotope analysis of amino-acid enantiomers by conventional isotope ratio mass spectrometry and combined gas-chromatography isotope ratio mass-spectrometry. Analytical Chemistry 63:370-374

Silfer JA, Qian Y, Macko SA, Engel MH (1994) Stable carbon isotope compositions of individual amino acid enantiomers in mollusk shell by GC/C/IRMS. Organic Geochemistry 21:603-609

Skomal GB, Zeeman SI, Chisholm JH, Summers EL, Walsh HJ, McMahon KW, Thorrold SR (2009) Transequatorial migrations by basking sharks in the western Atlanic Ocean. Current Biology 19:1019-1022

Smallwood BJ, Woller MJ, Myrna EJ, Fogel ML (2003) Isotopic and molecular distributions of biochemicals from fresh and buried Rhizophora mangle leaves. Geochemical Transactions 4:38-46

Solomon CT, Weber PK, Cech JJ, Ingram BL, Conrad ME, Machavaram MV, Pogodina AR, Franklin RL (2006) Experimental determination of the sources of otolith carbon and associated isotopic fractionation. Canadian Journal of Fisheries and Aquatic Sciences 63:79-89

Starr RM, Sala E, Ballesteros E, Zabala M (2007) Spatial dynamics of the Nassau grouper Epinephelus striatus in a Caribbean atoll. Marine Ecology Progress Series 343:239-249 
Stephenson PC, Edmonds JS, Moran MJ, Caputi N (2001) Analysis of stable isotope ratios to investigate stock structure of red emperor and Rankin cod in northern Western Australia. Journal of Fish Biology 58:126-144

Stewart MK, Taylor CB (1981) Environmental isotopes in New Zealand hydrology 1. Introduction: the role of ${ }^{18} \mathrm{O}$, deuterium, and tritium in hydrology. New Zealand Journal of Science 24:295-311

Stobutzki IC, Bellwood DR (1997) Sustained swimming abilities of the late pelagic stages of coral reef fishes. Marine Ecology Progress Series 149:35-41

Stott AW, Evershed RP, Jim S, Jones V, Rogers JM, Tuross N, Ambrose SH (1999) Cholesterol as a new source of palaeodietary information: experimental approaches and archaeological applications. Journal of Archaeological Science 26:705-716

Sumaila UR, Marsden AD, Watson R, Pauly D (2007) A global ex-vessel fish price database: construction and applications. Journal of Bioeconomics 9:39-51

Taylor PD, Fahrig L, Henin K, Merriam G (1993) Connectivity is a vital element of landscape structure. Oikos 68:571-573

Teece MA, Fogel ML (2007) Stable carbon isotope biogeochemistry of monosaccharides in aquatic organisms and terrestrial plants. Organic Geochemistry 38:458-473

Tieszen LL, Boutton TW, Tesdahl KG, Slade NA (1983) Fractionation and turnover of stable carbon isotopes in animal tissues: implications for $\delta^{13} \mathrm{C}$ analysis of diet. Oecologia 57:32-37

Thorrold SR, Campana SE, Jones CM, Swart PK (1997) Factors determining $\delta^{13} \mathrm{C}$ and $\delta^{18} \mathrm{O}$ fractionation in aragonitic otoliths of marine fish. Geochimica Et Cosmochimica Acta 61:2909-2919

Thorrold SR, Latkoczy C, Swart PK, Jones CM (2001) Natal homing in a marine fish metapopulation. Science 291:297-299

Thorrold SR, Jones GP, Hellberg ME, Burton RS, Swearer SE, Neigel JE, Morgan SG, Warner RR (2002) Quantifying larval retention and connectivity in marine populations with artificial and natural markers. Bulletin of Marine Science 70:291-308 
Tohse H, Mugiya Y (2004) Sources of carbonate in fish otoliths: Incorporation from bicarbonate and glucose. In (eds. Kobayashi I, Ozawa H) Biomineralization: Formation, diversity, evolution and application. Tokai University Press, Tokyo, Japan, pp. 190-193

Turgeon K, Robillard A, Gregoire J, Duclos V, Kramer DL (2010) Functional connectivity from a reef fish perspective: behavioral tactics for moving in a fragmented landscape. Ecology 91:3332-3342

Uhle ME, Macko SA, Spero SA, Engel MH, Lea DW (1997) Sources of carbon and nitrogen in modern plankton foraminifera: the role of algal symbionts as determined by bulk and compound specific stable isotope analysis. Organic Geochemistry 27:103-113

Unsworth RKF, Garrard SL, Salinas de Leon P, Cullen LC, Smith DJ, Sloman KA, Bell JJ (2009) Structuring of Indo-Pacific fish assemblages along the mangroveseagrass continuum. Aquatic Biology 5:85-95

Valiela I, Bowen JL, York JK (2001) Mangrove forests: one of the world's threatened major tropical environments. Bioscience 51:807-815

Vander Zanden MJ, Rasmussen JB (1999) Primary consumer $\delta^{13} \mathrm{C}$ and $\delta^{15} \mathrm{~N}$ and the trophic position of aquatic consumers. Ecology 80:1395-1404

Vander Zanden MJ, Rasmussen JB (2001) Trophic fractionation: implications for aquatic food web studies. Limnology and Oceanography 46:2061-2066

Verweij MC, Nagelkerken I, de Graaff D, Peeters M, Bakker EJ, van der Velde G (2006) Structure, food and shade attract juvenile coral reef fish to mangrove and seagrass habitats: a field experiment. Marine Ecology-Progress Series 306:257-268

Verweij MC, Nagelkerken I, Hans I, Ruseler SM, Mason PDR (2008) Seagrass nurseries contribute to coral reef fish populations. Limnology and Oceanography 53:15401547

Weidman CR, Millner R (2000) High-resolution stable isotope records from North Atlantic cod. Fisheries Research 46:327-342

Werner EE, Gilliam JF (1984) The ontogenetic niche and species interactions in sizestructured populations. Annual Reviews in Ecology and Systematics 15:393-425

West J, Bowen GJ, Dawson TE, Tu KP (2010) Isoscapes: Understanding Movement, Pattern and Process on Earth Through Isotope Mapping. Springer-Verlag, New York, NY 
White JW, Ruttenberg BI (2007) Discriminant function analysis in marine ecology: oversights and their solutions. Marine Ecology Progress Series 329:301-305

Wilson RP, Cowey CB (1985) Amino acid composition of whole body tissue of rainbow trout and Atlantic salmon. Aquaculture 48:373-376

Zapata FA, Herron PA (2002) Pelagic larval duration and geographic distribution of tropical eastern Pacific snappers (Pisces: Lutjanidae). Marine Ecology Progress Series 230:295-300

Ziegler S, Fogel ML (2003) Seasonal and diel relationships between the isotopic compositions of dissolved and particulate organic matter in freshwater ecosystems. Biogeochemistry 64:25-52

Zieman JC, Macko SA, Mills AL (1984) Role of seagrasses and mangroves in estuarine food webs: temporal and spatial changes in stable isotope composition and amino acid content during decomposition. Bulletin of Marine Science 35:380-392 


\section{APPENDIX I}

Table A1.1. Bulk tissue $\delta^{15} \mathrm{~N}$ and $\delta^{13} \mathrm{C}$ values of diet from four dietary treatments (VegiPro, Bio-Vita, squid, and clam) (Chapter 2).

\begin{tabular}{lrc}
\hline & $\delta^{15} \mathrm{~N}$ & $\delta^{13} \mathrm{C}$ \\
\hline \hline Vegi-Pro R1 & 1.15 & -22.82 \\
Vegi-Pro R2 & 0.94 & -23.13 \\
Vegi-Pro R3 & 1.00 & -23.34 \\
Vegi-Pro R4 & 0.54 & -23.67 \\
Vegi-Pro R5 & 1.23 & -23.60 \\
Bio-Vita R1 & 11.75 & -20.10 \\
Bio-Vita R2 & 12.31 & -20.01 \\
Bio-Vita R3 & 11.40 & -20.36 \\
Bio-Vita R4 & 11.78 & -20.19 \\
Bio-Vita R5 & 11.66 & -20.14 \\
Squid R1 & 13.28 & -18.49 \\
Squid R2 & 14.06 & -18.50 \\
Squid R3 & 13.69 & -18.76 \\
Squid R4 & 13.46 & -18.55 \\
Squid R5 & 13.76 & -18.47 \\
Clam R1 & 11.51 & -17.82 \\
Clam R2 & 11.36 & -17.93 \\
Clam R3 & 11.46 & -17.83 \\
Clam R4 & 11.09 & -18.05 \\
Clam R5 & 11.67 & -17.82 \\
\hline
\end{tabular}



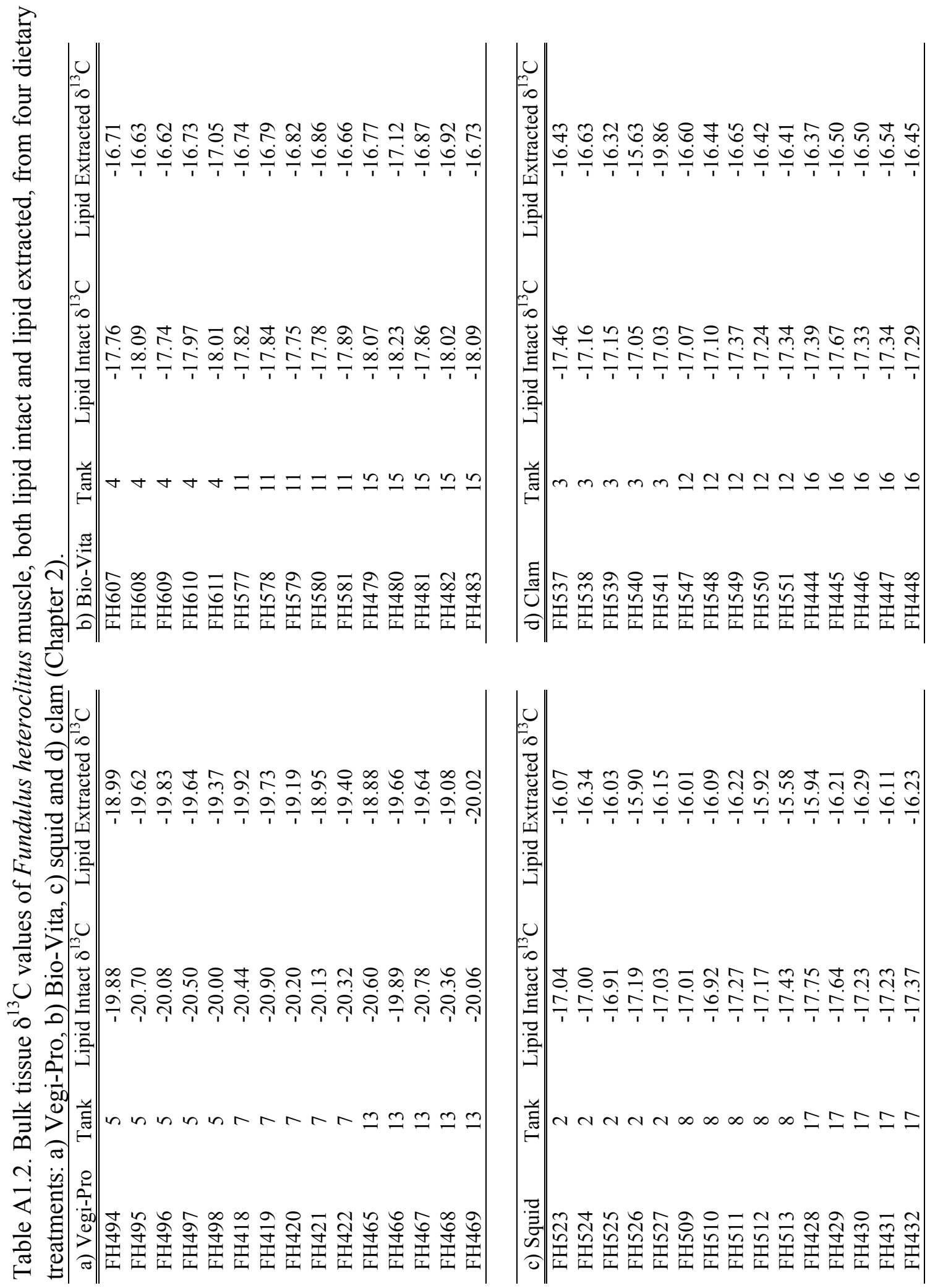


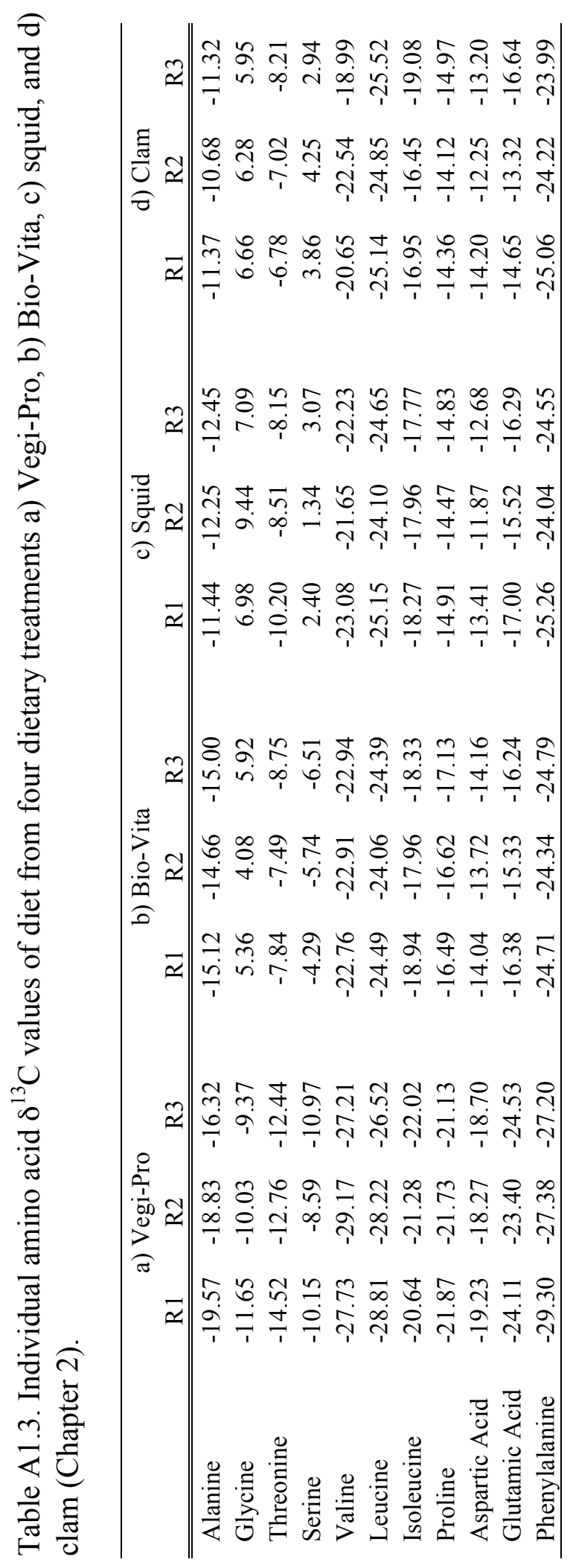




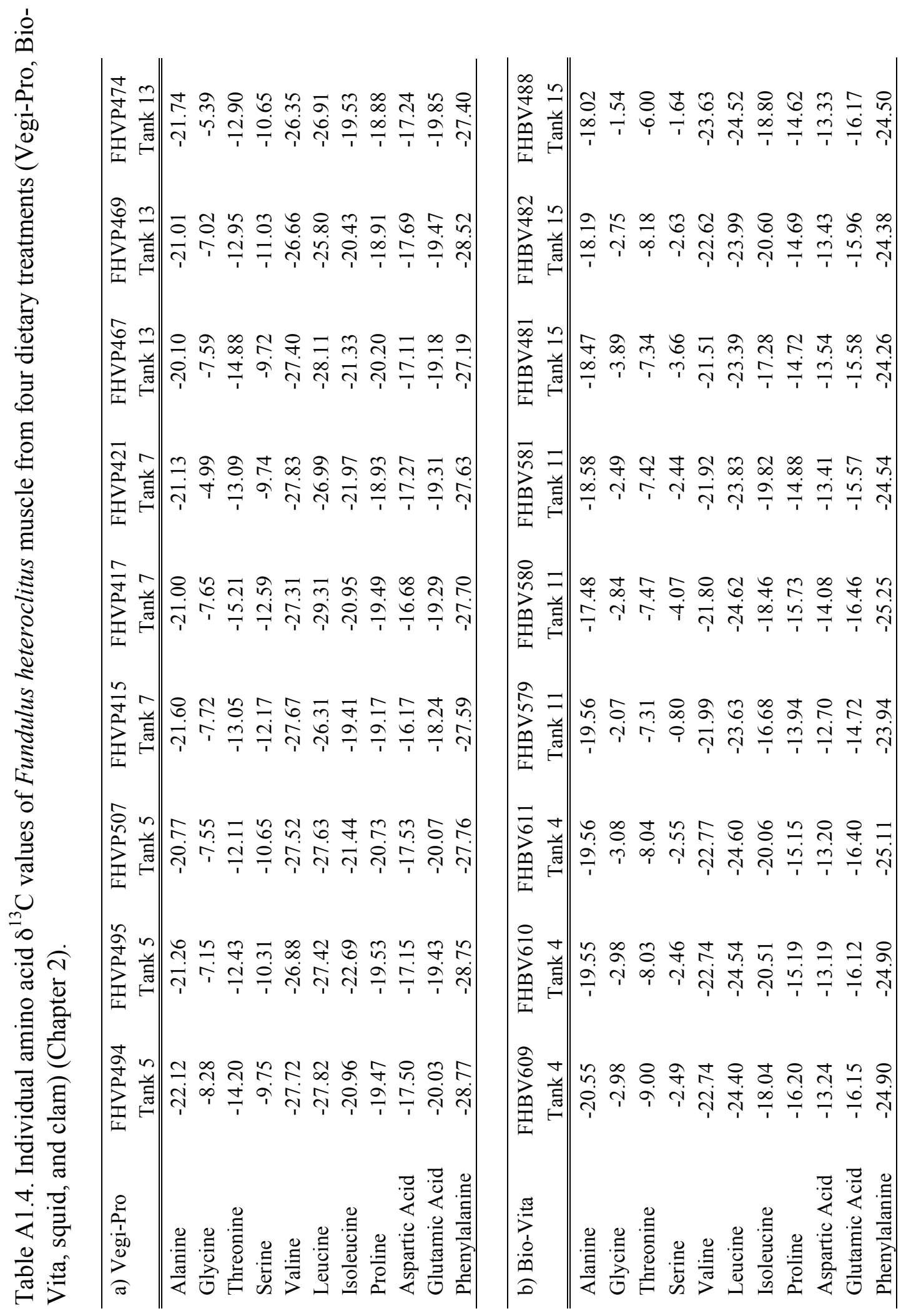



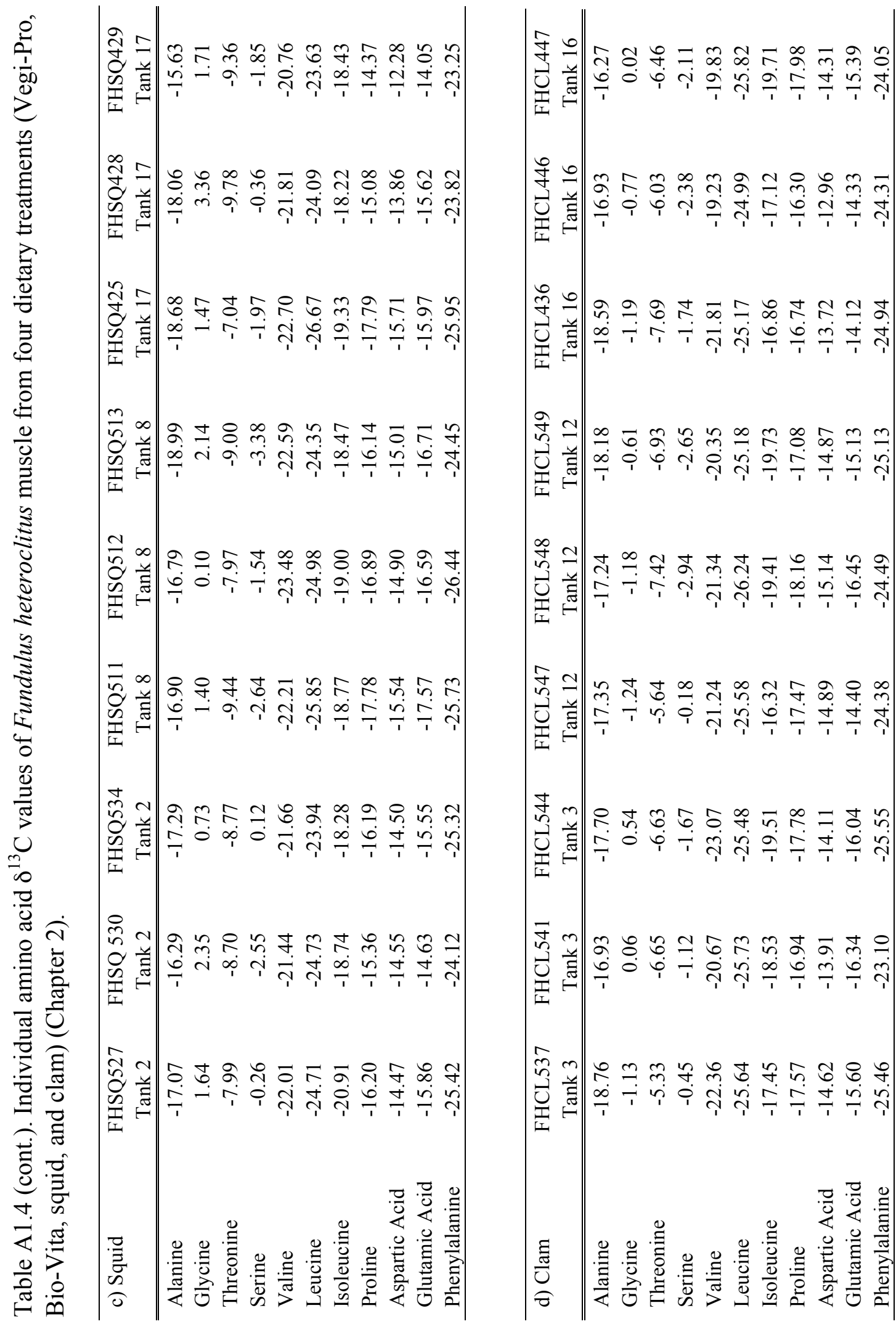


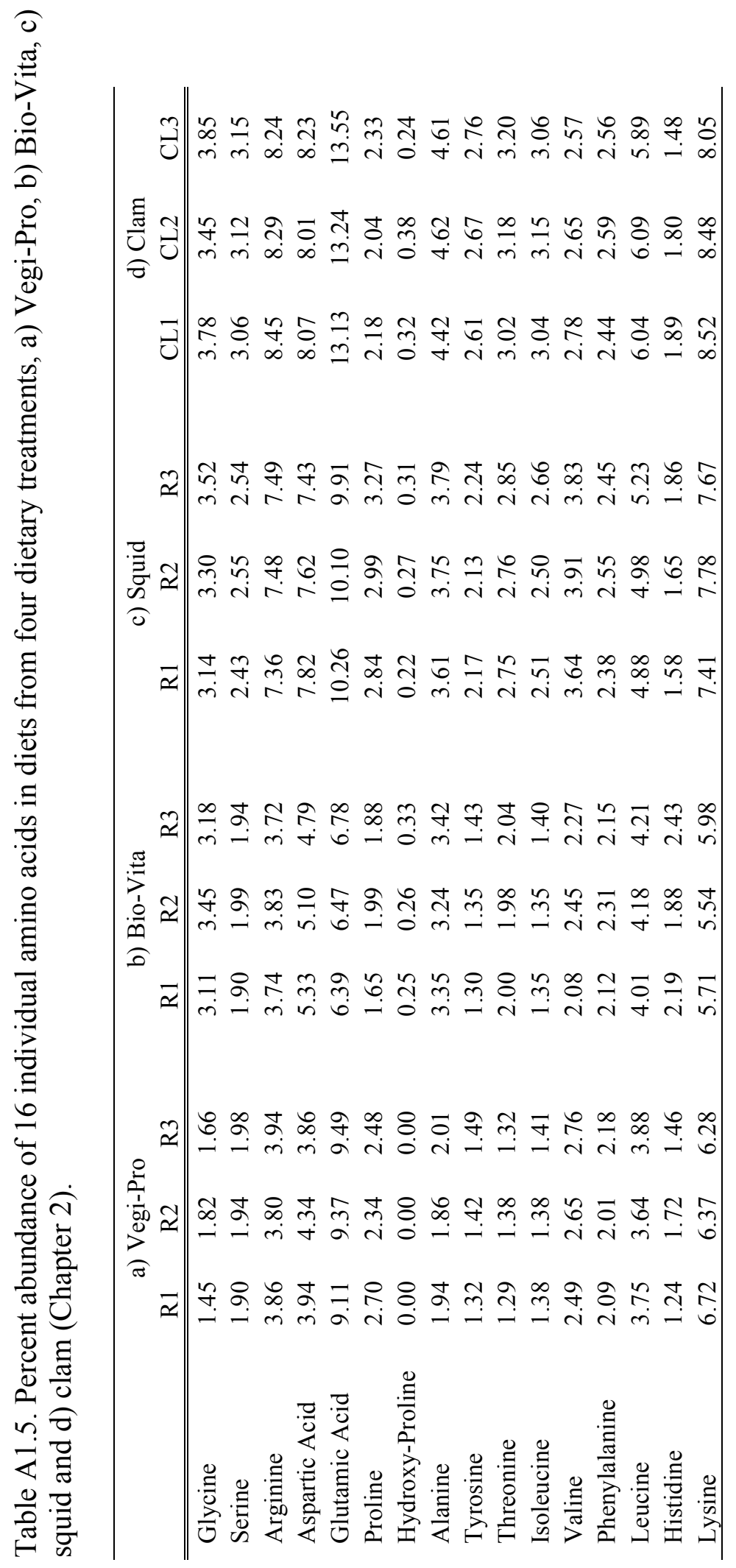




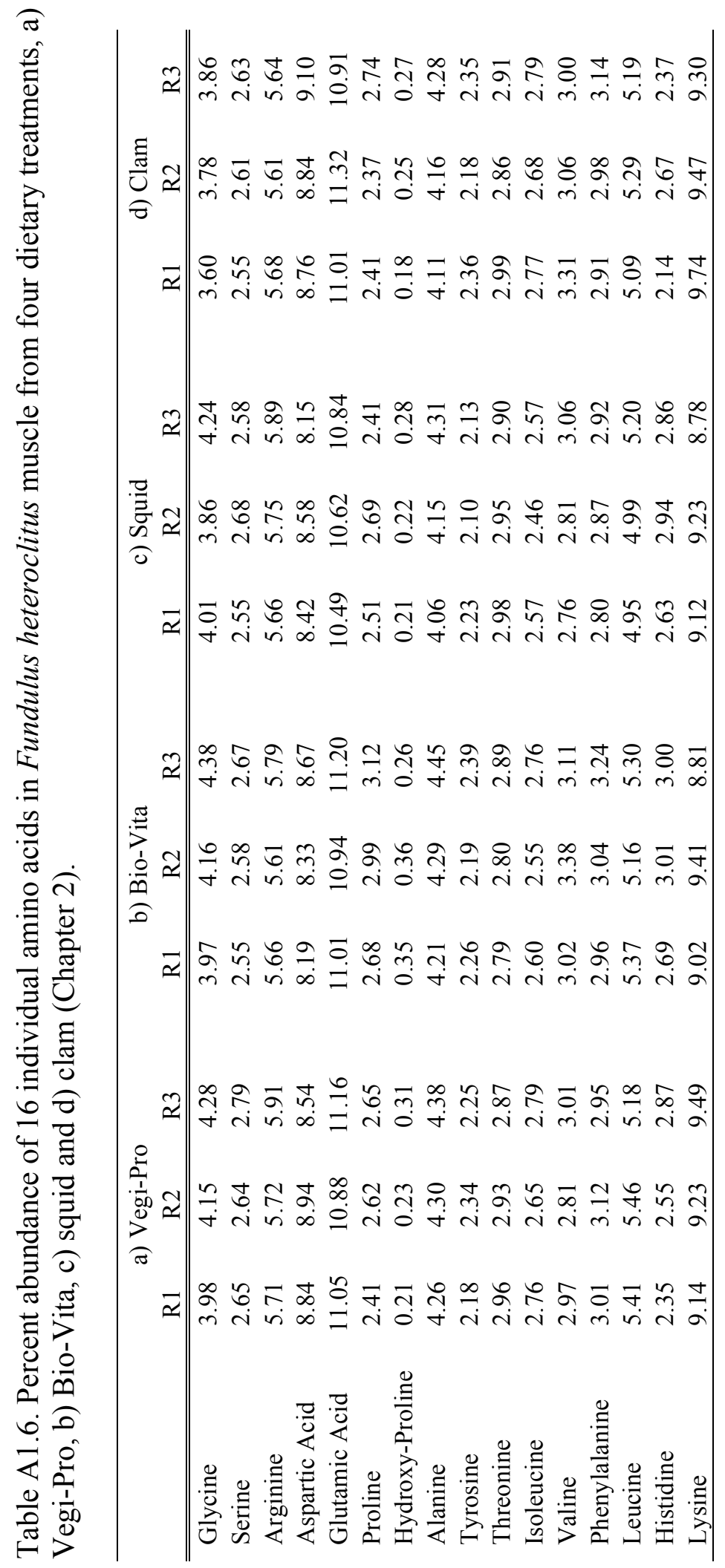




\section{APPENDIX II}

Table A2.1. Bulk muscle and otolith $\delta^{13} \mathrm{C}$ values of Lutjanus ehrenbergii collected from a) Al Lith Bay, b) Coast Guard Reef and c) Ron's Reef near Al Lith, Saudi Arabia in the Red Sea (Chapter 3). Whole otoliths were analyzed for juvenile L. ehrenbergii from Al Lith Bay, and the outer edge of otoliths were analyzed for adult L. ehrenbergii from Coast Guard Reef and Ron's Reef.

\begin{tabular}{ccclcc}
\hline $\begin{array}{c}\text { a) A1 Lith } \\
\text { Bay }\end{array}$ & $\begin{array}{c}\text { Bulk muscle } \\
\delta^{13} \mathrm{C}\end{array}$ & $\begin{array}{c}\text { Bulk otolith } \\
\delta^{13} \mathrm{C}\end{array}$ & $\begin{array}{c}\text { b) Coast } \\
\text { Guard Reef }\end{array}$ & $\begin{array}{c}\text { Bulk muscle } \\
\delta^{13} \mathrm{C}\end{array}$ & $\begin{array}{c}\text { Bulk otolith } \\
\delta^{13} \mathrm{C}\end{array}$ \\
\hline \hline L.ehr48 & -11.61 & -1.54 & L.ehr73 & -13.24 & -1.81 \\
L.ehr49 & -10.78 & -0.38 & L.ehr74 & -13.80 & -1.22 \\
L.ehr50 & -10.45 & -1.16 & L.ehr75 & -12.11 & -1.00 \\
L.ehr51 & -9.90 & -0.58 & L.ehr169 & -14.49 & -1.98 \\
L.ehr53 & -11.87 & -0.76 & L.ehr170 & -13.58 & -1.94 \\
L.ehr54 & -11.69 & -0.84 & L.ehr171 & -15.59 & -2.26 \\
L.ehr55 & -10.57 & -0.07 & L.ehr172 & -15.18 & -3.08 \\
L.ehr56 & -10.14 & -0.87 & L.ehr173 & -14.73 & -1.80 \\
L.ehr57 & -9.66 & -0.89 & L.ehr174 & -13.83 & -1.82 \\
L.ehr58 & -8.23 & -0.02 & L.ehr175 & -14.12 & -2.82 \\
L.ehr59 & -10.40 & -0.22 & L.ehr176 & -14.44 & -3.00 \\
L.ehr60 & -9.49 & -0.11 & L.ehr177 & -14.30 & -2.15 \\
L.ehr100 & -10.07 & -1.19 & L.ehr178 & -13.44 & -2.40 \\
L.ehr101 & -8.97 & -0.55 & L.ehr199 & -14.07 & -3.48 \\
L.ehr150 & -8.83 & -0.04 & L.ehr200 & -12.71 & -1.42 \\
L.ehr151 & -10.21 & -1.27 & L.ehr201 & -13.49 & -1.81 \\
L.ehr152 & -11.21 & -1.30 & L.ehr202 & -13.15 & -2.24 \\
L.ehr153 & -10.84 & -0.02 & L.ehr203 & -15.29 & -2.32 \\
L.ehr154 & -11.21 & -0.85 & L.ehr204 & -14.38 & -2.22 \\
L.ehr429 & -10.81 & -1.03 & L.ehr205 & -11.99 & -1.41 \\
L.ehr430 & -10.31 & -0.68 & L.ehr206 & -15.87 & -2.86 \\
L.ehr431 & -9.78 & 0.29 & L.ehr207 & -15.47 & -2.59 \\
L.ehr432 & -9.57 & -0.24 & L.ehr208 & -15.07 & -3.60 \\
L.ehr433 & -9.38 & -0.61 & & & \\
L.ehr434 & -9.97 & -0.48 & & & \\
L.ehr435 & -9.72 & 0.09 & & & \\
\hline
\end{tabular}


Table A2.1 (cont.). Bulk muscle and otolith $\delta^{13} \mathrm{C}$ values of Lutjanus ehrenbergii collected from a) Al Lith Bay, b) Coast Guard Reef and c) Ron's Reef near Al Lith, Saudi Arabia in the Red Sea (Chapter 3). Whole otoliths were analyzed for juvenile L. ehrenbergii from Al Lith Bay, and the outer edge of otoliths were analyzed for adult $L$. ehrenbergii from Coast Guard Reef and Ron's Reef.

\begin{tabular}{lcc}
\hline c) Ron's & $\begin{array}{c}\text { Bulk muscle } \\
\text { Reef }\end{array}$ & $\begin{array}{c}\text { Bulk otolith } \\
\delta^{13} \mathrm{C}\end{array}$ \\
\hline \hline L.ehr189 & -15.99 & -3.41 \\
L.ehr190 & -15.60 & -4.17 \\
L.ehr191 & -18.63 & -3.18 \\
L.ehr192 & -17.94 & -2.87 \\
L.ehr193 & -17.30 & -4.43 \\
L.ehr194 & -17.58 & -4.04 \\
L.ehr195 & -15.97 & -2.20 \\
L.ehr196 & -17.43 & -4.31 \\
L.ehr197 & -15.74 & -4.61 \\
L.ehr198 & -16.92 & -5.02 \\
L.ehr416 & -19.00 & -4.95 \\
L.ehr417 & -18.54 & -4.49 \\
L.ehr418 & -18.22 & -3.46 \\
L.ehr419 & -17.21 & -2.85 \\
L.ehr420 & -18.77 & -4.08 \\
L.ehr421 & -18.39 & -3.70 \\
L.ehr422 & -18.02 & -4.20 \\
L.ehr423 & -17.74 & -2.58 \\
L.ehr424 & -16.98 & -2.45 \\
L.ehr425 & -16.79 & -3.59 \\
L.ehr426 & -16.65 & -2.90 \\
L.ehr427 & -16.28 & -3.62 \\
L.ehr428 & -16.42 & -2.51 \\
L.ehr429 & -16.73 & -2.23 \\
\hline & &
\end{tabular}




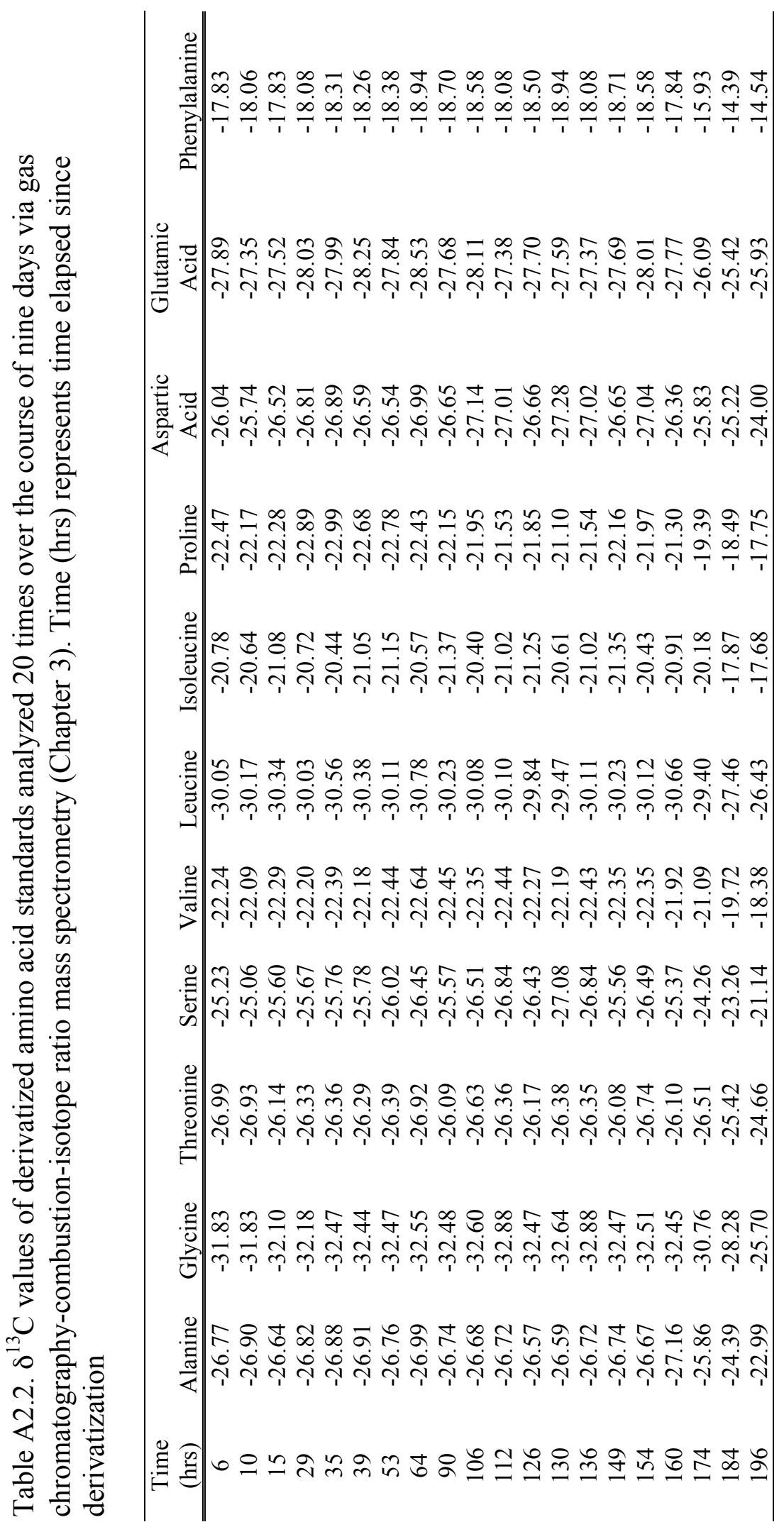


Table A2.3. Individual amino acid $\delta^{13} \mathrm{C}$ values of Lutjanus ehrenbergii muscle from a) $\mathrm{Al}$ Lith Bay, b) Coast Guard Reef and c) Ron's Reef (Chapter 3).

\begin{tabular}{|c|c|c|c|c|c|}
\hline a) Al Lith Bay & L.ehr48 & L.ehr49 & L.ehr50 & L.ehr51 & L.ehr150 \\
\hline Alanine & -7.22 & -6.12 & -7.24 & -7.90 & $\begin{array}{l}-6.81 \\
-6.1\end{array}$ \\
\hline Glycine & -0.39 & 1.15 & -0.31 & -1.38 & 0.78 \\
\hline Threonine & -2.10 & -3.11 & -4.82 & -4.00 & -2.64 \\
\hline Serine & -2.61 & -1.03 & -2.43 & -3.56 & -1.70 \\
\hline Valine & -13.51 & -12.49 & -13.40 & -13.56 & -13.26 \\
\hline Leucine & -16.75 & -17.88 & -16.65 & -15.00 & -17.64 \\
\hline Isoleucine & -13.20 & -11.04 & -11.36 & -10.02 & -10.88 \\
\hline Proline & -5.92 & -4.58 & -5.76 & -6.87 & -5.89 \\
\hline Aspartic Acid & -8.94 & -7.73 & -8.77 & -9.77 & -8.55 \\
\hline Glutamic Acid & -7.85 & -6.12 & -7.43 & -8.84 & -7.89 \\
\hline Phenylalanine & -17.81 & -17.96 & -18.28 & -19.67 & -18.37 \\
\hline b) Coast Guard Reef & L.ehr171 & L.ehr172 & L.ehr173 & L.ehr174 & L.ehr178 \\
\hline Alanine & -12.43 & -13.18 & -12.74 & -12.60 & -12.05 \\
\hline Glycine & -3.32 & -4.15 & -4.04 & -3.86 & -4.14 \\
\hline Threonine & -5.30 & -6.90 & -6.76 & -5.04 & -6.16 \\
\hline Serine & -2.31 & -2.93 & -1.24 & -2.40 & -2.66 \\
\hline Valine & -13.95 & -14.26 & -14.73 & -14.33 & -14.05 \\
\hline Leucine & -22.47 & -21.02 & -22.71 & -22.49 & -23.01 \\
\hline Isoleucine & -16.12 & -17.56 & -18.20 & -16.04 & -16.56 \\
\hline Proline & -11.00 & -9.36 & -9.85 & -10.29 & -10.44 \\
\hline Aspartic Acid & -10.33 & -9.96 & -9.26 & -11.11 & -10.46 \\
\hline Glutamic Acid & -11.75 & -10.47 & -10.10 & -11.69 & -11.35 \\
\hline Phenylalanine & -19.95 & -19.70 & -20.40 & -20.38 & -20.63 \\
\hline c) Ron's Reef & L.ehr191 & L.ehr192 & L.ehr193 & L.ehr194 & L.ehr196 \\
\hline Alanine & $\begin{array}{c}-10.77 \\
\end{array}$ & -11.89 & -10.80 & -8.45 & -10.30 \\
\hline Glycine & -8.44 & -6.72 & -7.48 & -4.27 & -5.79 \\
\hline Threonine & -9.69 & -10.49 & -9.19 & -8.26 & -7.84 \\
\hline Serine & -4.89 & -3.90 & -4.27 & -1.09 & -1.87 \\
\hline Valine & -16.31 & -16.58 & -15.95 & -14.87 & -15.45 \\
\hline Leucine & -24.03 & -23.08 & -23.73 & -23.26 & -22.36 \\
\hline Isoleucine & -17.45 & -17.55 & -16.46 & -15.69 & -15.04 \\
\hline Proline & -9.38 & -11.41 & -9.47 & -8.13 & -8.11 \\
\hline Aspartic Acid & -9.09 & -10.54 & -9.29 & -6.39 & -7.30 \\
\hline Glutamic Acid & -11.84 & -12.36 & -11.47 & -9.34 & -11.05 \\
\hline Phenylalanine & -21.59 & -22.17 & -20.95 & -20.80 & -20.76 \\
\hline
\end{tabular}


Table A2.4. Individual amino acid $\delta^{13} \mathrm{C}$ values of Lutjanus ehrenbergii otoliths from a) Al Lith Bay, b) Coast Guard Reef and c) Ron's Reef (Chapter 3). Whole otoliths were analyzed for juvenile L. ehrenbergii from Al Lith Bay, and the outer edge of otoliths were analyzed for adult $L$. ehrenbergii from Coast Guard Reef and Ron's Reef.

\begin{tabular}{|c|c|c|c|c|c|}
\hline a) Al Lith Bay & L.ehr48 & L.ehr49 & L.ehr50 & L.ehr51 & L.ehr150 \\
\hline Alanine & -5.73 & -5.56 & -7.55 & -5.41 & -5.65 \\
\hline Glycine & 2.03 & 4.73 & 1.40 & 0.61 & 0.11 \\
\hline Threonine & -3.65 & -6.19 & -5.79 & -5.68 & -1.88 \\
\hline Serine & -4.23 & -1.30 & -4.51 & -6.28 & -0.33 \\
\hline Valine & -12.57 & -13.92 & -16.10 & -12.81 & -12.86 \\
\hline Leucine & -18.17 & -16.34 & -16.23 & -17.46 & -17.56 \\
\hline Isoleucine & -9.65 & -11.82 & -10.02 & -10.36 & -9.92 \\
\hline Proline & -5.91 & -5.05 & -3.30 & -5.30 & -5.98 \\
\hline Aspartic Acid & -5.44 & -7.08 & -7.05 & -9.69 & -9.57 \\
\hline Glutamic Acid & -8.47 & -9.75 & -8.73 & -11.61 & -8.51 \\
\hline Phenylalanine & -19.08 & -17.71 & -18.56 & -19.63 & -18.91 \\
\hline b) Coast Guard Reef & L.ehr171 & L.ehr172 & L.ehr173 & L.ehr174 & L.ehr178 \\
\hline Alanine & -11.55 & -12.02 & -12.20 & -12.27 & -11.83 \\
\hline Glycine & -2.46 & -3.43 & -3.54 & -3.13 & -3.78 \\
\hline Threonine & -4.10 & -5.23 & -6.19 & -3.97 & -5.73 \\
\hline Serine & -0.95 & -1.84 & -1.08 & -0.47 & -2.04 \\
\hline Valine & -13.62 & -13.60 & -13.75 & -13.30 & -13.95 \\
\hline Leucine & -21.43 & -20.69 & -22.20 & -22.11 & -21.97 \\
\hline Isoleucine & -16.35 & -17.50 & -16.93 & -15.50 & -15.31 \\
\hline Proline & -10.37 & -9.26 & -8.46 & -9.01 & -9.70 \\
\hline Aspartic Acid & -9.96 & -8.48 & -8.46 & -10.46 & -9.60 \\
\hline Glutamic Acid & -11.01 & -9.97 & -9.49 & -11.15 & -10.73 \\
\hline Phenylalanine & -19.20 & -19.50 & -19.71 & -18.90 & -20.53 \\
\hline c) Ron's Reef & L.ehr191 & L.ehr192 & L.ehr193 & L.ehr194 & L.ehr196 \\
\hline Alanine & -10.22 & -10.79 & -10.21 & -8.06 & -9.32 \\
\hline Glycine & -6.00 & -5.76 & -7.02 & -3.84 & -4.36 \\
\hline Threonine & -8.98 & -10.21 & -9.07 & -7.11 & -6.74 \\
\hline Serine & -4.45 & -2.95 & -3.72 & -0.17 & -0.84 \\
\hline Valine & -15.47 & -15.60 & -14.96 & -13.89 & -14.68 \\
\hline Leucine & -23.21 & -22.02 & -22.55 & -22.44 & -21.47 \\
\hline Isoleucine & -16.24 & -16.33 & -15.91 & -14.71 & -14.36 \\
\hline Proline & -8.05 & -10.22 & -8.63 & -7.02 & -7.73 \\
\hline Aspartic Acid & -6.76 & -9.74 & -7.75 & -5.30 & -6.13 \\
\hline Glutamic Acid & -10.92 & -11.52 & -10.36 & -7.89 & -9.77 \\
\hline Phenylalanine & -20.56 & -21.98 & -20.61 & -19.46 & -18.91 \\
\hline
\end{tabular}




\section{APPENDIX III}

Table A3.1. Bulk otolith $\delta^{13} \mathrm{C}$ and $\delta^{18} \mathrm{O}$ values from Lutjanus ehrenbergii collected in a) Al Lith Bay, b) Khor Al Kharrar Bay, c) Cape Al-Askar Bay, d) Coast Guard Reef and e) Ron's Reef along the coast of Saudi Arabia in the Red Sea (Chapter 4). Whole otoliths were analyzed for juvenile $L$. ehrenbergii from sites a, b, and c, and the outer edge of otoliths were analyzed for adult $L$. ehrenbergii from $d$ and e.

\begin{tabular}{lcc}
\hline & Otolith & Otolith \\
a) Al Lith Bay & $\delta^{13} \mathrm{C}$ & $\delta^{18} \mathrm{O}$ \\
\hline \hline L.ehr48 & -1.54 & -0.75 \\
L.ehr49 & -0.38 & -1.16 \\
L.ehr50 & -1.16 & -0.65 \\
L.ehr51 & -0.58 & -0.46 \\
L.ehr150 & -0.04 & -1.22 \\
L.ehr151 & -1.27 & -1.19 \\
L.ehr152 & -0.15 & -0.23 \\
L.ehr153 & -0.02 & -0.16 \\
L.ehr154 & -1.30 & -1.05 \\
& & \\
\hline & & \\
\hline b) Khor Al & Otolith & Otolith \\
Kharrar Bay & $\delta^{13} \mathrm{C}$ & $\delta^{18} \mathrm{O}$ \\
\hline \hline L.ehr20 & -1.36 & -0.10 \\
L.ehr21 & -0.60 & -0.08 \\
L.ehr25 & 0.30 & 0.19 \\
L.ehr31 & 0.29 & -0.05 \\
L.ehr32 & -1.16 & -0.29 \\
L.ehr33 & -1.02 & -0.02 \\
L.ehr34 & -0.11 & -0.10 \\
L.ehr35 & 0.09 & 0.11 \\
L.ehr36 & -0.58 & -0.17 \\
L.ehr37 & -1.18 & -1.29 \\
\hline & & \\
\hline c) Cape Al- & Otolith & Otolith \\
Askar Bay & $\delta^{13} \mathrm{C}$ & $\delta^{18} \mathrm{O}$ \\
\hline \hline L.ehr404 & -2.53 & -1.06 \\
L.ehr405 & -1.04 & -0.73 \\
L.ehr406 & -1.23 & -0.91 \\
L.ehr407 & -0.88 & -0.12 \\
L.ehr408 & -2.61 & 0.02 \\
L.ehr409 & -1.54 & -0.23 \\
L.ehr411 & -1.43 & -0.81 \\
L.ehr412 & -1.24 & -0.14 \\
L.ehr413 & -1.00 & -0.28 \\
L.ehr414 & -0.34 & -0.97 \\
\hline & & \\
& & \\
\hline
\end{tabular}

\begin{tabular}{lcc}
\hline d) Coast & $\begin{array}{c}\text { Otolith } \\
\text { Guard Reef }\end{array}$ & $\begin{array}{c}\text { Otolith } \\
\delta^{13} \mathrm{C}\end{array}$ \\
\hline \hline L.ehr171 & -2.26 & -0.79 \\
L.ehr172 & -3.08 & -0.72 \\
L.ehr173 & -1.80 & -0.65 \\
L.ehr174 & -1.82 & -0.55 \\
L.ehr178 & -2.40 & -0.75 \\
L.ehr199 & -3.48 & -0.90 \\
L.ehr203 & -2.32 & -0.34 \\
L.ehr206 & -2.86 & -0.52 \\
L.ehr207 & -2.59 & -0.52 \\
L.ehr208 & -3.60 & -0.84 \\
\hline & & \\
\hline e) Ron's & Otolith & Otolith \\
Reef & $\delta^{13} \mathrm{C}$ & $\delta^{18} \mathrm{O}$ \\
\hline \hline L.ehr189 & -3.41 & -0.24 \\
L.ehr190 & -4.17 & -0.68 \\
L.ehr191 & -3.18 & -0.85 \\
L.ehr192 & -2.87 & -0.65 \\
L.ehr193 & -4.43 & -0.20 \\
L.ehr194 & -4.04 & -0.37 \\
L.ehr195 & -2.20 & -1.03 \\
L.ehr196 & -4.31 & -0.22 \\
L.ehr197 & -4.61 & -0.33 \\
L.ehr198 & -5.02 & -0.44 \\
\hline
\end{tabular}


Table A3.2 Bulk otolith $\delta^{13} \mathrm{C}$ and $\delta^{18} \mathrm{O}$ values from Lutjanus apodus collected in a) Great Pond, St. Croix, b) Salt River, St. Croix, c) Montalva Bay, Puerto Rico and d) Punta Guayanilla, Puerto Rico in the Caribbean Sea (Chapter 4). Whole otoliths were analyzed for all juvenile L. apodus samples.

\begin{tabular}{lcc}
\hline a) Great Pond, St. & $\begin{array}{c}\text { Otolith } \\
\text { Croix }\end{array}$ & $\begin{array}{c}\text { Otolith } \\
\delta^{13} \mathrm{C}\end{array}$ \\
\hline \hline GPS1 & -2.01 & -1.10 \\
GPS2 & -3.11 & -1.07 \\
GPS3 & -1.34 & -0.82 \\
GPS4 & -3.41 & -1.28 \\
\hline & & \\
\hline b) Salt River, St. & Otolith & Otolith \\
Croix & $\delta^{13} \mathrm{C}$ & $\delta^{18} \mathrm{O}$ \\
\hline \hline SRS1 & -2.17 & -0.92 \\
SRS2 & -2.02 & -0.73 \\
SRS3 & -3.52 & -0.98 \\
SRS4 & -4.17 & -0.54 \\
\hline & & \\
\hline c) Montalva Bay, & Otolith & Otolith \\
Puerto Rico & $\delta^{13} \mathrm{C}$ & $\delta^{18} \mathrm{O}$ \\
\hline \hline MOS1 & -7.03 & -0.84 \\
MOS2 & -5.72 & -1.16 \\
MOS3 & -1.32 & -1.25 \\
MOS4 & -1.17 & -0.90 \\
\hline & & \\
\hline d) Punta Guayanilla, & Otolith & Otolith \\
Puerto Rico & $\delta^{13} \mathrm{C}$ & $\delta^{18} \mathrm{O}$ \\
\hline \hline GUS2 & -4.87 & -1.80 \\
GUS3 & -4.21 & -1.34 \\
GUS5 & -4.61 & -1.68 \\
GUS6 & -4.83 & -1.52 \\
\hline & & \\
\hline
\end{tabular}


Table A3.3 Bulk otolith $\delta^{13} \mathrm{C}$ and $\delta^{18} \mathrm{O}$ values from Lutjanus argentiventris collected in a) Rio Luis, b) Rio Is Letta and c) Loraine along the west coast of Panama in the Eastern Pacific Ocean (Chapter 4). Whole otoliths were analyzed for all juvenile L. argentiventris samples.

\begin{tabular}{lcc}
\hline a) Rio Luis & Otolith $\delta^{13} \mathrm{C}$ & Otolith $\delta^{18} \mathrm{O}$ \\
\hline \hline LA288 & -7.32 & -3.14 \\
LA292 & -6.48 & -2.78 \\
LA300 & -6.99 & -2.38 \\
LA301 & -6.63 & -3.48 \\
LA302 & -7.23 & -2.74 \\
& & \\
\hline b) Rio Is Letta & Otolith $\delta^{13} \mathrm{C}$ & Otolith $\delta^{18} \mathrm{O}$ \\
\hline LA256 & -8.10 & -3.31 \\
LA258 & -8.46 & -3.80 \\
LA259 & -6.64 & -2.77 \\
LA262 & -7.44 & -2.27 \\
LA263 & -7.00 & -2.54 \\
\hline & & \\
\hline c) Loraine & Otolith $\delta^{13} \mathrm{C}$ & Otolith $\delta^{18} \mathrm{O}$ \\
\hline LA137 & -5.67 & -2.34 \\
LA138 & -6.42 & -2.52 \\
LA139 & -5.48 & -3.27 \\
LA141 & -5.73 & -2.47 \\
LA142 & -6.21 & -3.44 \\
\hline
\end{tabular}


Table A3.4 Bulk muscle $\delta^{13} \mathrm{C}$ and $\delta^{15} \mathrm{~N}$ values from Lutjanus ehrenbergii collected in a) Al Lith Bay, b) Khor Al Kharrar Bay, c) Cape Al-Askar Bay, d) Coast Guard Reef and e) Ron's Reef along the coast of Saudi Arabia in the Red Sea (Chapter 4).

\begin{tabular}{lcc}
\hline a) A1 Lith Bay & $\begin{array}{c}\text { Muscle } \\
\delta^{13} \mathrm{C}\end{array}$ & $\begin{array}{c}\text { Muscle } \\
\delta^{15} \mathrm{~N}\end{array}$ \\
\hline \hline L.ehr48 & -11.61 & 8.53 \\
L.ehr49 & -10.78 & 7.63 \\
L.ehr50 & -10.45 & 8.46 \\
L.ehr51 & -9.90 & 8.93 \\
L.ehr150 & -8.83 & 8.94 \\
L.ehr151 & -10.21 & 8.00 \\
L.ehr152 & -11.02 & 8.89 \\
L.ehr153 & -10.84 & 8.74 \\
L.ehr154 & -11.21 & 9.30 \\
& & \\
\hline & & \\
\hline b) Khor Al & Muscle & Muscle \\
Kharrar Bay & $\delta^{13} \mathrm{C}$ & $\delta^{15} \mathrm{~N}$ \\
\hline \hline L.ehr20 & -10.34 & 7.46 \\
L.ehr21 & -9.98 & 6.54 \\
L.ehr25 & -10.13 & 7.02 \\
L.ehr31 & -9.58 & 6.91 \\
L.ehr32 & -10.43 & 6.82 \\
L.ehr33 & -10.56 & 6.97 \\
L.ehr34 & -10.04 & 7.19 \\
L.ehr35 & -10.12 & 7.11 \\
L.ehr36 & -10.48 & 6.96 \\
L.ehr37 & -10.27 & 6.59 \\
\hline & & \\
\hline c) Cape Al- & Muscle & Muscle \\
Askar Bay & $\delta^{13} \mathrm{C}$ & $\delta^{15} \mathrm{~N}$ \\
\hline \hline L.ehr404 & -11.46 & 8.57 \\
L.ehr405 & -10.64 & 8.13 \\
L.ehr406 & -9.40 & 8.28 \\
L.ehr407 & -11.23 & 7.29 \\
L.ehr408 & -10.68 & 8.14 \\
L.ehr409 & -10.66 & 8.88 \\
L.ehr411 & -10.98 & 8.42 \\
L.ehr412 & -9.88 & 7.38 \\
L.ehr413 & -10.37 & 8.77 \\
L.ehr414 & -10.43 & 8.04 \\
\hline & & \\
& & \\
\hline
\end{tabular}

\begin{tabular}{ccc}
\hline $\begin{array}{c}\text { d) Coast } \\
\text { Guard Reef }\end{array}$ & $\begin{array}{c}\text { Muscle } \\
\delta^{13} \mathrm{C}\end{array}$ & $\begin{array}{c}\text { Muscle } \\
\delta^{15} \mathrm{~N}\end{array}$ \\
\hline \hline L.ehr171 & -15.59 & 7.82 \\
L.ehr172 & -15.18 & 8.69 \\
L.ehr173 & -14.73 & 8.58 \\
L.ehr174 & -13.83 & 8.53 \\
L.ehr178 & -13.44 & 9.07 \\
L.ehr199 & -14.07 & 9.15 \\
L.ehr203 & -15.29 & 8.60 \\
L.ehr206 & -15.87 & 8.91 \\
L.ehr207 & -15.47 & 9.40 \\
L.ehr208 & -15.07 & 7.57 \\
\hline
\end{tabular}

\begin{tabular}{ccc}
\hline $\begin{array}{c}\text { e) Ron's } \\
\text { Reef }\end{array}$ & $\begin{array}{c}\text { Muscle } \\
\delta^{13} \mathrm{C}\end{array}$ & $\begin{array}{c}\text { Muscle } \\
\delta^{15} \mathrm{~N}\end{array}$ \\
\hline \hline L.ehr189 & -15.99 & 8.88 \\
L.ehr190 & -15.60 & 8.62 \\
L.ehr191 & -18.63 & 8.14 \\
L.ehr192 & -17.94 & 7.94 \\
L.ehr193 & -17.30 & 8.42 \\
L.ehr194 & -17.58 & 8.98 \\
L.ehr195 & -15.97 & 8.25 \\
L.ehr196 & -17.43 & 7.48 \\
L.ehr197 & -15.74 & 8.39 \\
L.ehr198 & -16.92 & 8.21 \\
\hline
\end{tabular}


Table A3.5. Bulk tissue $\delta^{13} \mathrm{C}$ and $\delta^{15} \mathrm{~N}$ values from selected food web components collected in a) Al Lith Bay, b) Coast Guard Reef and c) Ron's Reef along the coast of Saudi Arabia in the Red Sea (Chapter 4).

\begin{tabular}{|c|c|c|}
\hline a) Al Lith Bay & Bulk $\delta^{13} \mathrm{C}$ & Bulk $\delta^{15} \mathrm{~N}$ \\
\hline Ribbon seagrass (Halodule uninervis) H.uni1 & -7.08 & -1.98 \\
\hline Ribbon seagrass (Halodule uninervis) H.uni2 & -8.08 & 1.03 \\
\hline Ribbon seagrass (Halodule uninervis) H.uni3 & -8.43 & -0.01 \\
\hline White mangrove (Avicennia marina) A.mar1 & -27.04 & 1.03 \\
\hline White mangrove (Avicennia marina) A.mar2 & -28.29 & 2.09 \\
\hline White mangrove (Avicennia marina) A.mar3 & -27.81 & 1.11 \\
\hline Zooplankton PT1 & -18.52 & 5.01 \\
\hline Zooplankton PT2 & -18.79 & 4.68 \\
\hline Zooplankton PT3 & -19.15 & 5.56 \\
\hline Crab (Metopograpsus thukuhar) M.thu1 & -12.34 & 4.83 \\
\hline Crab (Metopograpsus thukuhar) M.thu2 & -12.81 & 4.93 \\
\hline Crab (Metopograpsus thukuhar) M.thu3 & -13.16 & 5.20 \\
\hline b) Coast Guard Reef & Bulk $\delta^{13} \mathrm{C}$ & Bulk $\delta^{15} \mathrm{~N}$ \\
\hline Zooplankton PT4 & -17.26 & 5.11 \\
\hline Zooplankton PT5 & -17.70 & 4.24 \\
\hline Zooplankton PT6 & -15.74 & 4.56 \\
\hline Crab (Trapezia tigrina) T.tig1 & -15.37 & 5.02 \\
\hline Crab (Trapezia tigrina) T.tig2 & -15.11 & 5.57 \\
\hline Crab (Trapezia tigrina) T.tig3 & -15.01 & 6.62 \\
\hline c) Ron's Reef & Bulk $\delta^{13} \mathrm{C}$ & Bulk $\delta^{15} \mathrm{~N}$ \\
\hline Zooplankton PT7 & -19.89 & 4.24 \\
\hline Zooplankton PT8 & -19.95 & 4.12 \\
\hline Zooplankton PT9 & -20.26 & 4.02 \\
\hline Crab (Trapezia tigrina) T.tig4 & -17.57 & 5.16 \\
\hline Crab (Trapezia tigrina) T.tig5 & -17.73 & 6.12 \\
\hline Crab (Trapezia tigrina) T.tig6 & -17.29 & 5.85 \\
\hline
\end{tabular}




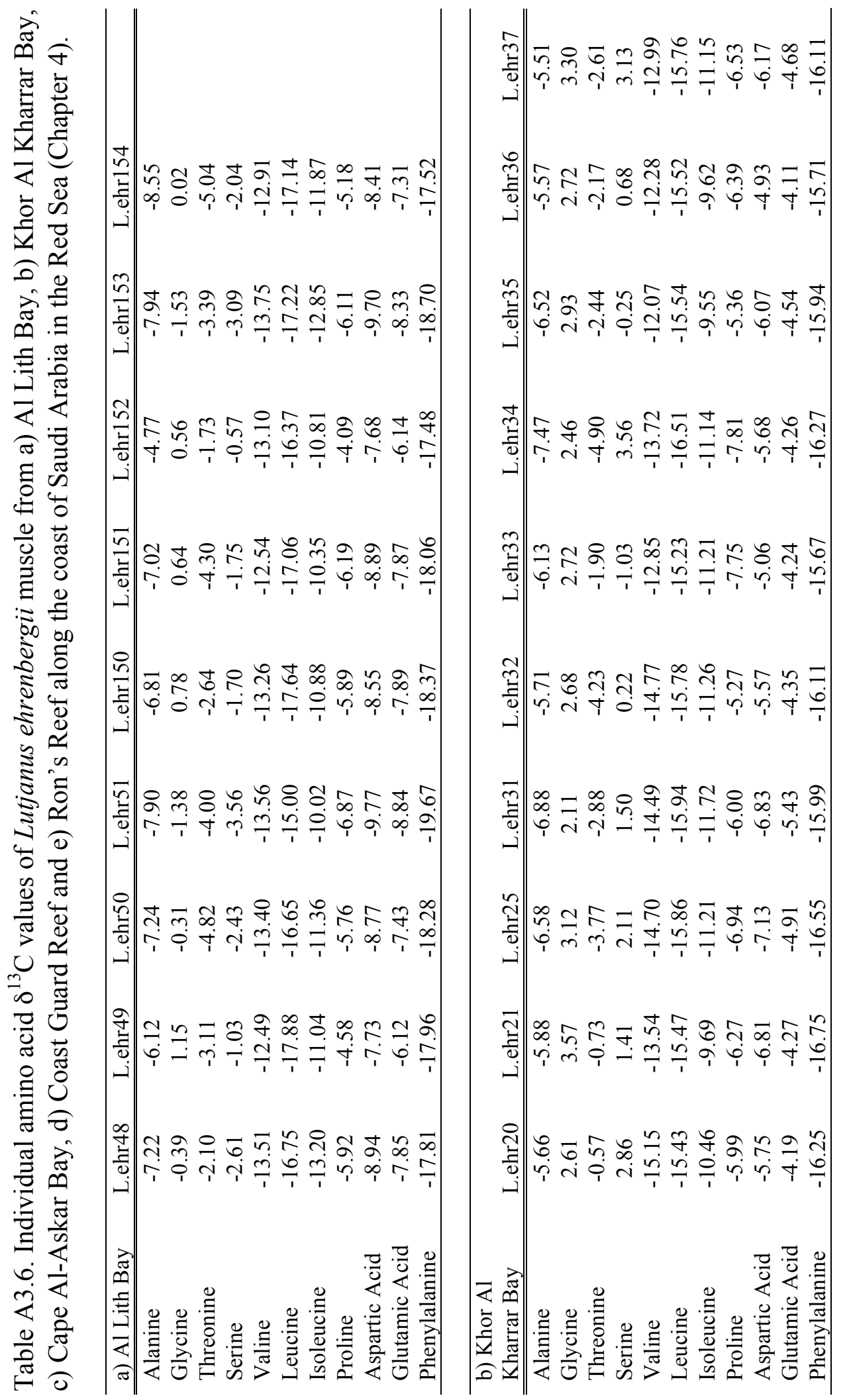




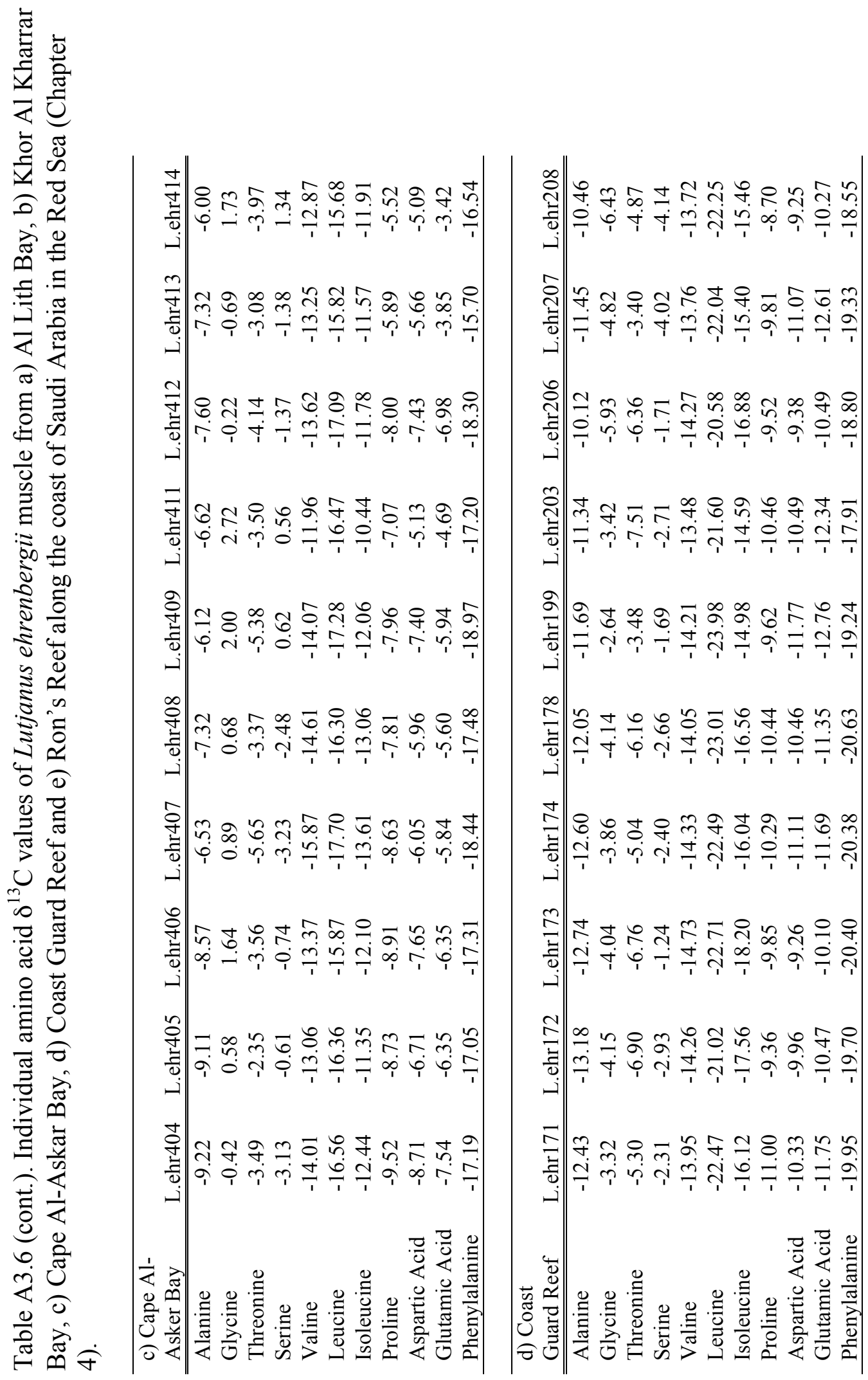




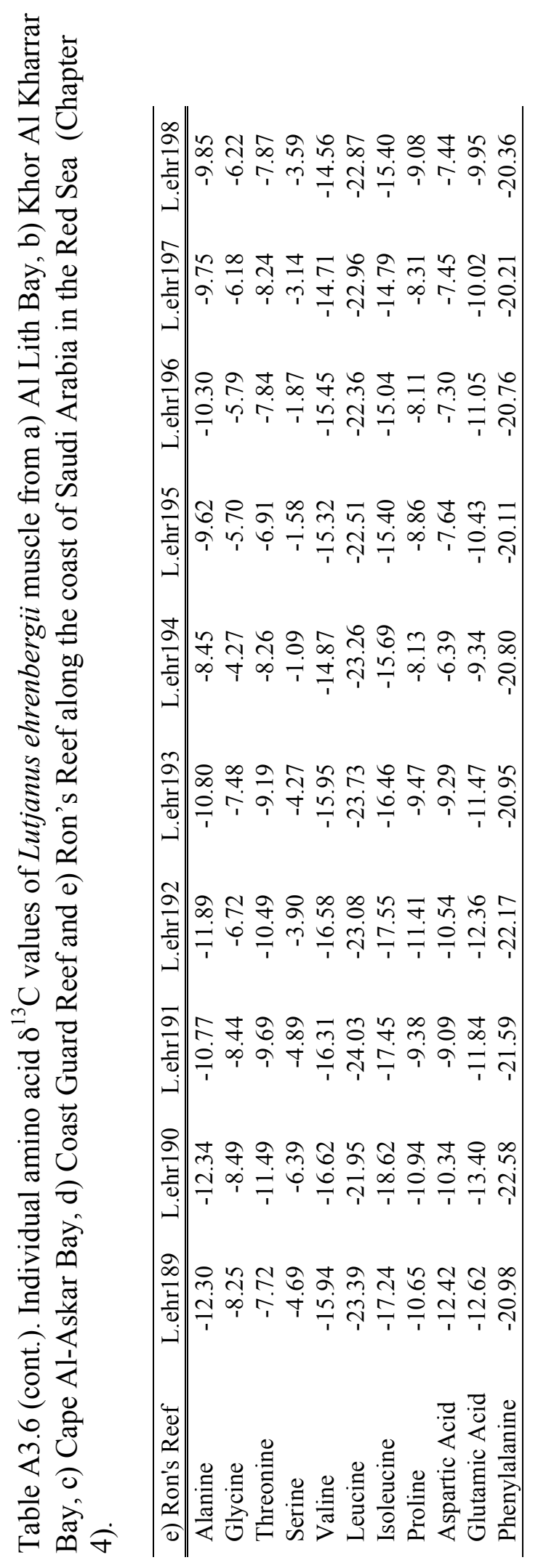


Table A3.7. Individual amino acid $\delta^{13} \mathrm{C}$ values from Lutjanus apodus muscle collected in a) Great Pond, St. Croix, b) Salt River, St. Croix, c) Montalva Bay, Puerto Rico and d) Punta Guayanilla, Puerto Rico in the Caribbean Sea (Chapter 4).

\begin{tabular}{lcccc}
\hline a) Great Pond, St. Croix & GPS1 & GPS2 & GPS3 & GPS4 \\
\hline \hline Alanine & -10.27 & -13.73 & -12.71 & -13.18 \\
Glycine & 3.03 & 0.61 & 7.90 & 4.18 \\
Threonine & -0.50 & -4.35 & -1.08 & -0.63 \\
Serine & 5.91 & 0.45 & 5.96 & 2.44 \\
Valine & -10.94 & -11.71 & -10.38 & -11.20 \\
Leucine & -13.60 & -17.09 & -11.74 & -13.51 \\
Isoleucine & -8.46 & -8.61 & -6.96 & -8.88 \\
Proline & -4.92 & -4.71 & -4.75 & -6.38 \\
Aspartic Acid & -2.90 & -6.09 & -2.71 & -3.66 \\
Glutamic Acid & -6.24 & -9.45 & -7.29 & -8.82 \\
Phenylalanine & -15.57 & -17.29 & -15.09 & -15.83 \\
\hline & & & & \\
\hline b) Salt River, St. Croix & SRS1 & SRS2 & SRS3 & SRS4 \\
\hline \hline Alanine & -16.54 & -18.08 & -19.14 & -19.05 \\
Glycine & -4.12 & -4.74 & -7.30 & -12.06 \\
Threonine & -12.32 & -14.19 & -11.97 & -13.60 \\
Serine & -4.52 & -8.13 & -6.41 & -12.15 \\
Valine & -20.40 & -18.50 & -20.63 & -22.07 \\
Leucine & -22.03 & -22.11 & -23.59 & -25.03 \\
Isoleucine & -15.97 & -15.27 & -16.28 & -18.41 \\
Proline & -13.97 & -13.11 & -15.47 & -16.12 \\
Aspartic Acid & -17.88 & -15.56 & -17.01 & -16.03 \\
Glutamic Acid & -13.37 & -15.40 & -18.80 & -17.38 \\
Phenylalanine & -21.73 & -22.08 & -22.01 & -21.21 \\
\hline
\end{tabular}


Table A3.7 (cont.). Individual amino acid $\delta^{13} \mathrm{C}$ values from Lutjanus apodus muscle collected in a) Great Pond, St. Croix, b) Salt River, St. Croix, c) Montalva Bay, Puerto Rico and d) Punta Guayanilla, Puerto Rico in the Caribbean Sea (Chapter 4).

\begin{tabular}{lcccc}
\hline c) Montalva Bay, Puerto Rico & MOS1 & MOS2 & MOS3 & MOS4 \\
\hline \hline Alanine & -20.58 & -16.77 & -11.23 & -8.75 \\
Glycine & -9.52 & -8.09 & 1.53 & 2.73 \\
Threonine & -17.99 & -16.31 & -6.13 & -5.88 \\
Serine & -7.01 & 1.29 & 1.29 & 2.44 \\
Valine & -24.12 & -22.41 & -18.28 & -17.02 \\
Leucine & -25.28 & -24.21 & -18.90 & -16.48 \\
Isoleucine & -19.29 & -18.83 & -11.42 & -10.35 \\
Proline & -14.92 & -12.19 & -4.76 & -4.74 \\
Aspartic Acid & -21.96 & -17.67 & -5.95 & -5.74 \\
Glutamic Acid & -19.24 & -15.52 & -7.97 & -5.40 \\
Phenylalanine & -24.41 & -23.53 & -17.29 & -17.19 \\
\hline & & & & \\
\hline d) Punta Guayanilla, Puerto Rico & GUS2 & GUS3 & GUS5 & GUS6 \\
\hline \hline Alanine & -14.64 & -17.72 & -18.98 & -16.95 \\
Glycine & -5.47 & -4.31 & -5.33 & -3.59 \\
Threonine & -9.07 & -12.97 & -13.37 & -13.99 \\
Serine & -2.69 & -2.27 & -6.47 & -4.62 \\
Valine & -24.67 & -24.20 & -24.66 & -24.53 \\
Leucine & -23.70 & -24.74 & -24.06 & -23.76 \\
Isoleucine & -13.82 & -15.66 & -16.25 & -16.68 \\
Proline & -12.21 & -12.29 & -15.45 & -15.41 \\
Aspartic Acid & -11.47 & -12.90 & -10.74 & -12.38 \\
Glutamic Acid & -10.12 & -13.64 & -14.81 & -13.45 \\
Phenylalanine & -23.38 & -22.20 & -21.67 & -20.47 \\
\hline
\end{tabular}




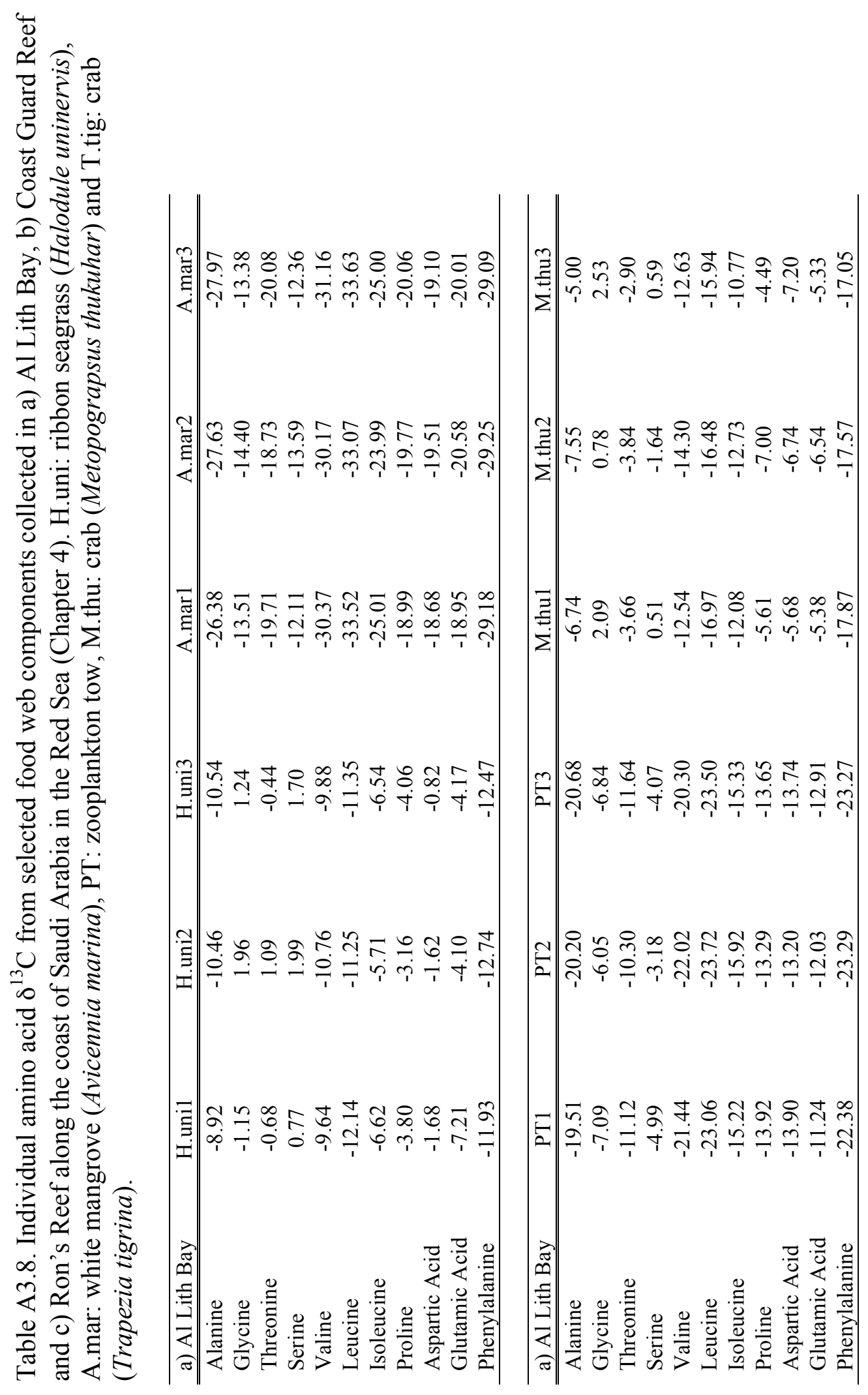




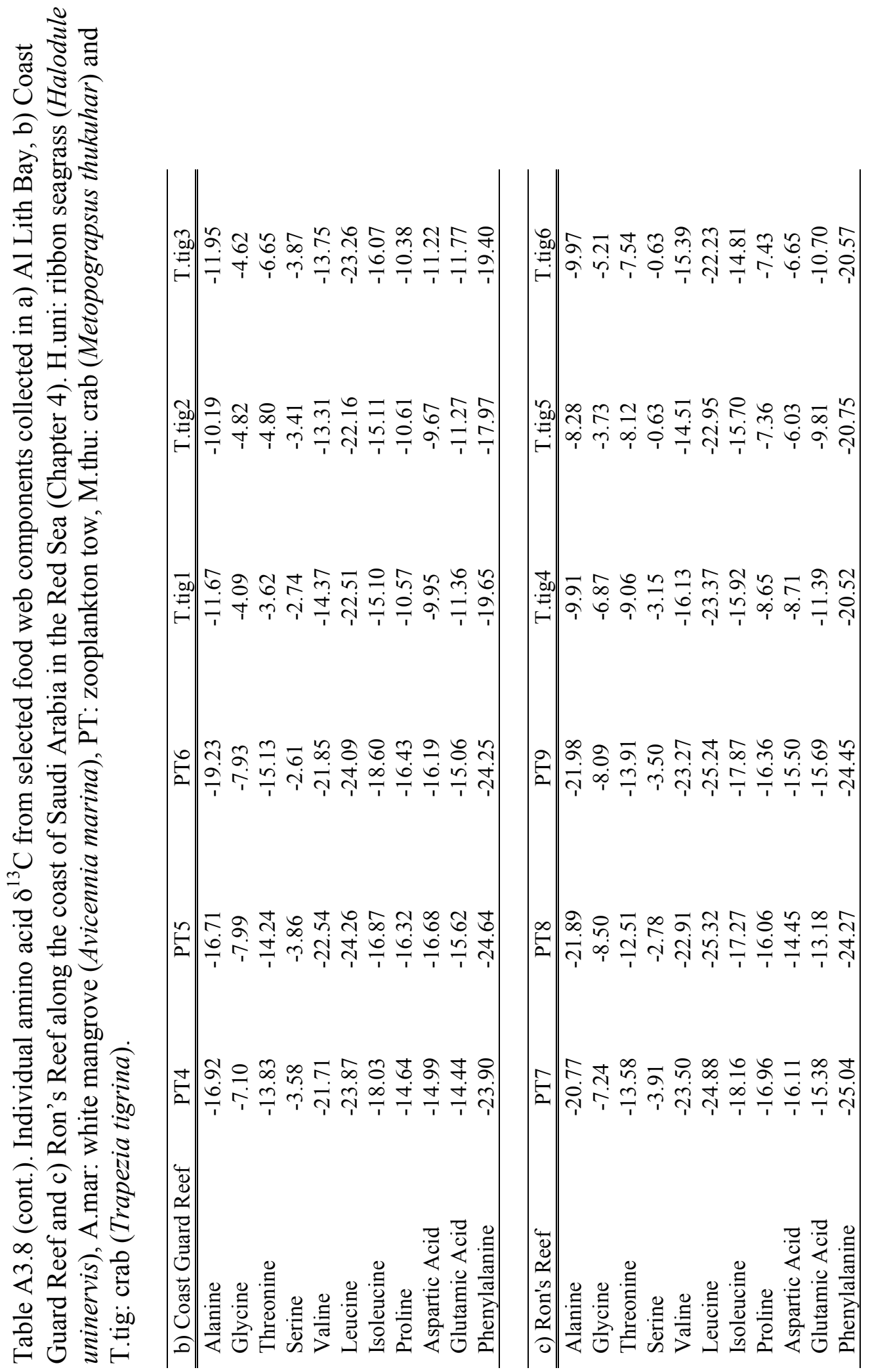




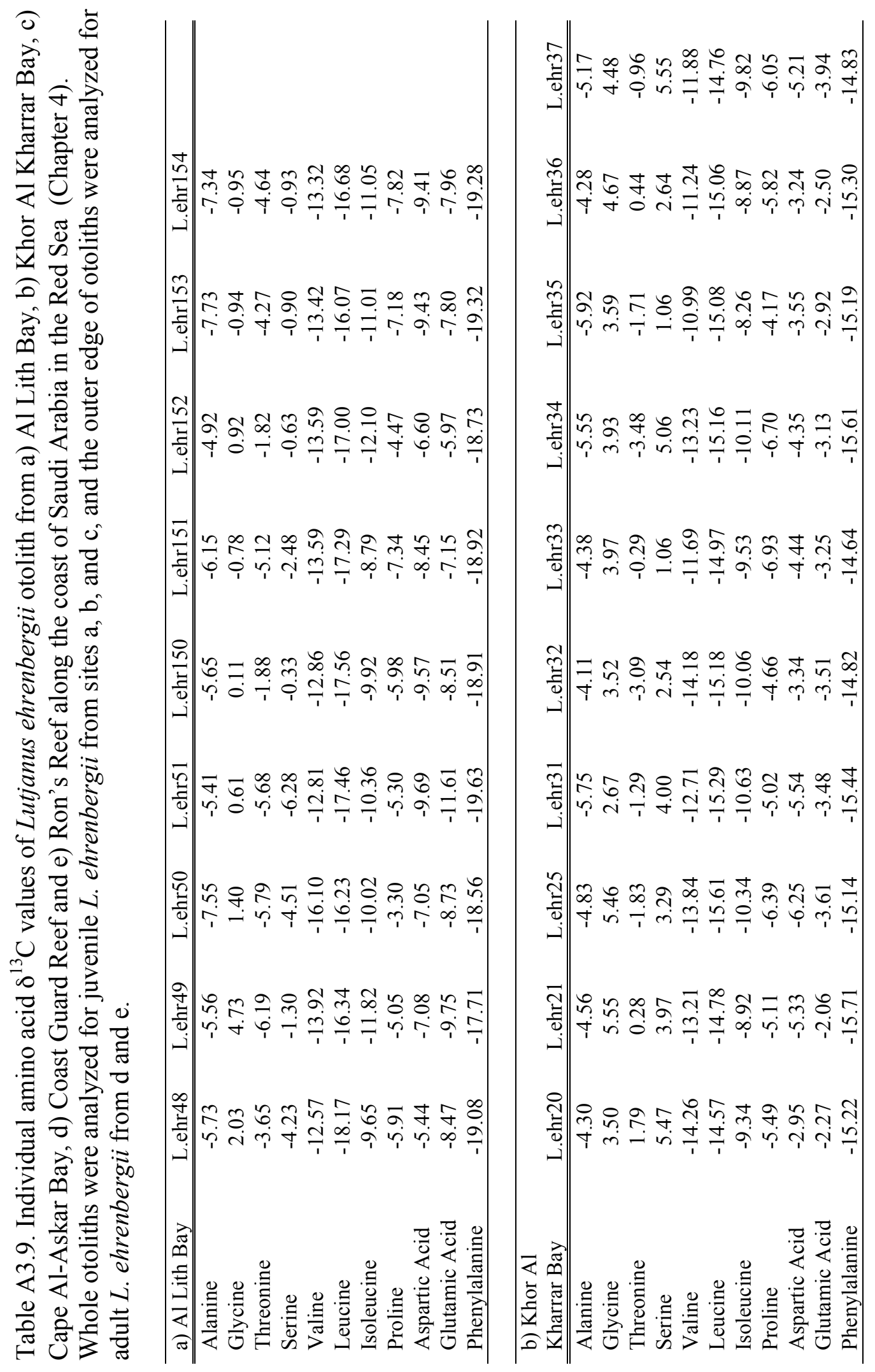




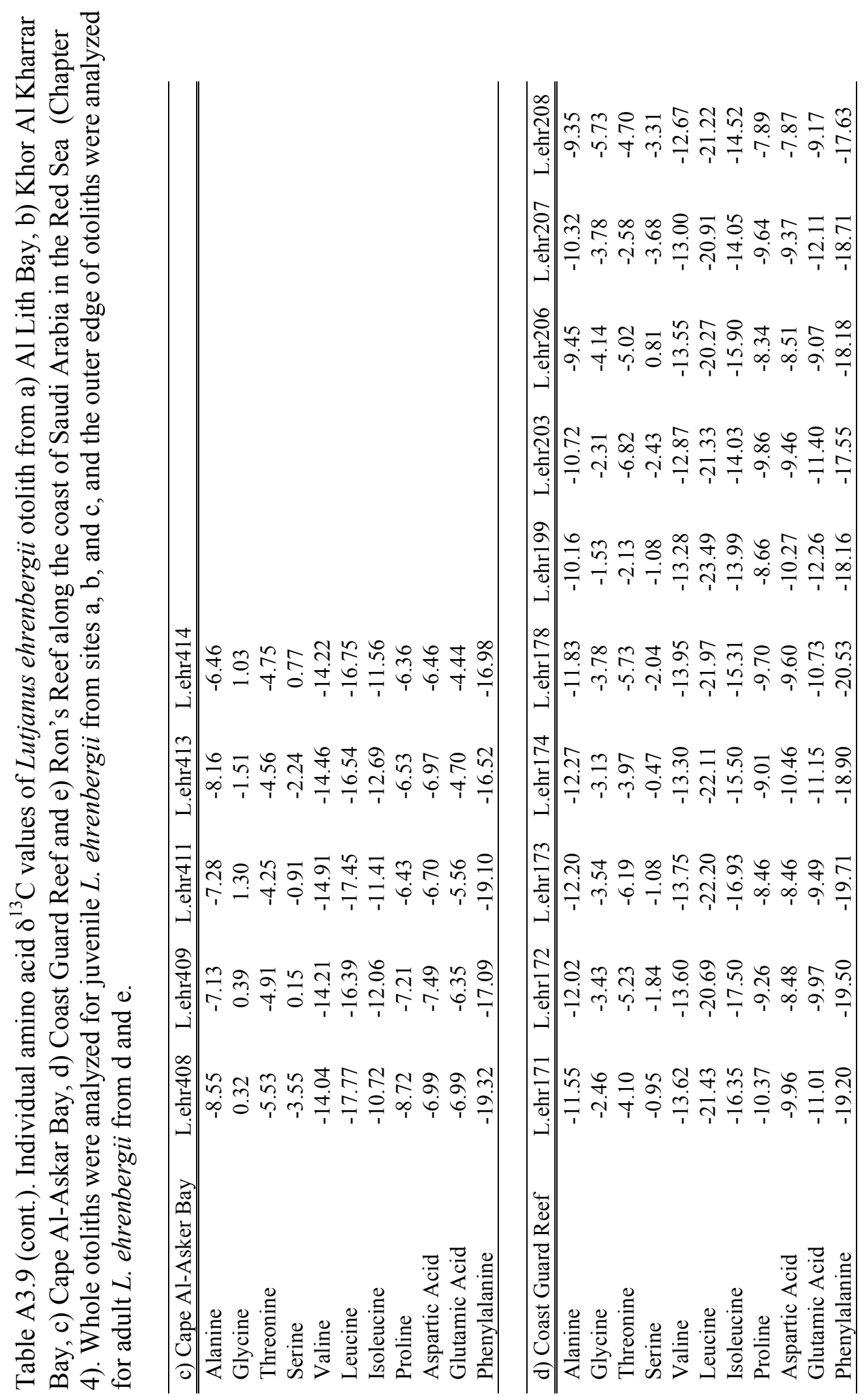




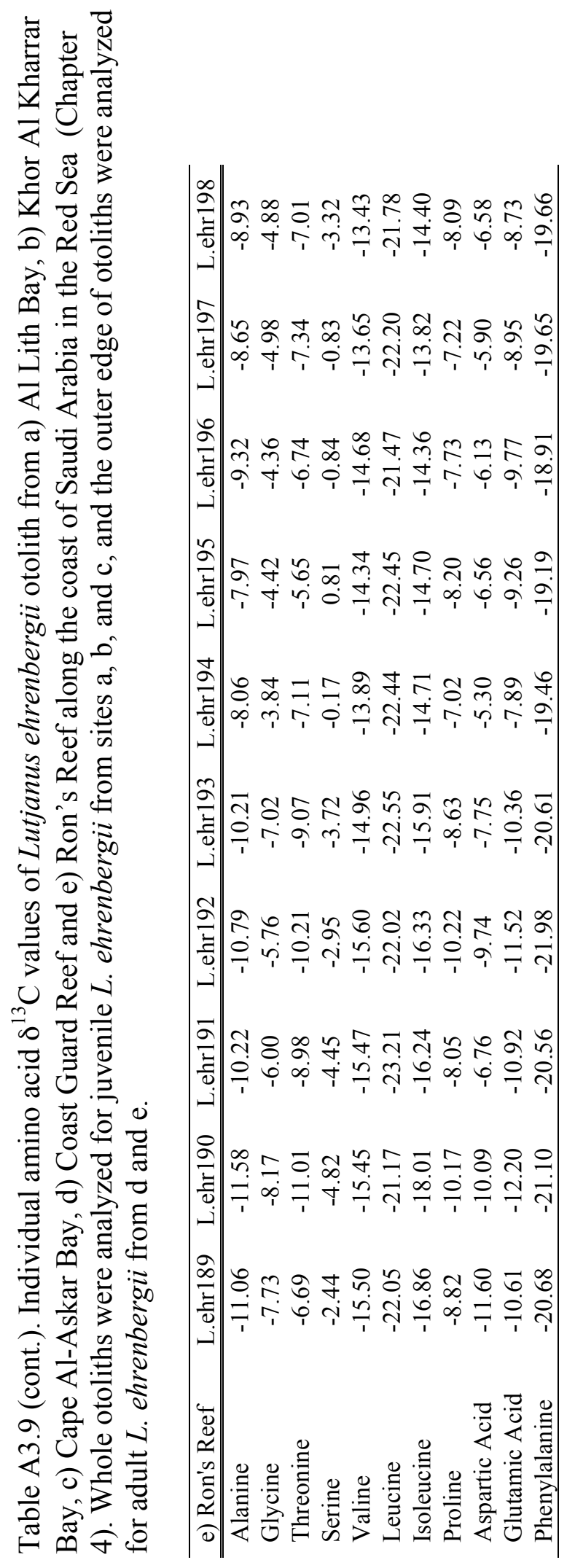


Table. A3.10. Individual amino acid $\delta^{13} \mathrm{C}$ values from Lutjanus apodus otolith collected in a) Great Pond, St. Croix, b) Salt River, St. Croix, c) Montalva Bay, Puerto Rico and d) Punta Guayanilla, Puerto Rico in the Caribbean Sea (Chapter 4). Whole otoliths were used for all L. apodus samples.

\begin{tabular}{lcccc}
\hline a) Great Pond, St. Croix & GPS1 & GPS2 & GPS3 & GPS4 \\
\hline \hline Alanine & -12.32 & -15.76 & -13.93 & -15.25 \\
Glycine & 0.80 & -1.84 & 4.29 & 2.57 \\
Threonine & -3.31 & -6.67 & -2.61 & -4.13 \\
Serine & 2.29 & -3.23 & 3.48 & 1.63 \\
Valine & -13.06 & -14.22 & -11.25 & -12.25 \\
Leucine & -15.81 & -18.79 & -13.65 & -14.56 \\
Isoleucine & -10.18 & -10.82 & -8.14 & -9.05 \\
Proline & -6.33 & -7.63 & -6.82 & -7.82 \\
Aspartic Acid & -4.89 & -7.27 & -2.92 & -4.44 \\
Glutamic Acid & -7.77 & -10.09 & -8.74 & -10.05 \\
Phenylalanine & -17.24 & -18.26 & -15.62 & -16.40 \\
\hline & & & & \\
\hline b) Salt River, St. Croix & SRS1 & SRS2 & SRS3 & SRS4 \\
\hline \hline Alanine & -18.89 & -20.10 & -21.93 & -23.20 \\
Glycine & -9.95 & -9.26 & -12.55 & -15.52 \\
Threonine & -14.75 & -15.67 & -16.11 & -17.90 \\
Serine & -11.29 & -12.34 & -11.75 & -14.65 \\
Valine & -21.73 & -21.16 & -23.15 & -24.38 \\
Leucine & -23.34 & -23.84 & -26.14 & -26.83 \\
Isoleucine & -17.17 & -17.59 & -18.85 & -20.04 \\
Proline & -16.47 & -15.17 & -17.06 & -17.92 \\
Aspartic Acid & -19.43 & -19.50 & -19.62 & -20.16 \\
Glutamic Acid & -16.60 & -18.19 & -19.59 & -20.51 \\
Phenylalanine & -23.31 & -23.62 & -23.18 & -23.78 \\
\hline & & & &
\end{tabular}


Table. A3.10 (cont.). Individual amino acid $\delta^{13} \mathrm{C}$ values from Lutjanus apodus otolith collected in a) Great Pond, St. Croix, b) Salt River, St. Croix, c) Montalva Bay, Puerto Rico and d) Punta Guayanilla, Puerto Rico in the Caribbean Sea (Chapter 4). Whole otoliths were used for all $L$. apodus samples.

\begin{tabular}{lcccc}
\hline c) Montalva Bay, Puerto Rico & MOS1 & MOS2 & MOS3 & MOS4 \\
\hline \hline Alanine & -20.45 & -20.07 & -13.12 & -10.43 \\
Glycine & -11.57 & -13.23 & -1.90 & -0.78 \\
Threonine & -21.35 & -19.14 & -8.17 & -8.13 \\
Serine & -9.53 & -2.40 & -2.40 & -1.32 \\
Valine & -26.47 & -25.26 & -19.67 & -18.44 \\
Leucine & -26.91 & -26.18 & -19.83 & -19.30 \\
Isoleucine & -20.99 & -20.47 & -13.52 & -12.57 \\
Proline & -16.23 & -15.23 & -6.92 & -6.29 \\
Aspartic Acid & -21.49 & -19.22 & -8.05 & -7.08 \\
Glutamic Acid & -19.92 & -18.23 & -9.41 & -8.64 \\
Phenylalanine & -26.27 & -25.16 & -18.86 & -18.49 \\
\hline & & & & \\
\hline d) Punta Guayanilla, Puerto Rico & GUS2 & GUS3 & GUS5 & GUS6 \\
\hline Alanine & -16.53 & -19.13 & -18.12 & -19.12 \\
Glycine & -6.60 & -6.57 & -8.64 & -8.03 \\
Threonine & -14.57 & -14.24 & -15.50 & -16.89 \\
Serine & -7.95 & -6.33 & -9.90 & -8.78 \\
Valine & -25.60 & -27.12 & -27.14 & -26.46 \\
Leucine & -24.86 & -25.92 & -25.65 & -25.28 \\
Isoleucine & -16.34 & -17.32 & -17.53 & -18.56 \\
Proline & -14.58 & -14.53 & -17.65 & -17.72 \\
Aspartic Acid & -15.31 & -15.43 & -14.39 & -14.13 \\
Glutamic Acid & -14.48 & -17.10 & -16.69 & -15.75 \\
Phenylalanine & -24.72 & -24.06 & -22.64 & -22.45 \\
\hline
\end{tabular}


Table A3.11. Individual amino acid $\delta^{13} \mathrm{C}$ values from Lutjanus argentiventris collected in a) Rio Luis, b) Rio Is Letta and c) Loraine along the west coast of Panama in the Eastern Pacific Ocean (Chapter 4). Whole otoliths were analyzed for all juvenile L. argentiventris samples.

\begin{tabular}{|c|c|c|c|c|c|}
\hline a) Rio Luis & LA288 & LA292 & LA300 & LA301 & LA302 \\
\hline Alanine & -21.33 & -20.85 & -22.46 & -20.76 & -20.84 \\
\hline Glycine & -10.31 & -8.58 & -10.14 & -8.73 & -9.87 \\
\hline Threonine & -15.33 & -14.56 & -15.82 & -15.61 & -15.54 \\
\hline Serine & -15.82 & -12.40 & -13.83 & -12.84 & -12.96 \\
\hline Valine & -25.95 & -24.33 & -25.21 & -24.24 & -24.65 \\
\hline Leucine & -29.76 & -29.99 & -31.31 & -29.72 & -31.20 \\
\hline Isoleucine & -19.10 & -19.54 & -18.13 & -19.05 & -19.16 \\
\hline Proline & -16.78 & -17.23 & -15.45 & -19.33 & -17.70 \\
\hline Aspartic Acid & -16.38 & -15.32 & -20.00 & -18.09 & -18.16 \\
\hline Glutamic Acid & -17.74 & -17.70 & -18.23 & -20.89 & -21.79 \\
\hline Phenylalanine & -27.01 & -27.47 & -27.99 & -27.62 & -28.19 \\
\hline b) Rio Is Letta & LA256 & LA258 & LA259 & LA262 & LA263 \\
\hline Alanine & -20.50 & -23.99 & -20.39 & -21.66 & -22.23 \\
\hline Glycine & -10.92 & -10.73 & -9.59 & -9.04 & -11.60 \\
\hline Threonine & -16.31 & -15.36 & -16.33 & -16.60 & -16.61 \\
\hline Serine & -9.76 & -10.15 & -10.57 & -9.37 & -9.46 \\
\hline Valine & -26.94 & -25.68 & -27.59 & -27.87 & -25.67 \\
\hline Leucine & -32.10 & -32.11 & -30.38 & -30.34 & -31.02 \\
\hline Isoleucine & -20.47 & -19.60 & -19.52 & -18.73 & -18.89 \\
\hline Proline & -18.22 & -16.81 & -19.42 & -19.07 & -18.75 \\
\hline Aspartic Acid & -18.81 & -21.48 & -21.66 & -19.87 & -20.34 \\
\hline Glutamic Acid & -17.43 & -19.88 & -20.55 & -18.58 & -19.47 \\
\hline Phenylalanine & -27.79 & -26.45 & -25.21 & -26.09 & -25.75 \\
\hline c) Loraine & LA137 & LA138 & LA139 & LA141 & LA142 \\
\hline Alanine & -19.19 & -20.25 & -21.14 & -19.84 & -19.97 \\
\hline Glycine & -13.09 & -12.43 & -13.80 & -12.98 & -12.11 \\
\hline Threonine & -14.70 & -15.14 & -14.51 & -13.53 & -15.19 \\
\hline Serine & -11.38 & -10.85 & -11.41 & -10.28 & -10.12 \\
\hline Valine & -24.01 & -23.51 & -22.91 & -23.60 & -23.57 \\
\hline Leucine & -27.15 & -27.22 & -26.54 & -26.41 & -26.79 \\
\hline Isoleucine & -17.41 & -17.07 & -17.53 & -16.94 & -16.76 \\
\hline Proline & -16.16 & -15.62 & -16.11 & -15.82 & -16.02 \\
\hline Aspartic Acid & -16.30 & -17.87 & -19.64 & -17.45 & -18.49 \\
\hline Glutamic Acid & -17.40 & -18.92 & -18.63 & -17.83 & -18.67 \\
\hline Phenylalanine & -23.09 & -23.67 & -23.71 & -23.73 & -23.97 \\
\hline
\end{tabular}




\section{APPENDIX IV}

Table A4.1. Total Length ( $\mathrm{mm}$ ) and muscle $\delta^{15} \mathrm{~N}$ values of Lutjanus ehrenbergii collected from coastal wetlands and coral reefs along a $50 \mathrm{~km}$ cross-shelf transect from Al Lith, Saudi Arabia in the Red Sea (Chapter 5).

\begin{tabular}{lcc}
\hline a) Al Lith Bay & Length $(\mathrm{mm})$ & Muscle $\delta^{15} \mathrm{~N}$ \\
\hline \hline L.ehr48 & 72 & 8.53 \\
L.ehr49 & 74 & 7.63 \\
L.ehr50 & 80 & 8.46 \\
L.ehr51 & 87 & 8.93 \\
L.ehr150 & 72 & 8.94 \\
L.ehr151 & 74 & 8.00 \\
L.ehr152 & 80 & 8.89 \\
L.ehr153 & 61 & 8.74 \\
L.ehr154 & 87 & 9.30 \\
\hline & & \\
\hline b) Cape Al-Askar Bay & Length $(\mathrm{mm})$ & Muscle $\delta^{15} \mathrm{~N}$ \\
\hline \hline L.ehr404 & 62 & 8.57 \\
L.ehr405 & 63 & 8.13 \\
L.ehr406 & 67 & 8.28 \\
L.ehr407 & 51 & 7.29 \\
L.ehr408 & 88 & 8.14 \\
L.ehr409 & 85 & 8.88 \\
L.ehr411 & 94 & 8.42 \\
L.ehr412 & 85 & 7.38 \\
L.ehr413 & 77 & 8.77 \\
L.ehr414 & 72 & 8.04 \\
\hline \multicolumn{2}{c}{} \\
\hline c) Cape Al-Askar Reef & Length $(\mathrm{mm})$ & Muscle $\delta^{15} \mathrm{~N}$ \\
\hline \hline L.ehr399 & 164 & 8.90 \\
L.ehr400 & 117 & 8.78 \\
L.ehr401 & 120 & 8.79 \\
L.ehr402 & 97 & 8.73 \\
L.ehr403 & 125 & 8.80 \\
\hline
\end{tabular}


Table A4.1 (cont.). Total Length ( $\mathrm{mm}$ ) and muscle $\delta^{15} \mathrm{~N}$ values of Lutjanus ehrenbergii collected from coastal wetlands and coral reefs along a $50 \mathrm{~km}$-cross shelf transect from Al Lith, Saudi Arabia in the Red Sea (Chapter 5).

\begin{tabular}{|c|c|c|}
\hline d) Coast Guard Reef & Length $(\mathrm{mm})$ & Muscle $\delta^{15} \mathrm{~N}$ \\
\hline L.ehr169 & 179 & 7.95 \\
\hline L.ehr170 & 183 & 8.52 \\
\hline L.ehr171 & 159 & 7.82 \\
\hline L.ehr172 & 154 & 8.69 \\
\hline L.ehr173 & 246 & 8.58 \\
\hline L.ehr174 & 248 & 8.53 \\
\hline L.ehr175 & 163 & 8.41 \\
\hline L.ehr176 & 187 & 8.79 \\
\hline L.ehr177 & 154 & 9.18 \\
\hline L.ehr178 & 236 & 9.07 \\
\hline L.ehr199 & 176 & 9.15 \\
\hline L.ehr200 & 156 & 9.26 \\
\hline L.ehr201 & 163 & 9.06 \\
\hline L.ehr202 & 181 & 9.21 \\
\hline L.ehr203 & 149 & 8.60 \\
\hline L.ehr204 & 149 & 9.42 \\
\hline L.ehr205 & 170 & 9.84 \\
\hline L.ehr206 & 187 & 8.91 \\
\hline L.ehr207 & 175 & 9.40 \\
\hline L.ehr208 & 146 & 7.57 \\
\hline e) Ron's Reef & Length (mm) & Muscle $\delta^{15} \mathrm{~N}$ \\
\hline L.ehr189 & 206 & 8.88 \\
\hline L.ehr190 & 218 & 8.62 \\
\hline L.ehr191 & 227 & 8.14 \\
\hline L.ehr192 & 238 & 7.94 \\
\hline L.ehr193 & 237 & 8.42 \\
\hline L.ehr194 & 230 & 8.98 \\
\hline L.ehr195 & 200 & 8.25 \\
\hline L.ehr196 & 230 & 7.48 \\
\hline L.ehr197 & 189 & 8.39 \\
\hline L.ehr198 & 196 & 8.21 \\
\hline f) LJ's Reef & Length (mm) & Muscle $\delta^{15} \mathrm{~N}$ \\
\hline L.ehr156 & 179 & 9.74 \\
\hline L.ehr157 & 218 & 9.44 \\
\hline L.ehr158 & 225 & 9.87 \\
\hline L.ehr160 & 217 & 9.12 \\
\hline L.ehr161 & 235 & 9.32 \\
\hline L.ehr162 & 230 & 9.64 \\
\hline L.ehr163 & 191 & 9.83 \\
\hline L.ehr164 & 210 & 8.98 \\
\hline L.ehr165 & 198 & 9.57 \\
\hline
\end{tabular}


Table A4.1 (cont.). Total Length ( $\mathrm{mm}$ ) and muscle $\delta^{15} \mathrm{~N}$ values of Lutjanus ehrenbergii collected from coastal wetlands and coral reefs along a $50 \mathrm{~km}$ cross-shelf transect from Al Lith, Saudi Arabia in the Red Sea (Chapter 5).

\begin{tabular}{|c|c|c|}
\hline g) Abu Latt Island & Length $(\mathrm{mm})$ & Muscle $\delta^{15} \mathrm{~N}$ \\
\hline L.ehr139 & 149 & 7.88 \\
\hline L.ehr140 & 166 & 8.69 \\
\hline L.ehr141 & 154 & 8.23 \\
\hline L.ehr142 & 125 & 9.35 \\
\hline L.ehr143 & 164 & 7.63 \\
\hline L.ehr144 & 184 & 8.78 \\
\hline L.ehr145 & 165 & 8.31 \\
\hline L.ehr146 & 172 & 10.16 \\
\hline L.ehr147 & 141 & 8.02 \\
\hline L.ehr148 & 142 & 8.66 \\
\hline h) Saut Reef & Length $(\mathrm{mm})$ & Muscle $\delta^{15} \mathrm{~N}$ \\
\hline L.ehr116 & 230 & 8.70 \\
\hline L.ehr117 & 196 & 8.36 \\
\hline L.ehr118 & 219 & 9.71 \\
\hline L.ehr119 & 227 & 9.95 \\
\hline L.ehr120 & 201 & 10.07 \\
\hline i) Brown Reef & Length $(\mathrm{mm})$ & Muscle $\delta^{15} \mathrm{~N}$ \\
\hline L.ehr209 & 225 & 9.41 \\
\hline L.ehr210 & 216 & 9.19 \\
\hline L.ehr211 & 203 & 9.68 \\
\hline L.ehr212 & 195 & 9.47 \\
\hline L.ehr213 & 179 & 8.90 \\
\hline L.ehr214 & 185 & 8.87 \\
\hline j) Shi'b Sulaym Reef & Length (mm) & Muscle $\delta^{15} \mathrm{~N}$ \\
\hline L.ehr128 & 215 & 8.28 \\
\hline L.ehr129 & 215 & 8.95 \\
\hline L.ehr130 & 218 & 8.54 \\
\hline L.ehr131 & 220 & 8.33 \\
\hline L.ehr132 & 197 & 8.64 \\
\hline L.ehr133 & 198 & 8.71 \\
\hline L.ehr134 & 200 & 8.92 \\
\hline L.ehr135 & 214 & 8.73 \\
\hline L.ehr136 & 213 & 8.99 \\
\hline L.ehr137 & 185 & 9.06 \\
\hline
\end{tabular}


Table A4.1 (cont.). Total Length ( $\mathrm{mm}$ ) and muscle $\delta^{15} \mathrm{~N}$ values of Lutjanus ehrenbergii collected from coastal wetlands and coral reefs along a $50 \mathrm{~km}$ cross-shelf transect from Al Lith, Saudi Arabia in the Red Sea (Chapter 5).

\begin{tabular}{|c|c|c|}
\hline k) Canyon Reef & Length $(\mathrm{mm})$ & Muscle $\delta^{15} \mathrm{~N}$ \\
\hline L.ehr179 & 189 & 8.80 \\
\hline L.ehr180 & 211 & 9.80 \\
\hline L.ehr181 & 220 & 9.67 \\
\hline L.ehr182 & 211 & 9.45 \\
\hline L.ehr183 & 227 & 9.09 \\
\hline L.ehr185 & 210 & 9.74 \\
\hline L.ehr186 & 221 & 9.28 \\
\hline L.ehr187 & 188 & 9.02 \\
\hline L.ehr188 & 223 & 9.82 \\
\hline L.ehr189 & 209 & 9.84 \\
\hline 1) MarMar Reef & Length $(\mathrm{mm})$ & Muscle $\delta^{15} \mathrm{~N}$ \\
\hline L.ehr102 & 204 & 9.17 \\
\hline L.ehr103 & 218 & 9.26 \\
\hline L.ehr104 & 228 & 9.49 \\
\hline L.ehr105 & 216 & 8.93 \\
\hline L.ehr106 & 220 & 9.98 \\
\hline L.ehr107 & 214 & 8.42 \\
\hline L.ehr108 & 220 & 10.10 \\
\hline L.ehr109 & 187 & 9.13 \\
\hline L.ehr111 & 224 & 8.96 \\
\hline L.ehr112 & 187 & 9.13 \\
\hline L.ehr113 & 196 & 9.51 \\
\hline L.ehr114 & 165 & 8.68 \\
\hline L.ehr115 & 189 & 9.23 \\
\hline m) Dohra Reef & Length (mm) & Muscle $\delta^{15} \mathrm{~N}$ \\
\hline L.ehr121 & 233 & 9.07 \\
\hline L.ehr122 & 231 & 9.06 \\
\hline L.ehr123 & 223 & 9.04 \\
\hline L.ehr124 & 215 & 9.02 \\
\hline L.ehr125 & 216 & 9.03 \\
\hline L.ehr126 & 192 & 8.97 \\
\hline L.ehr127 & 214 & 9.02 \\
\hline
\end{tabular}




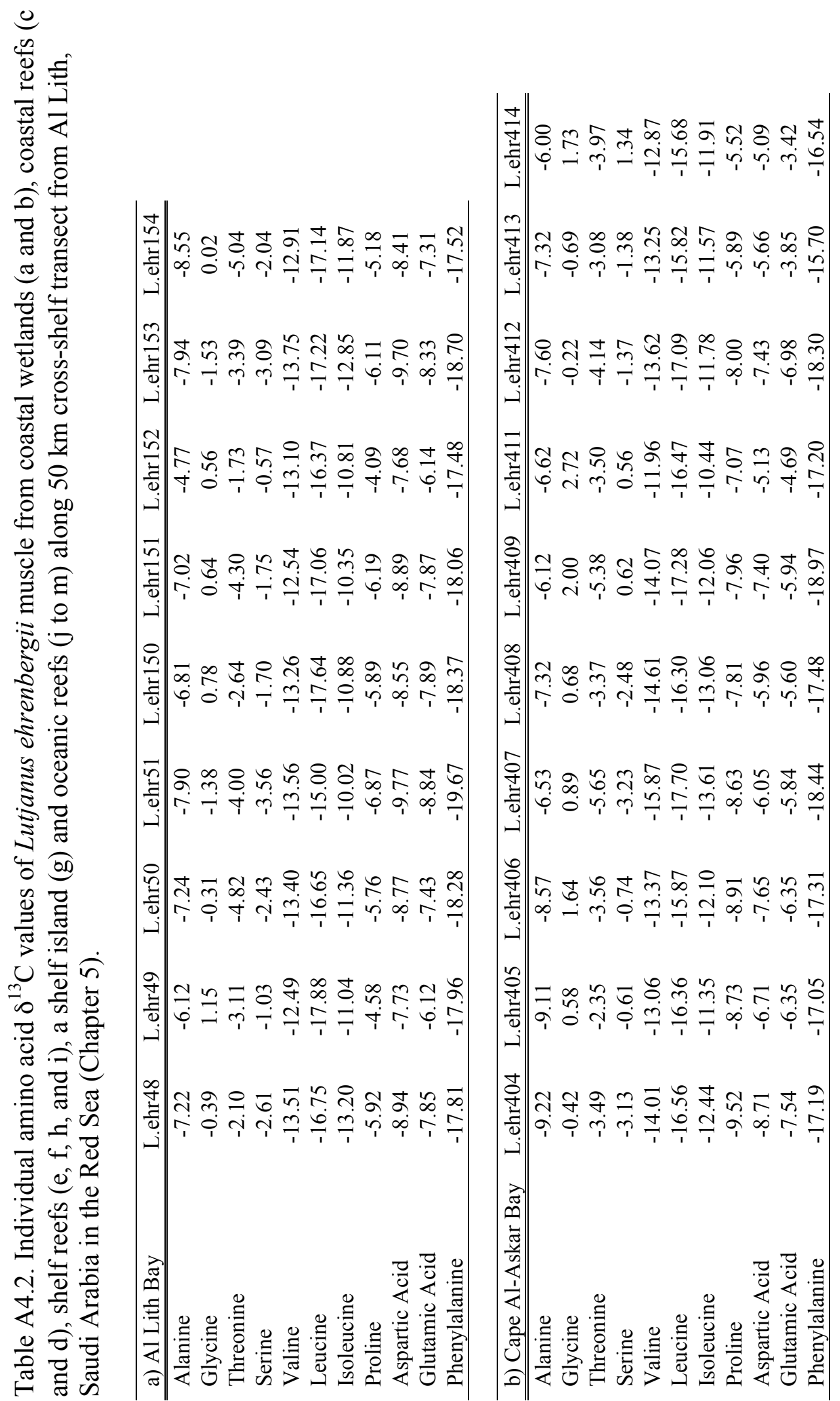




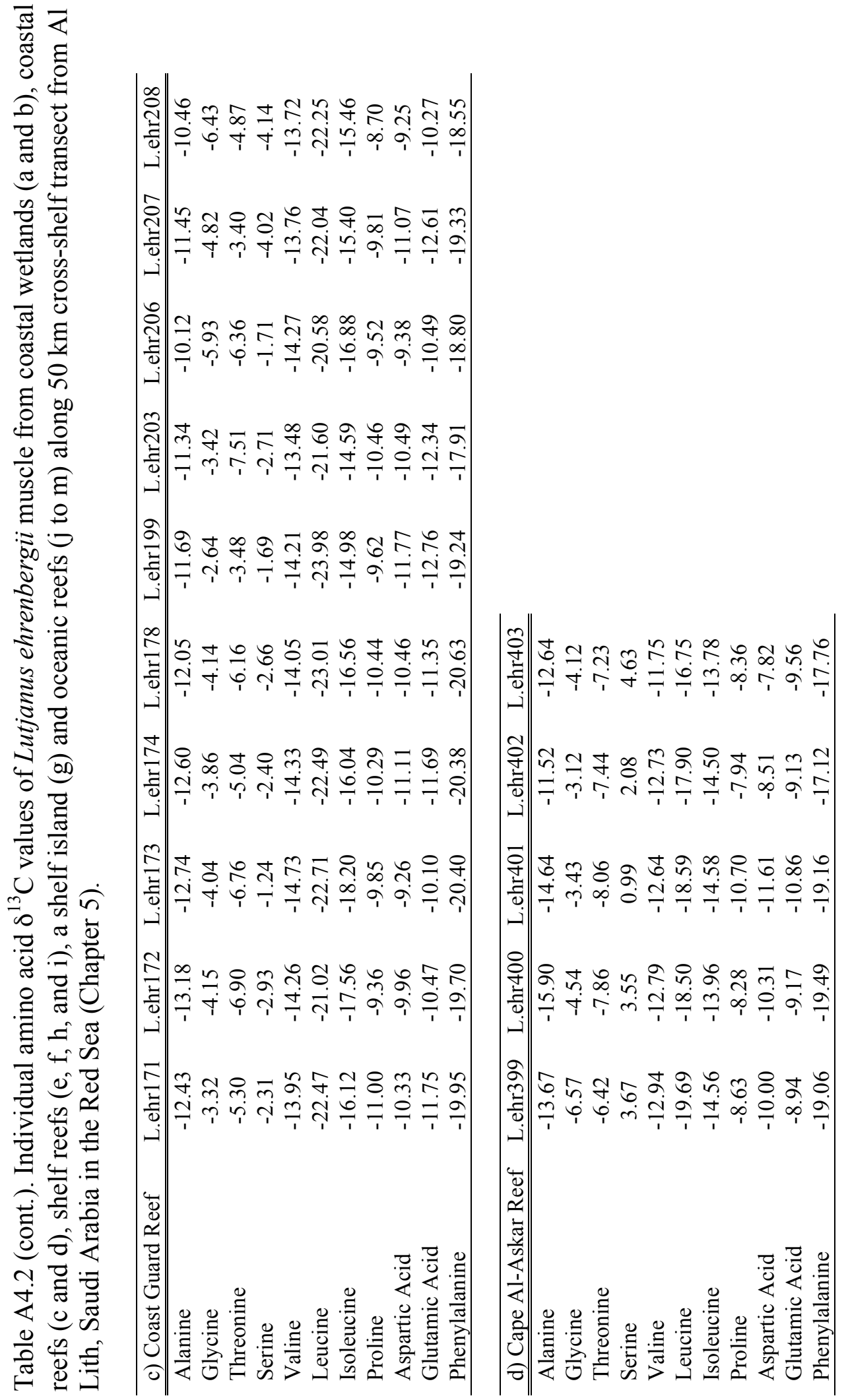




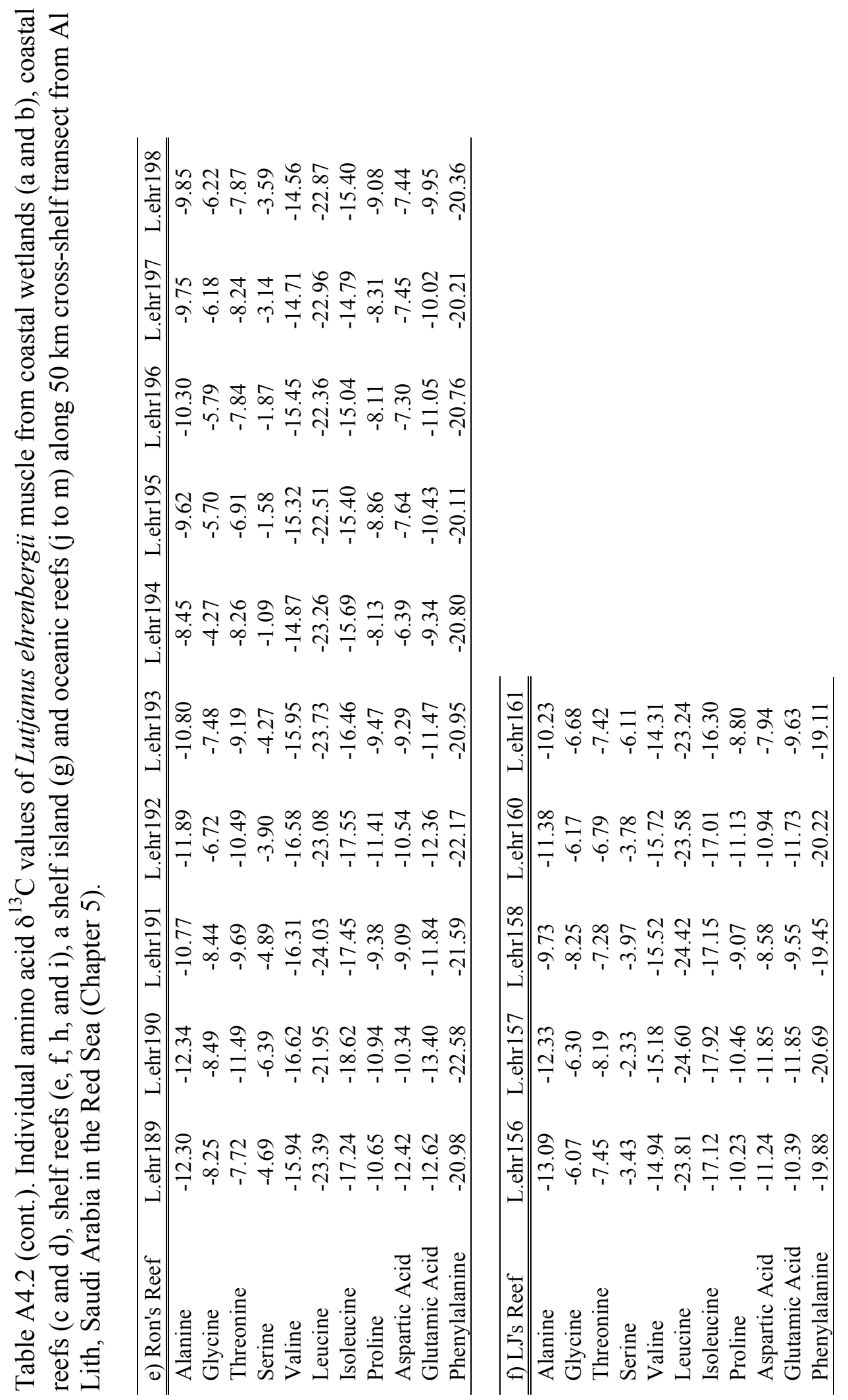




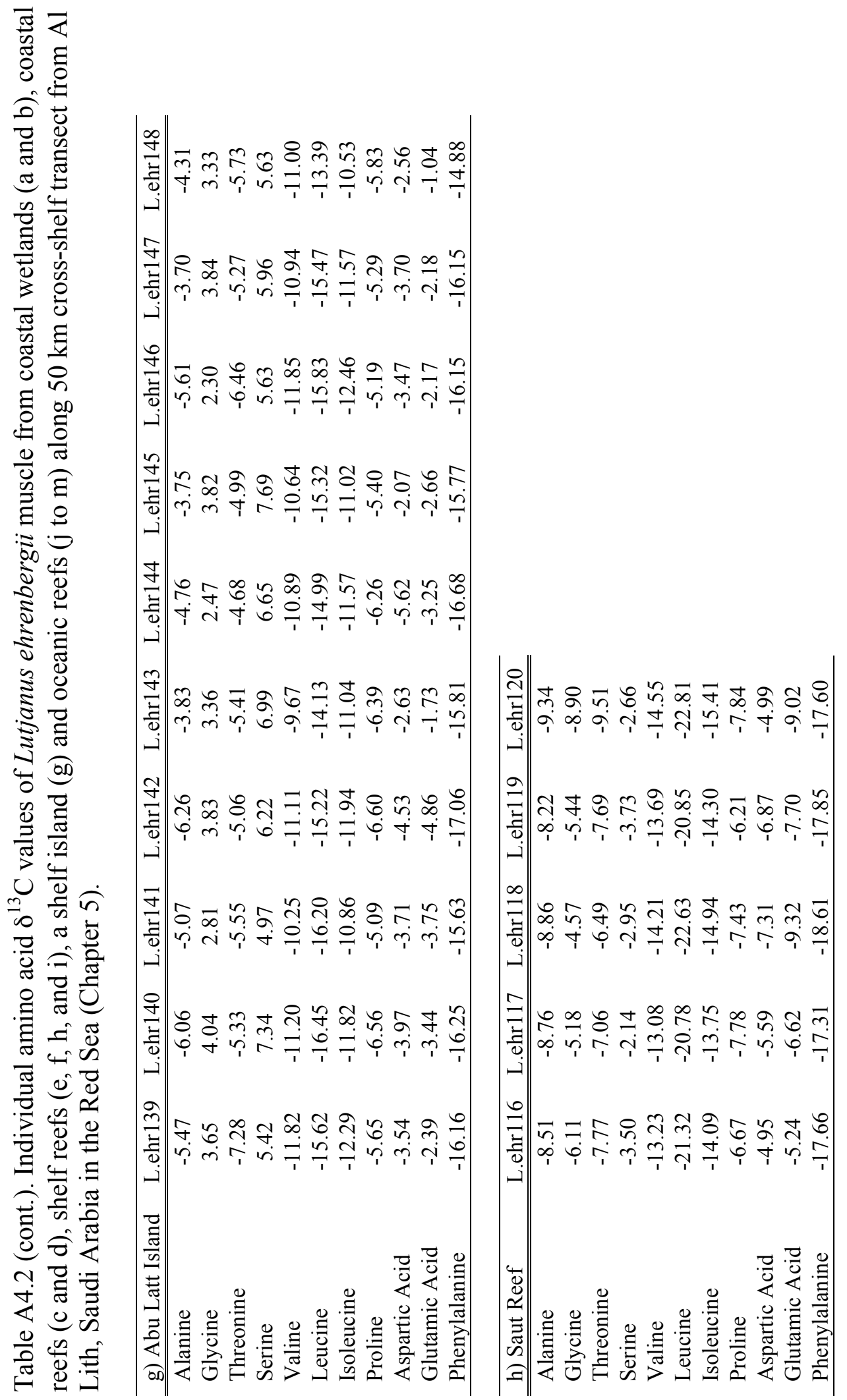


Table A4.2 (cont.). Individual amino acid $\delta^{13} \mathrm{C}$ values of Lutjanus ehrenbergii muscle from coastal wetlands (a and b), coastal reefs (c and d), shelf reefs (e, f, h, and i), a shelf island ( $\mathrm{g}$ ) and oceanic reefs ( $\mathrm{j}$ to $\mathrm{m}$ ) along $50 \mathrm{~km}$ cross-shelf transect from Al Lith, Saudi Arabia in the Red Sea (Chapter 5).

\begin{tabular}{|c|c|c|c|c|c|}
\hline i) Brown Reef & L.ehr209 & L.ehr210 & L.ehr211 & L.ehr212 & L.ehr213 \\
\hline Alanine & -11.87 & -9.57 & -9.41 & -10.65 & -11.59 \\
\hline Glycine & -7.86 & -7.16 & -6.90 & -6.79 & -6.57 \\
\hline Threonine & -7.10 & -6.29 & -8.10 & -9.50 & -9.08 \\
\hline Serine & -4.20 & -3.35 & -3.79 & -4.24 & -5.29 \\
\hline Valine & -15.24 & -14.55 & -14.73 & -14.08 & -15.16 \\
\hline Leucine & -23.65 & -22.97 & -23.59 & -24.46 & -25.06 \\
\hline Isoleucine & -16.64 & -16.20 & -16.31 & -16.24 & -15.93 \\
\hline Proline & -9.92 & -10.53 & -9.81 & -9.64 & -11.43 \\
\hline Aspartic Acid & -11.95 & -9.29 & -9.66 & -9.64 & -7.47 \\
\hline Glutamic Acid & -11.85 & -10.73 & -10.61 & -10.36 & -10.70 \\
\hline Phenylalanine & -20.29 & -19.70 & -19.76 & -19.51 & -19.42 \\
\hline j) Shi'b Sulaym Reef & L.ehr128 & L.ehr129 & L.ehr130 & L.ehr131 & L.ehr132 \\
\hline Alanine & -11.19 & -11.53 & -12.54 & -11.33 & -8.85 \\
\hline Glycine & -9.40 & -10.56 & -9.96 & -9.21 & -10.05 \\
\hline Threonine & -10.07 & -10.97 & -11.07 & -9.11 & -9.02 \\
\hline Serine & -5.36 & -7.43 & -6.90 & -4.28 & -7.06 \\
\hline Valine & -14.75 & -15.80 & -16.11 & -15.65 & -14.27 \\
\hline Leucine & -25.33 & -26.24 & -25.65 & -25.11 & -24.27 \\
\hline Isoleucine & -17.13 & -17.94 & -18.20 & -18.03 & -15.97 \\
\hline Proline & -10.85 & -9.26 & -9.98 & -10.15 & -8.36 \\
\hline Aspartic Acid & -11.43 & -11.07 & -10.20 & -10.91 & -8.59 \\
\hline Glutamic Acid & -12.35 & -12.82 & -12.32 & -12.59 & -10.93 \\
\hline Phenylalanine & -21.74 & -21.10 & -20.28 & -21.31 & -18.99 \\
\hline k) Canyon Reef & L.ehr179 & L.ehr180 & L.ehr181 & L.ehr182 & L.ehr183 \\
\hline Alanine & -11.25 & -12.73 & -10.76 & -8.89 & -13.52 \\
\hline Glycine & -7.24 & -7.54 & -6.82 & -8.57 & -6.94 \\
\hline Threonine & -8.67 & -7.75 & -9.82 & -8.59 & -9.12 \\
\hline Serine & -1.93 & -4.34 & -2.23 & -5.71 & -4.82 \\
\hline Valine & -14.98 & -14.57 & -13.38 & -12.93 & -14.04 \\
\hline Leucine & -25.48 & -26.13 & -24.14 & -23.45 & -24.73 \\
\hline Isoleucine & -17.34 & -16.72 & -15.78 & -15.81 & -17.56 \\
\hline Proline & -10.45 & -10.43 & -7.55 & -8.31 & -10.89 \\
\hline Aspartic Acid & -10.43 & -11.39 & -8.82 & -8.86 & -11.94 \\
\hline Glutamic Acid & -11.24 & -13.28 & -10.25 & -10.35 & -12.70 \\
\hline Phenylalanine & -19.12 & -20.05 & -18.04 & -18.28 & -20.43 \\
\hline
\end{tabular}


Table A4.2 (cont.). Individual amino acid $\delta^{13} \mathrm{C}$ values of Lutjanus ehrenbergii muscle from coastal wetlands (a and b), coastal reefs (c and d), shelf reefs (e, f, h, and i), a shelf island (g) and oceanic reefs ( $\mathrm{j}$ to $\mathrm{m}$ ) along $50 \mathrm{~km}$ cross-shelf transect from Al Lith, Saudi Arabia in the Red Sea (Chapter 5).

\begin{tabular}{lccccc}
\hline 1) MarMar Reef & L.ehr102 & L.ehr103 & L.ehr104 & L.ehr105 & L.ehr106 \\
\hline \hline Alanine & -8.05 & -7.88 & -10.24 & -9.86 & -7.97 \\
Glycine & -4.89 & -2.94 & -6.62 & -7.50 & -5.52 \\
Threonine & -8.14 & -8.73 & -7.75 & -9.34 & -8.85 \\
Serine & -1.77 & -0.24 & -3.19 & -3.96 & -3.47 \\
Valine & -12.62 & -13.30 & -13.51 & -13.56 & -12.52 \\
Leucine & -22.29 & -22.81 & -23.75 & -24.69 & -23.34 \\
Isoleucine & -14.04 & -14.46 & -14.78 & -15.21 & -14.08 \\
Proline & -8.46 & -9.24 & -10.14 & -8.42 & -6.95 \\
Aspartic Acid & -7.56 & -8.45 & -9.35 & -7.55 & -5.73 \\
Glutamic Acid & -10.06 & -10.93 & -10.58 & -10.98 & -9.21 \\
Phenylalanine & -16.76 & -17.77 & -18.18 & -19.07 & -16.54 \\
\hline & & & & & \\
\hline m) Dohra Reef & L.ehr121 & L.ehr122 & L.ehr123 & L.ehr124 & L.ehr125 \\
\hline \hline Alanine & -11.14 & -9.06 & -5.24 & -7.03 & -8.35 \\
Glycine & -4.98 & -4.15 & -5.13 & -5.16 & -7.37 \\
Threonine & -10.00 & -8.22 & -7.71 & -7.89 & -8.31 \\
Serine & -1.10 & -1.18 & -1.05 & -2.40 & -4.46 \\
Valine & -14.02 & -12.09 & -12.95 & -13.20 & -12.94 \\
Leucine & -24.52 & -22.39 & -23.51 & -24.03 & -23.59 \\
Isoleucine & -15.75 & -14.90 & -14.49 & -15.03 & -14.51 \\
Proline & -10.26 & -9.50 & -7.38 & -7.60 & -9.67 \\
Aspartic Acid & -9.60 & -8.13 & -6.76 & -5.09 & -8.63 \\
Glutamic Acid & -11.20 & -10.44 & -8.25 & -8.55 & -11.52 \\
Phenylalanine & -18.85 & -17.03 & -19.02 & -17.72 & -17.96 \\
\hline
\end{tabular}




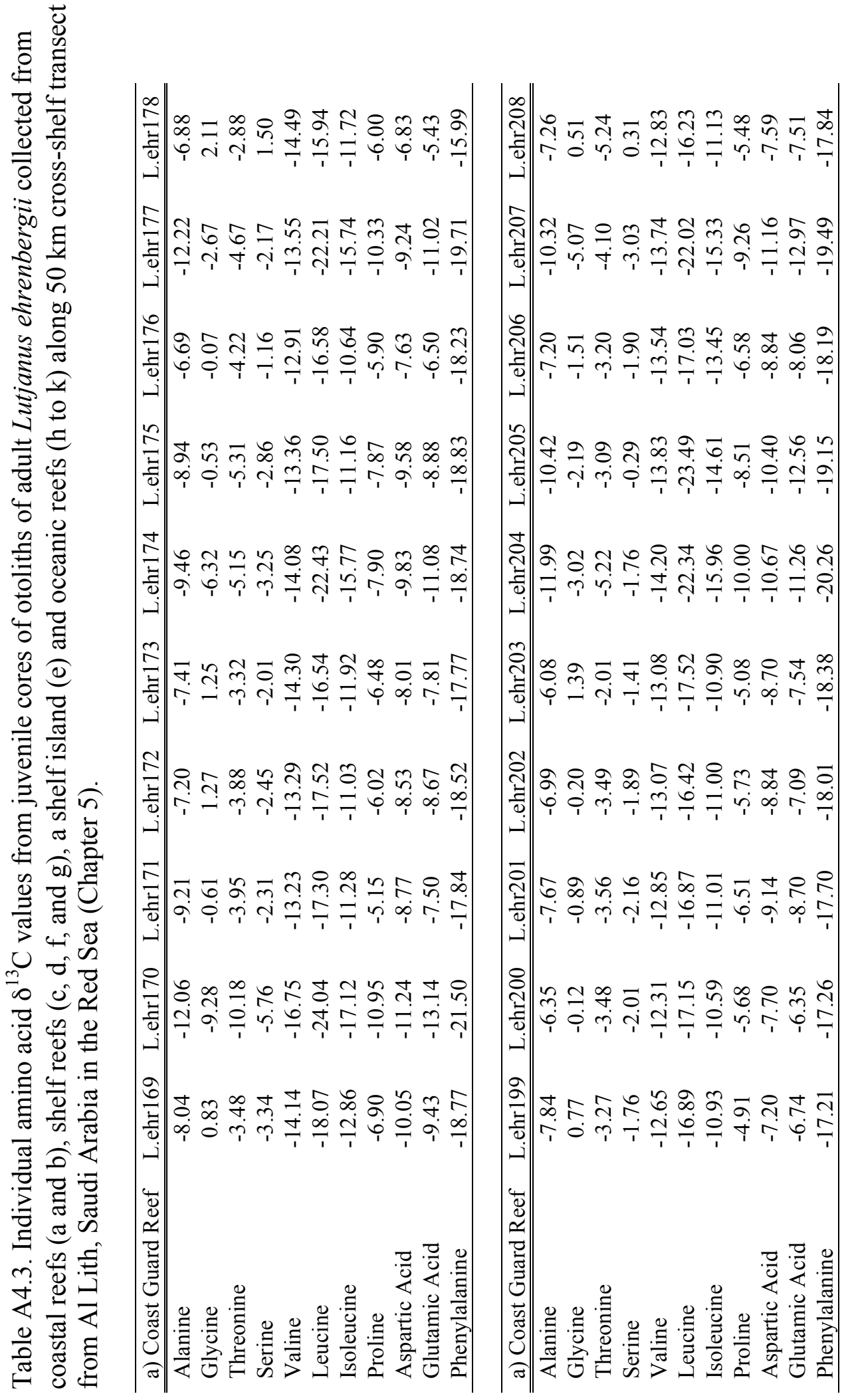




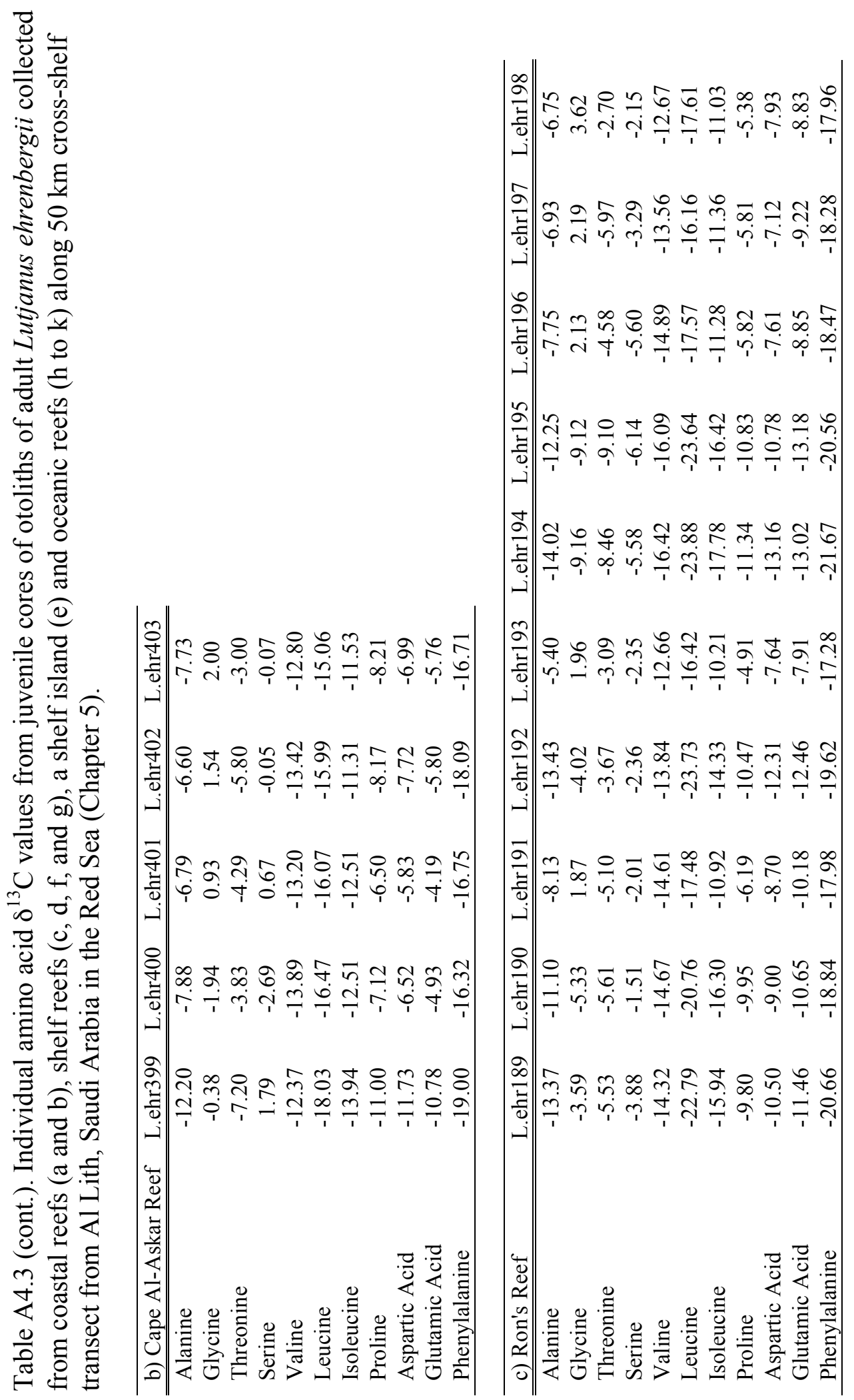




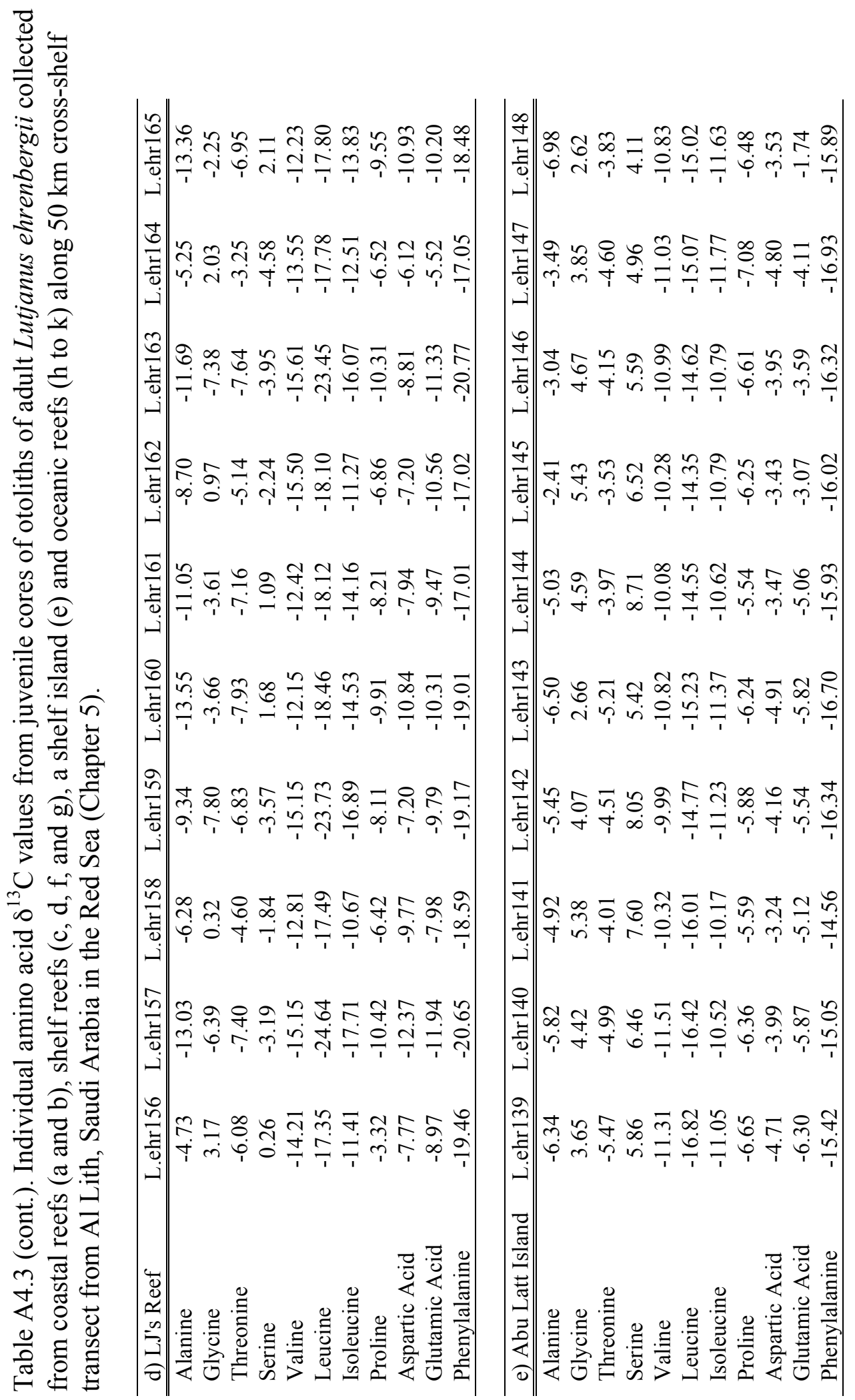


Table A4.3 (cont.). Individual amino acid $\delta^{13} \mathrm{C}$ values from juvenile cores of otoliths of adult Lutjanus ehrenbergii collected from coastal reefs (a and b), shelf reefs (c, d, f, and $\mathrm{g}$ ), a shelf island (e) and oceanic reefs (h to k) along $50 \mathrm{~km}$ cross-shelf transect from Al Lith, Saudi Arabia in the Red Sea (Chapter 5).

\begin{tabular}{lcccccc}
\hline f) Saut Reef & L.ehr116 & L.ehr117 & L.ehr118 & L.ehr119 & L.ehr120 & \\
\hline \hline Alanine & -7.20 & -9.27 & -8.20 & -7.00 & -7.21 & \\
Glycine & 2.13 & -4.97 & -6.83 & 3.16 & 1.68 & \\
Threonine & -4.97 & -7.60 & -7.26 & -3.92 & -4.17 & \\
Serine & 4.89 & -4.28 & -4.92 & -1.12 & 3.72 & \\
Valine & -10.92 & -13.50 & -13.22 & -12.56 & -11.32 & \\
Leucine & -16.41 & -21.26 & -20.97 & -15.48 & -15.12 & \\
Isoleucine & -12.31 & -14.10 & -13.90 & -11.63 & -12.08 & \\
Proline & -7.88 & -6.88 & -6.00 & -5.88 & -6.99 & \\
Aspartic Acid & -5.43 & -7.05 & -7.42 & -8.38 & -4.30 & \\
Glutamic Acid & -5.70 & -8.51 & -7.78 & -10.87 & -2.62 & \\
Phenylalanine & -16.72 & -18.45 & -18.21 & -16.57 & -16.47 & \\
& & & & & & \\
\hline g) Brown Reef & L.ehr209 & L.ehr210 & L.ehr211 & L.ehr212 & L.ehr213 & L.ehr214 \\
\hline \hline Alanine & -8.51 & -12.24 & -4.72 & -4.31 & -4.83 & -5.91 \\
Glycine & -7.80 & -7.56 & 1.06 & 2.51 & 1.64 & 1.42 \\
Threonine & -7.66 & -8.28 & -5.53 & -4.80 & -4.50 & -5.00 \\
Serine & -2.69 & -5.89 & 5.42 & 4.78 & 3.63 & -5.26 \\
Valine & -14.58 & -14.60 & -11.08 & -10.48 & -10.59 & -13.10 \\
Leucine & -23.14 & -24.43 & -15.04 & -14.67 & -14.51 & -17.00 \\
Isoleucine & -15.71 & -15.17 & -11.91 & -11.33 & -11.55 & -12.20 \\
Proline & -9.58 & -11.74 & -6.45 & -6.18 & -4.96 & -7.09 \\
Aspartic Acid & -9.07 & -7.80 & -5.72 & -3.64 & -3.19 & -6.03 \\
Glutamic Acid & -9.83 & -11.64 & -5.43 & -3.73 & -3.19 & -7.71 \\
Phenylalanine & -19.59 & -18.72 & -16.72 & -15.96 & -16.11 & -17.89 \\
\hline
\end{tabular}




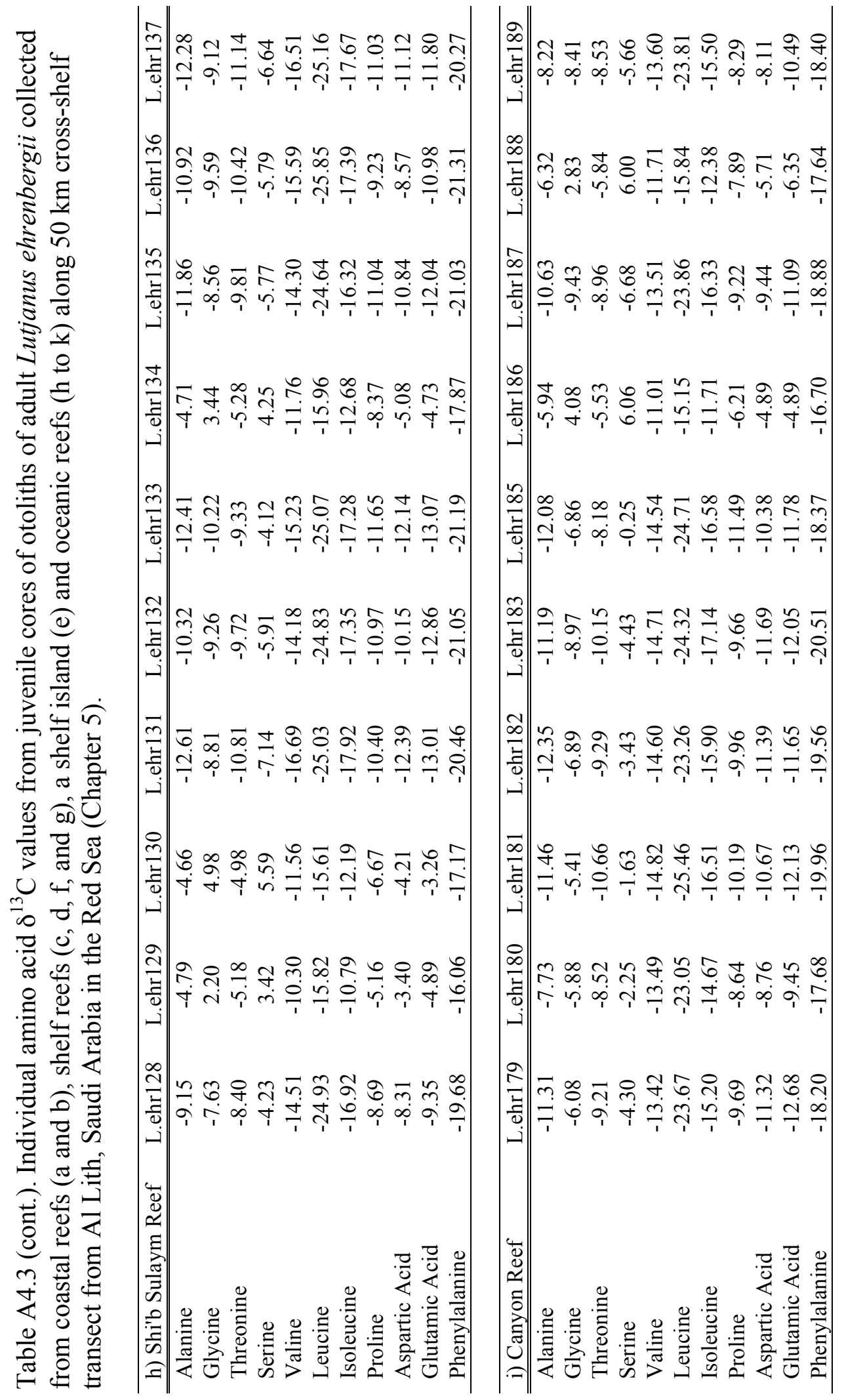


Table A4.3 (cont.). Individual amino acid $\delta^{13} \mathrm{C}$ values from juvenile cores of otoliths of adult Lutjanus ehrenbergii collected from coastal reefs (a and b), shelf reefs (c, d, f, and $\mathrm{g}$ ), a shelf island (e) and oceanic reefs (h to k) along $50 \mathrm{~km}$ cross-shelf transect from Al Lith, Saudi Arabia in the Red Sea (Chapter 5).

\begin{tabular}{|c|c|c|c|c|c|c|c|}
\hline j) MarMar Reef & L.ehr102 & L.ehr103 & L.ehr104 & L.ehr105 & L.ehr106 & L.ehr107 & L.ehr108 \\
\hline Alanine & -6.19 & -8.11 & -5.01 & -9.16 & -5.34 & -9.46 & -8.87 \\
\hline Glycine & 5.19 & -2.14 & 2.89 & -3.44 & 3.18 & -4.50 & -7.90 \\
\hline Threonine & -3.90 & -7.97 & -5.55 & -9.08 & -4.84 & -10.49 & -7.85 \\
\hline Serine & 7.63 & 1.28 & 6.79 & -0.92 & 6.61 & -1.52 & -4.84 \\
\hline Valine & -9.94 & -12.81 & -11.48 & -13.68 & -10.61 & -15.12 & -12.26 \\
\hline Leucine & -14.44 & -22.13 & -15.26 & -23.43 & -14.81 & -24.33 & -22.78 \\
\hline Isoleucine & -10.56 & -13.88 & -11.78 & -14.55 & -11.11 & -15.99 & -14.85 \\
\hline Proline & -7.13 & -8.56 & -5.16 & -9.45 & -3.99 & -10.28 & -7.27 \\
\hline Aspartic Acid & -4.01 & -6.51 & -1.97 & -9.17 & -0.86 & -9.37 & -7.75 \\
\hline Glutamic Acid & -5.28 & -11.02 & -1.55 & -11.11 & -1.08 & -12.44 & -9.44 \\
\hline Phenylalanine & -16.30 & -17.20 & -15.66 & -18.51 & -15.15 & -19.29 & -17.18 \\
\hline j) MarMar Reef & L.ehr109 & L.ehr111 & L.ehr112 & L.ehr113 & L.ehr114 & L.ehr115 & \\
\hline Alanine & -8.27 & -8.90 & -9.87 & -10.62 & $\begin{array}{c}-10.38 \\
\end{array}$ & -8.86 & \\
\hline Glycine & -6.47 & -5.60 & -6.13 & -6.70 & -7.02 & -6.61 & \\
\hline Threonine & -7.33 & -8.79 & -9.77 & -7.90 & -8.37 & -9.92 & \\
\hline Serine & -3.73 & -2.89 & -4.02 & -2.81 & -3.81 & -4.32 & \\
\hline Valine & -11.60 & -13.23 & -13.86 & -13.53 & -14.13 & -13.65 & \\
\hline Leucine & -22.06 & -23.12 & -23.76 & -24.23 & -24.83 & -24.43 & \\
\hline Isoleucine & -14.15 & -14.74 & -15.32 & -14.94 & -15.65 & -15.24 & \\
\hline Proline & -6.67 & -9.62 & -10.33 & -10.75 & -10.33 & -8.37 & \\
\hline Aspartic Acid & -7.29 & -8.85 & -10.26 & -9.36 & -9.85 & -6.21 & \\
\hline Glutamic Acid & -8.81 & -11.26 & -12.18 & -10.89 & -10.73 & -11.08 & \\
\hline Phenylalanine & -16.79 & -17.93 & -18.40 & -19.00 & -19.33 & -17.91 & \\
\hline k) Dohra Reef & L.ehr121 & L.ehr122 & L.ehr123 & L.ehr124 & L.ehr125 & L.ehr126 & L.ehr127 \\
\hline Alanine & -10.21 & -10.58 & -8.86 & -7.01 & -9.79 & -10.56 & -6.80 \\
\hline Glycine & -4.59 & -3.46 & -8.22 & 2.67 & -4.64 & -5.32 & -5.84 \\
\hline Threonine & -9.69 & -8.40 & -8.61 & -6.03 & -8.60 & -9.58 & -7.75 \\
\hline Serine & -1.36 & 0.87 & -5.28 & 6.11 & -1.22 & -1.16 & -2.12 \\
\hline Valine & -13.60 & -12.96 & -13.36 & -11.22 & -12.41 & -13.58 & -12.61 \\
\hline Leucine & -23.66 & -23.30 & -24.17 & -15.80 & -22.96 & -23.28 & -23.21 \\
\hline Isoleucine & -14.75 & -14.32 & -14.82 & -12.25 & -15.44 & -16.09 & -13.92 \\
\hline Proline & -9.70 & -8.78 & -10.81 & -7.46 & -10.58 & -9.66 & -7.43 \\
\hline Aspartic Acid & -8.71 & -7.31 & -9.96 & -5.46 & -8.63 & -9.92 & -7.33 \\
\hline Glutamic Acid & -11.23 & -9.69 & -11.88 & -6.57 & -11.11 & -12.10 & -8.86 \\
\hline Phenylalanine & -18.26 & -17.77 & -18.49 & -17.78 & -17.41 & -18.71 & -17.42 \\
\hline
\end{tabular}

